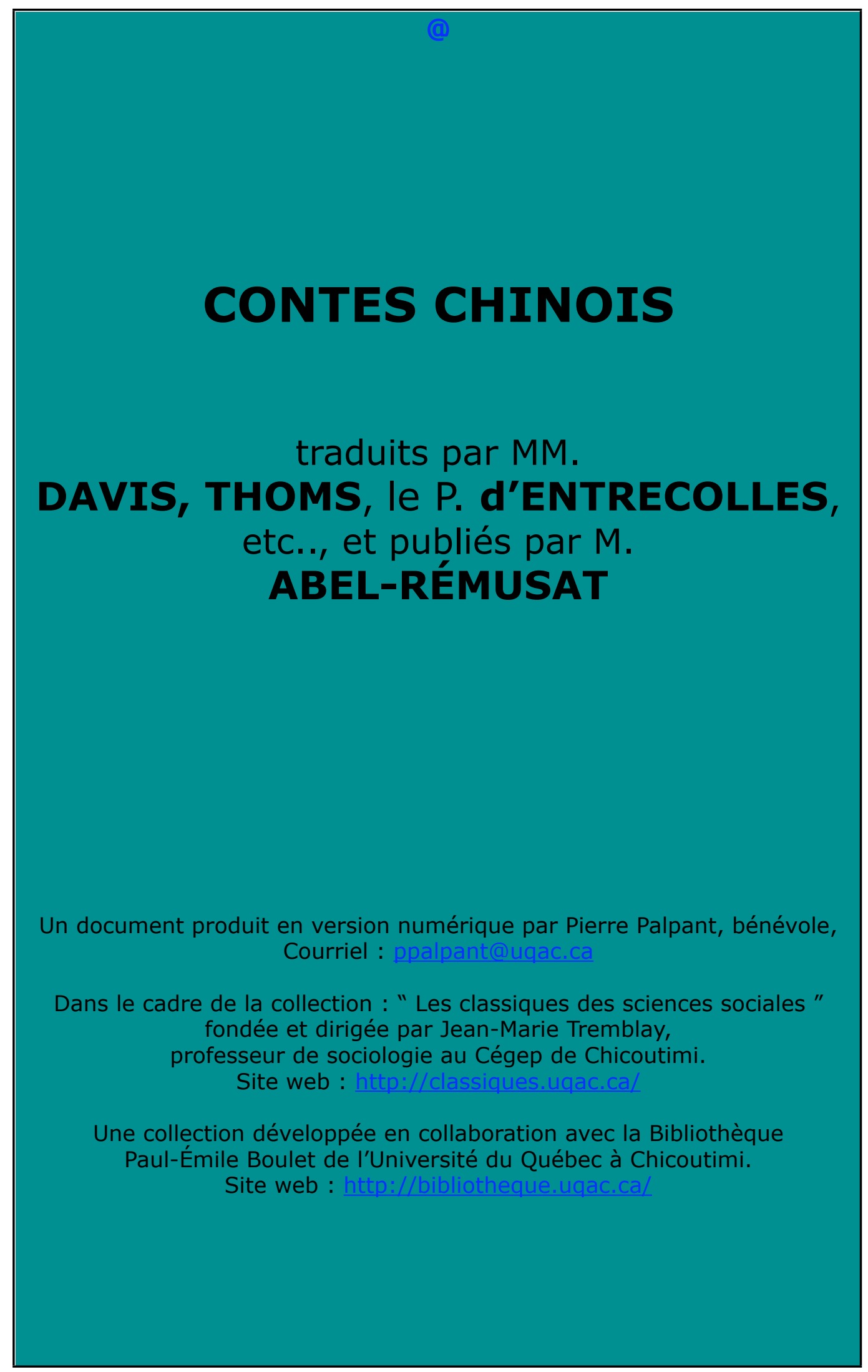




\section{Contes chinois}

Un document produit en version numérique par Pierre Palpant, collaborateur bénévole,

Courriel : ppalpant@uqac.ca

Cet ensemble est la réunion des trois tomes des :

\section{CONTES CHINOIS}

\section{traduits par MM. DAVIS, THOMS, le P. d'ENTRECOLLES, etc.., et publiés par M. ABEL-RÉMUSAT}

Première édition, chez Moutardier, Paris, 1827, 240+226+200 pages.

Reproduit en facsimile par Elibron Classics.

Police de caractères utilisée : Verdana, 12 et 10 points.

Mise en page sur papier format Lettre (US letter), $8.5^{\prime \prime} \times 11^{\prime \prime}$.

[note : un clic sur @ en tête de volume et des chapitres et en fin d'ouvrage, permet de rejoindre la table des matières]

Édition complétée le 31 décembre 2006 à Chicoutimi, Québec.

[css : outre les différences d'orthographe existant par rapport à l'orthographe contemporaine, cette édition présente aussi des inconstances d'écriture, notamment de noms propres (tirets,majuscules), et nous espérons ne pas trop en avoir rajouté involontairement. Cependant nous sommes certains que le lecteur pourra à chaque fois rectifier de lui-même selon ses souhaits.] 


\title{
Contes chinois
}

\section{TABLE DES MATIÈRES}

\author{
Tome premier
}

\author{
Avant-propos \\ L’héroïsme de la piété filiale \\ Les tendres époux : $\underline{\text { I }}$ II - $\underline{\text { III }}$ - IV \\ Tome second

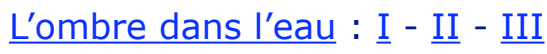

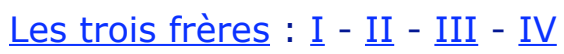 \\ Le crime puni \\ La calomnie démasquée : I - II \\ $\underline{\text { Histoire de Fan-Hi-Tcheou }}$ \\ Tome troisième \\ $\underline{\text { San-iu-leou ou les trois étages consacrés }}$ \\ Les deux jumelles \\ La matrone du pays de Soung
}

(a) 


\section{Contes chinois}

\section{CONTES

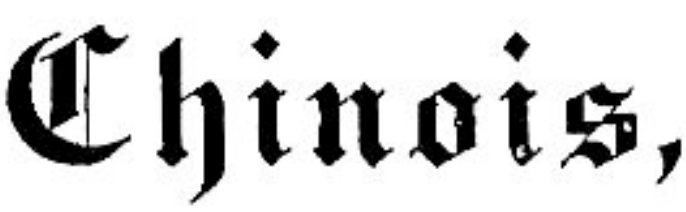

TRADU1TS

PAR MM. DAVIS, THOMS, LE R. D'ERTRLCOLLES, etc.,

ET PURLLES

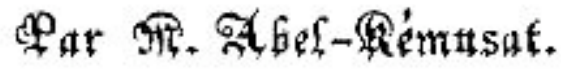

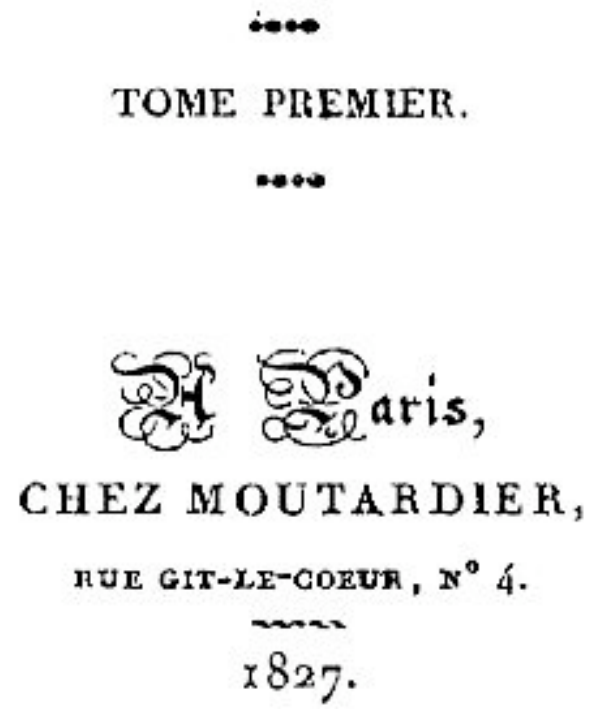




\section{Contes chinois}

\section{AVANT-PROPOS.}

Le P. Dentrecolles, membre de l'ancienne mission de la Chine, MM. Davis et Thoms, deux Anglais qui résident actuellement à Canton, ont tiré des recueils originaux et traduit du Chinois la plupart des nouvelles qui composent les trois volumes de ce recueil. Le mérite de les avoir choisies dans des collections qui en contiennent plusieurs milliers, celui de les avoir fait passer dans les langues de l'Europe, appartiennent en entier à ces auteurs ; nous ne saurions en réclamer la moindre partie, et c'est la première chose dont les lecteurs doivent être prévenus.

Le public a montré quelque disposition à accueillir les tableaux de la Société de la Chine, tels que les écrivains de ce pays les ont tracés dans les romans de mœurs. On désire que le nombre de ces romans, rendus accessibles aux lecteurs européens, devienne plus considérable. Mais ce travail présente quelques difficultés de plus que la traduction des œuvres de Sir Walter Scott ou de Wanderwelde, et, en attendant que le zèle des savans puisse contenter la curiosité des amateurs, on a jugé qu'il serait agréable à ceux-ci de posséder quelques échantillons du goût des Chinois dans un genre secondaire, celui des Contes Moraux et des nouvelles. Les morceaux de cette espèce, généralement peu étendus, ne sauraient, sous le rapport de l'art, entrer en comparaison avec les grandes compositions des romanciers ; mais si la contexture de la fable et la peinture des caractères y sont ordinairement plus négligées, on y trouve en revanche une multiplicité d'incidens et de détails propres à 


\section{Contes chinois}

soutenir l'attention, et à faire de plus en plus connaître l'intérieur de la vie privée, et les habitudes domestiques dans les conditions inférieures de la Société. Certains lecteurs ont été frappés, dans les conversations des Deux Cousines, d'une sorte d'uniformité provenant de ce que l'auteur s'est proposé surtout de représenter les manières et le langage des honnêtes gens, des gens bien élevés, des hommes de bonne compagnie, et des femmes d'un esprit cultivé. On a trouvé que les personnages de ce roman étaient trop délicats, et s'exprimaient avec trop d'élégance. Le même reproche ne pourra s'adresser aux récits qui forment cette collection; on y verra figurer des bateliers, des artisans, des usuriers ; on y observera des complots de frippons et des scènes de brigands ; et comme il y a de tout cela, même dans une nation d'Asie, ces traits complèteront la peinture des habitudes chinoises. Lazarille de Tormes et la princesse de Clèves sont également des tableaux d'après nature, et l'art du romancier a de quoi satisfaire tous les goûts.

La nouvelle qui ouvre ce recueil n'avait jamais été publiée ; le sujet en est bizarre pour des Européens, et il faut s'être bien pénétré des idées chinoises pour en apprécier le mérite. Une femme exposée pendant plusieurs années à d'odieuses persécutions, sans jamais perdre de vue la vengeance qu'elle doit à ses parens, et dès qu'elle l'a obtenue, quittant sans regret la vie qu'elle ne supportait que par devoir, est aux yeux des Chinois un modèle d'héroïsme, et l'exemple de la pitié filiale. On ne voudrait pas chez nous que le crime et le châtiment de Sextus fussent séparés par un aussi long intervalle. La nouvelle qui retrace cet étrange dévoûment offre encore une autre 


\section{Contes chinois}

singularité. Elle a été mise en latin par un Chinois, disciple de quelqu'un de nos missionnaires, et nommé Abel Yan. Ce traducteur d'une espèce nouvelle n'avait fait que de médiocres progrès dans la connaissance du rudiment ; il écrivait la langue de Cicéron à-peu-près comme ce capucin qui regardait la théologie comme une science trop supérieure à la grammaire pour être assujétie à ses lois, et qui, négligeant par suite de ce noble sentiment les règles de l'accord des noms et du régime des prépositions, écrivait Deo sanctam ou Credo Dei est sanctas. Le manuscrit d'Abel Yan, dont je dois la communication à M. le comte de Clarac, est tout entier dans ce genre de latinité. Il n'est pas bien étonnant qu'un Chinois sache mal le latin : ce qui est plus singulier, c'est que celui-ci n'entendait qu'imparfaitement sa propre langue, ainsi qu'on s'en est convaincu en comparant avec le texte plusieurs passages de sa traduction. Un jeune littérateur que je $\mathrm{m}$ 'honore de compter parmi mes meilleurs élèves, $M$. Stanislas Julien, a revu cette traduction tout entière, et se l'est en quelque sorte appropriée par les améliorations sans nombre qu'il y a faites. Il a lui-même mis en français plusieurs autres compositions de ce genre, et pourrait en donner une collection considérable, si le succès de celle-ci répondait aux espérances des éditeurs.

On a revu de la même manière les traductions du $P$. Dentrecolles. Elles avaient été faites assez légèrement pour avoir besoin d'être vérifiées en beaucoup d'endroits. Le style de ces petites narrations est pourtant en général très clair, privé d'ornemens et par conséquent exempt de difficultés. Mais apparemment le missionnaire n'y avait pas attaché 


\section{Contes chinois}

d'importance ; sa plume savante aurait rendu plus fidèlement les maximes de Confucius, que certains passages de la Matrone de Soung. Ce dernier conte, le plus piquant de ceux que Dentrecolles a traduits, est une preuve que les Chinois ont connu ces fables milésiennes dont il faisait partie, et qui ont couru le monde. C'est la supposition la plus naturelle qu'on puisse faire ; car comment imaginer qu'un second modèle ait pu fournir, au bout de I'Asie, l'aventure sur lequel est fondé ce récit satirique ? Il est curieux d'examiner la manière dont l'auteur chinois s'y est pris pour accommoder ce sujet aux mœurs de son pays. L'idée de l'éventail, l'indignation de la femme de Tchouang-tseu à la pensée d'une légèreté comme celle de la première veuve, sont des traits de génie que Voltaire n'a pas dédaigné d'emprunter au conteur chinois, et dont celui-ci n'était pas redevable aux premiers inventeurs. Le dénouement de la Matrone de Soung est d'une rare extravagance. Ceux des autres nouvelles, en général, en sont aussi la partie faible. C'est que l'idée ingénieuse qui se présente à un auteur, et les développemens agréables qu'il sait y donner, ne le soutiennent pas toujours jusqu'au bout, et que s'il y a mille moyens variés pour former une intrigue, il n'y en a qu'un très petit nombre pour la dénouer. Molière, dans son chefd'œuvre, un célèbre auteur de nos jours dans ses romans les plus estimés, nous fournissent la preuve de cette difficulté, qui n'a pas été complètement éludée dans les Deux Jumelles, les Tendres Époux, l'Ombre dans l'Eau, et dans d'autres nouvelles dont le sujet est gracieux, mais dont la terminaison laisse quelque chose à désirer. 


\section{Contes chinois}

On a revu sur le texte original les contes traduits par Dentrecolles et $\mathrm{M}$. Thoms, et I'on peut assurer que les premiers sont bien plus exactement rendus dans cette édition que dans celle qui fait partie de la collection de Duhalde. On a aussi rectifié les noms propres que l'usage est maintenant d'écrire d'après l'orthographe française. Il est resté, à cet égard, plusieurs irrégularités, surtout dans les nouvelles traduites par M. Davis, parce que nous ne possédons pas le texte chinois de ces dernières ; ni celui qui a réuni les matériaux de cette collection, ni les personnes qui lui ont prêté leur assistance, ne sauraient donc être responsables de cette partie de l'ouvrage, dont I'exactitude a pour garant le talent bien connu de M. Davis tout seul. Feu M. de Sorsum, qui a traduit de I'anglais les Trois Étages, s'est attaché à la première version de cet auteur, imprimée à Canton, et qu'on ne saurait se procurer maintenant en Europe. Le traducteur anglais a apporté lui-même quelques changemens à sa version, en la faisant imprimer à Londres, il y a cinq ans. Mais quoique ces changemens consistent principalement en suppressions, ils n'ont pas paru tourner à l'avantage du récit qui est devenu un peu sec et décharné. Les développemens de mœurs, les particularités qui se montrent dans les conversations sont ce que M. Davis a cru devoir abréger, et c'est justement là ce qui fait rechercher ces petites compositions avec plus d'intérêt, et ce qui les fait lire avec plus de curiosité. C'est, pour faire éviter l'ennui, un grand moyen que d'être court ; mais il ne faut pas en abuser.

A. R. 


\section{Contes chinois}

@

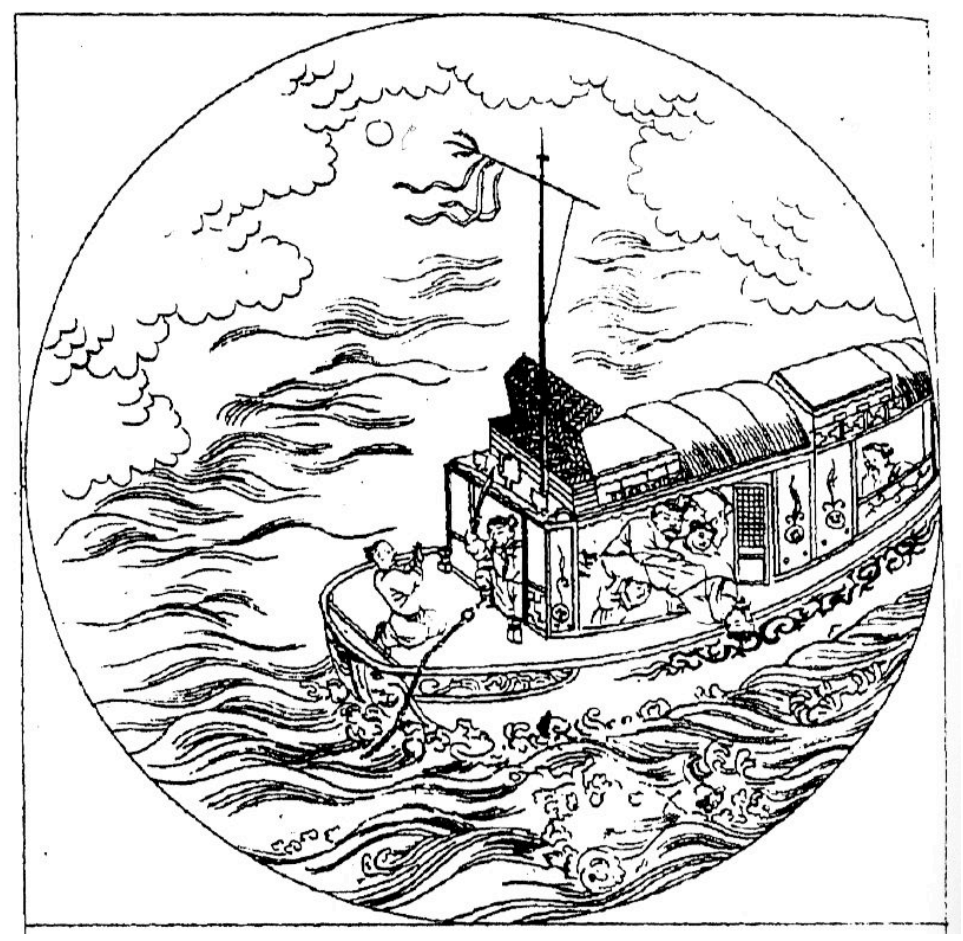

\section{L'HÉROÏSME DE LA PIÉTÉ FILIALE.}

Le vin peut épanouir et égayer le caractère ;

Il peut aussi dissiper les chagrins et bannir la tristesse.

Quatre ou cinq tasses vous procurent une joie délicieuse ;

Mais I'usage immodéré de cette liqueur avance le terme de vos jours.

Alors le caractère le plus doux devient dur et féroce, L'esprit le plus pénétrant devient lourd et stupide.

L'empereur Iu n'eut-il pas raison d'éloigner l'échanson I-ti ? Cette drogue fatale est la source d'une infinité de maux ! 


\section{Contes chinois}

Le but de ce passage est d'engager les hommes à boire avec sobriété. Nous allons parler d'un officier que la passion du vin entraîna dans un abîme de malheurs.

On raconte que dans les années Siouante ${ }^{1}$, dans le département de Hoaïgan, dépendant de la province du Tchili, il y avait dans la ville de Hoaïgan un officier dont le nom de famille était Tsa et le surnom Wou. Il jouissait d'une grande fortune et avait à son service une multitude de servantes et de domestiques. Il n'avait qu'une seule passion, celle de la bouteille. A peine apercevait-il la douce liqueur, qu'il oubliait tout, et la vie même était son moindre souci. De là lui vint le surnom de Iieou-Koueï, ou démon du vin. Ce défaut lui ayant fait perdre sa charge, il passait les jours entiers à boire et à se divertir.

L'officier Tsa n'était pas le seul qui eût le talent de boire, sa femme Tian s'entendait aussi à vider la tasse. On aurait dit, non pas deux époux, mais deux amis liés par le goût du vin. Cependant, chose étonnante ! M. et madame Tsa, si passionnés pour le vin, avaient trois enfans, deux garçons et une fille, qui ne pouvaient même en supporter ni l'odeur ni la vue.

Le fils aîné s'appelait Tsatao et le cadet Tsalio ; tous deux étaient encore en bas âge. La fille avait une quinzaine d'années.

Quand elle vint au monde, Tsawou ayant vu l'arc-en-ciel se dérouler au-dessus de sa maison et l'entourer d'une ceinture brillante de cinq couleurs, il prit ce phénomène pour un heureux

${ }^{1}$ C'est à dire de la diffusion de la vertu. C'est le nom donné aux années du règne de Siouan-Tsoung, de la dynastie des Ming, de 1426 à 1436. 


\section{Contes chinois}

présage et aussitôt donna à sa fille le nom de Souï-houng, c'està-dire arc-en-ciel de favorable augure.

Elle était douée d'une rare beauté et excellait à dessiner les dragons, à peindre le phénix et à exécuter à l'aiguille toutes sortes de broderies et de fleurs. Outre tous les talens qui font l'ornement de son sexe, elle possédait une pénétration, un discernement et une maturité de raison qui la rendaient capable de régler et de diriger toutes les affaires domestiques.

Souï-houng, voyant son père et sa mère du matin au soir plongés dans le vin, n'épargnait rien pour les détourner de cette funeste habitude. Le moyen que $M$. Tsa écoutât les avis de sa fille ! Mais laissons un instant les deux époux.

Dans ce même temps il y avait au bureau de la guerre un conseiller dont le nom de famille était Tchao et le surnom, Koueï.

Jadis, lorsqu'il n'était pas encore monté en charge, il demeurait dans la ville de Hoaïgan, tout près de Tsawou. Se voyant sans fortune, il étudiait jour et nuit, pâlissait sur les classiques et ne s'endormait qu'au chant du coq matinal.

Le père de Tsawou, le vieux Tsa, alors officier, l'aimait à cause de son ardeur infatigable pour l'étude, et I'aidait dans sa détresse, lui envoyant tantôt du bois, tantôt du riz et autres alimens.

Tchao koueï se présenta aux différens examens, et obtint ses degrés littéraires. A l'époque dont nous parlons, il venait d'être nommé conseiller au bureau de la guerre. 


\section{Contes chinois}

Par reconnaissance pour les bontés passées du vieux seigneur Tsa, il voulut avancer Tsawou et l'éleva au rang d'inspecteur militaire dans la province de Hou-kouang. C'était une place à la fois honorable et avantageuse.

Tsawou, transporté de joie, consulte sa femme, choisit un jour heureux et se dispose à partir pour sa destination.

- Mon père, lui dit Souï-houng, si vous m'en croyez, vous renoncerez à cette charge.

- Et pourquoi, répondit Tsawou?

- Les fonctionnaires publics, dit-elle, ont deux choses en vue, la gloire et l'intérêt. Pour y parvenir, il leur faut souvent traverser de vastes pays et errer dans les contrées lointaines. Vous, mon père, accoutumé à mener une vie tranquille, votre unique soin est de vous livrer au plaisir du vin : nulle autre affaire, nul autre souci ne saurait vous occuper. Mais une fois en charge, si vous persistez dans les mêmes habitudes, qui voudra vous accorder sa confiance et remettre de l'argent entre vos mains ? Ainsi, vous vous serez consumé en dépenses et en peines inutiles ! Oubliez-vous les dangers du voyage et la chance de n'en tirer aucun profit ? Mais ce dernier point est une bagatelle. Ce qui m'épouvante, ce sont les suites redoutables d'une pareille mission.

- C'est déjà bien assez de n'y gagner nul avantage pécuniaire, répondit Tsawou ; de quelles autres conséquences veux-tu encore parler? 


\section{Contes chinois}

- Quand vous étiez en charge, ô mon père, que de traverses n'avez-vous pas éprouvées ! Se peut-il que vous en ayez sitôt perdu le souvenir ? Dans la carrière des armes, cette place d'inspecteur offre mille avantages ; mais, dans le civil, c'est tout au plus un emploi subalterne. A tout moment l'on est de service dans les bureaux. Il faut reconduire l'un, recevoir I'autre, toute l'année se lever de bonne heure et se coucher tard ; c'est un esclavage perpétuel. Ici, au contraire, libre et tranquille, votre unique soin est de vider la coupe, et ce goût a tourné en habitude. Mais une fois arrivé à votre destination, si vous vivez comme par le passé, que de réprimandes, que de châtimens ne recevrez-vous pas de vos supérieurs ? Mais je veux bien encore ne pas envisager ces cruels affronts. Combien d'autres tourmens vous attendent! Tantôt ce sont des brigands qui fondent sur le district où vous êtes ; il vous faut partir sur l'heure et courir sur leurs traces. Tantôt, dans un canton éloigné, éclate une sédition, et l'on vous envoie pour l'apaiser. Ici, il faut galopper à cheval ; là, voguer sur une frêle nacelle; jour et nuit, la cuirasse sur le clos, le casque en tête et la lance au poing, vous êtes à chaque instant entre la vie et la mort. Si alors vous continuez à boire tout le long du jour, votre perte est assurée. Ne vaut-il pas mieux vivre en paix chez vous et passer le reste de votre vie dans la joie et le plaisir ? Peut-on chercher ainsi soi-même une foule d'embarras et de dangers ? 


\section{Contes chinois}

- Le proverbe dit, répond Tsawou : Le vin entre dans l'estomac, les affaires se mûrissent dans le cerveau. Comment dis-tu que je néglige mes devoirs et les intérêts de ma maison ? Il est vrai que, te trouvant si entendue aux soins du ménage et aux affaires domestiques, je me repose souvent sur toi pour me livrer à la gaîté et au plaisir. Mais, une fois rendu à mon poste, quand tu ne pourras pas me remplacer, tu me verras à mon tour avoir l'œil à tout.

D'ailleurs, une charge aussi honorable ne s'obtient le plus souvent qu'à force de présens et d'intrigues ; encore n'y réussit-on pas toujours ; mais cette place ne m'a coûté aucun sacrifice. Je la dois uniquement aux bontés du seigneur Tchao-koueï qui a daigné m'envoyer un exprès pour m'en remettre le diplôme. Si je refuse ce bienfait signalé, je me rendrai coupable de la plus noire ingratitude. Mon parti est arrêté, je te prie de ne rien faire pour m'en détourner.

Souï-houng voyant son père décidé à partir :

- Puisque votre résolution est prise, lui dit-elle, du moins corrigez-vous de la passion du vin et je serai sans inquiétude.

- Tu sais pourtant, répondit Tsawou, que le vin est I'unique soutien de ma vie : comment veux-tu que je m'en interdise entièrement l'usage ? Tout ce que je puis faire, c'est de boire quelques tasses de moins. 


\section{Contes chinois}

Puis il se mit à débiter le passage suivant qui roule sur la même idée :

L'existence de ton vieux père

N'a d'autre soutien que la bouteille.

J'aime mieux m'abstenir de manger

Que de m'interdire l'usage du vin.

Désormais docile aux avis de ta piété filiale,

Je boirai sobrement et vivrai avec tempérance.

Auparavant, je buvais dix fois le jour ;

Ce sera désormais une fois ajoutée à neuf.

Auparavant je buvais dix petites tasses ;

Désormais une grande seulement.

Auparavant, je buvais un verre d'un trait ;

Désormais, je le viderai en deux coups.

Auparavant, je buvais au lit ;

Maintenant, j'en descendrai pour boire.

Auparavant, je buvais jusqu'à la troisième veille ;

Désormais jusqu'à la fin de la seconde.

Si tu veux m'imposer de nouvelles privations,

Je cours risque de perdre la vie.

Le lendemain, Tsawou ordonna à un domestique nommé Tsayoung d'aller au port de Hoaï-gan louer un bateau pour lui et sa famille. Il emballa les vêtemens, les parures et tous les objets précieux, serra sous la clé les meubles d'un transport difficile et les effets de peu de valeur, et en confia la garde à un de ses serviteurs. Toutes les autres personnes attachées à son service devaient le suivre à sa destination. Ensuite il acheta une grande quantité d'excellent vin pour boire pendant le voyage, choisit un jour heureux, et, après avoir offert un sacrifice au fleuve, prit congé de ses parens et amis, et s'embarqua.

Le pilote déploie la voile et navigue dans la direction de Yangtcheou. 


\section{Contes chinois}

Cet homme s'appelait Tchin-siaosse ; il était de la ville de Hoaï-gan, et avait déjà atteint sa trentième année. Il avait sous ses ordres sept bateliers dont voici les noms : Peman, Lihoutseun, Tchin-tiefa, Tsiu-siaoyouan, Homan-eul, Iu-kiapa et Ling-waïtsouï. C'étaient des gens vicieux et cruels qui passaient leur vie à naviguer sur les fleuves, dans l'unique but de dépouiller les voyageurs et les marchands.

Le malheur voulut que Tsawou choisît leur bateau pour s'embarquer.

En voyant apporter une grande quantité de caisses et de ballots, Tchin-siaosse promenait déjà sur ce butin des yeux enflammés par la cupidité ; mais lorsque toute la famille descendit et qu'il aperçut Souï-houng, qui était d'une beauté accomplie, une émotion secrète s'empara de ses sens, et ne fit qu'allumer davantage sa cupidité.

Déjà, dans son cœur, il forme de coupables projets ; mais, de peur de se trahir lui-même, il veut être plus éloigné de la terre pour les exécuter.

Le vent fut favorable, et, en moins d'un jour, le bateau arriva en présence d'Hoang-tcheou.

« La fortune nous sourit, se dit-il à lui-même, encore quelques instans et nous mettrons la main à l'œuvre.

- Camarades, dit-il aux matelots, nous avons là une bonne capture à faire ; n'ayons pas la folie de la laisser échapper d'entre nos mains. Allons, point de retard ; il faut que, ce soir même, elle soit en notre pouvoir. 


\section{Contes chinois}

- Il y a déjà longtemps, répondirent-ils, que nous avions la même idée; mais, vous voyant garder le silence, nous avons cru que vous leur faisiez grace en qualité de compatriotes; et cette pensée nous a retenus.

- Durant tout le trajet, reprit Tchin-siaosse, nous n'avions pas encore rencontré d'occasion favorable. C'est pour eux une bonne fortune d'avoir vécu quelques jours de plus.

- Le seigneur Tsawou est un brave militaire, ajoutèrent les matelots ; ce n'est pas un homme ordinaire ; et puis il a beaucoup de monde à sa suite. Nous avons besoin de courage et de prudence.

- Lui, répond le pilote, il est brave, mais c'est à boire ; voilà tout son mérite. Quelle crainte vous peut inspirer un pareil champion ? Laissons-le s'enivrer tranquillement, et, quand il aura bu tout à son aise, sa femme et lui verront beau jeu. Épargnons seulement cette jeune demoiselle; elle restera pour être l'épouse de votre patron.

A peine avaient-ils pris cette résolution qu'ils arrivent à Hoang-tcheou, situé sur les bords du fleuve Yangtseu-kiang. Ils jettent l'ancre et descendent pour acheter des vivres et du vin. Après un repas copieux, où les matelots n'épargnèrent ni la chère ni le vin, on met à la voile et le bateau part comme un trait. 


\section{Contes chinois}

Ce jour-là était le quinzième du mois, et le disque brillant de la lune répandait une clarté aussi vive que le soleil à son midi.

Sitôt qu'on eut gagné le large :

- N'allons pas plus loin, s'écria Tchin-siaosse ; camarades, voici le lieu qui doit être témoin de nos exploits.

A ces mots, l'ancre est jetée, et les voiles s'abaissent ; chacun d'eux prend ses armes et s'élance vers la cabane où dormait Tsawou.

Un domestique se présente au devant d'eux, il voit le danger et pousse un cri d'alarme ; mais il était trop tard pour appeler au secours. Un matelot lui assène au front un coup de hache et l'étend sans vie à ses pieds. Les autres serviteurs s'apprêtent à combattre ; mais que peuvent-ils contre une troupe de brigands forcenés?

Tsawou, depuis qu'il s'était embarqué, avait bu fort peu les premiers jours ; mais, insensiblement, lui et sa femme reprirent leur funeste habitude, sans que les avis de Souï-houng eussent pu les en détourner.

Ce soir-là les deux époux s'étaient épanoui l'ame en buvant, et avaient presque laissé au fond de la bouteille leurs sens et leur raison.

Tout-à-coup des cris perçans se font entendre dans la cabane antérieure du bateau. Souï-houng y envoie ses femmes ; mais celles-ci, glacées d'effroi, n'osent faire un pas en avant ; 


\section{Contes chinois}

- Seigneur, s'écrient-elles sur le devant du bateau, on massacre vos gens!

A ces mots, madame Tsa est frappée de stupeur. Elle allait se lever, lorsque ces brigands furieux entrent à pas précipités.

- Me voici, dit Tsawou, les yeux encore obscurcis par les fumées du vin, qu'est-ce qui oserait... ?

En même temps Tchin-tiefa le frappe d'un coup de hache et le renverse à ses pieds.

Tous les domestiques, hommes et femmes, tombent à genoux devant les meurtriers :

- Si c'est notre or que vous voulez, leur dirent-ils, prenez-le ; mais nous vous en supplions, laissez-nous la vie.

- Nous voulons l'un et l'autre, répondent-ils d'une voix effrayante.

- Pourtant, dit Tchin-siaosse, en qualité de compatriotes, je leur fais grace de la hache ; je veux bien qu'ils emportent dans l'autre monde leur cadavre tout entier.

Sur-le-champ il ordonne aux matelots de prendre des cordes et d'attacher ensemble $M$. et madame Tsa, ainsi que leurs deux fils, mais de respecter les jours de Souïhoung. Pour avoir été sourd à tes avis, lui dit en pleurant Tsawou, j'ai fait mon malheur et celui de ma famille. 


\section{Contes chinois}

A peine avait-il cessé de parler, qu'ils sont précipités dans le fleuve. Les servantes qui restaient furent impitoyablement massacrées.

« Un général décoré du cachet d'or était passionné pour le vin ;

Il tombe sous les coups d'un hôte injuste et cruel.

Les flots sans pitié s'amoncèlent jusqu'aux cieux.

On dirait que tous les fleuves soulèvent leurs vagues courroucées.

Souï-houng, qui avait vu immoler toute sa famille sans qu'on lui fit à elle-même le moindre mal, ne douta plus des dangers qui menaçaient son honneur. Elle sort précipitamment de la cabane, et veut s'élancer dans le fleuve.

Mais Tchin-siaosse, abandonnant la hache qu'il tenait, la saisit à deux mains et l'arrête :

- Ne craignez rien, mademoiselle, lui dit-il, je vous rends la vie pour m'occuper du soin de votre bonheur.

- Brigands forcenés, s'écrie Souï-houng, enflammée de colère, c'est peu d'avoir massacré toute ma famille, vous osez encore me ravir I'honneur ! Lâchez-moi ; laissez-moi mourir.

- Serait-il possible, répondit Tchin-siaosse, qu'une personne fraîche comme les fleurs et belle comme la lune, pérît au milieu des flots ? Non, je ne le souffrirai pas; je veux que vous viviez.

En disant ces mots, il l'emporte dans ses bras et entre dans l'arrière cabane.

Souï-houng l'appelle cent fois voleur, brigand, scélérat, et vomit contre lui un torrent d'injures. 


\section{Contes chinois}

-Maître, s'écrient les autres matelots transportés de rage, pourquoi ne pas chercher une épouse ? Pouvezvous endurer les outrages de cette méprisable créature?

Et tout-à-coup ils veulent s'élancer dans la cabane et tuer Souïhoung.

-Camarades, s'écrie Tchin-siaosse en les arrêtant, par égard pour moi, laissez-lui la vie ; demain je l'obligerai bien à vous demander pardon.

Puis il dit à Souï-houng :

- Et vous, taisez-vous au plus tôt. S'il vous échappe encore quelqu'injure, je ne pourrai moi-même vous protéger contre eux.

Souï-houng, fondant en larmes, se dit à elle-même : Si je meurs, qui vengera la mort de toute ma famille ? Endurons le déshonneur ; mais quand la vengeance sera accomplie, je ne survivrai pas longtemps à ma honte.

Elle se tut alors, frappant la terre de ses pieds et poussant de profonds sanglots.

Tchin-siaosse s'efforce, mais en vain, de la consoler. Pendant ce temps-là, les matelots jettent dans le fleuve le reste des cadavres, lavent le bateau et font disparaître les traces du sang qu'ils ont versé. Ensuite, ils déploient la voile et continuent leur route.

Arrivés au bord d'une île, ils prennent les caisses de Tsawou, en enlèvent les effets et se disposent à les partager entre eux. 


\section{Contes chinois}

- Ne vous pressez pas tant, s'écrie Tchin-siaosse. C'est aujourd'hui le quinzième jour du mois, la lune montre son disque circulaire et brille du plus vif éclat. Ne vaut-il pas mieux profiter d'une si belle nuit pour célébrer mon mariage et partager ensemble le joyeux festin qui doit le précéder.

- Vous avez raison, répondirent-ils.

Aussitôt ils prennent quelques cruches de vin excellent et des vivres qu'avait apportés Tsawou, préparent le repas, et s'asseyent en cercle au milieu de la cabane qu'éclairent de nombreuses lumières. Chaque matelot prend une des tasses d'argent de Tsawou et s'abreuve à longs traits.

Tchin-siaosse amène Souï-houng en la tenant dans ses bras, et la fait asseoir à ses côtés :

- Mademoiselle, lui dit-il, je vous prends aujourd'hui pour mon épouse. Ne craignez de ma part aucun affront. Cette nuit même, je veux former cette union qui doit durer jusqu'à ce que l'âge ait blanchi nos cheveux.

Souï-houng, se cachant le visage, ne songeait qu'à verser des larmes.

- Amis, dirent les matelots, offrons chacun un verre de vin à l'épouse de notre frère.

Et de suite l'un d'eux remplit une coupe et la lui présenta.

Tchin-siaosse la prit, et la portant à la bouche de Souïhoung : 


\section{Contes chinois}

- Remerciez ces messieurs de leur courtoisie, lui dit-il, et buvez un peu du vin qu'ils vous offrent.

Mais Souï-houng, sans répondre, repoussait de sa main la tasse que tenait Tchin-siaosse.

- Messieurs, dit-il en riant, mille remercîmens pour votre honnêteté ; permettez-moi de boire pour mademoiselle.

A ces mots, il leva la tasse et la vida d'un trait.

- Frère, dit Tchin-siaoyouan, ne vous contentez pas d'une simple tasse ; buvez-en deux en mémoire de votre union qui doit durer jusqu'à la vieillesse la plus avancée. Aussitôt il remplit une autre tasse que Tchinsiaosse vide comme la première. Pressé par ses camarades, il répond à toutes les invitations, accepte tous les défis, et bientôt se trouve étourdi par ]es fumées du vin.

- Nous sommes en train de nous égayer et de boire, dirent les matelots, mais il ne faut pas tourmenter davantage la jeune épouse. Maître, allez prendre du repos.

- Eh bien ! messieurs, dit Tchin-siaosse, mettez-vous à votre aise et excusez-moi ; je ne puis vous tenir compagnie.

Il emporte dans ses bras Souï-houng, prend une lumière, et passe dans l'arrière cabane qu'il ferme à clé. 


\section{Contes chinois}

Souï-houng, tremblante, éperdue, n'oppose qu'une résistance inutile. Quel dommage qu'un tel trésor soit tombé entre les mains d'un brigand!

Une pluie d'orage flétrit les brillantes étamines des fleurs ;

Un vent impétueux fait périr les tendres bourgeons.

Ne parlons point de tendresse et de félicité conjugale !

Cette union violente n'inspire que la haine et I'horreur !

Cependant les autres matelots étaient encore à table occupés à boire.

- A cette heure, dit Peman, Tchin-siaosse est au comble du bonheur.

- Oui, dit Tchin-tiefa, il s'enivre de délices ; nous au contraire, nous éprouvons de mortels déplaisirs.

- Et lesquels, reprit Tsin-siaoyouan?

-Nous tous, répondit-il, nous avons également pris part à cette expédition, nous avons les mêmes droits, et pourtant il s'est emparé seul de la plus belle portion du butin. Croyez-vous, messieurs, que demain, quand se fera le partage, il daignera nous dédommager et nous accorder un meilleur lot?

- Vous trouvez là du plaisir, dit Li-houtseu ; mais moi, je ne vois dans cette jouissance qu'une source de malheur.

-Et pourquoi des malheurs, repartirent les autres ?

—Vous savez le proverbe, répondit Li-houtseu : Quand on coupe les mauvaises herbes, si l'on n'arrache les racines, elles repoussent bientôt. Après nous avoir vus 


\section{Contes chinois}

massacrer sa famille, Souï-houng voudrait nous arracher le cœur et le dévorer pour assouvir sa vengeance. Croyez-vous qu'elle puisse oublier sa douleur et vivre conjugalement avec Tchin-siaosse ? A peine serons-nous arrivés près d'un village ou de quelqu'endroit habité, elle poussera des cris et nous perdra tous ; notre vie est entre ses mains.

- L'observation est juste, répondent les matelots ; demain nous communiquerons cette idée à Tchinsiaosse. Lui-même l'expédiera, et nous serons tous hors de souci.

- Cette nuit même, répondit un autre, Tchin-siaosse a goûté dans ses bras le comble du bonheur. Comment consentira-t-il à l'immoler de sa main ?

- En ce cas, dit Peman, ne parlons de rien à Tchinsiaosse ; il vaut mieux prendre des mesures secrètes et nous en défaire nous-mêmes.

- Si nous la faisons mourir à son insu, dit Li-houtseu, c'est oublier notre tendresse pour un frère, et transgresser les lois de l'amitié ; mais il me vient une idée qui présente le double avantage que nous cherchons. La voici : Profitons du sommeil de Tchinsiaosse, ouvrons les caisses, et, après nous être partagé les effets qu'elles contiennent, nous disparaîtrons au plus vite. Comme Tchin-siaosse s'est emparé de cette charmante personne et jouit déjà de la meilleure partie du butin, son lot sera bientôt fait. Si 


\section{Contes chinois}

plus tard l'affaire se découvre, lui seul en subira les conséquences ; mais si, par hasard, le crime reste caché, tant mieux pour lui : ce sera reflet de sa bonne étoile. De cette manière, nous respecterons les droits de l'amitié, et nous nous mettrons hors d'embarras.

—C'est bien pensé, s'écrient-ils tous ensemble.

Ils se lèvent, ouvrent les coffres, prennent l'or et l'argent, les habits, les parures et les coupes, et se les partageant entre eux, laissent seulement quelques objets inutiles et de peu de valeur. Chacun prend son lot et fait ses paquets. De suite ils ferment la cabane, conduisent le bateau le long d'un rivage qui communiquait à une grande route, s'élancent à terre et disparaissent en un clin d'œil.

« L'or et l'argent des coffres leur appartiennent en commun ; mais un seul s'enivre de parfums sur la couche du plaisir. L'impudent frelon dépouille de leur miel les ruches étrangères, et dort au sein de la fleur dont il a terni l'éclat.

Tchin-siaosse, plongé dans l'ivresse du plaisir, n'entendit rien de ce qui se passait au dehors de sa cabane et ne se leva que le lendemain à une heure très avancée. Il cherche les gens de l'équipage et ne voit personne : «Ils se seront enivrés la nuit dernière, se dit-il, et ils dorment encore profondément. » Il va dans la cabane antérieure, parcourt le bateau d'un bout à l'autre et ne voit pas l'ombre d'un homme. « Où seraient-ils donc allés, » s'écrie-t-il rempli d'étonnement et de crainte ? Il commence à concevoir des doutes et retourne dans la cabane 


\section{Contes chinois}

antérieure. Quel fut son étonnement ! Toutes les caisses étaient ouvertes : il les parcourt l'une après l'autre, et les trouve toutes vides, excepté une qui ne contenait que des objets de peu de valeur, des lettres, des billets de visite et des papiers insignifians.

Il comprit alors le motif de la fuite des matelots. Il était enflammé de colère ; mais il n'osait montrer les sentimens qui l'agitaient.

« Je le vois bien, se dit-il à lui-même, mes camarades ont craint que cette jeune personne que je gardais ne nous trahît dans la suite, et ils sont partis à la dérobée. Me voilà seul maintenant, comment faire pour conduire le bateau ? Je suis vraiment dans un mortel embarras. J'irais bien chercher un homme dans le voisinage pour me prêter l'épaule ; mais, sitôt que nous serons arrivés dans un lieu habité, n'est-il pas à craindre que cette jeune personne ne pousse des cris et des gémissemens, et alors je suis un homme perdu. J'aimerais mieux, comme l'on dit, être assis sur le dos d'un tigre. Cependant je ne puis la garder plus longtemps. Allons, j'ai déjà coupé l'herbe, arrachons jusqu'à la racine.

Il dit, prend une hache et entre précipitamment dans l'arrière cabane. Souï-houng, encore étendue sur son lit, ne cessait de gémir et de verser des larmes. Quoique son visage fût baigné de pleurs, elle n'en paraissait que plus belle et plus séduisante.

A peine cet homme féroce l'eut-il considérée un instant, ses esprits se troublent, son ame est ébranlée, et ses bras, déjà 


\section{Contes chinois}

levés contre elle, retombent sans mouvement. Soudain il ouvre à la pitié son cœur sanguinaire, et, dans son émotion, il laisse échapper la hache dont il est armé. Ensuite il s'élance vers Souïhoung, I'enlace dans ses bras et donne de nouveau cours à ses transports. Quel dommage ! Comment une fleur brillante et délicate peut-elle supporter la fougue des vents et les assauts d'une pluie orageuse?

Mais bientôt oubliant sa passion effrénée :

- Je vois, lui dit-il, que vous êtes faible et languissante ; attendez un peu, je vais vous apporter à manger, et ensuite vous prendrez du repos.

Tout en préparant le repas, il se disait en lui-même :

« Si je me passionne follement pour cette jeune personne, je suis perdu sans ressource ; j'ai bien envie de lui ôter la vie ; mais je ne me sens point la force de lever le bras sur elle. Eh bien ! si j'abandonnais mon bateau et que j'allasse m'établir dans un autre endroit, peut-être trouverais-je encore une aussi belle occasion ; j'amasserais de l'argent pour faire construire une autre barque et je reprendrais mon train de vie accoutumée. Je laisserai Souï-houng dans le bateau : si le destin n'a point décidé sa mort, elle trouvera sans doute un libérateur, et cette conduite m'attirera les bénédictions du ciel.

Puis réfléchissant un instant : 


\section{Contes chinois}

«Non, non, s'écria-t-il, point de miséricorde : si je ne l'extermine, pendant le reste de ma vie, elle sera pour moi une source continuelle de malheurs. Tout ce que je puis faire, c'est de lui faire grace du couteau et de l'envoyer dans l'autre monde avec son cadavre tout entier.

Il prépare pour lui quelques alimens, recueille les effets qui lui appartenaient ainsi que les effets qui lui avaient été laissés et en fait un ballot qu'il met de côté. Ensuite prenant une corde avec un nœud coulant, il entre précipitamment dans l'arrière cabane.

En ce moment, Souï-houng, redoutant le retour du brigand, s'était enveloppée dans ses vêtemens, et, la tête cachée dans le lit, pleurait en songeant aux moyens de venger son honneur et la mort de sa famille. Elle ne pensait pas que cet homme dénaturé viendrait consommer ses forfaits.

Il accourt auprès d'elle, d'une main soulève sa tête et de I'autre la fait passer dans le nœud coulant.

Souï-hoang veut crier, mais la corde, serrée avec force, l'empêche de proférer un seul mot. Pressée par la douleur, elle agite les pieds et les mains, bondit plusieurs fois d'un mouvement convulsif, retombe enfin et reste étendue sans mouvement.

Le brigand, la croyant privée de vie, abandonne la corde et va ramasser le ballot qu'il avait laissé en-dehors de la cabane ensuite il s'élance sur le rivage et s'échappe à pas précipités. 


\section{Contes chinois}

Cependant Souï-houng ne devait pas encore mourir. Heureusement pour elle, le meurtrier n'avait formé qu'un simple nœud, et quoique dans le moment elle eût perdu la respiration et I'usage de ses sens, peu-à-peu elle put étendre la main et desserrer la boucle fatale. Sa situation était bien différente de celle des personnes suspendues à un lacet que le mouvement ou le poids de leur corps ne fait que serrer de plus en plus.

Bientôt son cou est dégagé des liens qui le pressent, l'air s'insinue dans son sein et donne un libre cours à sa respiration. Insensiblement elle revient à elle-même ; mais ses membres étaient d'une faiblesse extrême et ne lui permettaient pas de faire le moindre mouvement. Après quelques instans de repos, elle fait un dernier effort et arrache tout-à-fait la corde qui l'avait si cruellement serrée.

« $O$ mon père, dit-elle en elle-même, les yeux baignés de larmes et le cœur navré de douleur, si, dans le temps, vous eussiez écouté mes conseils, aurions-nous pu éprouver de si grands malheurs ? Dans la vie passée, quel mal avions-nous fait à ces brigands pour devenir aujourd'hui victimes de leur cruauté ? Après avoir enduré le déshonneur, je n'ai consenti à vivre que pour venger ma famille et laver ma honte. Je ne croyais pas que ce brigand me laissât la vie. Que ne puis-je mourir à l'instant ! Mais, ô mon père, notre injure est profonde comme les abîmes de la mer ! Quelle douleur j'éprouverais de fermer les yeux avant de I'avoir effacée! 


\section{Contes chinois}

Elle était agitée de mille pensées, et chaque réflexion ne faisait qu'augmenter l'amertume de son ame.

Comme elle pleurait encore, le bateau reçoit une commotion qui le fait vaciller quelques instans et renverse presque le lit où elle était couchée.

La frayeur suspend les gémissemens de Souï-houng ; elle prête l'oreille et entend les hommes d'un bateau voisin qui poussaient de grands cris en frappant l'eau de leurs rames. Mais dans la barque où elle se trouvait elle n'entendit pas le plus léger bruit. «Pourquoi, se dit-elle dans son incertitude, cette troupe de brigands voit-elle heurter le bateau sans ouvrir la bouche ? Peut-être ces matelots sont-ils leurs camarades, peut-être aussi la barque qui vient de frapper contre la nôtre est celle du magistrat chargé de prendre les voleurs, et c'est pour cela sans doute qu'ils n'osent élever la voix pour se plaindre.

Elle allait pousser des cris et appeler à son secours, mais elle eut peur de s'être trompée dans ses conjectures. Comme elle était dans le trouble et l'incertitude, soudain elle voit plusieurs hommes s'élancer dans le bateau qu'ils s'étonnent de trouver vide, et entrer précipitamment dans l'arrière cabane où elle était.

« Si ce sont les camarades de ces brigands, se dit à elle-même Souï-houng, je suis perdue sans ressource.

-Qu'est devenu cet infortuné magistrat, disent les étrangers ? Où sont ses gens et toute sa famille dont il ne reste pas la moindre trace ? 


\section{Contes chinois}

A ces mots, Souï-houng reconnut bien que ce n'étaient pas des voleurs. Elle se relève, et poussant de grands cris, implore leur assistance.

Ils se retournent et voient une jeune femme d'une beauté accomplie ; ils lui donnent la main, l'aident à descendre et lui demandent des détails sur tout ce qui s'est passé.

Souï-houng, sans pouvoir répondre, verse un torrent de larmes ; ensuite elle leur parle du rang de son père, du motif de son voyage et leur fait le récit exact de tous ses malheurs.

- Messieurs, ajouta-t-elle, prenez pitié d'une malheureuse qui a été indignement outragée et qui n'a personne pour la venger. Je vous en supplie, conduisezmoi devant le magistrat afin que je lui présente une requête et qu'il fasse prendre les brigands qui ont causé mon malheur et anéanti toute ma famille. Un si grand bienfait attirera sur vous les faveurs du ciel.

- Quelle horreur d'avoir traité si indignement cette charmante demoiselle! s'écrièrent-ils. Cependant nous ne pouvons prendre sur nous de faire ce que vous demandez. Attendez que nous appelions le seigneur notre maître ; vous pourrez vous expliquer avec lui.

A ces mots, I'un d'entre eux courut le chercher et arriva avec lui quelques instans après. En le voyant venir, tout l'équipage s'écrie :

- Voici son excellence. 


\section{Contes chinois}

Souï-houng lève les yeux ; elle aperçoit un homme d'un air grave et majestueux, et dont le costume et le maintien imprimaient un sentiment de respect.

Comme elle avait entendu les gens du bateau l'appeler leur seigneur, elle ne douta point que ce ne fût un homme d'une haute naissance. Les yeux en pleurs, elle se prosterne devant lui jusqu'à terre. Mais lui, la relevant avec empressement,

- Mademoiselle, lui dit-il, qu'est-il besoin de me faire cette profonde révérence ? Si vous avez quelque demande à m'adresser, parlez, expliquez-vous.

Souï-houng lui raconte en détail tout ce qui lui était arrivé.

- Seigneur, ajouta-t-elle, prenez pitié de moi, daignez être mon libérateur et me retirer de l'abîme de maux où je suis tombée; je n'oublierai jamais un si grand bienfait.

- Mademoiselle, répondit-il, modérez votre douleur. Ces brigands se sont sauvés, mais ils ne doivent pas être bien loin. Je vais avec vous trouver le magistrat afin que vous lui présentiez une requête. Il enverra de tous côtés des officiers de justice, et il est impossible qu'ils échappent à leurs poursuites.

Souï-houng, retenant ses pleurs, lui témoigne la gratitude dont elle est pénétrée.

Il appelle quelques hommes du bateau et leur donne ses ordres. 


\section{Contes chinois}

- Hâtez-vous, leur dit-il, cette affaire ne peut souffrir de retard. Soutenez mademoiselle Souï-houng et aidezla à passer sur notre embarcation.

Souï-houng cherche ses souliers, se chausse et se dispose à les suivre. En sortant de la cabane, elle voit un bateau à deux voiles chargé de marchandises.

Aussitôt qu'elle y fut descendue, le capitaine la prie d'entrer dans une cabane pour y prendre du repos.

Les matelots enlèvent tous les ustensiles et les effets que contenait la barque des brigands, déploient les voiles et continuent leur route.

Cet homme s'appelait Pofo ; il était originaire du département de Han-yang. Il faisait le commerce en naviguant d'un lieu à un autre. Au bout de quelque temps, ayant amassé une grande fortune, il avait fait construire à ses frais ce large bateau et transformé en mariniers tous les gens de sa maison.

Cette fois, ayant vendu le long du chemin toute sa cargaison de grains, il avait acheté des marchandises d'un débit facile dans son pays et profitait d'un temps favorable pour s'en retourner, lorsque tout-à-coup un vent impétueux chasse le bateau au bord du rivage. Le pilote saisit le gouvernail et commande la manœuvre aux matelots; mais tous leurs efforts sont inutiles. Un nouveau coup de vent ramène le bateau et le pousse contre celui des voleurs. Les nautonniers voyant une barque couverte et pensant qu'elle appartenait à un magistrat, craignaient de s'attirer une mauvaise affaire. Tout l'équipage fait de nouveaux efforts pour se détourner, mais leur bateau s'arrêta dans un bas- 


\section{Contes chinois}

fond. Cet embarras était la cause de leurs cris confus et des tentatives multipliées qu'ils faisaient pour gagner le large, lorsqu'ils vinrent heurter contre l'autre bateau.

Pofo, étonné de n'y voir pas même l'ombre d'un homme, envoie plusieurs matelots pour en savoir la cause.

Un instant après, ils reviennent et lui annoncent qu'ils n'ont trouvé qu'une jeune personne d'une rare beauté qui demandait assistance et appelait un libérateur.

A ce récit Pofo conçut des pensées indignes d'un homme de son caractère et employa la ruse et le mensonge pour la faire passer dans son bateau. Mais comment supposer que ces belles démonstrations ne partaient point du fond de son cœur et qu'il ne songeait à rien moins qu'à redresser ses griefs et à prendre le soin de sa vengeance.

Souï-houng, après avoir été en proie à tant de malheurs, n'avait personne à qui elle put confier ses peines. Aussitôt qu'elle eut vu Pofo, elle le regarda comme un parent et implora son appui. Comme elle l'avait entendu prononcer le nom de brigands, elle ne douta point de sa droiture et se rendit sans la moindre inquiétude sur son bateau.

Quand elle eut pris un peu de repos :

« J'ai commis une grave imprudence, se dit-elle en ellemême ; cet étranger n'est ni mon parent, ni l'ami de ma famille ; à quel titre puis-je espérer qu'il me prêtera secours ? quoiqu'il m'ait promis assistance et protection, je ne saurais encore juger de la sincérité de 


\section{Contes chinois}

ses sentimens. S'il avait des vues coupables, comment pourrais-je m'en garantir?

Comme elle était agitée par ces inquiétudes, elle voit venir Pofo. Il ordonne à ses gens de faire chauffer d'excellent vin et de préparer un repas splendide pour traiter convenablement Souïhoung.

- Mademoiselle, lui dit-il, vous devez avoir faim ; veuillez accepter le repas que j'ai I'honneur de vous offrir.

Mais Souï-houng, qui avait l'esprit occupé du souvenir de son père et de sa mère, ne put obéir à son invitation.

Pofo assis à ses côtés lui parlait d'un ton plein de douceur et lui prodiguait mille caresses.

Ayant réussi à lui faire accepter deux petites tasses de vin :

- Mademoiselle, lui dit-il, j'ai un mot à vous communiquer, mais j'ignore si vous voudrez bien m'écouter et me donner votre avis.

- Seigneur, répondit Souï-houng, quelles instructions avez-vous à donner à votre servante ?

- Mademoiselle, lui dit-il, dans le premier moment, touché de pitié pour vous, je vous ai promis de vous conduire devant le magistrat pour lui adresser une accusation ; j'oubliais que mon bateau est rempli de marchandises dont la vente ne saurait être retardée. Je songe aujourd'hui que les poursuites judiciaires sont d'une longueur désespérante. Si l'affaire qui nous 


\section{Contes chinois}

occupe traîne pendant six mois ou un an, je ne pourrai me défaire de mes marchandises, et ainsi nous aurons tous deux perdu beaucoup de temps à attendre vainement. Il vaut mieux, mademoiselle, que vous me suiviez chez moi : je vendrai d'abord mes marchandises, ensuite nous prenons un petit bateau et nous viendrons ensemble informer la justice et poursuivre cette affaire. Quand il faudrait alors attendre des années entières, peu m'importe ; je n'aurai point de repos que vous ne soyez vengée. Il y a encore un point sur lequel je veux vous consulter. Je suis veuf et vous paraissez être veuve aussi. En allant et venant, nous ne manquerons pas d'éveiller les soupçons et de donner lieu à des propos injurieux. Quand nous nous conserverions tous deux dans la plus grande pureté, nous n'obtiendrons pas plus d'indulgence. D'ailleurs vous êtes sans parens, sans appui et sans ressources. Quoique je ne sois qu'un simple marchand, j'ai du bien chez moi et je jouis d'une heureuse aisance. Si vous ne dédaignez pas mon alliance, unissons-nous de suite et soyons époux. Ensuite, je prendrai le soin de vous venger, et quand il faudrait traverser les flots, ou passer au milieu du feu pour y parvenir, il n'est point de danger que je n'affronte. Je veux moi-même prendre les brigands et les amener liés et garottés, afin que vous ayez la satisfaction de les voir subir le châtiment qu'ils méritent. J'ignore encore ce que pense mademoiselle et quel est son avis. 


\section{Contes chinois}

A ce discours, Souï-houng, le cœur navré de douleur, versa un torrent de larmes.

« Infortunée que je suis, se dit-elle à elle-même, j'ai encore rencontré un homme pervers ; il me tient dans son piège : comment lui échapper! Au reste, s'écria-telle en soupirant, mon déshonneur est peu de chose auprès de la mort de mon père et de ma mère. Après avoir été outragée par un brigand, quand je mourrais aujourd'hui, je ne puis me regarder comme pure et intacte. Attendons le jour de la vengeance ; il sera temps alors de mettre un terme à ma vie pour laver mon déshonneur. »

Après s'être remise de son trouble et avoir essuyé ses larmes:

- Seigneur, dit-elle, si vos paroles sont d'accord avec vos sentimens, et que vous daigniez venger votre servante et effacer sa honte, je vous suivrai avec plaisir et j'obéirai à vos ordres ; mais je désire que vous confirmiez par un serment les promesses que vous m'avez faites.

Pofo à cette réponse ne peut contenir sa joie, et soudain se jetant à genoux, il prononce le serment qu'elle exige :

« Je jure de venger mademoiselle et de laver son déshonneur. Si je manque à cet engagement sacré, puissé-je périr au milieu des flots. 


\section{Contes chinois}

Il dit et se relève. Il ordonne ensuite aux matelots d'arrêter le bateau au rivage, et d'aller dans un bourg voisin acheter du poisson, de la viande, du vin et des fruits afin que tout l'équipage célébrât le repas nuptial. La nuit vint et fut pour Pofo une source de délices.

Ils partent, et, en moins d'un jour, arrivent à Han-yang.

Pofo avait pour épouse une femme acariâtre et de la plus basse jalousie. Comme il la craignait et tremblait d'éveiller ses soupçons, il plaça Souï-houng dans une maison qu'il avait louée loin de chez lui, et recommanda soigneusement à ses gens d'en garder le secret.

Or, parmi ces domestiques, il y en avait un d'un caractère faux et hypocrite, qui mettait tout son plaisir à épier les secrets et à semer la division. Il ne fut pas plus tôt instruit de cette circonstance, qu'il alla en informer la dame Pofo.

Celle-ci entre en fureur et veut dans le premier mouvement chercher querelle à son mari ; mais, réfléchissant qu'elle n'avait ni le temps, ni l'occasion de disputer avec lui, elle prit le parti de ne dire mot. Elle envoie chercher secrètement des revendeurs et s'engage à leur livrer cette jeune personne en recevant un prix convenu.

Le jour dit, la dame Pofo enivre son mari et l'enferme dans sa chambre. Elle prend ensuite une chaise et se fait conduire à la maison où demeurait Souï-houng. Les revendeurs étaient déjà au rendez-vous et attendaient son arrivée. 


\section{Contes chinois}

Madame Pofo entre et envoie quelqu'un annoncer à Souïhoung que l'épouse du seigneur Pofo vient lui faire visite.

Souï-houng, ne pouvant se dispenser d'un devoir que lui imposent les convenances, sort de son appartement et va la recevoir.

Les revendeurs, qui se tenaient à l'écart, l'observent attentivement, et sont transportés de joie en voyant une personne d'une beauté si accomplie.

Madame Pofo, prenant un air riant et épanoui :

- Il faut convenir, dit-elle à Souï-houng, que j'ai un mari bien ridicule et bien extravagant. Puisqu'il vous a épousée, pourquoi vous a-t-il ensevelie dans ce réduit ? Est-ce là le fait d'un homme qui tient à sa considération ? Les gens du dehors en rejettent la faute sur moi, et ne cessent de dire que je suis seule la cause de cette conduite. Je viens exprès aujourd'hui pour faire taire ces propos injurieux et vous emmener avec moi. Prenez vos vêtemens, faites-en un paquet et disposezvous à m'accompagner.

Souï-houng, ne voyant point Pofo, conçut des doutes, et imagina mille prétextes pour se dispenser de lui obéir.

- Si vous ne voulez pas habiter avec moi, lui dit madame Pofo, venez au moins passer un ou deux jours à la maison pour vous récréer et prendre quelque délassement. 


\section{Contes chinois}

Souï-houng, séduite par ses dernières instances qui lui semblaient dictées par la franchise, n'insiste pas davantage, et va dans son appartement mettre en ordre ses vêtemens et se disposer à partir.

Pendant ce temps-là, la dame Pofo sort un instant et fixe avec les revendeurs le prix qu'elle exige. En même temps elle ordonne à un domestique d'aller louer une chaise.

Elle amène Souï-houng dont elle avait surpris la bonne foi et la fait monter avant elle. Les porteurs, fidèles au mot d'ordre, courent comme s'ils avaient des ailes et ne s'arrêtent que dans un lieu inhabité, situé auprès du fleuve.

Les marchands viennent recevoir Souï-houng, et la conduisent dans un bateau qui était à l'ancre.

Souï-houng reconnut bientôt qu'elle était tombée dans un piège. Elle pleure, elle gémit, et veut s'élancer dans le fleuve.

Mais les revendeurs, la saisissant de chaque côté, l'empêchent de faire le moindre mouvement, et la poussent de force dans l'intérieur du bateau. Ensuite ils congédient les porteurs, lèvent l'ancre, déploient les voiles et se mettent en route.

La dame Pofo, ayant vendu Souï-houng, recueille tous les effets qu'elle avait laissés, les met en paquets et les emporte ; puis elle ferme la chambre à clé, et revient chez elle.

Pofo, échauffé par le vin, dormait encore d'un profond sommeil. Sa femme, lui donnant trois ou quatre soufflets, le tire de son ivresse pour le vexer par ses reproches et lui adresser 


\section{Contes chinois}

des injures. Pendant plusieurs jours, elle ne cessa de le contrarier et de le harceler de mille manières.

Pofo, qui craignait d'éveiller les soupçons de sa femme, n'osait mettre le pied hors du seuil.

Un jour, profitant de son absence, il court au domicile de Souï-houng. Quel fut son étonnement quand il vit la porte fermée ! Il interroge les domestiques, et apprend qu'il y a déjà longtemps que sa femme l'a vendue.

La colère s'empare de lui, et lui ôte l'usage de ses sens.

Comme Pofo n'avait point vengé Souï-houng, le ciel permit que, quelque temps après, il tombât dans le fleuve et qu'il y trouvât la mort, suivant le serment qu'il avait prononcé peu de jours auparavant.

Cette femme, vicieuse et dépravée, vit à peine son mari mort qu'elle se plongea de plus en plus dans la débauche, et fut réduite à engager et à vendre tout ce qu'elle possédait. Bientôt après elle fut enlevée par un homme à qui elle s'était abandonnée, et finit par être vendue pour figurer dans une maison de mauvaise renommée.

Cet exemple fait voir que le ciel est souverainement juste, et qu'en châtiant le coupable il ne saurait se tromper de l'épaisseur d'un cheveu.

Une jeune fille endure le déshonneur pour venger sa famille ;

Qui eût dit que sa piété héroïque devait causer sa perte ?

Ne prononçons jamais des sermens que dénient notre cœur.

Le ciel, dont le regard est si pénétrant, veille au-dessus de nos têtes. 


\section{Contes chinois}

Souï-houng, que les revendeurs avaient entraînée de force dans leur bateau, ne cessait de pleurer et de gémir.

- Pourquoi vous affliger ainsi ? lui disaient-ils pour la consoler ; une fois débarquée, vous aurez à souhait de riches vêtemens, et des mets abondans et recherchés; vous jouirez d'un contentement parfait, et de toutes sortes de plaisirs. N'est-ce pas un sort plus heureux que de rester chez cette grande dame pour essuyer tout le jour ses rebuts et sa colère?

Souï-houng, tout entière à sa douleur, ne faisait nulle attention à eux. Réfléchissant en elle-même sur sa position, elle cherchait un moyen de se défaire de la vie; mais comment mourir sans être vengée elle et sa famille ? Et cependant, en consentant à vivre, elle deviendra incertaine et agitée comme une personne qui erre au gré des flots. Eh bien ! se dit-elle, le soin de venger ma famille l'emporte sur toutes les considérations ; prenons patience, attendons le temps favorable au dessein qui m'occupe.

Après une courte navigation, la nuit tombe et les oblige de jeter l'ancre au bord du rivage.

Un des revendeurs vient trouver Souïhoung et la presse de partager son lit.

Souï-houng, sourde à ses discours, s'enveloppe dans ses vêtemens et va se tapir dans un coin de la cabane. Le revendeur renouvelle ses instances, mais Souï-houng, loin de céder, crie : au meurtre, à l'assassin. Celui-ci, qui craignait que ses 


\section{Contes chinois}

camarades ne l'entendissent et ne lui suscitassent quelque mauvaise affaire, la laissa tranquille et cessa de la tourmenter.

A peine furent-ils arrivés au département de Woutchang, ils revendirent Souï-houng au patron d'une maison de plaisir.

Il y avait déjà dans cette maison deux ou trois courtisanes parées avec la dernière recherche, et le visage couvert d'une couche de blanc et de vermillon ; elles étaient à la porte, étalant leur beauté vénale et attendant fortune.

Souï-houng, en voyant le sort de ces malheureuses, se sentit de plus en plus pénétrée de douleur. Hélas ! se dit-elle à ellemême, aujourd'hui que je suis tombée dans ce repaire de débauche, il faut renoncer à tout espoir de vengeance. De quel front oserai-je supporter la vie?

Dès ce moment son parti est pris ; elle cherche le chemin de la mort, et repousse avec dédain les habitués de cette maison.

Mais une chose bien singulière, c'est que toutes les fois que Souï-houng songeait aux moyens de quitter la vie, il survenait toujours quelqu'un qui la tirait de peine et apaisait son désespoir.

Le patron du lieu consultant à ce sujet une de ces nymphes surannées :

- Puisque Souï-houng, lui dit-il, ne veut pas se prêter à nos coutumes, que sert de la garder ici ? Cette petite sotte n'a qu'à faire un tour de sa tête, c'est moi qui paierai son étourderie. Ne vaut-il pas mieux la revendre, et en trouver une autre? 


\section{Contes chinois}

Le hasard voulut qu'il se trouvât dans le même endroit un homme du département de Tchaohing, dont le nom de famille était Hou, et le surnom Youe.

Comme le gouverneur de Woutchang était son proche parent, il était venu exprès dans cette ville pour lui demander un secours pécuniaire, et avait obtenu de lui une forte somme d'argent.

Le jeune homme, qui aimait les femmes et le vin, avait loué un hôtel voisin de la maison où était Souï-houng ; et sitôt qu'il avait du loisir, il y venait faire un tour, et passer le temps dans la joie et la bonne chère.

A peine eut-il remarqué la beauté de Souï-houng et les agrémens répandus sur toute sa personne, qu'il en devint éperdument amoureux, et la pressa plusieurs fois de répondre à ses sentimens. Mais comme Souï-houng ne songeait qu'à quitter la vie, il ne put triompher de son désespoir.

Quelque temps après, ayant entendu dire que le patron songeait à s'en défaire, il lui offrit un prix considérable, désirant la prendre à titre de seconde femme. Celui-ci consentit de suite à sa proposition, et remit la jeune personne entre ses mains.

Hou-youe, possesseur de Souï-houng, la conduisit à son hôtel, et fit préparer un repas splendide pour traiter sa nouvelle épouse ; il lui ouvrit son cœur et l'entretint des sentimens qu'il éprouvait pour elle. Mais Souï-houng, ne songeant qu'à pleurer et à gémir, s'éloignait de lui, et repoussait ses caresses. Houyoue essaya plusieurs fois, mais inutilement, de la consoler : 


\section{Contes chinois}

- Mademoiselle, lui dit-il, je conçois qu'étant naguère dans un lieu infâme, vous vous soyez constamment refusée à toute espèce de sollicitations. Aujourd'hui que vous êtes devenue mon épouse, votre sort n'est-il pas mille fois plus heureux qu'auparavant ? Pourquoi vous affliger de la sorte ? Si vous avez quelques peines qui pèsent sur votre cœur, confiez-les à votre époux ; il adoucira vos douleurs en les partageant, et tâchera d'y apporter remède. Mais s'il s'agit d'une affaire grave, le gouverneur de cette ville est mon proche parent, je le prierai d'en prendre fait et cause, et de vous faire rendre justice. Pourquoi vous abandonner ainsi à des chagrins déchirans?

Souï-houng, voyant que ce discours semblait partir du fond de son cœur, lui fit en détail le récit de tous ses malheurs.

- Seigneur, ajouta-t-elle, si vous daignez chercher un vengeur à votre servante, et effacer mon déshonneur, non seulement je consens à être votre épouse mais quand je deviendrais votre esclave, je m'estimerais heureuse.

Elle dit, et verse un torrent de larmes.

- Je vois bien, lui dit Hou-youe, que vous appartenez à une famille de distinction. Quel dommage qu'une personne de votre rang ait éprouvé d'aussi grands malheurs! Mais ce n'est pas l'affaire d'un jour que celle qui nous occupe. Je vais d'abord prier le gouverneur, mon parent, d'envoyer en tous lieux des officiers de 


\section{Contes chinois}

justice pour saisir et amener les coupables. Ensuite nous irons ensemble à Hoaïgan adresser une accusation au magistrat compétent. On prendra les coupables, et l'affaire se terminera à votre satisfaction.

Souï-houng, vivement émue, se prosterna jusqu'à terre pour le remercier.

- Si votre seigneurie daigne me prêter ce généreux secours, toute ma vie j'en conserverai le souvenir.

-Puisque nous sommes époux, dit Hou-youe en la relevant, votre affaire devient la mienne ; pourquoi parler de reconnaissance?

Ensuite il la prend par la main et la conduit dans sa chambre qu'elle croyait être celle d'un époux.

Qui eût pensé que Hou-youe était un homme faux et trompeur, et qu'il n'avait employé ce langage que pour abuser pendant quelques jours Souï-houng ? Comme il avait promis de remettre cette affaire entre les mains du gouverneur, et de faire envoyer des officiers de paix pour saisir les brigands, Souïhoung, séduite par une apparence de vérité qu'il savait donner à ses discours, crut aveuglément à ses promesses et s'épuisa en remercîmens.

Après quelque temps de séjour, il loua un bateau, arrangea ses bagages et partit.

Le voyage fut heureux, et, à la faveur d'un vent favorable, il arriva en dix jours à Tchinkiang. Il loua un autre petit bateau 


\section{Contes chinois}

pour s'en retourner chez lui. Quant à l'affaire de Souï-houng, il la mit tout-à-fait de côté et n'y pensa plus.

Souï-houng reconnut bien que ses espérances étaient déçues, mais, ne voyant aucun moyen de sortir de cette cruelle position, elle se mit à jeûner, passant les nuits et les jours à invoquer le ciel pour trouver un vengeur.

En moins d'un jour Hou-youe arriva chez lui.

Sa femme, le voyant revenir avec une jeune personne aussi belle, en conçut une noire jalousie et se mit à quereller Souïhoung du matin au soir. Celle-ci opposa à ses injures une patience à toute épreuve et la laissa disputer tout à son aise ; de plus elle se refusa absolument à ce que Hou-youe mît le pied dans sa chambre. A la fin, la dame Hou-youe s'apaisa peu-à-peu et cessa de la tourmenter.

Les habitans du département de Tchao-hing ont coutume de faire un trafic qui mérite quelques détails. Ceux qui ont de l'argent et du savoir-faire se rendent à la capitale, achètent un titre littéraire, et, à force d'intrigue et d'argent, se procurent une charge avantageuse. Ils s'adjoignent une personne entendue qui partage leurs fonctions et même les remplace au besoin. Cela s'appelle vulgairement Feikouohaï, (c'est-à-dire, traverser les mers en volant). Voici la raison de cette expression : En général, lorsque le temps d'une charge est expiré et qu'on cherche un remplaçant, chacun ne vient qu'à son tour, et, en suivant la marche régulière, il faut des années pour atteindre une place. Mais ceux dont nous parlons n'ont qu'à donner de l'argent, ils l'emportent sur les autres concurrens, et obtiennent de suite la 


\section{Contes chinois}

charge vacante. Si, par hasard, elle échoit à un homme d'un esprit borné, il s'associe quatre ou cinq individus de la même trempe, dont un seul prête son nom et paie de sa personne ; les autres, sans rien faire, partagent avec lui les profits attachés à ses fonctions.

Dès qu'il est en possession de sa charge, il commence par faire de riches présens aux magistrats qui sont au-dessus de lui, afin d'exercer le monopole des affaires ; et il n'en passe pas une par son bureau, si petite qu'elle soit, qui ne lui fournisse le moyen d'escroquer cinq ou six onces d'argent. Quand ils voient que leur jeu est découvert et qu'il ne leur est pas possible de tenir plus longtemps, ils finissent par fuir secrètement et disparaître. Sur dix, il est difficile d'en trouver un ou deux qui s'occupent d'acquérir de I'honneur ou de la réputation. Tels sont presque tous les fonctionnaires qui sortent du département de Tchaohing.

Hou-youe, étant resté environ un an chez lui, songea à aller à la capitale et tenter fortune de ce côté-là. Il était d'autant plus disposé à prendre ce parti, qu'un de ses amis, qui était du métier, lui avait écrit à ce sujet et lui avait promis de l'appuyer de tout son pouvoir. Cette offre lui causa une joie inexprimable. Il alla de tous côtés ramasser de l'argent pour acheter sa charge, fit ses préparatifs de voyage et se disposa à partir. Mais, craignant que ses deux épouses ne vécussent pas en bonne intelligence, il consulta Souï-houng et la pressa de le suivre, lui promettant, sitôt qu'il aurait obtenu la charge qu'il désirait, de 


\section{Contes chinois}

faire des recherches pour trouver les brigands et leur infliger le châtiment qu'ils méritaient.

Souï-houng, qu'il avait déjà trompée une fois, ne croyait nullement à ses promesses ; mais, espérant trouver, en allant de côté et d'autre, une occasion favorable à son dessein, elle consentit à l'accompagner.

A cette nouvelle, la dame Hou-youe entra en fureur, fit un vacarme d'enfer, et chercha à son mari une querelle qui ne se termina qu'après bien des coups et des injures.

Hou-youe resta inflexible dans sa résolution ; il choisit un jour heureux, loua un bateau, et partit avec Souï-houng.

Arrivé à la capitale, il cherche un hôtel et y installe Souïhoung. Le lendemain, il prépare des présens et va présenter ses hommages à son ami le magistrat.

Malheureusement, ce fonctionnaire était tombé malade un mois auparavant et avait été emporté subitement. Toute sa famille était dans le trouble et la désolation, et ses parens, après avoir disposé le cercueil qui renfermait ses dépouilles, allaient retourner dans leur pays.

Hou-youe, se voyant privé de cet appui, commença à tomber dans le découragement. Réfléchissant qu'il n'avait apporté que peu d'argent, et que l'ami sur lequel il avait compté venait de mourir, il ne voyait plus aucun moyen d'arriver à la charge qu'il avait en vue. Il aurait bien voulu s'en retourner, mais il était retenu par la crainte de se faire railler de ses compatriotes. 


\section{Contes chinois}

Comme il flottait dans l'incertitude et ne savait quel parti prendre, il alla trouver un de ses amis à qui il raconta son aventure et lui demanda ses conseils. Cet homme, qui voulait courir la même carrière et à qui il manquait de l'argent pour conclure l'achat de sa charge, eut de suite l'idée de jouer un tour à Hou-youe. Il lui promit de se charger de son affaire et d'aplanir tous les obstacles, ajoutant que s'il manquait quelque chose de la somme nécessaire il en emprunterait le complément à un de ses amis.

Hou-youe se laissa séduire par les paroles flatteuses et les propos adroits de son compatriote, prit tout l'argent qu'il avait apporté et le remit entre ses mains. Celui-ci, transporté de joie, conclut l'affaire, et, partant en secret, va prendre possession de la charge qu'il avait sollicitée.

Hou-youe, se trouvant les mains vides, se vit bientôt privé des moyens de pourvoir à son existence. Il écrivit à sa femme, lui demandant de quoi faire le voyage pour revenir chez lui. Mais la dame, qui était encore furieuse contre son mari, ne lui envoya pas le plus léger secours.

Dès ce moment, il se mit à voyager dans la capitale, allant, sans but, tantôt d'un côté tantôt d'un autre. Ensuite il s'associa avec une troupe de gens sans aveu dont I'unique occupation était de faire des dupes et d'escroquer de l'argent.

Un jour qu'ils avaient besoin d'une forte somme et qu'ils se trouvaient au bout de leurs ruses et de leurs ressources, ils portèrent leur attention sur Souï-houng. Ils eurent l'idée de 


\section{Contes chinois}

I'engager à se faire passer pour la sœur de Hou-youe, afin de faire tourner à leur profit le succès de ses charmes.

Le projet était déjà arrêté, mais Hou-youe craignit de ne pas obtenir le consentement de Souï-houng. Pour y réussir, il imagina un détour dicté par la ruse et le mensonge.

- Précédemment, dit-il, j'espérais obtenir la charge que vous savez et ensuite aller avec vous sur la trace des brigands ; mais tout-à-coup, le destin me devient contraire : mon ami a été emporté par une mort subite, et pour comble d'infortune, ce pendard d'homme m'escroque tout mon argent. Ces revers m'on réduit à une extrême détresse, et je ne puis ni avancer ni reculer. Je désirerais bien retourner chez moi ; mais je ne vois aucun moyen de me procurer les provisions du voyage. Hier soir, en consultant quelques amis, j'ai trouvé un expédient admirable.

- Et quel est cet expédient, repartit Souï-houng ?

- Vous n'avez qu'à vous faire passer pour ma sœur, je chercherai une personne qui vous prenne en qualité de seconde femme. Si quelqu'un vient vous voir pour cet objet, faites-lui un accueil flatteur. Sitôt que nous aurons en main l'argent convenu, nous partirons sans mot dire et nous disparaîtrons tout-à-fait. Comment nos dupes oseront-ils venir vous demander ? Nous irons droit à Hoaï-gan, je ferai des recherches pour découvrir les brigands, et je pourrai ainsi accomplir la promesse 


\section{Contes chinois}

que j'ai faite et dont l'exécution occupe mon cœur tout entier.

Souï-houng, d'abord, refusait fermement d'obéir, mais ayant appris ensuite qu'il la conduirait droit dans sa patrie, elle se rendit à ses instances.

Hou-youe, ayant reçu le consentement de Souï-houng, en ressentit une joie inexprimable et de suite pria ses camarades de chercher en tous lieux un prétendant.

Ainsi :

Le méchant déploie ses ruses comme un vaste réseau :

Il attend que l'homme probe et confiant tombe dans son piège.

A cette même époque, il y avait dans la province de TcheKiang, dans le département de Wen-Tcheou, un licencié nommé Tchou et surnommé Young ; il avait passé sa quarantième année et n'avait pas encore de rejeton mâle. Sa femme l'engageait souvent à prendre une seconde épouse ; mais lui, tout occupé de son avancement, ne songeait nullement à suivre ce conseil.

Bientôt arriva l'examen d'automne ; il se rendit au concours ; mais il ne fut point heureux dans ses compositions, et ne put obtenir le grade qui était l'objet de ses vœux. Honteux de ce mauvais succès, et n'osant retourner chez lui, il se lia avec quelques compagnons d'étude, et resta dans la capitale pour étudier avec eux en attendant le nouvel examen.

Ceux-ci, qui savaient que Tchou-Youan n'avait pas encore de fils, le pressaient instamment de prendre une seconde épouse : Tchou-Youan, cédant à leurs conseils, pria quelqu'un alors de prendre des informations à ce sujet. 


\section{Contes chinois}

A peine cette nouvelle se fut-elle répandue que plusieurs entremetteuses vinrent lui faire des propositions; mais de toutes les femmes qui lui furent présentées, aucune ne se trouva à son gré.

Les vauriens que s'était associés Hou-youe, profitant de cette circonstance, vinrent, sur-le-champ trouver Tchou-Youan pour le faire tomber dans le piège qu'ils méditaient. Ils vantent les charmes de Souï-houng, ajoutant que c'était une beauté sans égale, et que l'antiquité ni les temps modernes n'avaient rien produit de si accompli. Tchou-Youan, séduit par leurs promesses, tomba d'accord avec eux et fixa un jour pour aller voir sa nouvelle épouse.

Comme les vêtemens de Souï-houng avaient quelque chose de commun et de négligé, Hou-youe dit à ses camarades d'en emprunter de neufs et d'élégans, afin de la montrer sous un costume qui la fit paraître avec avantage.

Ceux-ci ayant introduit Tchou-Youan, Hou-youe vint le recevoir. Après les cérémonies d'usage, il lui offre un siège et l'invite à prendre une tasse de thé. Ensuite il fait venir Souïhoung et lui dit de rester debout à la porte du pavillon qu'elle habitait.

Tchou-Youan fait un pas vers elle ; Souï-houng s'incline avec modestie et lui fait une révérence. Celui-ci répond par un salut bienveillant, et s'approchant de plus près pour la considérer, il reconnaît qu'elle est en effet parfaitement belle. Oh la charmante personne, se dit-il en lui-même ; est-il possible de réunir plus de grace et d'attraits ! 


\section{Contes chinois}

Souï-houng de son côté fut frappée des manières nobles et distinguées de Tchou-Youan et de I'agrément répandu sur toute sa personne.

«Ce seigneur est fort bien, se dit-elle en elle-même ; son maintien est à la fois plein d'élégance et de dignité, et l'on peut dire qu'il est doué de ce charme indicible qui plaît et qui séduit. Par quel malheur vient-il tomber dans le piège qui lui est tendu?

Cette pensée la pénètre de honte et de regrets, et aussitôt elle rentre dans le pavillon.

Nos fripons prenant à l'écart Tchou-Youan,

- Que vous en semble, seigneur, lui dirent-ils ; votre excellence trouve-t-elle que nous lui en ayons imposé ?

-Non assurément, répondit Tchou-Youan en faisant un mouvement de tête et laissant échapper un léger sourire. Venez à mon hôtel, nous conviendrons du prix et nous choisirons le jour où je dois offrir les présens de noce.

Il dit et prend congé d'eux.

Ceux-ci le suivent de près, le rejoignent bientôt et fixent la somme à cent onces d'argent 1 .

Tchou-youan, qui avait appris que la capitale était remplie de fripons de toute espèce, craignit qu'on ne lui eût tendu quelque piège. Il exigea donc que sitôt l'argent reçu, on lui amenât son épouse. Ils le quittent et courent promptement en conférer avec

1750 fr. environ. 


\section{Contes chinois}

Houyoue. Hou-youe, ayant réfléchi quelques instans, imagina un expédient dont le succès lui parut assuré, mais il craignit que Souï-houng ne voulût point s'y prêter.

Il fait retirer à l'écart ses camarades et vient la trouver pour s'entendre avec elle.

- Ce licencié, lui dit-il, est bien I'homme qu'il nous faut pour le tour que nous méditons; mais il veut vous posséder le jour même où il aura donné l'argent, et cette circonstance ne laisse pas de me causer quelque embarras. Pour le moment, je suis d'avis de le contenter et de vous conduire à son hôtel. Il ne manquera pas de préparer un repas splendide. Pour vous, ayez soin de boire avec réserve. A la cinquième veille ${ }^{1}$, je viendrai avec mes camarades, nous entrerons de force, en criant qu'il a enlevé une femme mariée, et nous le menacerons, devant témoins, de porter plainte en justice contre lui. Ce licencié aura peur que cette affaire ne nuise à son avancement ; il viendra nous faire des excuses et vous remettre entre nos mains. Nous pourrons alors retourner chez nous tranquillement et profiter de cette heureuse aubaine.

A ces mots, Souï-houng éprouva un vif déplaisir :

«Quelle faute ai-je commise dans ma vie passée, se dit-elle, pour essuyer dans celle-ci tant de peines et de tribulations ? Comment puis-je me prêter à cet indigne artifice ? Non, je n'y puis consentir.

\footnotetext{
${ }^{1}$ A 6 heures du matin.
} 


\section{Contes chinois}

- Mademoiselle, lui dit Hou-youe, c'est avec un regret infini que j'ai recours à la ruse; mais la situation où je me trouve m'en fait une nécessité. Je vous en conjure, ne soyez pas sourde à ma prière.

Souï-houng, sans se laisser fléchir, persiste dans sa résolution ; mais Hou-youe se jetant à ses genoux :

- Le sacrifice que je fais me pénètre de douleur, lui ditil ; mais rien au monde ne peut m'en dispenser. Cette fois sera la dernière, et vous n'éprouverez jamais de ma part de nouvelles importunités.

Souï-houng, fatiguée de ses instances, se vit obligée de consentir. Hou-youe sort avec empressement et va informer ses camarades du succès qu'il vient d'obtenir.

Ils applaudissent tous à cette idée, et retournent ensemble à I'hôtel de Tchou-youan, qui, de suite,pèse la somme convenue et la remet à Houyoue.

Ses compagnons d'industrie réclament la part de l'argent.

- Ne vous pressez pas tant, leur dit-il, attendez que I'affaire soit tout-à-fait terminée ; ensuite nous partagerons.

Quand le soir fut venu, Tchou-youan ordonna à ses gens de louer une chaise et d'aller au devant de Souï-houng. En même temps il fit préparer un festin et attendit son arrivée. Au bout de quelques instans, il la voit venir, s'empresse d'aller la recevoir, et, après les premières salutations, l'invite à entrer dans son 


\section{Contes chinois}

appartement. Il n'est pas besoin de dire qu'il régala comme il faut les entremetteuses.

En entrant dans la salle avec son époux, Souï-houng vit toute la maison illuminée d'une infinité de cierges et de lanternes, et un repas magnifique préparé pour la recevoir.

Tchou-youan, l'ayant considérée à la clarté des lumières, la trouva encore plus belle et plus séduisante qu'auparavant ; il ne pouvait modérer ses transports de joie. Il lui offre un siège ; elle rougit, et s'assied sans oser proférer un seul mot. Ensuite il ordonne à un domestique de remplir un verre de vin, de le lui offrir avec les cérémonies proscrites et de le déposer devant elle.

-Jeune femme, dit Tchou-youan, acceptez la coupe que vous offre votre époux.

Mais Souï-houng n'ose ni ouvrir la bouche, ni se montrer sensible à sa courtoisie.

Tchou-youan, voyant que c'était l'effet de la timidité, laissa échapper un sourire ; il remplit lui-même son verre, et lui dit :

- Jeune amie, nous sommes aujourd'hui mari et femme, pourquoi rougir ainsi devant moi ? Je vous en prie, buvez un peu du vin qui vous est offert, je finirai le reste.

Mais Souï-houng baissait la tête et ne répondait point.

Tchou-youan se dit à lui-même :

« Cette jeune personne est modeste et timide ; sans doute que la présence de ces domestiques cause seule la honte qu'elle éprouve. 


\section{Contes chinois}

Sur-le-champ il les congédie et ferme la porte de l'appartement. Ensuite, s'approchant de Souï-houng :

- Je crois, lui dit-il, que votre vin est refroidi ; je vais vous en donner du plus chaud, buvez une tasse, je vous prie, et ne repoussez pas la tendresse que vous m'inspirez.

En achevant ces mots il verse une nouvelle tasse et la présente à Souï-houng.

Celle-ci, réfléchissant sur sa position, se sentît davantage pénétrée de honte et de douleur.

«Quand j'étais avec mes parens, se disait-elle à ellemême, j'étais l'objet de leur plus tendre affection ; mais aujourd'hui dans quel abîme de maux ne suis-je pas plongée ? J'ai perdu I'honneur, j'ai vu immoler ma famille et je ne puis la venger! Aujourd'hui encore, je me vois forcée à jouer un rôle indigne et à devenir I'instrument d'une noire perfidie. Quelle honte pour mes ancêtres !

Ces tristes pensées l'attendrissent jusqu'au fond du cœur, et lui font verser un torrent de larmes.

En la voyant baignée de pleurs :

- Chère épouse, lui dit Tchou-youan avec tendresse, nous sommes comme deux amis qui se rencontrent après une séparation de mille milles. C'est le ciel qui nous a réunis ; jouissons de notre bonheur. Que manque-t-il à votre contentement ? Pourquoi vous 


\section{Contes chinois}

désoler de la sorte ? Avez-vous quelqu'affaire de famille qui pèse sur votre cœur et vous cause cette douleur que je vois?

Il la pressa plusieurs fois pour lui arracher son secret, mais elle gardait toujours un silence obstiné. Voyant que son visage devenait à chaque instant plus triste et plus abattu, il insiste de nouveau :

- Jeune amie, lui dit-il, je le vois, vous avez éprouvé des peines inouïes ; ouvrez-moi votre cœur, et s'il est temps encore d'y apporter remède, il n'est rien au monde que je ne fasse pour y réussir.

Souï-houng ne répondit rien, et continua de pleurer. Tchouyouan, voyant ses instances inutiles, se mit à remplir son verre et à boire. Insensiblement le temps s'écoule et il entend sonner la seconde veille.

- La nuit est déjà avancée, dit-il à Souï-houng, je vous prie de venir prendre du repos.

Mais, tout entière à sa douleur, elle reste sourde à ses paroles.

Tchou-youan, sans la presser davantage, va prendre un livre à son bureau, et se met à le parcourir en lui tenant compagnie.

Souï-houng voyant que Tchou-youan dont elle avait tant de fois repoussé les consolations, ne conservait sur son visage aucune trace de colère et de mécontentement, se dit en ellemême :

«Ce lettré est vraiment un sage d'une vertu accomplie. $\mathrm{Si}$, dans l'origine, j'avais rencontré un homme de ce 


\section{Contes chinois}

mérite, la mort de ma famille serait déjà vengée et mon déshonneur effacé. Quant à Hou-youe, ses discours ne sont que ruse et mensonge : si je me repose sur lui, comment obtiendrais-je la vengeance que j'attends ? Aujourd'hui il a reçu les présens de ce lettré, et m'a remise entre ses mains ; je suis maintenant à lui ; pourquoi ne le suivrais-je pas ; peut-être, avec lui, rencontrerai-je l'occasion si désirée de venger ma famille et de laver ma honte !

Elle était agitée de mille pensées et flottait encore incertaine, lorsque Tchou-youan I'invita à venir goûter le sommeil.

Souï-houng à dessein garde encore le silence. Mais Tchouyouan, sans témoignage de mécontentement, prend le livre et se remet à. lire. Vers la troisième veille, Souï-houng prend son parti, et comme Tchou-youan la pressait de nouveau de venir reposer :

- Dès ce moment, lui dit-elle, j'entre dans votre famille.

- Eh quoi ! reprit Tchou-youan, en faisant un sourire, est-ce qu'auparavant vous apparteniez à une autre maison?

- Seigneur, répondit Souï-houng, je vais vous avouer la vérité. Je suis la seconde femme de Hou-youe. Comme il se trouvait dans une extrême détresse, il a consulté quelques fripons qui exploitent la capitale, et a imaginé ce stratagème pour vous escroquer de l'argent. Tout-àI'heure il doit venir avec ses camarades ; il entrera avec 


\section{Contes chinois}

force chez vous, m'enlèvera de votre maison et vous accusera d'avoir ravi une femme mariée. Il compte que, pour éviter un éclat qui nuirait à votre avancement, vous ferez toutes sortes de sacrifices afin d'avoir la paix et la tranquillité.

- Est-il possible ? s'écria Tchou-youan frappé de surprise, qu'il ait conçu un projet si odieux! Si vous ne m'eussiez pas averti, je tombais dans leur piège. Et vous, comment se fait-il qu'étant la femme de Houyoue, vous m'ayez fait cette révélation?

- Hélas ! s'écria Souï-houng les yeux en pleurs, je poursuis la vengeance d'un grand crime et n'ai encore pu I'obtenir. Vous voyant, seigneur, doué d'une éminente sagesse, je ne doute point que vous ne puissiez châtier le coupable et effacer ma honte. Je me confie à vous, et j'implore votre appui.

- Quel est ce crime, reprit Tchou-youan, parlez-moi sans détour. Cette affaire devient la mienne, et j'emploierai tous mes efforts pour vous faire obtenir la satisfaction que vous demandez.

Soueï-houng reprit dès le commencement le récit de ses malheurs et les exposa en pleurant. Tchou-youan en fut vivement attendri et ne put s'empêcher de verser des larmes.

Elle parlait encore, lorsque la quatrième veille vint à sonner : 


\section{Contes chinois}

- Seigneur, dit Souï-houng, cette troupe de brigands va arriver tout-à-l'heure; si vous ne fuyez au plus vite, vous ne pourrez éviter le piège qu'ils méditent.

- N'ayez point d'inquiétude, répondit Tchou-youan, un de mes compagnons d'étude à son hôtel tout près d'ici, les appartemens en sont profonds et ne donnent point sur la rue. Allons y passer une nuit, demain nous choisirons un autre domicile; et ensuite nous nous éloignerons. Quels malheurs pourront alors nous atteindre ?

Aussitôt il ouvre la porte, appelle sans bruit un domestique et lui ordonne de prendre à la main une lanterne et de les conduire tous deux à I'hôtel de son compagnon d'étude. Celui-ci, le voyant venir si tard et avec une femme d'une beauté accomplie, soupçonna quelque mystère caché et lui en témoigna son extrême surprise.

Tchou-youan lui raconta la chose en détail. Alors son ami leur céda le pavillon intérieur, et alla passer la nuit dans celui qui était situé en devant de la maison. Ensuite il ordonna à ses domestiques d'aller chercher tous les bagages et les effets de ses nouveaux hôtes et de laisser vides les chambres qu'ils venaient de quitter.

Quand Souï-houng fut montée en chaise, nos fripons vinrent presser Hou-youe de partager avec eux l'argent qu'il avait reçu. Ils achetèrent de la viande et du vin et burent jusqu'à la cinquième veille. Ensuite, ils s'élancent de table, courent à I'hôtel de Tchou-youan, et enfoncent les portes en poussant des cris 


\section{Contes chinois}

furieux. Ils trouvent les deux chambres vides et n'aperçoivent pas l'ombre d'un homme.

Hou-youe est frappé de stupeur :

« Comment, se dit-il, Tchou-youan a-t-il pu deviner mon projet et s'enfuir d'avance?

- C'est sans doute vous, dit-il à ses camarades d'industrie, qui avez concerté ce tour odieux pour me perdre ; allons, rendez-moi vite l'argent que je vous ai donné.

Ceux-ci, entrant en fureur :

- Vous avez vendu votre femme, lui répondirent-ils, et vous vouliez encore que nous allassions l'enlever à celui qui la possède. Maintenant vous nous accusez de vous avoir fait tort ; qu'y pouvons-nous ? C'est votre affaire.

A ces mots, ils prennent Hou-youe, l'accablent de coups et le laissent à demi-mort.

En ce moment la patrouille vient à passer ; elle les prend et les amène tous liés et garottés devant le magistrat. On les juge, leur artifice se découvre et chacun d'eux est condamné à payer au profit du trésor trente onces d'argent ${ }^{1}$. Hou-youe fut reconduit chez lui sous l'escorte du gouvernement.

Ainsi :

Un homme a recours aux charmes d'une belle pour tendre un piège à un autre.

Mais cette belle n'avait point pour lui une affection de cœur.

$1225 \mathrm{fr}$. environ. 


\section{Contes chinois}

C'est peu de se voir enlever sa femme, il est encore battu.

Et après avoir perdu le trésor qu'il possédait, il retombe dans la détresse ;

Tchou-youan et Souï-houng, devenus époux, éprouvaient I'un pour l'autre une estime et une tendresse qui s'augmentaient de jour en jour. Après quelque temps de mariage, Souï-houng devint enceinte, et, au bout de neuf mois, elle donna le jour à un fils.

Tchou-youan en fut transporté de joie et écrivit à sa première épouse pour l'informer de cette heureuse nouvelle. Mais le temps passe aussi vite que l'éclair qui fend la nue. Un ail s'était déjà écoulé depuis la naissance de ce fils tant désiré, quand le nouveau concours arriva. Souï-houng passait les jours et les nuits en prière, demandant au ciel que son époux vit inscrire son nom sur la liste d'or, afin de venger promptement les malheurs de la maison de Tsa-wou.

Quand la liste du concours fut publiée, Tchou-youan se trouva le cinquantième de cette promotion avec le titre de docteur. Trois mois après l'examen, il fut élevé à la dignité de préfet. Par une circonstance heureuse, celui de la ville de Wen-tchang devait être remplacé dans ses fonctions ; Tchou-youan se mit sur les rangs et obtint la place.

- Les brigands, dit-il à Souï-houng, ne doivent pas être éloignés du lieu où nous allons. Je crains seulement qu'ils ne soient morts et que je ne puisse apaiser, par leur supplice, votre juste ressentiment. Mais s'ils respirent encore, je veux les prendre les uns après les autres et verser jusqu'à la dernière goutte de leur sang 


\section{Contes chinois}

pour l'offrir en sacrifice à vos parens. Quand ils s'en iraient au ciel, je ne crains point qu'ils ne m'échappent.

- Seigneur, lui dit Souï-houng, si vous réalisez vos généreuses promesses, votre servante pourra mourir sans regrets.

Tchou-youan ordonna à un domestique d'aller chez lui et de conduire tous les gens de sa maison à Young-tcheou où il les prendrait avec lui en se rendant à sa destination. Pendant ce temps-là, il attendait sa nomination légalisée par le bureau des cérémonies.

Son diplôme arriva bientôt ; il prit congé de la cour et partit de la capitale. De là il se rendit au port de Lin-tsing pour louer un bateau. Il s'y trouvait en tous temps un grand nombre de barques qui avaient été porter à Peking les grains envoyés en tribut.

Comme elles s'en retournaient à vide, les pilotes saisissaient avec empressement l'occasion de conduire avec eux un magistrat, afin de s'exempter des droits qu'ils étaient obligés de payer aux douanes.

Tchou-youan étant donc venu au port de Lin-tsing avec sa jeune épouse pour louer un bateau, examina tous ceux qui s'y trouvaient ; mais aucun ne fut à son gré excepté un seul qui lui parut commode et élégant. Le patron lui présenta son nom et son livret en lui faisant une profonde salutation.

Les serviteurs de Tchou-youan prennent les bagages, les déposent dans le bateau et viennent prier leur maître de 


\section{Contes chinois}

s'embarquer. Ensuite, le pilote fait un sacrifice aux génies du fleuve et ordonne aux matelots de mettre à la voile.

Dès que Souï-houng fut dans le bateau, elle reconnut à l'accent du pilote qu'il était de Houï-gan. Elle remarqua aussi qu'il ressemblait tout-à-fait à Tchin-siaosse, le chef des brigands, et pria son mari de lui dire son nom.

Tchou-youan regarde la carte du batelier et vit qu'il s'appelait Oukin. Cette différence de nom mit en défaut les conjectures de Souï-houng ; mais en l'examinant avec une scrupuleuse attention, ses premiers doutes se fortifièrent, et elle se sentit tellement tourmentée de cette pensée, qu'elle ne pouvait prendre aucun repos. Elle en fit part à son époux et le pria d'appeler le pilote, sous prétexte de lui donner des ordres.

Pendant qu'il parlait, Souï-houng l'observa furtivement, et, dès lors ses doutes se changèrent en certitude. A sa voix, aux traits de son visage, elle reconnut que lui et Tchin-siaosse ne faisaient qu'un ; mais la différence de son nom ne laissait pas de lui causer de la surprise. Elle voulait elle-même l'interroger ; mais elle n'en trouvait ni le prétexte ni l'occasion.

Un jour que Tchou-youan était allé visiter un de ses amis qui était dans une barque voisine, la femme du pilote vint présenter ses civilités à Souï-houng et lui offrir le thé. On ne peut pas dire que ce fût une beauté accomplie, mais elle avait un ton distingué et ne manquait ni de grace ni d'enjoûment.

Souï-houng profita de cette circonstance pour savoir ce qu'elle désirait. 


\section{Contes chinois}

- Quel âge avez-vous, lui dit-elle ?

- J'ai vingt-neuf ans, répondit la femme du pilote.

- De quel pays êtes-vous ?

- De Tchi-yang.

- Mais votre mari n'a point l'accent ni le costume d'un homme de Tchi-yang, reprit Souï-houng.

- Cet homme est mon second mari.

- Combien y a-t-il de temps que vous avez perdu le premier, ajouta Souï-houng ?

- Mon premier époux et moi, répondit-elle, nous étions venus dans ce port pour amener des graines. Tout-àcoup il tomba malade, et me laissa veuve. Celui que j'ai maintenant est de la ville de Wen-Tchang. Il était à notre service et aidait mon époux à conduire le bateau. Au moment des funérailles, il me prêta de l'argent pour subvenir aux dépenses prescrites et me rendit toutes sortes de bons offices. Me voyant veuve et sans appui, je pris le parti de le suivre et de l'épouser. Il adopta le nom de mon premier mari, et devint ainsi le chef et le propriétaire du bateau.

Souï-houng, satisfaite des détails qu'elle avait obtenus de cette femme, lui offrit plusieurs pièces de soie qu'elle reçut avec une vive reconnaissance, et se retira. Elle attendit que Tchouyouan fût de retour, et lui raconta tout ce qu'elle venait d'apprendre. 


\section{Contes chinois}

- Ce batelier Oukin, dit-elle, n'est autre que Tchinsiaosse, le chef des brigands, et le meurtrier de ma famille.

- Pendant la route, répondit Tchou-youan, n'allons point agir précipitamment. Attendons que nous soyons arrivés au lieu de ma destination, alors nous poursuivrons l'affaire, et nous ferons en sorte d'obtenir de lui les renseignemens nécessaires pour saisir ses complices.

- L'idée de votre excellence est extrêmement juste, répondit Souï-houng; seulement le meurtrier de ma famille est sous mes yeux à chaque instant du jour. Combien il me sera pénible d'attendre pendant le peu de jours qui nous restent ! Plût au ciel qu'un vent favorable nous poussât avec la vitesse de l'oiseau dans le port de Wen-Tchang !

Quand le bateau de Tchou-youan aborda à Yang-Tcheou, les personnes qu'il avait envoyées pour chercher son épouse, madame Tchou-youan, n'étaient pas encore venues. Cette circonstance l'obligea à arrêter sa barque dans le port, en attendant leur arrivée. Pendant ce temps-là, Souï-houng sentait redoubler sa douleur et son indignation.

Le lendemain, une rixe violente éclata sur le port ; Tchouyouan envoya ses gens pour savoir la cause de ce différent. C'était le patron du bateau sur lequel ils étaient montés, qui luttait contre deux individus. On criait, on tempêtait, on se renvoyait mutuellement des coups et des injures. Dans ce conflit 


\section{Contes chinois}

de paroles, on entendait seulement : Tu ne risques pas ! tu as fait un beau coup !

Tchou-youan, voyant le chagrin de sa jeune épouse que rien ne pouvait adoucir, profita de cette circonstance pour faire donner un acompte de bastonnade à ce chef de brigands. A I'instant il ordonna aux bateliers d'aller prendre les querelleurs et de les lui amener.

Or, ces bateliers faisaient bonne mine à leur patron ; mais au fond du cœur ils l'avaient en aversion, et voici pourquoi : Dans I'origine, quand Tchin-siaosse eut perdu Souï-houng, il prit la fuite et ne sachant où trouver un asile, il errait à l'aventure dans le pays de Tchin-yang.

Il arriva que Oukin, qui conduisait des grains à la capitale, eut besoin d'un second pour conduire son bateau ; il trouva Tchinsiaosse, et le prit à son service..

Celui-ci, voyant que la femme d'Oukin avait l'air d'être assez légère, il n'eut pas de peine à la captiver et à en faire ce qu'il voulut. Tout le long du voyage, leur attachement se fortifia et bientôt ils devinrent inséparables. Une seule chose les gênait, c'était la présence du patron.

Quand on eut passé le fleuve jaune, Oukin eut une légère fièvre. Tchinsiaosse fit semblant de prendre un tendre intérêt à sa santé et lui donna une médecine qu'il avait achetée. Mais cette potion préparée par une main ennemie produisit de suite son effet : elle emporta Oukin. 


\section{Contes chinois}

Sa veuve prit tout l'argent qu'elle avait avec elle et le donna à Tchinsiaosse, en lui recommandant de dire que c'était lui-même qui lui avait fourni les moyens de subvenir aux frais des funérailles de son mari.

Une ou deux semaines après, elle dit à Tchinsiaosse, devant ses camarades, je vous dois beaucoup, mais je suis hors d'état de vous payer, je vous prie de m'agréer pour votre épouse ; c'est le seul moyen que j'aie de m'acquitter envers vous.

Ensuite ils firent le repas de noces, régalèrent les matelots et leur fermèrent ainsi la bouche ; cependant ils ne purent réussir à leur inspirer un véritable attachement.

Dès qu'ils eurent entendu le magistrat qui se trouvait dans leur bateau prononcer les mots prenez-moi ces gens-là ; ils s'élancent sur le rivage comme un essaim d'abeilles, saisissent les trois querelleurs, les amènent dans le bateau et les font mettre à genoux à côté du grand mât.

- Pourquoi vous battiez-vous, leur demanda Tchouyouan ?

- Seigneur, répondit le patron du bateau, ces deux hommes étaient jadis associés avec moi : un jour, profitant de mon absence, ils me dérobèrent la caisse et s'enfuirent. Il y avait déjà trois ans que je n'en avais eu de nouvelles, lorsqu'aujourd'hui le ciel me les fit rencontrer. Je leur ai demandé mon argent, et au lieu de me le rendre, ils m'ont accablé d'injures et se sont jetés sur moi en me frappant d'une manière indigne. 


\section{Contes chinois}

J'ose espérer que votre excellence me prendra sous sa protection et me fera rendre justice.

-Et vous deux, dit Tchou-youan, qu'avez-vous à répondre?

- Nous ne savons ce qu'il veut dire : tous ses propos sont un tissu de mensonges.

- Il faut bien qu'il y ait quelque chose là-dessous, reprit Tchou-youan ; se peut-il que, sans motif ni raison, vous alliez vous battre de la sorte?

- Eh bien ! oui, seigneur, répondirent-ils, cette querelle a un motif ; le voici : Autrefois nous étions à la vérité associés avec lui, mais voyant qu'il était devenu follement épris d'une jeune personne, et craignant qu'il ne compromît nos intérêts, nous prîmes chacun les fonds que nous avions mis en commun et nous nous en allâmes chacun de notre côté. Mais nous ne lui devons pas un denier.

- Quel est votre nom à tous deux, dit Tchou-youan ?

Ils gardèrent le silence. Tchin-siaosse répondant pour eux, « L'un s'appelle Tchin-tiefa et l'autre Thsin-siaoyouan. »

Tchou-youan allait leur adresser de nouvelles questions lorsqu'il se sentit tirer par sa robe. Il se retourne et voit une suivante qui lui dit à l'oreille :

- Seigneur, votre jeune épouse voudrait dire un mot à votre excellence. 


\section{Contes chinois}

Il rentre dans l'arrière cabane et trouve Souï-houng fondant en larmes.

- Seigneur, lui dit-elle à voix basse, ces deux hommes sont précisément les complices du chef des brigands, gardez-vous de les laisser échapper.

- Dans ce cas, répondit Tchou-youan, il n'est pas possible d'attendre jusqu'à ce que nous soyons arrivés à Woutchang.

De suite, il écrivit un billet de visite, fit demander une chaise et ordonna à des gens du pays de lier ensemble ces trois malfaiteurs et de les amener derrière lui.

Il alla trouver le gouverneur de Yang-tcheou et lui raconta l'affaire dans tous ses détails.

A ce récit, le gouverneur fait prendre les trois coupables et les envoie en prison, afin de les juger le lendemain. Tchou-youan étant revenu dans le bateau, les autres bateliers, qui connaissaient Tchin-siaosse pour un voleur, racontèrent sa conduite passée et la manière dont il s'était défait de Oukin. Il écrivit de nouveau une lettre au gouverneur pour l'informer de ces nouveaux détails, et le pria en même temps de prendre des informations pour découvrir les autres complices.

Le gouverneur, après avoir lu la lettre, envoya plusieurs officiers de police, avec ordre de lui amener la femme du patron du bateau, afin de la juger avec lui pour ce nouveau crime.

Cette nouvelle fut bientôt répandue dans Yang-tcheou ; il s'agissait de vol, d'assassinat, d'adultère ; en fallait-il davantage 


\section{Contes chinois}

pour faire jaser toute la ville et attirer les curieux ? La veille du jugement, c'était un tumulte général : on accourait de toutes parts et une foule innombrable inondait la salle d'audience

Une bonne nouvelle ne passe pas le seuil de la porte :

Une mauvaise se répand jusqu'à mille milles.

Le gouverneur, s'étant assis dans son tribunal, se fit amener les trois voleurs dont nous venons de parler, et avec eux la femme du pilote, et leur ordonna de se mettre à genoux au bas des marches.

Quand Tchin-siaosse eut vu cette femme, il fut frappé de surprise et de crainte. Une querelle, une batterie, se dit-il en luimême, ce n'est qu'une bagatelle, à quoi bon poursuivre pour si peu de chose une famille entière ? Mais lorsque le gouverneur lui donna le nom de Tchin-siaosse et non celui de Oukin qu'il avait adopté, il resta immobile de stupeur.

On I'appelle une fois, deux fois, il ne répond rien.

Alors le gouverneur, faisant un rire amer :

- Vous rappelez-vous, lui dit-il, ce qui arriva il y a trois ans au capitaine Tsa-wou ? Le réseau de la justice céleste est immense comme le ciel ; il n'est point de coupable qui puisse l'éviter. Qu'avez-vous à répondre pour vous justifier?

Les trois brigands se regardent les uns les autres et ne peuvent proférer un seul mot.

Le gouverneur les interrogeant de nouveau : 


\section{Contes chinois}

- Vous avez encore d'autres complices, leur dit-il, Lihoutseu, Peman, Kou-man-eul, Ling-waïthsouï et Yukia-pa ; où sont-ils maintenant ?

- Seigneur, répondit Tchin-siaosse, quoique je me sois trouvé alors avec eux, je n'ai rien pris, ni effets ni argent ; ce sont eux qui ont emporté tout ce que je possédais et ont pris la fuite. Si votre excellence daigne les interroger tous deux, elle verra si je lui en impose. »

- Quoiqu'il soit vrai, répondirent Tchintie-fa et Thsinsiao-youan, que nous avons emporté tous deux un peu d'argent, nous sommes bien loin de ressembler à Tchinsiaosse qui déshonora la fille du capitaine.

Le gouverneur, qui savait à fond toute sa conduite, I'interrompit brusquement par égard pour Tchou-youan.

- Tout cela est étranger à ma question, lui dit-il ; bornez-vous à dire où sont ces brigands.

- Quand nous eûmes partagé l'argent, dit Thsin-siaoyouan, nous nous en allâmes chacun de notre côté. J'ai entendu dire que Li-houtseu et Peman étaient au service d'un marchand du Chensi, qui vend de la laine et des peaux. Quant Hou-man-eul, Ling-waï-tsouï et Yu-kia-pa, ils se sont enfuis à Hoang-tcheou et font le métier de bateliers. Depuis ce temps-là nous ne nous sommes pas revus.

Ensuite, le gouverneur fit appeler la femme du pilote : 


\section{Contes chinois}

- Vous avez, lui dit-il, commis un adultère avec Tchinsiaosse, et vous avez empoisonné votre mari pour devenir son épouse ; votre crime est avéré : qu'avezvous à répondre?

Elle allait chercher à se justifier, lorsque les bateliers se présentèrent tous ensemble pour confirmer le rapport qu'ils avaient fait à Tchou-youan, et lui fermèrent la bouche.

Le gouverneur entra en fureur, et ordonna de choisir des bamboux du plus gros calibre et de leur en appliquer à chacun quarante coups, sans considérer l'âge ni le sexe. Ce châtiment fut si rude que leur chair tombait en lambeaux et que le sang ruisselait de toutes parts.

Ensuite, il inscrivit la déposition, et condamna les trois hommes à la peine capitale et la femme à être coupée en mille morceaux. En attendant, il les envoya dans la prison des personnes destinées à la mort. En même temps, il dépêcha plusieurs officiers de police pour chercher et saisir Peman, Lihoutseu et leurs complices.

Le gouverneur, ayant prononcé cette sentence, vint lui-même sur le bateau saluer Tchou-youan et lui faire lire le jugement qu'il venait de porter. Tchou-youan ne pouvait assez lui témoigner la gratitude dont il était pénétré ; et Souï-houng, a cette nouvelle, se sentit presque soulagée du poids de chagrin qui l'accablait.

Quelques jours après, madame Tchou-youan arriva auprès de son mari. Souï-houng alla lui faire visite. A peine se furent-elles vues, qu'elles se lièrent ensemble d'une étroite amitié et vécurent dans la plus parfaite harmonie. 


\section{Contes chinois}

En voyant le nouveau né que la nature avait rempli d'agrémens, madame Tchou-youan ne pouvait modérer les transports de sa joie.

En moins d'un jour, Tchou-youan arriva à Wou-tchang, et entra en fonctions. A peine avait-il commencé à exercer sa charge, que les officiers de justice qui avaient été envoyés pour prendre des informations sur les autres coupables, vinrent faire leur rapport et rendre compte de leur mission. Houman-eul et Ling-waïtsouï étaient en effet dans le port de Yang-tcheou et faisaient le métier de bateliers. On les prit et on les amena devant le juge. Ils avouèrent que Yu-kia-pa était mort depuis un an, et que Peman et Li-houtseu étaient au service d'un marchand établi dans la capitale du Chensi.

Tchou-youan les mit d'abord en prison en attendant les autres complices, afin de les condamner et exécuter tous ensemble.

La capitale du Chensi étant peu éloignée de Wou-tchang, au bout de quelques jours, les officiers de police trouvèrent Peman et Li-houtseu, et les amenèrent liés et garottés dans la ville de Wou-tchang.

Tchou-youan, après avoir écrit leur déposition, leur fit appliquer à chacun quarante coups de bâton, et les renvoya ensuite à Yang-tcheou, afin qu'ils fussent jugés avec leurs complices et exécutés ensemble.

Tchou-youan exerça pendant trois ans les fonctions de préfet à Wou-tchang. Par une sage administration, il sut maintenir la 


\section{Contes chinois}

paix dans cette ville, veiller au bien-être des habitans et empêcher les désordres.

Quelque temps après, il fut nommé censeur impérial, et reçut ordre d'aller faire une inspection à Hoaï-gan et à Yang-tcheou.

- Ces brigands, lui dit Souï-houng, sont depuis plusieurs années dans la prison de Yang-tcheou, en attendant leur supplice, qui, je crois, n'a pas encore reçu son exécution. Quand votre excellence sera arrivée en ce lieu, je la supplie de terminer l'affaire qui m'occupe, et d'offrir leur sang en sacrifice à mon père, à ma mère et à mes deux sœurs. Par là, votre servante fera éclater sa piété filiale, et votre excellence accomplira les promesses qu'elle a faites. J'ai encore une affaire à vous recommander. Jadis, mon père eut des liaisons avec une suivante, nommée Pe-lian. Elle devint enceinte ; mais ma mère s'étant opposée à ce qu'il l'épousât, il la maria à un de ses compatriotes, nommé Tchou tsaï. J'ai appris plus tard que l'enfant auquel elle avait donné le jour était un garçon. Je vous prie, seigneur, de vouloir bien prendre des informations sur cet enfant, et, s'il vit encore, de le prendre sous votre protection et de lui rendre le nom de son père, afin qu'il puisse rendre à ses parens les honneurs funèbres qui leur sont dus. Un si grand bienfait vivra dans la postérité la plus reculée.

Elle dit, et se prosterne à ses pieds en poussant de profonds soupirs. 


\section{Contes chinois}

Mais Tchou-youan la relevant avec empressement :

- Les deux demandes que vous venez de m'adresser, lui dit-il, deviennent l'objet de toute ma sollicitude. Sitôt que je serai arrivé, je ferai tous mes efforts pour les réaliser selon vos vœux, et de suite j'écrirai pour vous informer du résultat de mes démarches.

Souï-houng le salua de nouveau pour lui témoigner la gratitude dont elle était pénétrée.

Tchou-youan se rendit à sa destination, et visita, au nom de l'empereur, Hoaï-gan et Yang-tcheou ; jamais le préfet d'un district ne fut entouré, à son installation, d'une estime plus générale et mieux méritée.

On était alors au quinzième jour de la septième lune, et l'époque des exécutions n'était pas encore arrivée.

Tchou-youan alla d'abord visiter Hoaï-gan. Alors il ordonna au préfet et au sous-préfet de prendre des renseignemens sur Tchou-tsaï et sur Pe-lian. Il apprit que l'enfant existait en effet ; qu'il avait déjà atteint sa huitième année, et qu'il joignait aux graces de la figure les plus heureuses dispositions.

Ceux-ci obéirent aux ordres du censeur impérial, et firent tous leurs efforts pour se rendre dignes de sa confiance. Le jour même, ils baignèrent l'enfant dans une eau parfumée, le vêtirent de nouveaux habits, et le conduisirent au palais de Tchou-youan.

Celui-ci changea son nom en celui de Tsasiu, et rédigea pour lui un placet dans lequel il exposait à l'empereur tous les malheurs arrivés à la famille Tsa. 


\section{Contes chinois}

« Tsawou, disait-il, a rendu de grands services à l'État ; votre majesté ne permettra pas qu'il soit sans postérité. Maintenant il a un fils nommé Tsasiu, encore en bas âge : il est juste de lui rendre le rang qui lui appartient et de le reconnaître pour le descendant de Tsawou, lorsqu'il sera sorti de l'enfance. Quant à Tchin-siaosse et ses complices, qu'il plaise à votre majesté de les faire exécuter avant la fin de l'automne.

L'empereur accorda toutes les demandes que contenait le placet.

Dans I'hiver de la même année, Tchou-youan, revenant de sa tournée, arriva à Yang-tcheou. Il fit sortit de sa prison Tchinsiaosse, ses complices, et la femme de Oukin, au nombre de huit ; il les fit lier ensemble, et conduire au lieu d'exécution. Les brigands furent décapités, et la femme du batelier fut coupée en mille pièces, et ainsi les dernières traces du crime furent effacées.

On peut dire avec raison :

Le bien et le mal, la vertu et le vice

Trouvent leur récompense et leur châtiment ;

Quelquefois le ciel semble les oublier ;

C'est que I'heure n'est pas encore venue.

Tchou-youan ordonna à l'exécuteur de mettre dans des boîtes exactement fermées les têtes des brigands, et les plaça dans la chapelle appelée Tching-hoang, au bas de la tablette de Tsawou et de celle de sa famille. Ensuite il offrit un sacrifice, et choisit les bonzes les plus renommés par leur vertu, pour réciter, pendant sept jours, l'office des morts. 


\section{Contes chinois}

Après avoir fait toutes les cérémonies funéraires, il envoya chez lui un de ses serviteurs avec une lettre, pour informer Souïhoung des pieux devoirs qu'il avait rendus à sa famille. Souïhoung, voyant que Tsawou avait un héritier, que les brigands avaient reçu leur châtiment, et que leur sang avait été offert en sacrifice à toute sa famille, éleva les mains au ciel, et lui rendit mille actions de grâces.

Cette même nuit, Souï-houng se baigna, mit de nouveaux vêtemens, écrivit à son époux pour lui témoigner sa gratitude, et alla rendre visite à madame Tchou-youan, pour la remercier de ses bontés. Ensuite elle rentra dans sa chambre, ferma la porte sur elle et se donna la mort.

Madame Tchou-youan, ayant appris la mort de Souï-houng, en fut vivement affligée et lui donna de continuels regrets. Après lui avoir fait de pompeuses funérailles, elle cacheta la lettre qui contenait ses derniers sentimens, et l'envoya à son époux. Celuici la lut et pleura amèrement ; dans l'excès de sa douleur, il perdit presque l'usage de ses sens et de sa raison. Ce chagrin profond se changea en maladie; pendant plusieurs jours il s'enferma chez lui et ne vaqua point à ses fonctions.

Les magistrats et les officiers civils qui lui étaient soumis vinrent le voir, et lui offrir des consolations.

Tchou-youan racontait, en pleurant, le motif de son affliction. Les assistans ne pouvaient s'empêcher de verser des larmes ; ils exaltaient la chasteté et la piété filiale de Souï-houng, la mettant au-dessus des héroïnes de l'antiquité et des temps modernes. 


\section{Contes chinois}

Quelque temps après, Tchou-youan, ayant rempli les fonctions dont il avait été revêtu, s'en revint à la capitale, et fut ensuite élevé à la dignité de gouverneur général d'une province.

Le fils de Souï-houng était surnommé Tchou-meou. Quoique fort jeune, il se présenta aux examens et obtint ses degrés littéraires. Ensuite, il adressa à l'empereur une requête, dans laquelle il exposa les malheurs de Souï-houng sa mère, et demanda la faveur d'avoir chez lui la tablette de sa famille.

L'empereur accorda sa demande, et fit élever un arc de triomphe pour perpétuer le souvenir de ce modèle de chasteté et de piété filiale.

Ce monument subsiste encore aujourd'hui. Sur la façade on lit les vers suivans :

Venger une injure et laver un affront, c'est le fait d'un homme courageux :

Qui eût cru qu'une femme timide fût douée de cette mâle intrépidité ? 


\title{
Contes chinois
}

\section{LES TENDRES ÉPOUX.}

\author{
CHAPITRE I ${ }^{\text {er }}$ \\ Ceux qui ne sont pas mariés ne doivent pas rechercher le \\ mariage avec trop de sollicitude. \\ Tous les mariages sont décrétés par le ciel. \\ Il est donc inutile de murmurer. \\ Soyons calmes quand même les vagues furieuses s'élèveraient \\ jusqu'au ciel. \\ Il y a un chemin du milieu ; suivez-le ; et votre barque glissera \\ doucement en avant.
}

On dit que sous le règne de Tching-ti, dans la principale rue de Kouan-chan, dans la province de Sou-tcheou-fou, demeurait une famille nommée Tun et dont le surnom était Soung ; il paraît aussi qu'ils étaient issus de personnes qui avaient rempli des charges dans le gouvernement. Le mari et la femme ne faisaient aucun commerce, mais vivaient du revenu des terres que leurs ancêtres leur avaient laissées, et qui, étant affermées, suffisaient à leur existence. Ils avaient tous les deux plus de quarante ans et n'avaient point de fils ni de fille. Soung-tun dit un jour à sa femme :

- Il y a un vieil adage qui nous enseigne qu'on doit élever des enfans pour en être soigné dans sa vieillesse, et amasser des provisions pour le temps de famine : vous et moi avons maintenant passé quarante ans et nous sommes encore sans enfans. Dans un clin d'œil nos cheveux seront gris ; sur qui pourrons-nous 


\section{Contes chinois}

compter pour nous soutenir, lorsque nous serons devenus vieux et infirmes?

Tandis qu'il parlait ainsi, les larmes tombaient involontairement le long de ses joues.

Sa femme Lieou-chi répliqua :

- La famille est riche des vertus de ses ancêtres, et n'a pas acquis de biens par des moyens injustes. Vous êtes leur unique descendant, et le ciel qui est juste ne laissera certainement pas finir la ligne directe de votre famille en vous privant d'héritier ; car ceux qui souhaitent des enfans en ont tôt ou tard.

« Mais eussions-nous un enfant, si ce n'était pas à l'époque que nous pouvons désirer, à peine aurait-il atteint l'âge d'homme, que déjà nous ne serions plus, et tous nos soins et nos inquiétudes ne nous auraient servi de rien, mais seraient, au contraire, un sujet de chagrins et de tourmens.

Soung-tun, secouant la tête, convint de la vérité de ces observations ; mais avant qu'il eût essuyé ses larmes, il entendit quelqu'un dans la salle, qui appelait et demandait si Iu-foung était chez lui.

Il faut savoir que contre l'usage ancien, les pauvres comme les riches ont maintenant un double surnom ; ainsi quand on demandait Iu-foung, on nommait Soung-tun par son autre surnom. Soung-tun écouta, et entendant appeler une seconde fois, il reconnut la voix de Lieou-chun-tsiouan. 


\section{Contes chinois}

Le surnom de Lieou-chun-tsiouan, était yeou-tsai ; ses ancêtres possédaient un grand vaisseau avec lequel ils transportaient des marchandises d'une province à l'autre, et par ce moyen, ils avaient acquis une fortune considérable qu'ils avaient mise tout entière sur leur vaisseau, de sorte qu'il devait valoir plusieurs centaines de pièces d'or. Il était construit entièrement en bois de cèdre, et ils s'en servaient pour trafiquer sur les côtes de la province, de Kiang-nan où il se fait un commerce considérable.

Lieou-chun-tsiouan était l'ami le plus intime de Soung-tun ; aussitôt que celui-ci reconnut sa voix, il se hâta d'aller dans la salle. Ils ne firent pas de cérémonie formelle en s'abordant ; mais ils élevèrent simplement leurs mains devant leur poitrine et s'assirent vis-à-vis l'un de l'autre pour prendre le thé ensemble.

Soung-Tun demanda à Chun-Tsiouan comment il se faisait qu'il fut libre ce jour-là. Lieou-chun-tsiouan répondit qu'il était venu exprès pour emprunter quelque chose à Iu-foung :

- Que peut-il manquer sur votre riche vaisseau, lui dit Soung-tun en souriant, pour que vous veniez le chercher sous mon humble toit ?

Lieou-chun-tsiouan répliqua :

- Si je viens vous déranger pour un objet, c'est que vous en avez plus d'un ; c'est pourquoi je me hasarde à vous demander cette faveur.

- Si, véritablement, je I'ai en ma possession, lui dit Soung-tun, sans contredit elle vous sera accordée. 


\section{Contes chinois}

Lieou-chan-tsiouan se mit alors, sans aucune hésitation, à lui désigner ce qu'il voulait ; or cet objet...

« Lorsqu'on le porte sur le dos, ce n'est pas pour porter le message impérial ; si on le porte par-devant, ce n'est pas pour soutenir la poitrine; mais il est d'une belle étoffe jaune, et quand on l'offre, c'est avec des mains pures. Il contient les offrandes mystérieuses qui accompagnent les actions de grace, et on le présente avec respect lorsqu'on adore les dieux ; à force de paraître dans les vieux temples, il est sali par la fumée de l'encens qui s'y brûle.

Il paraît que comme il y avait un empêchement à ce que Soung-Tun et sa femme eussent des enfans, ils brûlaient de l'encens et faisaient des prières en divers endroits, pour avoir un fils. Ils avaient fait un pou-fou (ou serviette) jaune, et un pou-taï (ou sac) de la même couleur, pour contenir le cheval de Fo, ainsi que d'autres offrandes dorées. Après qu'on avait brûlé l'encens, ces objets étaient suspendus dans le temple de famille consacré au dieu Fo. Ils observaient toutes ces cérémonies avec une grande dévotion.

Lieou-yeou-tsaï avait cinq ans de plus que Soung-Tun, étant âgé de quarante-six ans, et sa femme Lieou-Chi n'avait pas non plus d'enfans. Ils avaient entendu dire qu'un marchand de sel de Fetcheou, désirant avoir un fils, avait rebâti le temple des Dames de Tchin-tcheou, qui est hors de la porte de la ville de Sou-tcheou-fou, et qu'il y allait continuellement beaucoup de 


\section{Contes chinois}

monde pour offrir de l'encens qui brûlait toujours en grande abondance.

Lieou-yeou-tsaï, se trouvant libre, pensa que c'était une occasion favorable, et demanda que la barque s'arrêtât au pont, parce qu'il voulait entrer dans le temple pour y présenter de l'encens ; mais comme il n'avait pas encore préparé le pou-fou ni le pou-taï, il était venu tout exprès pour les emprunter de Soung-tun. Quand il eut exposé le motif de sa visite, Soung-tun resta quelque temps sans lui faire de réponse. Lieou-yeou-tsaï lui dit alors :

- Êtes-vous d'un caractère si égoïste ? Si l'un ou l'autre de ces objets venait à être gâté avant que je vous le rende, je vous en donnerai deux pour un.

- Qu'y a-t-il besoin de cela, répliqua Soung-tun, la chose n'est qu'une bagatelle, et puisque les dieux du temple des Dames manifestent leur puissance, je désire y aller aussi ; mais je ne sais à quelle heure le bateau doit partir.

Lieou-yeou-tsaï lui répondit qu'il devait partir à l'instant. Soungtun dit alors :

- Il y a déjà une paire de pou-fou et de pou-taï enveloppée ; nous en avons encore une autre paire, cela sera suffisant pour tous les deux.

- C'est très bien ainsi, dit Lieou-yeou-tsaï.

Soung-tun vint dire à sa femme qu'il allait à la ville pour offrir de l'encens, ce qui la réjouit beaucoup. Il alla ensuite dans 


\section{Contes chinois}

le temple de Fo, pour prendre les deux paires de pou-fou et de pou-taï ; il en prêta un à Lieou-yeou-tsaï et garda l'autre pour son propre usage.

- J'irai le premier, lui dit Lieou-yeou-tsaï, je vous attendrai, dépêchez-vous de venir après moi : le bateau est à la petite arche de l'ouest du pont des Quatre Chevaux et, pour éviter tout retard, si vous voulez prendre votre part d'un peu de riz de ménage sur le vaisseau, il ne sera pas nécessaire que vous en apportiez.

Soung-tun accepte, et se hâte de préparer quelques cierges, des bâtons d'encens, du papier découpé en forme de chevaux ${ }^{1}$, ainsi que d'autres offrandes en papier, et les enveloppa soigneusement ; il mit aussi un long vêtement de soie blanche et se rendit de suite à la petite arche de l'ouest. Le vent étant favorable, ils mirent à la voile et en moins d'une journée ils firent plus de soixante-dix lis 2 , de sorte qu'ils arrivèrent dans la soirée sans éprouver de fatigue. Quand il fut nuit, ils allèrent au pont

1 On n'est pas sûr de l'époque où on commença à faire usage en Chine d'offrandes en papier ; mais c'est probablement peu après I'horrible action de Chihoangi (environ 150 ans avant Jésus-Christ), qui ordonna qu'on tuât ses femmes et ses domestiques et qu'on les enterrât avec lui, pour le servir dans l'existence à venir. Maintenant toutes les fois qu'on adore les dieux ou les esprits des morts, on fait constamment usage d'offrandes de plusieurs espèces, qui sont ordinairement accompagnées de divers objets, comme viande, volaille, riz, etc., etc. Il est d'usage aux funérailles de brûler du papier représentant des hommes, des femmes, des maisons, des bateaux et des matelots, des coffres, des habillemens et autres choses semblables. L'offrande d'un cheval de papier semble être prise des temples de Kouan-Fou-Tseu, le dieu Mars des Chinois, où I'on voit toujours l'image d'un écuyer avec son cheval tout prêt, et qui, à ce qu'on croit, reçoit toutes les pétitions et s'empresse de les remettre à la divinité.

${ }^{2}$ Il faut environ dix lis et demi pour faire une lieue de France. 


\section{Contes chinois}

avec le vaisseau, pour l'y mettre à l'ancre. Auprès de ce pont, un nombre immense de vaisseaux marchands de tous les pays forme une ligne qui s'étend à perte de vue. Il y a une ancienne ode qui fait allusion à cela ; la voici :

Quand la lune se baigne et que les nuages sont chargés de gelée, les oiseaux gazouillent ;

Qu'il est agréable, en se penchant, de voir depuis le pont les feux odorans des pêcheurs ${ }^{1}$,

Sur la montagne glacée qui est hors de la ville de Kou-sou, est le temple solitaire :

Pendant la moitié de la nuit le son de la cloche visite le bateau de l'étranger.

Ils se levèrent le lendemain matin avant qu'il fit jour, et après avoir fait leur toilette à bord, ils prirent ensemble un peu de riz ; ensuite ils se lavèrent les mains et la bouche et prirent chacun leur pou fou, où ils mirent le papier doré destiné aux offrandes. Ils placèrent le cheval de papier avec les prières dans le pou-taï jaune, et les suspendirent à leur cou. Ils quittèrent ensuite le vaisseau et s'avancèrent d'un pas lent, jusqu'à ce qu'ils furent arrivés au temple des Dames à Tchin-Tcheou, au moment où le jour commençait à poindre ; mais quoique les portes extérieures du temple fussent ouvertes, celles qui conduisaient à l'autel étaient fermées ; ils se promenèrent sous les portiques pour examiner le bâtiment qui était élégant et vraiment beau à voir. Comme ils étaient là à attendre, ils entendirent une porte s'ouvrir, et le prêtre vint les engager à entrer dans le temple. Il était alors de bonne heure ; ceux qui journellement brûlaient de l'encens n'étaient pas encore arrivés, et le chandelier était vide.

${ }^{1}$ Les bâtons d'encens qui brûlent au front des bâtimens. 


\section{Contes chinois}

Le prêtre prit donc une lampe et alluma une chandelle. Les deux amis lui remirent les pétitions pour les mettre en présence du dieu ; quand ils eurent offert de l'encens et fini leur prière, ils donnèrent une petite somme au prêtre, et après avoir brûlé les offrandes de papier, ils quittèrent le temple.

Lieou-iu-tsaï pria Soung-tun de l'accompagner jusqu'au vaisseau, mais celui-ci s'y refusa. Lieou-tsaï prit alors le pou-fou et le pou-taï, et les rendit à Soung-tun ; ils se remercièrent réciproquement et se séparèrent.

Lieou-iu-tsaï s'en alla tout seul au pont ; il appela son bateau et s'en retourna. Soung-tun, s'apercevant au jour qu'il était encore de bonne heure, eut envie d'aller à Leou-Men, et d'y prendre un bateau pour retourner chez lui ; mais comme il s'en allait, il entendit des gémissemens qui partaient du bas de la muraille, et en approchant il découvrit, sous un toit de chaume adossé le long du temple, un vieux prêtre infirme, qui attendait, étant couché, son dernier instant. Si on l'appelait, il n'entendait pas ; si on I'interrogeait, il était incapable de répondre ; Soungtun ne put supporter ce spectacle.

Un desservant du temple s'avança vers lui, et lui dit :

- Étranger, si vous avez le désir de faire un acte de bienfaisance, vous n'avez qu'à jeter les yeux sur ce vieillard.

- Quel acte de bienfaisance puis-je faire, lui demanda Soung-tun? 


\section{Contes chinois}

- Ce prêtre, lui répondit le desservant, est du Chen-si,

et il a soixante-dix-huit ans ; il déclare qu'il n'a jamais fait usage de choses défendues ${ }^{1}$, et qu'il a répété tous les jours le king-kang-king, ou livre de prières. Il y a trois ans qu'il a fait une pétition pour rebâtir son temple ; mais il n'a pu se procurer de souscriptions ; il a donc bâti cette chaumière où il demeure, et il répète constamment les formules des prières 2 ; il y a une auberge dans le voisinage, et tous les jours, vers midi, il prend quelque chose, mais après cette heure il ne mange rien. Quelques personnes, par compassion, lui ont donné un peu de monnaie pour acheter du riz ; mais il a tout dépensé à l'auberge, et maintenant il ne lui reste pas une obole ; il y a environ quinze jours qu'il est tombé malade, et depuis ce temps il ne mange ni ne boit plus. Il pouvait encore parler il y a deux jours, et

\footnotetext{
${ }^{1}$ Il n'est pas permis aux prêtres de Fo ou Boudha de manger de la viande, ni du poisson, ni même des légumes du genre des oignons. Ils ne mettent que des légumes avec leur riz et leurs pois : on regarde les oignons et les poireaux comme impurs à cause de leur saveur forte ; ils ne font usage ni de beurre, ni d'huile de poisson, pour accommoder leurs alimens, mais seulement d'huile extraite de graines. Ils regardent comme un graud crime d'ôter la vie à aucun animal, et c'est pour cela qu'ils s'abstiennent de toute nourriture animale.

2 Les formules de prières auxquelles on fait allusion ici et que les prêtres de Fo récitent dans leurs temples, le premier, le septième, le quatorzième et le vingt-huitième jour de chaque lune, sont pour la plupart des litanies ou des invocations prises daus la religion des Hindous, et sont tout-à-fait inintelligibles, même pour les prêtres. La tolérance qu'on accorde à la Chine à une religion aussi absurde que celle de Fo ou Boudha, montre assez l'état d'ignorance où était plongé le siècle où elle s'est introduite et le défaut d'un meilleur système de religion. Les sentimens de piété filiale qu'on inculque de bonne heure aux Chinois et la ferme confiance qu'ils ont dans les décrets du ciel, sont un bienfait inappréciable pour la Chine. Ce sont ces doctrines qui ont donné aux moralistes les moyens de répandre tant d'excellens principes, et qui sont, généralement parlant, la source de tout ce qu'il y a de bon et d'excellent en eux.
} 


\section{Contes chinois}

nous lui avons demandé comment il était devenu si infirme et pourquoi il n'était pas parti plus tôt. Il nous a répondu que son heure n'était pas encore venue, et nous a prié d'attendre encore deux jours. Ce matin, de bonne heure, il a essayé de parler, mais cela ne lui a pas été possible, et à chaque instant nous pensons qu'il va expirer. Étranger, si vous prenez de lui quelque compassion, vous lui achèterez un cercueil ordinaire dans lequel on puisse le brûler ${ }^{1}$; vous ferez ainsi un acte de charité. Comme il a dit que son heure n'était pas encore arrivée, il est probable, monsieur, qu'elle dépend de vous.

Soung-tun, après quelques réflexions, se dit :

« Je suis venu aujourd'hui pour demander un fils ; si je remplis cet acte de charité avant de retourner chez moi, le dieu du ciel le saura.

Il demanda s'il y avait un marchand de cercueils dans le voisinage ; le desservant lui dit :

- Si vous voulez aller jusqu'au bout de cette ruelle, vous trouverez la maison de Tchin-san.

- Je vous prierai de m'accompagner, lui dit alors Soung-tun, afin de me montrer l'endroit ;

\footnotetext{
${ }^{1}$ C'est une coutume chez les Chinois qu'aussitôt après la mort d'un prêtre de $\mathrm{Fe}$, on l'asseoit avec les jambes croisées et les mains levées en avant. Alors quelques-uns de leur confrérie l'accompagnent jusqu'à un endroit convenable où on le brille. Au célèbre temple de Haï-Nan, à Canton, on a élevé un endroit dans le Jardin pour brûler les prêtres ; après qu'on les a brûlés, on recueille leurs cendres, qu'on met dans un vase pour les enterrer.
} 


\section{Contes chinois}

le desservant le conduisit à la maison de Tchin-san, qui était occupé dans ce moment à scier du bois dans sa boutique; il lui dit :

-M. ${ }^{1}$ Tchin-san, je vous ai amené un chaland.

Celui-ci, s'adressant à Soung-tun, lui dit :

- Monsieur, si vous désirez voir des cercueils, j'en ai de la première qualité qui viennent de Wou-kouen, et il y en a là dedans qui sont en magasin ; mais, si vous en voulez de tout montés, entrez et choisissez vous-même.

Soung-tun répondit qu'il en voulait de tout prêts.

- Voici les meilleurs, lui dit M. Tchin-san, en lui en montrant plusieurs, ils coûtent trois taëls.

Soung-tun ne pouvait néanmoins en donner ce prix,

- Ce monsieur, dit le desservant au marchand, est venu pour acheter un cercueil, et comme c'est un acte de charité, il faut que vous y contribuiez en n'exigeant pas un prix trop élevé

- Puisque c'est un acte de charité, répondit $M$. Tchinsan, j'en demanderai moins, et je le laisserai pour un taël et six mas, qui est le prix coûtant, mais vous ne l'aurez point à une obole de moins.

Soung-tun convint que le prix était très raisonnable, et, tout en réfléchissant, il ouvrit le coin de son mouchoir, et en tira un

${ }^{1}$ Cette manière d'ajouter Monsieur aux noms chinois déplaira sans doute à beaucoup de lecteurs; on doit cependant leur faire remarquer que le traducteur n'en met que lorsqu'il y a dans le texte des titres d'honneur correspondans. 


\section{Contes chinois}

morceau d'argent pesant environ cinq ou six mas ${ }^{1}$. Il ne lui était resté, après qu'il eut brûlé l'encens le matin, qu'une centaine de caches, de sorte que les deux sommes réunies ne faisaient pas encore la moitié de la valeur du cercueil.

« Je sais ce que je vais faire, se dit Soung-tun en luimême. Le bateau de Lieou-chun-tsio est au pont qui n'est pas loin d'ici,

et s'adressant à M. Tchin-san, il lui dit :

- Je suis convenu avec vous du prix du cercueil ; je ne ferai qu'aller chez un ami pour emprunter une petite somme, et je reviens à l'instant.

- C'est bien, monsieur, je compte sur votre parole, lui répondit M. Tchin-san.

Mais le desservant fut mécontent, et lui dit tout en colère :

- Où donc est votre compassion, monsieur ; faitesvous le projet de vous sauver ? Aussitôt que vous vous êtes aperçu que vous n'aviez pas d'argent sur vous, vous auriez dû le dire; voyez tout ce monde dans la rue ! Tous regrettent le prêtre qu'ils entendaient il y a quinze jours encore réciter la formule des prières; mais hélas ! il n'est plus maintenant ! ainsi, avec trois pouces d'haleine 2, un homme exécute mille projets. En est-il privé un jour, la nature entière cesse d'exister pour lui.

\footnotetext{
1 Environ 13 liv.

${ }^{2}$ On fait allusion à la longueur de la trachée artère, qui, pendant la vie, est continuellement employée à l'inspiration et à l'expiration.
} 


\section{Contes chinois}

« N'entendez-vous pas ce qu'ils disent, monsieur, continua le desservant ? Le vieux prêtre est mort et il est maintenant loin de sa demeure terrestre ; mais il vous attend pour le faire enterrer.

Soung-tun, sans répondre, avait l'esprit très agité et se dit à luimême :

«Puisque je suis convenu du prix du cercueil, j'irai jusqu'au pont, et s'il n'est pas à bord, je m'asseyerai en attendant son retour; mais il y a un proverbe qui dit : Quand un marchand trouve un bon prix de sa marchandise, il ne choisit pas son chaland ; si, par conséquent, quelqu'un venait à lui offrir un peu plus que moi, il lui donnera le cercueil et je manquerai à la promesse que j'ai faite au prêtre, hélas !

Soung-tu prit encore une fois l'argent qu'il avait sur lui, consistant en un seul morceau, et, en le pesant, il fit une exclamation de surprise, car il se trouva que c'était une masse d'argent fin, qui, quoique petite en apparence, pesait plus de sept mas ; il le donna à M. Tchin-san, et, ayant ôté son beau vêtement de soie blanche, il le lui remit aussi, en lui disant :

-J'évalue cet habillement à plus d'un taël ; si vous ne vous souciez pas de le garder à ce prix, je vous le laisserai en gage ; mais si, d'ici à ce que je vienne le chercher, il a été porté, vous me ferez une déduction.

-Je suis un honnête homme, répondit $M$. Tchin, ainsi ne vous tourmentez pas. 


\section{Contes chinois}

Il prit toutefois l'habit et l'argent. Soung-tun ôta ensuite une épingle d'argent qui rattachait ses cheveux, qui pouvait valoir environ deux mas, et la donna au desservant, en le priant de la faire changer contre de la monnaie de cuivre, afin de payer les dépenses de l'enterrement. Ceux qui étaient dans la boutique à regarder, dirent entre eux :

- Que c'est malheureux ! ce seigneur bienfaisant a réussi à exécuter le plus difficile de l'affaire et le plus facile reste encore à achever : nous qui sommes les habitans de cet endroit, nous devrions donc contribuer un peu à I'aider :

Chacun donna alors quelque chose et s'en alla ensuite.

Soung-tun sortit et retourna à la hutte pour regarder encore une fois le vieux prêtre, qui, hélas ! avait cessé de vivre. Ses larmes coulèrent avec abondance, comme si c'eût été pour la perte d'un de ses proches parens. Son ame semblait abattue ; il éprouva plus de trouble qu'il n'aurait cru devoir en sentir, et il ne put supporter la vue du cadavre. Lorsqu'il eut cessé de pleurer, il retourna à Leou-men ; puis la barque étant partie, il demanda un bateau pour le reconduire chez lui le même jour.

Quand sa femme le vit revenir le soir, sans sa robe de dessus et le visage tout défait, elle s'écria :

- Vous venez de vous battre avec quelqu'un, entrez bien vite, afin que je sache les détails:

-Cela ne vaut pas la peine d'être raconté, lui dit Soung-tun en secouant la tête, 


\section{Contes chinois}

et il alla directement au temple de Fo pour y suspendre les deux paires de pou-fou et de pou-taï : il adora la divinité en frappant la terre de son front, et il retourna ensuite dans sa chambre où il s'assit pour prendre du thé ; quand il eut fini, il se mit à entretenir sa femme du vieux prêtre et lui raconta tout ce qui s'était passé.

-Vous avez agi comme vous le deviez dans cette affaire, lui dit-elle, ainsi vous n'avez aucun sujet de vous tourmenter.

Soung-tun approuva ce discours sensé de sa femme, et, bannissant leurs craintes, tous deux passèrent la soirée à se divertir.

Le mari et la femme se mirent au lit ensemble et dormirent jusqu'à cinq heures du matin. Soung-tun rêva qu'il voyait entrer dans sa chambre le vieux prêtre, qui, le saluant et le remerciant, lui dit :

- Mon bienfaiteur, jusqu'ici vous avez vécu sans enfans, et cette année devait être la dernière de votre vie ; mais comme votre cœur s'est montré compatissant et vertueux, le Chang-ti (la divinité) a décrété qu'il serait ajouté à votre existence la moitié d'un âge d'homme. Je demande aussi à mon bienfaiteur de devenir son fils, afin de le récompenser de la bonté dont il a usé envers moi, en me procurant un cercueil.

Lieou-chi eut aussi un songe dans lequel elle vit l'image d'or du dieu Louhan entrer dans sa chambre ; elle s'éveilla en faisant 


\section{Contes chinois}

un cri qui effraya son mari. Ils se communiquèrent leur rêve où la vérité et le mensonge se trouvaient également.

Ainsi :

Plantez le pépin d'un melon et vous obtiendrez un melon.

Semez la graine d'un pois et vous aurez un pois.

L'homme qui suit avec soin les inspirations de son cœur bienfaisant

Travaille pour lui-même en agissant d'après ses sentimens.

Lieou-chi devint enceinte à cette époque et eut un fils à l'expiration des dix mois lunaires. Elle lui donna le surnom de Kin, à cause du songe dans lequel elle avait vu le corps $d^{\prime}$ or du dieu Lou-han, et il fut appelé Soung-kin. Il est inutile de dire combien de joie cet événement causa à Soung et à sa femme.

Environ à la même époque, Lieou-iu-tsaï eut une fille qu'on nomma Yi-tchouan. Lorsque les deux jeunes gens furent devenus grands, on fit des propositions pour les marier ensemble ; Lieou-iu-tsaï y consentit avec joie, car c'était le vœu de son cœur ; mais Soung-tun y fit quelques objections, parce que Lieou-iu-tsaï descendait de parens qui habitaient les bateaux et qu'il n'était pas d'une famille ancienne. Quoiqu'il ne voulût pas le dire, c'était, à ses yeux, un obstacle insurmontable.

Soung-kin ${ }^{1}$ n'avait que six ans, lorsque son père tomba malade malheureusement, et mourut au grand détriment de sa famille. Il y a un vieux proverbe qui dit : La prospérité d'une famille tient uniquement à l'existence du chef ; et les efforts réunis de dix femmes ne sont pas à comparer à ceux d'un seul homme.

\footnotetext{
${ }^{1}$ Kin signifie or ; ainsi il est appelé l'enfant d'or ou l'être précieux.
} 


\section{Contes chinois}

Après la mort de Soung-tun, Lieou-chi prit la direction des affaires de la famille, jusqu'à l'époque où il survint une grande disette ; les gens du village haïssaient la veuve et I'orphelin aussi bien que ses domestiques; et Lieou-chi, s'apercevant que son revenu était incertain, se défit de ses maisons et de ses terres à mesure que l'occasion se présentait, et loua une maison pour y demeurer. Dans le premier moment, elle avait feint d'être pauvre ; mais dix ans s'écoulèrent à peine, qu'elle le devint en effet. Ayant vécu des débris de sa fortune, elle tomba malade : elle mourut peu de temps après, et on l'enterra.

Soung-kin, devenu orphelin et sans secours, fut chassé de la maison par le propriétaire, n'ayant pas un seul endroit pour se réfugier. Il avait, heureusement pour lui, appris à écrire et à compter dès son enfance ; car le hasard voulait qu'il se trouvât dans sa ville natale un homme de lettres, du rang des kiu-jin, nommé M. Fan, qui venait d'être nommé Tchi-hian de Soutchiou-fou dans le Tche-Kiang, et qui cherchait une personne sachant bien écrire et compter. Quelqu'un en informa Soungkin ; il se présenta chez M. Fan, qui donna ordre qu'on le fit entrer. Il fut très content de trouver Soung-kin jeune et d'un extérieur agréable, et il lui fit une foule de questions, surtout pour savoir s'il connaissait bien les formes régulières et cursives de l'écriture, et l'arithmétique simple et composée.

Soung-kin entra ce jour même dans sa place, et reçut un habillement neuf complet. Il mangeait à la même table que son maître qui le traitait avec la plus grande bonté. Le jour heureux qu'on attendait pour s'embarquer étant enfin arrivé, Soung-kin 


\section{Contes chinois}

monta sur un vaisseau du gouvernement avec M. Fan, le tchihian, qui se rendait à sa destination.

\section{Ainsi :}

Le son du bassin d'airain encourage le matelot à ramer ${ }^{1}$

Quand un vent léger enfle la voile.

Quoique Soung-kin fût pauvre, il était issu d'une famille respectable, et maintenant qu'il se voyait secrétaire de M. Fan, il se serait avili en faisant société avec les domestiques, comme les rayons du soleil qui se mêlent aux particules de poussière ; mais il encourut par-là leur ressentiment. Les domestiques I'avaient dédaigné à cause de sa jeunesse ; mais cette conduite les aigrit encore davantage contre lui.

De Kouan-Chan, le cortège continua sa route par eau jusqu'à Kang-tcheou ; et de là, il voyagea par terre. Ce fut en cet endroit que les domestiques se concertèrent pour porter leurs plaintes à leur maître contre Soung ; ce qu'ils firent en ces termes :

- Ce jeune homme, lui dirent-ils, qui est chez vous en qualité de secrétaire et pour vous servir, devrait être soigneux et soumis ; mais il ne sait nullement remplir ses devoirs. Vos bontés pour lui, monsieur, ont été portées à l'excès ; vous lui permettez de s'asseoir et de manger avec vous, ce qui peut être toléré quand on est à bord ; mais maintenant que vous allez voyager par

\footnotetext{
1 C'est une coutume dominante parmi les matelots chinois d'invoquer les dieux des vents et de la mer au lever et au coucher du soleil, en battant du gou et en brûlant des offrandes de papier. La même coutume a lieu lorsqu'on met à la voile ou qu'on arrive dans le port. Il en est de même quand on passe devant un temple situé sur le bord de la rive, ou près de quelque rocher célèbre.
} 


\section{Contes chinois}

terre et arriver dans des auberges, il serait convenable, monsieur, que vous exigeassiez de lui du respect. Nous nous sommes consultés ensemble, et nous pensons qu'il faudrait qu'il signât un engagement avec son signalement, afin qu'il ne puisse pas se permettre la moindre négligence ou le plus petit oubli dans son emploi.

M. Fan le kiu-jin était d'un caractère doux et facile, et s'en rapportant à ce que ses domestiques venaient de lui dire, il fit appeler Soung-kin dans son cabinet, pour le prier de signer l'engagement avec son signalement mais celui-ci s'y refusa quoiqu'on l'en sollicitât à plusieurs reprises, ce qui mit M. Fan si fort en colère, qu'il ordonna à ses domestiques de dépouiller Soung de ses habillemens, et de le chasser du vaisseau. Ceux-ci s'en emparèrent à l'instant et le jetèrent sur le rivage, après lui avoir arraché tous ses vêtemens, à l'exception d'un seul. Plus d'une heure s'était écoulée avant que Soung-kin se remît de sa frayeur, lorsque le premier objet qui frappa sa vue fut le palanquin et les chevaux qui attendaient M. Fan le kiu-jin, pour continuer son voyage; il se retint de pleurer et tourna le dos pour s'en aller. Comme il n'avait sur lui aucun objet de valeur, et qu'il sentait une faim très vive, il ne put mieux faire que d'imiter deux anciens sages :

Wou-siang, quand il était pauvre et dans la détresse à Woumen, allait de porte en porte en jouant du chalumeau. 


\section{Contes chinois}

Han-yu, jeune et affamé, ne refusa pas le secours d'une batelière 1 .

Soung-kin restait, pendant le jour, dans les rues, à mendier ; mais, à la nuit, il se retirait dans un vieux temple. Il conservait cependant une sorte de supériorité dans sa situation ; étant d'une famille respectable, quoiqu'il fût dans la plus grande misère, il gardait encore les trois quarts de leur souffle et de leurs os; et il ne voulut pas faire comme ces mendians des rues, qui n'avaient pas honte de se mettre à genoux et d'employer les expressions les plus serviles ; s'il obtenait quelque aumône, il s'en servait, sinon il savait endurer la faim avec patience ; quelquefois, il avait de quoi se procurer un repas ; d'autres fois, il s'en passait plusieurs jours de suite, jusqu'à ce que, ne conservant aucune trace de sa gaîté passée, il fut enfin réduit à un extrême état de maigreur et de dépérissement.

\section{Ainsi :}

Les pluies abondantes fanent la fleur qui va s'épanouir, Et une gelée blanche suffit pour priver l'herbe de sa verdeur.

L'automne maintenant s'avançait, et les vents du nord amenaient le froid avec rapidité, lorsque tout-à-coup il tomba une pluie abondante. Soung-kin avait épuisé sa légère provision de nourriture, et n'ayant qu'un seul vêtement pour se couvrir, il

\footnotetext{
1 On raconte que Han-Yu était d'une naissance commune, et que dans sa jeunesse il aimait beaucoup à porter une épée au côté. Un jour qu'il était à la pêche hors de la ville, une femme qui demeurait sur l'eau lui offrit du riz à manger. «Il faudra, lui dit Han-Yu, en le prenant, qu'un jour ou l'autre je vous récompense généreusement de votre bonté. » « Je vous le donne par compassion, mon prince, lui répliqua la femme d'un ton un peu ironique, ainsi pourquoi m'attendrais-je à une récompense ? » Lorsque Han-Yu fut nommé roi de Tsou, il se ressouvint de la bonté de cette femme, et l'ayant envoyé chercher, il lui donna mille pièces d'or pour récompense.
} 


\section{Contes chinois}

restait dans le temple appartenant à la nouvelle douane, ne pouvant sortir, malgré les souffrances que lui faisaient éprouver et la faim et le froid, à cause de la pluie qui était tombée sans discontinuer depuis sept heures du matin jusqu'à midi ; alors le temps s'éclaircit ; Soung-kin prit sa ceinture, et la serrant autour de ses reins, il sortit du temple ; mais à peine avait-il fait quelques pas qu'il rencontra une personne qu'il reconnut au premier coup-d'œil. Lieou-iu-tsaï, dont le surnom était Chuntsiouan, avait été I'ami le plus intime de son père Soungtun. Soung-kin n'eut pas assez de résolution pour regarder son père du rivage oriental, et, afin d'éviter d'en être remarqué, il tenait la tête baissée, et continuait son chemin les yeux fixés sur la terre. Mais Lieou-iu-tsaï l'avait déjà reconnu, et s'approchant de lui par derrière, il l'arrêta avec la main, en lui disant :

- N'êtes-vous pas le jeune Soung ? Comment se fait-il que vous soyez dans cet état?

Soung-kin, tandis que ses larmes coulaient en abondance, lui répliqua en joignant les mains devant lui :

- Mon vêtement est tel que je n'ose vous rendre mes devoirs ; mais puisque vous, mon vénérable oncle, vous avez la bonté de vous informer de moi, je vais entrer dans tous les détails.

Il lui raconta alors la manière inconvenante dont $\mathrm{M}$. Fan le tchihian s'était conduit avec lui, et l'informa de toutes les circonstances.

- La compassion, lui dit M. Lieou, est un sentiment naturel, et tous les hommes l'éprouvent. Vous allez 


\section{Contes chinois}

venir avec moi sur mon vaisseau ; vous travaillerez, et, en retour de vos peines, je vous nourrirai et je fournirai à votre entretien.

Soung-kin, se mettant à genoux, lui répliqua :

- Mon vénérable oncle, si vous me donnez de I'occupation, je vous servirai avec autant de fidélité que si vous étiez mon père ou ma mère rendu à la vie.

M. Lieou conduisit alors Soung-kin au bord de l'eau ; mais avant de l'amener sur le vaisseau, il alla informer sa femme de ce qui venait d'arriver. Madame Lieou lui dit que cet arrangement était avantageux pour les deux partis et très fort à désirer. Alors M. Lieou fit signe à Soung-kin, du vaisseau, pour qu'il vînt à bord, et ôtant un vieil habit qu'il avait sur lui, il le donna à Soung pour s'en revêtir, et le conduisit ensuite dans la cabane pour voir madame Lieou ; sa fille Yi-tchouan était à côté d'elle ; Soung-kin rendit ses devoirs à toutes les deux et s'en alla immédiatement sur le tillac. M. Lieou dit à sa femme de donner un peu de riz à maître Soung, afin qu'il pût manger ; elle lui dit qu'il y en avait, mais qu'il était froid. Yi-tchouan dit aussitôt qu'il y avait du thé chaud dans la bouilloire, et, prenant une tasse, elle la remplit. Madame Lieou alla à la cuisine chercher quelques cornichons dans le buffet et les présenta à Soung-kin, en lui disant :

Maître Soung, nous qui vivons sur un vaisseau marchand, nous n'avons pas toutes nos aises comme ceux qui habitent leurs maisons ; mais si vous pouvez manger un peu, quoique cela ne soit pas aussi bien servi, vous nous ferez plaisir. Soungkin I'accepta. M. Lieou, s'apercevant qu'il tombait un peu de 


\section{Contes chinois}

brouillard, appela sa fille pour prendre le vieux chapeau qui était derrière la cabine, et le donner à maître Soung pour se couvrir la tête. Mais Yi-tchouan s'étant aperçue, en le prenant, qu'il était déchiré d'un côté, elle tira vite une aiguille et du fil qu'elle avait dans son bonnet pour recoudre la fente ; elle le jeta ensuite sur le tillac, en appelant Soung pour lui dire de le prendre et de s'en servir. Soung-kin mit le vieux chapeau sur sa tête, mêla ensuite le thé chaud avec le riz froid et se mit à manger.

Quand il eut fini, M. Lieou lui dit de mettre tout en place et de nettoyer le tillac, parce qu'il allait à terre pour voir quelqu'un et qu'il ne reviendrait que tard. Il ne se passa rien de plus ce soirlà ; mais le lendemain quand $M$. Lieou se leva, il trouva Soungkin qui était assis à la proue à ne rien faire ; il pensa en luimême que ce n'était pas l'ordinaire aux nouveaux venus de se conduire de la sorte, et il lui dit d'un ton fâché :

- Garçon, vous mangez mon riz et vous portez mes habits, et malgré cela vous êtes paresseux : allons, allons, tournez cette corde, travaillez à ce câble et mettez chaque chose à sa place ; pourquoi êtes-vous assis à rien faire ?

Soung-kin s'empresse de lui répondre.

- Quels que soient les ordres que vous me donnerez, je les suivrai et vous obéirai avec plaisir.

Alors M. Lieou prit un paquet d'écorce d'arbre et le donna à Soung, en lui montrant comment il fallait le travailler.

Ainsi

Sous le toit le plus humble, si c'est celui d'un autre, 


\section{Contes chinois}

Comment songer à y entrer sans ployer la tête ?

Soung-kin travaillait avec ardeur du matin au soir et n'était jamais oisif.

Comme il s'entendait bien à la tenue des livres, il inscrivait sur le registre du vaisseau toutes les marchandises qui entraient ou qui sortaient, sans jamais commettre aucune erreur ; souvent même il arrivait que les gens des autres vaisseaux venaient le chercher lorsqu'ils avaient quelque transaction à faire, en le priant d'apporter avec lui le souan pan pour arranger leurs comptes. Chacun I'aimait, le respectait et disait de lui qu'il était d'un bon caractère et que, malgré sa grande jeunesse, il montrait déjà beaucoup d'intelligence. S'apercevant qu'il savait se rendre utile et qu'il avait beaucoup d'activité, $M$. et Madame Lieou non seulement jetèrent sur lui des regards de bienveillance, mais lui fournirent encore de bons vêtemens et une bonne nourriture, et le reconnurent pour leur neveu, en présence des étrangers. Soung-kin fut très satisfait de leur conduite à son égard, et, se trouvant dans une situation agréable, il reprit bientôt sa mine accoutumée, de sorte que les habitans des bateaux prenaient tous plaisir à le voir.

Le temps avait passé avec la rapidité d'une flèche et plus de deux années s'étaient écoulées sans qu'ils s'en aperçussent, lorsque M. Lieou vint à songer que lui et sa femme avançaient en âge et qu'il lui restait encore à chercher pour sa fille un mari sur lequel elle pût compter pour la vie ; maître Soung lui semblait I'homme qu'il fallait, mais il ne savait pas comment cela s'accorderait avec les idées de sa femme. Le même soir, comme 


\section{Contes chinois}

il buvait du vin avec celle-ci et que sa fille Yi-tchouan était à côté d'eux, il la montra à sa femme en lui disant :

- Yi-tchouan est maintenant d'âge à être mariée ; mais puisqu'elle n'a encore personne pour soutien, qu'y a-t-il à faire ?

- C'est une affaire importante, lui répondit madame Lieou, et qui, à raison de notre âge avancé, est d'un grand intérêt pour nous : pourquoi ne vous en êtesvous pas occupé avec plus de soin ?

- Cela n'est pas sorti de ma pensée un seul jour, lui répliqua monsieur Lieou ; mais il est difficile de trouver quelqu'un qui nous convienne parfaitement comme maître Soung qui est sur notre vaisseau, qui sache conduire bien un commerce et qui soit homme de mérite ; dans mille, nous ne trouverons pas son égal.

- Pourquoi donc ne lui donnez-vous pas votre fille en mariage, lui dit madame Lieou ?

- Que voulezvous dire, ma-ma, lui demanda M. Lieou avec ironie ? Il n'a pas de maison, ni de moyens d'existence ; mais il dépend absolument des secours que nous lui donnons, et ne possède pas un seul denier ; conviendrait-il que nous lui donnassions notre fille?

- Maître Soung, répliqua madame Lieou, est le fils d'un homme qui a occupé un emploi, et en outre c'est le fils de votre ami défunt ; de son vivant, il y avait eu des 


\section{Contes chinois}

propositions pour ce mariage, ainsi que vous pouvez vous en souvenir; quelque malheureuse que soit sa position actuelle, il n'en est pas moins un homme habile, sachant parfaitement compter et tenir les livres : faites-le donc entrer pour qu'il devienne notre gendre ; nous ne ferons pas tort à notre famille par cette alliance, et quand nous serons tous deux vieux, nous aurons quelqu'un pour nous soutenir.

- Est-ce là votre dernier mot, ma-ma, lui dit M. Lieou ?

Madame Liou lui demanda pourquoi il en serait autrement?

- Puisqu'il en est ainsi, répliqua M. Lieou, c'est bon.

Il paraît que Lieou-iu-tsaï craignait sa femme ; depuis longtemps il avait jeté ses vues sur Soung-kin, mais il avait peur qu'elle ne voulût pas donner son consentement. Il fut donc enchanté de voir qu'elle désirait elle-même cette union et il appela Soung-kin en présence de sa femme pour lui promettre sa fille en mariage.

Au premier moment, Soung refusa cette offre avec modestie ; mais quand il fut assuré des bonnes dispositions de $M$. et madame Lieou et qu'ils ne lui demandaient pas de dépenser un denier, il ne put faire autrement que de se conformer à leur désirs.

M. Lieou alla consulter les astrologues et choisit dans le calendrier un jour heureux pour célébrer la noce. Il retourna ensuite près de sa femme et partit avec son vaisseau pour Kouan-chan. La première chose dont il s'occupa fut de mettre le 


\section{Contes chinois}

bonnet de cérémonie à maître Soung ${ }^{1}$; il lui fit faire aussi un bel habillement de soie. Tout ce qu'il portait était absolument neuf depuis les pieds jusqu'à la tête, et quand il fut ainsi habillé, il avait très bonne mine, quoiqu'il ne possédât pas les talens extraordinaires de Tsaï-kian 2.

Il surpassait de beaucoup Fan-gan ${ }^{3}$ par les agrémens de sa personne.

Madame Lieou, de son côté, avait préparé tout ce qui était nécessaire pour les vêtemens et les bijoux de sa fille. Le jour heureux étant arrivé, on invita les amis et les parens pour la noce, et il y eut un festin splendide. Soung-kin se rendit à bord

\footnotetext{
${ }^{1}$ La coutume chinoise de mettre ce bonnet répond à la publication des bans et au contrat de mariage que I'on fait en Europe. Cette cérémonie a lieu ordinairement le matin même du jour où l'on fait le mariage. On invite à cette cérémonie les amis et les parens, ainsi qu'une personne respectable pour y présider. On fait asseoir le marié, le président délie ses cheveux pour les rassembler, et tout le temps il fait des réflexions sur les avantages du mariage et sur les richesses et le grand bonheur qui en résultent. Après avoir fini de lui natter les cheveux, il lui met un bonnet d'un genre particulier qui est fait exprès, et lui présente ses félicitations. Le reste du jour est consacré à se réjouir. On fait une cérémonie semblable à la mariée; ses cheveux, qui auparavant tombaient sur son front, sont relevés alors et attachés derrière sa tête avec des épingles, etc.

2 Tsaï-kian, fils du célèbre Tsao-tsao, avait un talent extraordinaire pour écrire des thêmes et des essais. Tsiay-ling-hoan, un de ses contemporains, surpassait tous les lettrés de Yang-hia dans ce genre, et il n'y en avait aucun qui fût digne de lui être comparé ; mais il était vain et orgueilleux. En parlant des talens parfaits de l'empire, il les évaluait à dix, et disait qu'il en possédait un ; que les autres lettrés réunis en avaient un autre, mais que Tsaï-kian en possédait huit à lui seul.

${ }^{3}$ Fan-gan, qui vivait sous la dynastie des Tsin, était regardé comme un très bel homme et fort aimé des dames. On raconte que lorsqu'il sortait de Loyang, pour s'exercer à tirer de l'arc, les dames avaient coutume de prendre des fruits et d'en jeter dans sa voiture jusqu'à ce qu'elle en fût remplie.
} 


\section{Contes chinois}

dans la soirée, et fut présenté à sa femme ${ }^{1}$. Le jour suivant, tous leurs parens et amis vinrent les féliciter sur leur mariage, et on passa trois jours consécutifs dans les fêtes et les réjouissances.

Il est inutile de dire qu'après leur mariage Soung et sa femme vécurent dans la plus tendre union ; ils continuèrent à trafiquer avec leur vaisseau, et leur prospérité semblait croître de jour en jour.

Le temps fuit comme une flèche, et un an et deux mois s'étaient écoulés sans qu'ils s'en aperçussent, lorsque Yi-tchouan lui donna une fille. Le mari et la femme l'aimaient plus qu'un trésor, et chacun d'eux en prenait soin à son tour.

Environ un an après, l'enfant tomba malade de la petite vérole ; on fit venir des médecins, mais tout fut inutile, et I'enfant mourut le douzième jour de sa maladie : Soung pleura sa fille chérie jusqu'à ce que ses forces étant épuisées, il tomba en consomption ; tantôt il se plaignait du froid et tantôt de la chaleur ; il perdit l'appétit, et mangeait moins de jour en jour, tant qu'à la fin il ne lui resta plus de chair sur les os, et qu'il lui fut impossible de s'occuper de la moindre chose.

M. et madame Lieou espérèrent d'abord qu'il se rétablirait ; ils avaient consulté les devins à son sujet ; mais plus d'une année venait de s'écouler sans qu'il éprouvât du mieux ; il semblait même que sa maladie avait augmenté, si bien qu'il ressemblait plutôt à un spectre qu'à un être vivant. Il ne pouvait

${ }^{1}$ Il est d'usage qu'on conduise la mariée à la maison dans le vaisseau de l'époux, mais ici la coutume est renversée, Soung-kin n'ayant pas de vaisseau à lui pour la recevoir. 


\section{Contes chinois}

plus tenir les livres ni faire aucun compte, et rien qu'en le regardant on sentait couler ses larmes, comme si on se fût mis un clou dans l'œil. Il eût été à désirer que la mort le délivrât de ce misérable état ; mais il ne devait pas en être ainsi.

Les vieux époux se repentaient sans cesse de lui avoir donné leur fille, et se firent l'un à l'autre tant de reproches, qu'ils finirent par se mettre dans une violente colère. Ils avaient compté sur lui pour leur servir de fils, et les soutenir dans leur vieillesse ; mais maintenant, à le juger à sa mine, il n'était ni mort ni vivant, mais il ressemblait à un serpent venimeux enroulé autour d'un cadavre qui ne peut s'en débarrasser.

- En lui donnant notre charmante fille, nous l'avons privée d'un soutien pour l'avenir, et nous avons mal agi. Il faut que nous trouvions quelque expédient pour nous délivrer de cet embarras ; nous pourrons alors marier notre fille à quelque beau jeune homme, et nous aurons encore une fois l'esprit en repos.

Après s'être consultés longtemps, ils arrêtèrent enfin un plan ; mais ils le cachèrent avec soin à leur fille, et se contentèrent de lui dire qu'ils avaient quelques affaires au nord du Kiang, et qu'ils y allaient avec leur vaisseau. Comme ils avançaient du côté de Wou-ki, dans le Si-tcheou, ils arrivèrent à un endroit inhabité, où ils virent une montagne isolée, et où tout avait un aspect solitaire. Dans le lointain, on entendait le bruit d'une chute d'eau, mais on ne pouvait découvrir aucun vestige d'homme, soit sur le sable, soit sur le rivage. 


\section{Contes chinois}

Le vent étant un peu contraire ce jour-là, M. Lieou, pour exécuter son projet, prit le gouvernail, et dirigeant le vaisseau dans une direction opposée, il le fit donner sur le sable. Il appela alors Soung-kin pour le dégager ; mais celui-ci n'en put venir à bout. M. Lieou se mit à l'injurier en lui disant :

- Misérable exténué, puisque vous n'avez pas assez de force pour vous rendre utile à bord, descendez sur le rivage pour couper du bois de chauffage, et apportez-le, afin que nous ne soyions pas obligés d'en acheter à la ville.

Soung-kin, quoique très effrayé, prit le crochet, serra sa ceinture autour de lui, et descendant à terre s'avança dans la partie la plus épaisse du bois ; mais quoiqu'il y eût des arbres en abondance, il aurait fallu de la force pour les abattre; Soung se contenta donc de cueillir quelques branches desséchées et de couper quelques broussailles; ensuite il arracha un rotin pour lier ce qu'il avait rassemblé, et il en fit deux gros tas ; mais n'ayant pas même assez de forces pour les porter, il lui vint à l'idée d'arracher encore un rotin et de mettre les deux tas en un, en laissant passer un bout du lien avec lequel il pût le traîner de la même manière que le pâtre conduit une vache. Après avoir marché quelque temps, il se ressouvint qu'il avait laissé le crochet par terre ; il retourna donc sur ses pas, et l'ayant retrouvé, il l'enfonça dans son fagot, qu'il traîna ensuite lentement vers le rivage, à l'endroit où le vaisseau avait été à I'ancre ; mais il ne put le retrouver, et aussi loin que la vue pouvait s'étendre, on n'apercevait que le rivage et la rivière. 


\section{Contes chinois}

Soung-kin erra le long de l'eau pour découvrir le vaisseau ; mais il ne put en apercevoir ni l'ombre ni la moindre trace. Tandis qu'il cherchait ainsi, il vit le soleil qui se couchait à l'occident, et conclut alors que son beau-père l'avait abandonné.

Dans un tel embarras, que pouvait-il faire ? Il n'y a pas de chemin pour monter au ciel, ni de porte par laquelle on puisse entrer dans la terre... Donnant un libre cours à sa douleur, il poussa des cris jusqu'à ce que ses forces étant épuisées, il tomba par terre sans connaissance. Il resta environ une heure dans cet état, et en reprenant ses sens, il aperçut sur le rivage, à son grand étonnement, un vieux prêtre qui s'approcha de lui, en s'appuyant sur un bâton, et lui parla ainsi :

- Mon bienfaiteur et mon compagnon, comment êtesvous venu ici ? ce n'est pas un lieu où vous puissiez demeurer.

Soung-kin se leva aussitôt, lui rendit ses devoirs, et lui ayant raconté la manière dont son beau-père l'avait abandonné, il lui dit qu'il n'avait aucun asile, et le supplia de le protéger et de lui conserver la vie. Le vieux prêtre lui répondit :

- Ma chaumière n'est pas loin d'ici ; vous pourrez rester avec moi pour le présent, et nous verrons ensuite ce qu'il conviendra de faire.

Soung-kin le remercia et se hâta de le suivre : ils arrivèrent à la chaumière après avoir fait environ un quart de mille. Le vieux prêtre prit alors un caillou et un briquet pour allumer du feu, et fit bouillir un peu de gruau qu'il donna à Soung-kin, en lui 


\section{Contes chinois}

demandant de nouveau comment il était arrivé que son beaupère et lui ne s'étaient pas accordés ensemble.

- Je désire, ajouta-t-il, que vous m'informiez de toutes les circonstances.

Soung-kin entra dans le détail de ce qui s'était passé depuis le moment où il avait été reçu à bord du vaisseau, jusqu'à celui où il était tombé malade.

- Mon très digne bienfaiteur, lui demanda le vieux prêtre, entretient-il quelque animosité contre son beaupère ?

- Lorsque j'ai sollicité sa bonté, il s'est montré plein de charité pour moi ; car il m'a reçu sur son vaisseau et m'a nourri ; il m'a ensuite donné sa fille. Mais voyant que je suis dangereusement malade et près de mourir, il m'a abandonné. Comment oserais-je toutefois entretenir de l'animosité contre lui ?

-Les sentimens que mon fils vient d'exprimer sont pleins de noblesse et de vertu. Votre maladie, monsieur, ne provient que de l'abattement d'un cœur malade, et il n'est pas au pouvoir de la médecine de vous guérir ; mais si vous parvenez à vous tranquilliser I'esprit, vous vous rétablirez. Jusqu'ici avez-vous observé les règles 1 et récité les prières que Fo a prescrites?

\footnotetext{
${ }^{1}$ Les principales de ces règles sont de ne pas tuer, et ce mot doit être pris dans la plus grande étendue; de ne pas dérober ni voler ; d'être chaste ; de ne pas mentir ; de s'abstenir de vin.
} 


\section{Contes chinois}

Soung-kin lui répondit que, jusqu'alors, il ne l'avait pas fait. Le vieux prêtre tira alors de sa manche un volume qu'il présenta à Soung, en lui disant :

- Voici le kingkang-pan-go ou le livre des prières scellé avec le cœur de Fo.

Il assura Soung-kin que s'il en répétait un chapitre tous les jours, il serait délivré de toute mauvaise pensée, et qu'au lieu d'être en proie à l'affliction, il posséderait des richesses considérables, et atteindrait un âge avancé.

Il paraît que Soung-kin, n'était autre que le vieux prêtre du temple des Dames à Tchin-tcheou, revenu au monde par la métamorphose ; dans sa première existence, il avait récité le livre de prières, et maintenant, dès qu'il eut jeté un coup-d'œil sur l'une des sections, il fut en état de la répéter de mémoire : ce qui provenait de ce que sa première existence n'était pas entièrement anéantie.

Soung-kin et le vieux prêtre s'assirent pour faire un acte d'adoration ; ils fermèrent les yeux et se mirent à prier jusqu'à ce que le jour fût près de paraître ; mais Soung-kin s'endormit involontairement, et, lorsqu'il se réveilla, il ne vit plus ni le vieux prêtre ni la hutte ; mais le livre de prières, à sa grande surprise, se trouva dans son sein, et, en l'ouvrant, il s'aperçut qu'il le savait en entier. Soung-kin fut obligé de reconnaître qu'il y avait quelque chose de surnaturel dans cet événement : il alla ensuite se rincer la bouche à une mare qui était près de là, et adressa une prière au dieu Kin-lang ; il sentit son chagrin diminuer par degrés, et ses forces revinrent immédiatement. Il reconnut alors 


\section{Contes chinois}

que le prêtre avait été envoyé à son secours par la Providence, à cause de sa vertu passée, et, levant les yeux vers le ciel, il s'inclina et rendit des actions de graces ferventes à Loung, le dieu du ciel, pour sa guérison.

Cependant Soung-kin était encore aussi flottant qu'un brin d'herbe à la surface de l'Océan. Ne sachant où rester, il errait à l'aventure ; mais il commença bientôt à sentir la faim, quand tout-à-coup, en jetant les yeux sur une montagne qui était devant lui, il crut apercevoir quelque chose qui ressemblait à une maison, et, n'ayant pas, dans la circonstance où il se trouvait, d'autre ressource que de reprendre son ancien métier, il s'avança vers la montagne avec l'intention de mendier.

Dans le chapitre suivant, nous verrons comment maître Soung vit ses chagrins remplacés par le bonheur, et comment du sein de ses infortunes naquit sa prospérité.

Quand vous êtes arrivé au bout d'une route, une autre se présente ; Lorsque les eaux viennent à manquer, de nouvelles sources jaillissent. 


\section{Contes chinois}

\section{LES TENDRES ÉPOUX.}

\section{CHAPITRE II.}

Quand Soung-kin arriva à la montagne, il n'aperçut plus de maison ; il fut très étonné d'y voir des piques et des lances plantées dans la terre. Après avoir repris haleine, il continua sa marche, et parvint à un vieux temple en ruines dans lequel il y avait huit coffres fermés et scellés, et recouverts de branches de sapin. Soung-kin en voyant les coffres se douta aussitôt qu'ils contenaient quelque riche butin, et qu'on les avait entourés de piques et de lances, afin de détourner les gens d'approcher. Quoiqu'il ignorât comment ils se trouvaient là, il résolut de les emporter. Voici ce qu'il imagina pour venir à bout de ce dessein : il arracha des branches de sapin et les planta à mesure qu'il avançait, afin de reconnaître la route, marchant avec beaucoup de précaution jusqu'à ce qu'il fût hors du bois ; il alla ensuite directement au rivage où il trouva, par un heureux hasard, un vaisseau qui avait mis l'ancre dans la baie pour réparer des dommages arrivés au gouvernail par suite d'un gros temps ; une partie de l'équipage était occupée à le raccommoder. Soung-kin feignit d'être très agité, et, appelant ceux qui étaient à bord, il leur dit :

- Je me nomme Tsian-kin du Chen-si, et j'accompagnais mon oncle dans le Hou-kouang pour affaires lorsque nous avons été assaillis par des voleurs qui l'ont assassiné ; je leur ai dit que j'étais son domestique malade depuis longtemps, et je les ai 


\section{Contes chinois}

suppliés de me conserver la vie. Les voleurs m'ont remis sous la surveillance d'un des leurs, et nous ont envoyés tous deux au temple pour veiller au butin, tandis qu'ils se disperseraient en différentes directions. Le ciel m'a été propice en m'ôtant mon gardien ; La nuit dernière il a été mordu par un serpent venimeux, et il est mort. C'est ainsi que je me suis échappé, et je suis d'autant plus heureux que vous pourrez m'emmener avec vous.

Les gens de l'équipage l'écoutaient, mais sans accorder une entière confiance à tout ce qu'il venait de dire. Soung-kin ajouta :

- J'ai vu dans le temple qui n'est pas loin d'ici les huit coffres contenant toute la fortune de ma famille, je vous prie de me donner quelques-uns d'entre vous pour les aller prendre et les mettre sur le vaisseau, et en récompense de vos peines, je vous en donnerai un et je vous aurai mille obligations ; mais il faut vous hâter, car il y a mille contre un à parier que les voleurs viendront, et alors cette entreprise ne pourrait s'exécuter qu'en courant les plus grands dangers.

On irait à la distance de mille li pour trouver des richesses. Les matelots furent enchantés en apprenant qu'il y avait huit caisses de marchandises, et voulurent partir sur-le-champ. Ils choisirent huit des plus forts d'entr'eux, et, s'étant munis de huit paires de brancards en bambou, ils suivirent Soung-kin au temple où ils trouvèrent effectivement les huit caisses ; mais 


\section{Contes chinois}

comme elles étaient très pesantes, il fallait deux hommes pour en porter une seule, de sorte qu'ils eurent à se louer d'avoir pris les bambous. Soung-kin arracha les lances et les piques, et les cacha dans I'herbe qui était très haute. On transporta les huit caisses sur le vaisseau, et, le gouvernail étant réparé, les matelots demandèrent à Soung-kin où il voulait qu'on le conduisit ; Soung-kin répondit qu'il désirait aller à Nanking, sa ville natale.

- Notre vaisseau y va justement, lui répliquèrent les matelots, et cela arrange tout le monde.

Ils mirent à la voile, et après avoir fait mille li, ils s'arrêtèrent. Tous les gens de l'équipage vinrent présenter leurs respects au seigneur du Chen-si, et ceux qui avaient quelqu'argent se cotisèrent pour acheter de quoi faire un repas en commun.

Le lendemain, comme il y avait un bon vent d'ouest, ils déployèrent les voiles et arrivèrent en peu de temps à Kouatcheou, où ils jetèrent l'ancre. En traversant la rivière, il n'y avait que dix li de là à Nanking. Soung-kin appela un bateau, et ayant choisi les sept caisses les plus pesantes, il les fit mettre à bord et en donna ensuite une aux matelots qui l'acceptèrent avec de grandes démonstrations de reconnaissance. Ils s'assemblèrent tous pour assister en silence à l'ouverture de la caisse et partager entr'eux le contenu.

Aussitôt que Soung-kin fut débarqué à la maison de la douane, il arrêta un appartement et fit appeler un serrurier pour enlever les serrures des coffres; et, en les ouvrant, il les trouva remplies de perles, de diamans et d'autres objets précieux. 


\section{Contes chinois}

Il parait que ce butin avait été accumulé depuis bien des années, et qu'il n'avait pas été pris à une seule personne ni en une seule fois.

Soung-kin ne porta d'abord au marché que le centième d'une des caisses, ce qui lui valut plusieurs milliers de pièces d'or. Craignant toutefois que l'acheteur ne se fût trompé en lui en donnant un prix si considérable, il quitta son appartement et alla demeurer dans l'intérieur de la ville ; ensuite il acheta des esclaves pour le servir, s'habilla magnifiquement et adopta un genre de vie très brillant. Il choisit dans les six autres caisses les objets les plus élégans qu'il garda pour son propre usage, et vendit le reste des sommes immenses. Il fit l'acquisition d'un terrain situé en dedans de la porte de la ville de Nanking, où il bâtit une maison superbe avec des pavillons d'été et l'entoura de jardins qui en dépendaient; il meubla ensuite la maison de la manière la plus somptueuse.

Il établit une boutique de prêteur sur gages, sur le devant de la maison, et acheta des terres en divers endroits. Il avait un grand nombre de domestiques pour le service de sa maison, et dix autres pour conduire les affaires du dehors ; il prit en outre quatre valets de bonne mine pour le suivre quand il sortait. Toute la ville se remplit de sa renommée, et on lui donna le titre du seigneur Tsian. Il sortait toujours en voiture ou à cheval, et de retour chez lui, il était entouré de tout ce qui contribue aux agrémens de la vie. 


\section{Contes chinois}

Il y a un vieux proverbe qui dit que ceux qui vivent dans l'abondance, changent de caractère, et que ceux qui vivent dans le luxe changent de taille.

Soung-kin était maintenant opulent, plein de vigueur et de santé, et d'un embonpoint considérable ; il ne conservait plus rien du chétif extérieur qu'il avait eu jadis ; ainsi :

L'homme que la fortune favorise se montre plein de vivacité et de gaîté ;

Et la lune, quand elle atteint le solstice d'automne, brille d'une clarté resplendissante.

@ 


\section{Contes chinois}

\section{LES TENDRES ÉPOUX. \\ CHAPITRE III.}

Nous allons raconter maintenant ce qui arriva à Yi-tchouan, lorsqu'elle entendit son père ordonner à Soung-kin d'aller à terre pour couper du bois ; elle pensa qu'il fallait que son père ne s'aperçût pas que son mari était malade, sans quoi il ne lui aurait pas demandé une chose semblable ; elle aurait bien désiré lui dire de ne pas y aller ; mais elle craignait de s'opposer aux volontés de son père. Pendant qu'elle était à se consulter sur ce qu'elle devait faire, elle vit Lieou qui s'éloignait en toute hâte du rivage, et qui prenait le gouvernail pour changer la direction du vaisseau, et mettre à la voile.

Yi-tchouan, très effrayée, s'écria :

- Mon père, mon père, mon mari est à terre, pourquoi vous en allez-vous?

Sa mère lui dit d'un ton dédaigneux :

- Qui est votre mari ? cette chétive créature ? Pouvezvous encore penser à lui ?

- Ma mère, ma mère, que dites-vous ? s'écria Yitchouan tout en larmes.

- Votre père, lui dit madame Lieou, voyant que Soungkin est toujours malade et qu'il ne peut se guérir, a peur que vous ne gagniez sa maladie, et il s'est avisé d'un moyen pour vous débarrasser de ce malheureux cacochyme. 


\section{Contes chinois}

Yi-tchouan fut agitée de frayeur et les larmes coulaient de ses yeux comme d'une fontaine; elle courut hors de la cabane et s'empara d'une corde pour mettre à la voile et tourner le vaisseau ; mais sa mère la saisit comme animée d'une crainte mortelle, et la fit rentrer de force dans la cabane. Yi-tchouan, se frappant la poitrine, pleurait à chaudes larmes, et invoquait le ciel et la terre pour les prier de lui rendre son cher Soung.

Pendant ces débats, le vent et la marée étant favorables, le vaisseau avait déjà fait plusieurs milles, quand monsieur Lieou entra dans la cabane, et adressa à sa fille les remontrances suivantes :

- Mon enfant, écoutez un mot d'avis de ma part ; les femmes mariées ont un proverbe qui dit, qu'une année malheureuse égale un siècle de misère. La maladie de votre mari causera tôt ou tard sa mort, et ceux qui nous entourent souhaitent que ce lien soit rompu ; n'est-ce pas aussi votre désir ? le plus tôt que vous serez séparés, sera le mieux ; tout ira bien alors et vous qui êtes comme une source pure ${ }^{1}$, vous ne serez pas souillée par ce misérable; attendez quelque temps, et je vous chercherai un autre mari qui demeurera avec vous pour la vie; cessez donc de vous occuper de lui.

- Comment pouvez-vous agir ainsi, mon père, lui répondit Yi-tchouan ? Cette conduite est contraire à la justice et à I'humanité, et vous violez toutes les lois du

${ }^{1}$ Tchouan qui entre dans le nom de Yi-tchouan signifie fontaine ; c'est pour cela qu'il la qualifie de source pure. 


\section{Contes chinois}

ciel. Mon mariage avec Soung-kin a été de votre choix et de celui de ma mère; nous sommes devenus mari et femme pour ne cesser de l'être qu'à la mort. Comment revenir sur ce qui a été fait et changer ainsi de sentimens ? Quand il devrait rester malade le reste de ses jours, nous devrions attendre avec patience la fin de son innocente existence. Comment pouvez-vous supporter la pensée de l'avoir abandonné dans une île déserte ? Mon cher Soung mourra à cause de moi, et je ne lui survivrai certainement pas : mon père, si vous avez pitié de votre fille, tournez sur-le-champ le vaisseau et remontez le courant pour alter à la recherche de mon mari ; si vous le ramenez, vous éviterez les reproches de vos voisins.

- Lorsque ce malheureux étique, lui dit M. Lieou, aura vu que le vaisseau était parti, il se sera sans doute traîné dans quelqu'autre endroit pour se procurer de la nourriture ; ainsi à quoi nous avancerait de le chercher? puisque nous voguons avec un vent favorable et le secours de la marée, et que déjà nous avons fait cent lieues, n'est-il pas mieux de suivre le courant que de lutter contre ? Je vous engage à vous calmer, et tout ira bien.

Yi-tchouan, voyant que son père ne voulait pas consentir à ses désirs, se mit à pleurer et à jeter des cris, et s'élança hors de la cabane pour se précipiter à l'eau. Heureusement madame Lieou s'empara d'elle et I'en empêcha. Yi-tchouan jura que néanmoins 


\section{Contes chinois}

elle mettrait fin à son existence, et continua de pleurer. Les vieillards ne s'imaginaient pas que leur fille persisterait dans sa résolution ; combien alors se trouvèrent-ils à plaindre ! Ils veillèrent près d'elle toute la nuit, et le lendemain, pour contenter son désir, ils virèrent de bord ; mais comme ils allaient contre le vent et le courant, ils ne firent ce jour-là que la moitié du chemin qu'ils avaient fait la veille. Yi-tchouan passa encore la nuit entière à pleurer et à gémir, de sorte qu'il fut impossible à Lieou et à sa femme de se reposer un seul instant. Le troisième jour, ils arrivèrent enfin à l'endroit où ils avaient mis à l'ancre précédemment.

Yi-tchouan descendit à terre et accompagna son père pour aller à la recherche de son mari. Lorsqu'elle vit les deux tas de bois jetés sans ordre sur le sable et à côté le crochet qu'elle reconnut pour avoir appartenu au vaisseau, elle s'écria :

- Voici le bois que mon cher Soung a apporté, il y est encore, mais lui, hélas, il n'est plus !...

Cette réflexion ajouta à sa douleur. Comme elle ne pouvait cependant encore se persuader qu'il fût réellement mort, elle résolut d'avancer plus loin pour le chercher, et son père l'accompagnait partout où elle allait ; après avoir marché longtemps sans découvrir même la trace d'un pas, ils s'aperçurent qu'il faisait déjà sombre sous les arbres, et $M$. Lieou, voyant que la montagne s'étendait au loin, conseilla à sa fille de retourner au vaisseau ; là elle passa de nouveau la nuit à pleurer. Le quatrième jour, avant l'aurore, Yi-tchouan appela son père pour aller encore une fois à la recherche de son mari ; mais 


\section{Contes chinois}

quoiqu'ils parcourussent toute l'île, ils ne purent ni en découvrir l'ombre, ni entendre le moindre son. Elle pleura jusqu'à ce qu'elle fut de retour sur le vaisseau ; là tout en se livrant à ses réflexions, elle se dit :

« Dans un endroit aussi désert, à qui aura-t-il pu s'adresser pour demander à manger ; malade et ne pouvant marcher, il aura sans doute laissé le crochet sur le sable, et se sera précipité dans l'eau pour mettre fin à son existence.

Elle répandit de nouveau des larmes en abondance, et regardant fixement la rivière, elle voulut encore s'y jeter ; mais madame Lieou la retint avec force.

- Vous pouvez nourrir mon corps, lui dit-elle, mais il ne vous sera pas possible de nourrir mon ame ; je ne désire que la mort, laissez-moi donc mourir maintenant, afin que je puisse revoir bientôt la figure de mon bienaimé Soung.

Les vieillards, voyant l'excessif chagrin de leur fille, ne savaient plus que faire; ils l'appelèrent et lui dirent :

- Chère enfant, vos parens ont mal agi ; ils se sont trompés dans leurs projets, et ils reconnaissent leur faute ; mais hélas ! le repentir ne peut rien changer. Ayez pitié de nous! nous sommes vieux, et si vous, qui êtes notre unique enfant, veniez à mourir, nous passerions le reste de nos jours dans la tristesse ; nous prions notre fille de pardonner le crime de ses parens, et de se montrer indulgente et généreuse : votre père 


\section{Contes chinois}

écrira un avertissement et le fera afficher dans tous les endroits publics, et si Soung est encore en vie, il le lira et se décidera à revenir près de nous ; mais si, au bout de trois mois, nous n'avons pas entendu parler de lui, vous pourrez alors prendre le deuil, et prier pour sa félicité : nous vous défraierons largement de toutes les dépenses.

Yi-tchouan, tout en larmes, les remercia et leur dit :

- Si vous agissez ainsi, votre fille mourra en paix.

Lieou écrivit alors un avertissement et le fit afficher sur tous les murs.

Trois mois s'étant écoulés sans qu'on reçût aucune nouvelle de Soung, Yi-tchouan dit à ses parens que son mari était certainement mort : elle prit donc un grand deuil, et porta des habillemens de chanvre, laissant ses cheveux sans les nouer et flottant sur ses épaules. Elle suspendit la tablette de son mari au mur, et lui fit des offrandes ; elle envoya chercher neuf prêtres ${ }^{1}$ pour dire des prières pendant trois jours et trois nuits consécutifs, et elle détacha ses boucles d'oreille et l'épingle de sa

\footnotetext{
${ }^{1}$ Les prêtres de la Chine ne jouissent pas d'une grande considération parmi les Chinois eux-mêmes et sont regardés comme paresseux et malpropres. Ils ont eu pourtant à différentes époques des gens de lettres dans leur corps, puisqu'ils ont beaucoup de livres de prières et d'ouvrages sur la religion. Kaïtao et Koueï-hiu se firent distinguer par des empereur des dynasties de Tang et de Soung qui, par estime pour leurs talens et leurs vertus, les engagèrent à quitter le sacerdoce et à se consacrer aux affaires de l'État. Malgré ces deux exemples, on conserve toujours de fâcheuses impressions contre les prêtres, et l'auteur d'un ouvrage chinois très remarquable en 20 volumes, en a consacré plusieurs à rabaisser les prêtres de la Chine. Un de ses héros est un prêtre, qui, sans pouvoir être comparé au Dominiquin pour la nature de ses supercheries, peut du moins soutenir la comparaison sous le rapport de la fertilité de ses conceptions et du nombre de ses entreprises.
} 


\section{Contes chinois}

coiffure qu'elle leur donna, afin qu'ils continuassent à prier pour la félicité de son défunt mari.

M. et madame Lieou aimaient maintenant plus que jamais leur fille, et, ne voulant la contrarier en rien, ils supportèrent jusqu'à la fin les clameurs des prêtres, qui durèrent plusieurs jours ${ }^{1}$. Yi-tchouan continua de pleurer régulièrement à cinq heures du matin, et le soir, quand la nuit approchait. Lorsque les habitans des bateaux voisins eurent connaissance de sa douleur non interrompue, ils envoyèrent pour en savoir le sujet, et s'informer des circonstances. Il n'y eut personne qui ne regrettât Soung, et qui ne plaignît la fille de $M$. Lieou. Yi-tchouan, après avoir pleuré six mois entiers son mari, cessa enfin de répandre des larmes.

M. Lieou dit à Oma (sa femme) :

- Notre fille n'a pas pleuré depuis plusieurs jours, et son chagrin diminue insensiblement. Il faudrait songer à la remarier, afin qu'elle ait un autre soutien que nous, qui sommes vieux, ; comment pourrons-nous la protéger longtemps?

\footnotetext{
${ }^{1}$ Il est d'usage dans ces sortes d'occasions que les prêtres soient dans une autre pièce que celle où le corps est déposé, et dans laquelle on arrange les offrandes ; après les avoir bénies et avoir allumé l'encens, ils s'asseoient sur une chaise ou sur un tabouret, les jambes croisées et commencent à chanter leurs prières à haute voix, en se faisant accompagner de temps à autre par le bruit de cymbales ; pendant ce temps ils font un grand nombre de signes avec les mains pour éviter de profaner les noms de leurs divinités. Le plus âgé des prêtres agite continuellement une petite sonnette ; à mesure qu'ils approchent de la fin du service, ils répètent ce bruit avec précipitation ; ils sont ordinairemeut deux heures à réciter les prières.
} 


\section{Contes chinois}

- Vous avez raison, mon cher, lui répondit madame Lieou ; je crains seulement que notre fille ne s'y refuse. Il faut se contenter de le lui conseiller légèrement pour le moment, et nous reviendrons sur ce sujet quand il se sera écoulé un mois ou deux.

Le 24 de la douzième lune, M. Lieou revint avec son vaisseau à Kouan-chan pour y passer les derniers momens de l'année. Comme il était à se divertir avec sa femme et déjà un peu ivre, il prit une tasse de vin et la présenta à sa fille, en disant :

- Le printemps approche ; je vous conseille de quitter votre deuil.

- Celui d'un mari, lui répondit Yi-tchouan, doit se porter toute la vie; comment donc pourrais-je le quitter ?...

- Porter le deuil toute la vie ! s'écria son père en la regardant avec surprise ; vous le porterez si j'y consens, sinon vous le quitterez.

Madame Lieou, s'apercevant que le vieillard parlait à sa fille avec dureté, s'entremit et lui dit :

- Notre fille le portera encore cette année, et, la veille du nouvel an prochain, nous aurons un vase d'excellente soupe avec du riz ; nous ôterons alors la tablette de Soung, Yi-tchouan quittera son deuil, et tout ira bien. 


\section{Contes chinois}

Yi-tchouan ne put s'empêcher de pleurer, en voyant que son père et sa mère continuaient à faire de nouveaux projets, et leur dit :

-Vous avez tramé la perte de mon époux ; vous vous opposez maintenant à ce que je porte le deuil pour lui, et vous voudrez sans doute bientôt que j'en épouse un autre ; comment oserai-je manquer aux sermens que j'ai faits à Soung ? Oh ! j'aime mieux mourir en le pleurant, car je ne pourrais vivre après l'avoir trahi.

Ce discours mit $M$. Lieou dans une violente colère ; mais sa femme le gronda, et le poussa hors de la chambre par les épaules, en lui disant d'aller dormir. Yi-tchouan passa toute la nuit à pleurer dans ses habits de deuil.

Lorsque la lune eut fini son circuit, ce qui arriva le 30 du mois, et la veille du jour de la nouvelle année, Yi-tchouan présenta des offrandes et versa des libations à son défunt mari ; quand elle eut pleuré quelque temps, sa mère lui conseilla de faire enfin trêve à sa douleur ; ils versèrent tous les trois des libations à Soung, et le pleurèrent conjointement ; après quoi sa mère l'engagea derechef à se consoler : ils s'assirent ensemble pour le repas du soir ; mais lorsque son père et sa mère s'aperçurent qu'elle ne pouvait supporter l'odeur du vin (le vin étant défendu aux veuves), ils lui en témoignèrent leur mécontentement.

- Si vous ne voulez pas quitter votre deuil, du moins il faut prendre un peu de nourriture animale : qui peut 


\section{Contes chinois}

vous en empêcher ? Les jeunes gens ne doivent pas faire de tort à leur santé !

-Cette jatte de jagoun est suffisante pour moi, dit Yitchouan, qui ne suis pas, à la vérité, morte, mais qui existe à peine ;

et elle rendit le plat de viande à ses parens.

- Puisque vous ne voulez pas manger de viande, lui dit M. Lieou, prenez du moins une tasse de vin pour dissiper votre chagrin.

Mais Yi-tchouan répondit :

- Il n'est pas encore parvenu la plus petite quantité de vin chez les ombres des morts ${ }^{1}$, comment pourrais-je en boire en pensant à celui qui n'est plus ?

Ayant achevé ces mots, elle sentit une vive douleur, fondit en larmes, et ne pouvant manger son riz, elle se retira pour se coucher.

M. et madame Lieou, voyant que leur fille persistait dans sa résolution, convinrent de la laisser tranquille, et de ne plus user d'aucune violence. Les modernes ont une ode qui contient ceci :

\footnotetext{
${ }^{1}$ C'est une opinion généralement répandue en Chine que les esprits des morts descendent aux enfers, où ils expient leurs péchés par des souffrances et montent ensuite dans le séjour de la félicité, tandis que d'autres ont la permission de passer d'un corps à l'autre pour repeupler le monde. La présentation d'offrandes à ses ancêtres et à ses parens décédés est regardée comme un devoir de piété filiale ; les plus sages Chinois considèrent de même l'action de présenter des offrandes à ceux qui n'ont pas laissé de descendans pour remplir ce devoir, ainsi qu'à ceux qui ont péri de mort prématurée, soit qu'ils aient été assassinés ou qu'ils soient morts de faim ou de maladie; ils pensent que cette action est aussi méritoire que de soulager les pauvres. Ils ne décident pas si les esprits font on non usage de ces offrandes, mais ils concluent, que ces actes sont agréables aux dieu.
} 


\section{Contes chinois}

Parmi les femmes vertueuses qui ont gardé fidèlement leurs vœux de mariage, La jeune fille du Bateau, qui n'avait jamais parcouru une seule page d'histoire, Jura qu'elle voulait mourir, pure comme l'or et inébranlable comme un rocher. En présence de son sexe la fille du Bateau n'aura point à rougir. 


\section{Contes chinois}

\section{LES TENDRES ÉPOUX.}

\section{CHAPITRE IV.}

Nous allons maintenant revenir aux aventures de Soung. Il y avait environ deux ans qu'il était à Nanking et qu'il avait monté sa maison sur le ton de la plus grande élégance, lorsque le souvenir de son beau-père et de sa belle-mère se présenta de nouveau à son esprit. Ils s'étaient, à la vérité, conduits d'une manière cruelle envers lui. Mais sa femme était d'un caractère doux et aimable, et n'avait pas consenti à ce qu'on I'abandonnât : il ne pouvait par conséquent penser à en épouser une autre. Il remit le soin de sa maison à son intendant, et, prenant avec lui une somme de trois mille taëls d'argent, il se fit accompagner des quatre domestiques et de deux valets de bonne mine, et loua un vaisseau pour aller directement à Konanchan, s'informer de ce qu'étaient devenus M. et madame Lieou ; les voisins lui apprirent qu'ils étaient partis depuis trois jours pour Yi-thing. Soung-kin employa l'argent qu'il avait avec lui à acheter des ballots de drap, et se rendit à Yi-thing. Arrivé dans cet endroit, il descendit à une auberge très famée, et y déposa ses marchandises. Le jour suivant, il alla à l'embouchure de la rivière pour chercher le bateau dans lequel demeurait Lieou et sa famille. En approchant, il aperçut sa femme tout en deuil ; il connut par-là qu'elle avait gardé avec fidélité ses vœux de mariage ; ce qui le toucha vivement. Il retourna à son auberge, et dit au maître, qui s'appelait M. Wang : 


\section{Contes chinois}

- J'ai vu sur la rivière une très belle batelière en deuil ; je crois que le bateau appartenait à M. Lieou, et que c'est sa fille que j'ai vue. Voilà trois ans que je suis veuf, je voudrais bien l'épouser en secondes noces.

Il tira de sa manche trois taëls d'argent qu'il donna à M. Wang en lui disant :

—Prenez cette bagatelle pour préparer un peu de vin ; vous irez ensuite inviter $M$. Lieou à venir en prendre sa part, et vous lui demanderez sa fille en mariage pour moi. Si ce mariage se fait, je vous récompenserai généreusement. Si M. Lieou exige de l'argent, quand ce serait la valeur d'un millier de pièces d'or, je ne les refuserai pas.

M. Wang fut très content de cette commission ; il prit l'argent et alla immédiatement au bateau de $\mathrm{M}$. Lieou pour l'engager à venir dîner à I'auberge où il avait préparé un repas abondant. M. Lieou fut conduit à la place d'honneur des étrangers, ce qui le surprit beaucoup :

- Je ne suis qu'un simple batelier, s'écria-t-il, d'où vient-il donc qu'on a fait tant de frais et de préparatifs pour moi ? Quel peut en être le motif ?

- Quand nous aurons pris deux ou trois jattes de vin, lui répondit $M$. Wang, nous pourrons nous en entretenir.

M. Lieou, l'esprit en suspens, lui répliqua :

- Si vous ne m’apprenez pas ce dont il s'agit, je n'oserai pas prendre un siège. 


\section{Contes chinois}

M. Wang lui dit alors :

- Il y a maintenant dans ma maison un certain seigneur Tsin de Chan-si qui est extrêmement riche ; il est veuf depuis trois ans, et ayant pris beaucoup d'amour pour votre charmante fille il désire en faire sa seconde femme. Il veut, dès que la promesse de mariage aura lieu, lui donner mille pièces d'or ; et il m'a prié de vous faire part de ses propositions. J'espère que vous n'aurez aucune raison de refuser des offres aussi avantageuses.

- Il ne peut y avoir rien de plus heureux pour une fille de bateau, lui répondit $M$. Lieou, que d'épouser un homme riche; mais ma fille est fidèle à son vœu de mariage, et déclare qu'elle mourra plutôt que de se remarier : je ne puis donc me mêler de cette affaire. Quant au repas, je désire n'y pas toucher, et je voudrais prendre congé de vous.

M. Wang, l'arrêtant par le bras, lui dit :

- Le repas a été commandé par le seigneur Tsin ; le voilà prêt, et je dois en faire les honneurs; ne nous refusons pas à y prendre part : si nous n'arrangeons pas cette affaire, il ne faut pas pour cela que nous nous quittions en mauvaise intelligence.

M. Lieou accepta donc un siège, et tout en prenant le vin, M. Wang revint encore à la demande du seigneur Tsin, en assurant qu'il n'avait rien avancé à cet égard qui ne fût vrai, et qu'il espérait que M. Lieou, de retour sur le bateau, se consulterait 


\section{Contes chinois}

encore. Mais celui-ci qui se rappelait que sa fille avait voulu plus d'une fois se jeter à la rivière, branla la tête sans proférer un seul mot. Quand on eut emporté le vin, ils se séparèrent.

M. Wang alla trouver le seigneur Tsin et lui répéta mot pour mot ce que M. Lieou venait de lui dire; et Soung eut encore une nouvelle preuve de la constance avec laquelle sa femme demeurait fidèle à son vœu.

- Eh bien, dit-il à M. Wang, puisqu'il ne veut pas m'accorder sa fille, je désirerais du moins louer son vaisseau pour transporter des marchandises dont je veux me défaire ; peut-être fera-t-il encore des difficultés contre cela.

- Les vaisseaux du pays, lui répliqua M. Wang, sont tous au service de seigneurs de l'empire ; vous n'avez donc pas besoin de prier, mais seulement de donner vos ordres.

Et il alla de suite trouver M. Lieou pour louer son vaisseau. Celuici y consentit sans aucune difficulté.

Soung-kin ordonna à ses domestiques d'apporter ses effets sur le vaisseau, et de ne transporter les marchandises que le lendemain matin, où elles devaient être embarquées de bonne heure. Soung-kin mit un habillement de soie magnifique et un bonnet de fourrure; ses valets avaient des livrées vertes et portaient à la main un encensoir où ils brûlaient de l'encens.

M. Lieou et sa femme, en le voyant venir, se doutèrent bien que c'était le seigneur Tsin de Chan-si, et ne se donnèrent pas la 


\section{Contes chinois}

peine de s'informer davantage de lui : en quoi ils ne ressemblaient pas à tout le monde. Dans cet instant, Yi-tchouan, qui était au fond de la cabane, aperçut Soung, et, quoiqu'elle n'osât pas se livrer à l'idée que ce pouvait être son mari, elle tressaillit cependant en pensant à lui, et dit qu'il avait sept ou huit dixièmes de ressemblance avec son défunt époux.

Dès que le seigneur Tsin fut sur le vaisseau, elle le vit s'approcher de la cabane en disant :

- J'ai faim et je voudrais avoir un peu de riz ; s'il est froid, prenez un peu de thé chaud pour le mêler avec, cela suffira.

Ces paroles confirmèrent encore plus les conjectures de Yitchouan. Le seigneur Tsin dit ensuite en grondant ses domestiques :

- Garçons, vous mangez mon riz, vous portez mes habillemens et vous faites les paresseux. Allons, allons, tournez cette corde, travaillez à ce cable et arrangez chaque chose à sa place. Pourquoi êtes vous assis à ne rien faire?

C'étaient exactement les mêmes paroles que M. Lieou lui avait adressées la première fois qu'il était venu sur le vaisseau. Yitchouan, qui l'écoutait toujours, sentit augmenter sa conviction. Quelques instans après, M. Lieou présenta lui-même du thé au seigneur Tsin. Celui-ci lui dit :

- Vous avez un vieux chapeau dans le haut de votre cabane, prêtez-le moi. 


\section{Contes chinois}

M. Lieou, qui ne se doutait de rien, alla tout de suite le demander à sa fille; elle le lui remit en lui récitant ces quatre vers :

Le chapeau de feutre déchiré fut raccommodé de la main de votre propre fille

Parce qu'elle pensait alors que celui qui le porterait ne reviendrait plus avec sa figure d'autrefois.

Le seigneur Lieou, qui se tenait derrière sa cabane, entendit ce quatrain, et, cherchant à recueillir ses idées, il récita les quatre vers suivans en rendant le chapeau :

Les villageois de l'endroit ne reconnaissent plus celui dont les génies ont changé la personne; quoique de retour et richement vêtu, il lui est difficile de retrouver le vieux chapeau.

Le même soir Yi-tchouan dit à monsieur Lieou :

- Le seigneur Tsin, qui est maintenant à bord, n'est certainement autre que mon cher Soung ; sans cela comment aurait-il su qu'il y avait un vieux chapeau déchiré dans notre bateau ? d'ailleurs il lui ressemble de visage, et en l'entendant parler, comment pourrait-on conserver le moindre doute ? Demandez-lui ce qui en est.

- Sotte que vous êtes, lui dit M. Lieou avec un sourire insignifiant, la chair et les os de ce misérable étique doivent être consumés maintenant, et s'il n'est pas mort cette année, il était du moins hors d'état d'aller mendier son pain dans un autre village. Calmez-vous donc et réfléchissez où il pourrait avoir acquis toutes ces richesses. 


\section{Contes chinois}

- Lorsque votre père, lui dit madame Lieou, vous engageait à quitter votre deuil et à vous remarier, cela vous effrayait ; vous refusiez d'y consentir et vous vouliez vous jeter à l'eau et abandonner la vie ; mais maintenant que vous voyez ce riche seigneur, vous cherchez à reconnaître en lui votre mari. Supposez que d'un côté il ne vous connaisse pas, ce qui arrivera indubitablement, combien ne serez-vous pas honteuse alors ?

Ces reproches firent rougir Yi-tchouan, et elle resta tout interdite et confuse.

M. Lieou appela sa femme à part et lui dit :

- Oma, il ne faut pas parler ainsi ; car tous les mariages sont décrétés dans le ciel. Avant hier $M$. Wang, le maître d'auberge m'a invité pour prendre du vin chez lui, et m'a dit que le seigneur Tsin de Chansi désirerait épouser notre fille, et qu'au moment où on ferait la promesse de mariage, il lui donnerait mille pièces d'or ; mais connaissant l'entêtement d'Yitchouan, je n'en ai rien voulu dire. Il est difficile de se rendre compte du changement qui vient de se faire en elle ; mais enfin, puisqu'elle semble disposée d'ellemême à ce mariage, pourquoi ne saisirions-nous pas cette occasion de la marier avec le seigneur Tsin ? Ce sera un événement heureux pour vous et moi, puisque cela nous donnera un appui pour le reste de nos jours. 


\section{Contes chinois}

- Vous avez raison, mon cher, lui répondit madame Lieou, le seigneur Tsin doit avoir eu quelque motif pour venir ici et pour louer notre vaisseau ; il faut aller le trouver demain pour vous entendre avec lui.

- C'est bien, lui répliqua M. Lieou, je sais comment il faut conduire cette affaire.

Le lendemain matin, aussitôt que Soung fut levé et qu'il eut achevé de s'habiller, il prit le vieux chapeau et alla sur le tillac en le tournant de tous côtés.

- Pourquoi regardez-vous tant ce vieux chapeau, lui demanda M. Lieou ?

- J'examine l'endroit où il est recousu, répondit $M$. Tsin : il faut que ce soit une main bien habile qui I'ait si bien raccommodé.

- L'endroit où il est si bien recousu est de l'ouvrage de ma fille. Il y a quelques jours que $M$. Wang, l'aubergiste, m'a parlé de la demande de votre seigneurie ; il y avait néanmoins, dans cette demande, quelque chose que je voudrais éclaircir.

Le seigneur Tsin, curieux d'apprendre ce que c'était, lui demande ce qu'il voulait dire :

- M. Wang, répliqua Lieou, m'a dit que votre seigneurie avait pleuré sa femme depuis trois ans et que vous n'étiez pas encore remarié, mais que vous désiriez maintenant épouser ma fille. 


\section{Contes chinois}

- Et vous, monsieur, lui demanda Soung, le voulezvous?

- Que je le veuille ou non, ma volonté aura peu de puissance, car ma fille s'obstine à demeurer fermement attachée à son vœu de mariage, et déclare qu'elle ne veut pas se remarier ; ainsi je ne veux m'engager à rien.

- Comment votre honoré beau-fils est-il mort ?

- Mon indigne beau-fils eut le malheur de tomber en consomption : il descendit un jour à terre pour couper du bois, et j'ai mis à la voile sans y penser. J'ai fait aussitôt après publier un avertissement, et je I'ai cherché pendant trois mois, sans pouvoir m'en procurer la moindre nouvelle. Tout le monde en a conclu qu'il s'était jeté à la rivière, et qu'il était mort.

- Votre honoré beau-fils n'est pas mort, il, a rencontré un personnage extraordinaire qui l'a guéri de sa maladie, et il est devenu excessivement riche ; si vous voulez avoir une entrevue avec lui, priez sa bien-aimée de venir ici.

Yi-tchouan qui avait écouté depuis le commencement, et qui n'avait pas perdu un seul mot, fondit en larmes, et s'écria :

- Cœur froid, homme insensible que vous êtes ! J'ai porté le deuil depuis trois ans ; j'ai souffert mille peines et mille tourmens à cause de vous, et dans cet instant 


\section{Contes chinois}

même, vous ne vous expliquez pas encore... Qui êtesvous? Qu'attendez-vous?

Soung-kin, les yeux baignés de larmes, l'appela :

- Venez, ma chère femme, venez, que je vous voie.

Le mari et la femme se jetèrent dans les bras l'un de l'autre en pleurant.

- Oma, dit M. Lieou à sa femme, regardez, n'est-ce pas là le seigneur Tsin ? Il faut que nous allions le trouver et lui avouer notre crime.

M. et madame Lieou entrèrent sur-le-champ dans la cabane et le prièrent de leur pardonner.

- Mon père et ma mère, il n'est pas besoin que vous me suppliiez pour cela ; seulement, si votre indigne beau-fils devient encore malade, ne l'abandonnez plus.

Les vieillards furent honteux et confus.

Yi-tchouan quitta ses habits de deuil ; elle arracha la tablette de son mari, et la jeta dans l'eau. Soung-kin appela alors ses domestiques et ses valets et leur dit de rendre leurs devoirs à leur maîtresse, ce qui se fait en touchant la terre avec le front.

Madame Lieou tua quelques volailles, prépara un peu de vin et servit sa fille, comme si elle eût été une étrangère. Dans un autre moment, tandis qu'ils étaient à table à se divertir, madame Lieou se mit à parler de sa fille en racontant à Soung que, depuis son absence, elle n'avait voulu boire ni manger aucune chose défendue. Soung-kin en fut affligé, et, tout en pleurant, il prit une tasse de vin et la présenta à sa femme en l'engageant à 


\section{Contes chinois}

renoncer à ces privations. Puis, s'adressant à Lieou et à sa femme, il leur dit, avec un air colère :

- Puisque vous avez eu le cœur de m'abandonner dans l'espoir de mettre fin à mon existence, vous avez perdu le mérite de votre bienfaisance et vous avez renoncé à votre vertu. Vous ne méritez pas qu'on fasse attention à vous ; c'est avec peine que je bois ce vin et je ne le ferais pas si ce n'était pour votre fille.

- Si vous n'aviez pas été abandonné, lui dit Yi-tchouan, ce changement extraordinaire aurait-il eu lieu ? Mon père et ma mère vous ont autrefois témoigné beaucoup de tendresse ; vous devez donc vous souvenir de leurs bontés et oublier leur cruauté.

- J'agirai conformément aux désirs de ma très chère femme, répliqua Soung, j'ai déjà bâti une maison à Nanking ; il y a des jardins et des prés qui en dépendent et je suis suffisamment riche. Ainsi, vieillards, vous pouvez quitter les occupations de votre bateau et m'accompagner pour partager notre fortune et notre félicité. N'est-ce pas ce qu'il y a de plus désirable?

M. et madame Lieou lui firent leurs remercîmens ; il ne fut plus question de rien ce jour-là. Le lendemain, M. Wang, ayant bientôt appris cet événement, vint sur le vaisseau pour les féliciter et il passa la journée avec eux. Soung-kin laissa trois domestiques chez M. Wang, pour vendre le drap qu'il avait apporté et pour régler les comptes. Il loua ensuite un bateau et 


\section{Contes chinois}

se rendit en premier lieu à sa maison de Nanking, où il demeura trois jours ; puis il alla avec sa femme à Kouan-chan, qui était le lieu de sa naissance, pour réparer et faire nettoyer les tombeaux de ses ancêtres; chacune des personnes de la famille présenta séparément des offrandes abondantes.

M. Fan, le tchi-hian, avait résigné son emploi, et il était chez lui quand il apprit l'arrivée de Soung à son village natal, ainsi que le changement extraordinaire arrivé dans sa fortune ; il resta chez lui dans la crainte de le rencontrer, ce qui lui aurait été fort désagréable, et il fut plus d'un mois sans oser entrer dans la ville.

Quand Soung eut fini les affaires qui l'avaient appelé dans le lieu de sa naissance, il se hâta de retourner à Nan-king. Il est inutile de dire que toute la famille fut enchantée de son retour et partagea sa félicité.

On dit qu'Yi-tchouan, voyant Soung-kin entrer tous les jours de bonne heure dans le temple de Fo pour réciter une prière, lui en demanda la raison, et que Soung-kin lui raconta tout ce que le vieux prêtre lui avait dit concernant le kin-kang-king, ou livre de prières ; il l'entretint aussi de la manière dont il avait été guéri et lui apprit comment il avait conservé la vie. Yi-tchouan crut aussi aux doctrines de Fo, et pria son mari de lui enseigner les formules de prières.

Le mari et la femme répétaient chaque jour une prière, et ils voyaient sans regret approcher la vieillesse. Ils avaient quatrevingt-dix ans lorsqu'ils moururent, n'ayant jamais éprouvé de maladies. 


\section{Contes chinois}

Leurs enfans et leurs petits-enfans demeurèrent à Nanking et jouirent tous d'une grande aisance.

Les modernes ont une pièce de vers qui dit :

Les vertus du vieux Lieou n'ont pas duré jusqu'à sa mort,

Et les malheurs de maître Soung lui ont procuré la prospérité.

La prière du Kin-kang a guéri par degrés sa cruelle maladie,

Et le vieux chapeau déchiré a réuni la chair et les os.

FIN DU PREMIER VOLUME.

@ 


\section{Contes chinois}

\section{CONTES

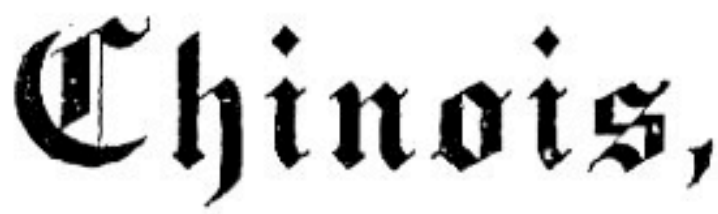

TRADUITS

PAR MM. DAVIS, Thoiks, LE P. D'ENTRIColles, etc,

ET PUBLIESS

Gat TR. A Gef-Rémusat.

40

TOME SECOND.

$\leftrightarrow$

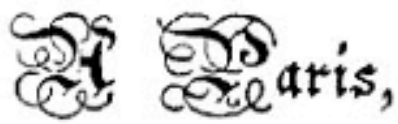

CHEZ MOUTARDIER, RUR GIT-LE-COEUR, $x^{\circ} 4$.

$\mathbf{1 8 2 7}$. 


\section{Contes chinois}

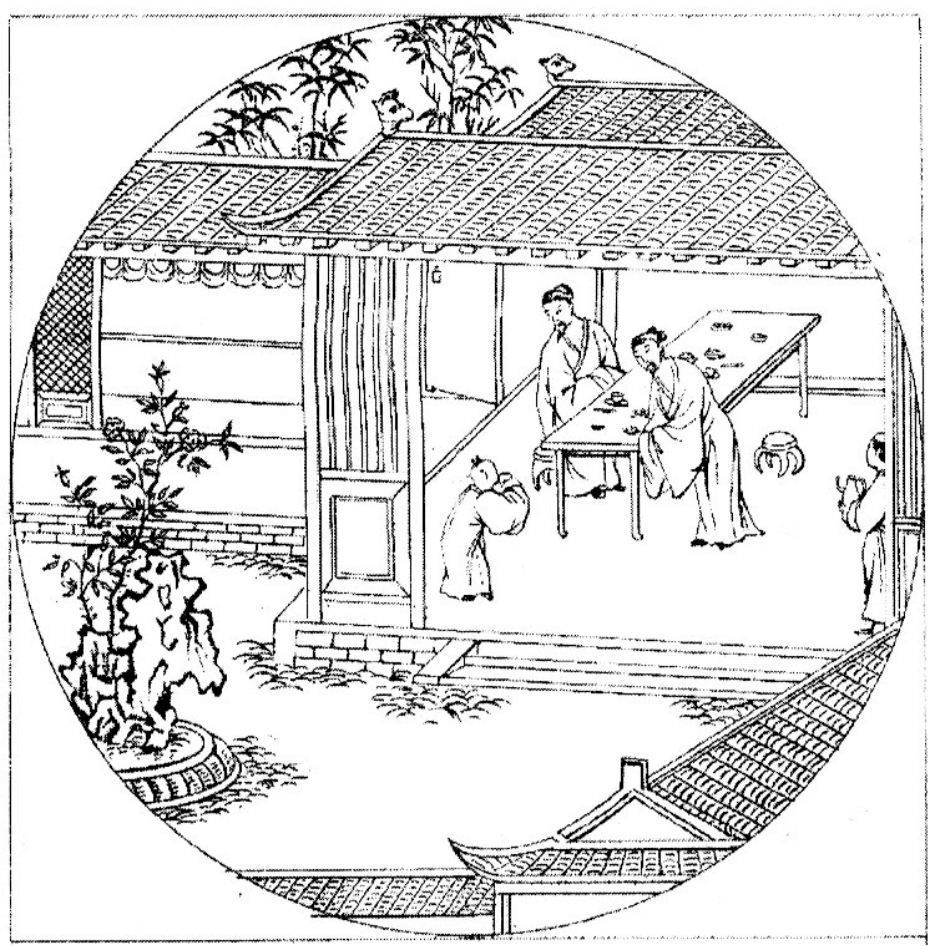

L'OMBRE DANS L'EAU.

Sous le règne d'un empereur de la dynastie de Youan, dans un district de la province de Canton, vivaient deux hommes qui, après avoir occupé des emplois, s'étaient retirés des affaires ; ils s'appelaient Tou et Kouan : le premier avait obtenu les plus grandes distinctions littéraires, et avait rempli les fonctions d'inspecteur-général d'une province, tandis que Kouan, étant resté dans un rang moins élevé, n'avait eu qu'une place inférieure. Ils avaient épousé les deux sœurs, et, comme leur beau-père n'avait pas de fils, ils demeuraient tous deux dans sa famille. Quant à l'esprit et aux connaissances, ils allaient à peu près de pair ; mais ils différaient beaucoup par le caractère : 


\section{Contes chinois}

celui de Kouan était grave et sévère ; Tou, au contraire, était d'une humeur enjouée et aimait le plaisir. Les deux femmes avaient commencé par avoir les mêmes goûts ; mais, après leur mariage, chacune d'elles se conforma à I'humeur de son mari, et peu à peu leurs inclinations devinrent de plus en plus différentes. Celle qui avait coutume de n'entendre que des discours graves ne pouvait souffrir qu'on parlât de plaisir. L'autre, accoutumée à la dissipation, avait de l'éloignement pour tout ce qui tenait à l'étude. Ainsi, ces quatre personnes qui étaient unies par des liens si étroits, par la seule différence de leurs dispositions se trouvaient toujours en contradiction, et chaque jour amenait de nouvelles disputes et des querelles continuelles ${ }^{1}$. Ils continuèrent néanmoins à vivre quelque temps ensemble ; mais, après la mort de leur beau-père et de leur belle-mère, ils divisèrent la maison en deux parties et les séparèrent par un mur qu'ils firent élever assez haut pour qu'on ne pût voir de l'un chez l'autre. Il y avait au milieu du jardin deux pavillons ou maisons d'été, qui étaient sur les bords opposés d'une petite pièce d'eau, et chacun des deux beaux-frères en eut un en partage. On bâtit facilement un mur de séparation aussi loin que le terrain s'étendait ; mais l'eau étant profonde, il devenait difficile d'y jeter des fondations. Cependant, on continua le mur par-dessus l'eau, quoique l'étang seul fût une barrière aussi efficace que la rivière jaune elle-même. Kouan, qui ne voulait pas que son beau-frère aperçût rien de ce qui se passait chez lui,

\footnotetext{
${ }^{1}$ C'est la démonstration de cette maxime chinoise : Quand la manière de voir et le caractère des gens s'accordent, ceux qui sont étrangers I'un à l'autre peuvent se lier d'amitié ; mais les plus proches parens seront bientôt ennemis si leurs dispositions diffèrent.
} 


\section{Contes chinois}

n'épargnait ni soins ni dépense pour continuer ce mur, ce qu'il fit au moyen de piliers en pierre placés au milieu du bassin, où on prolongea le mur d'un bout à l'autre. Depuis cette époque, non seulement les hommes ne voyaient plus les femmes de l'autre famille, mais ils ne se rencontraient guère qu'une fois l'an.

Tou eut un fils qu'il nomma Tchin-Seng, et Kouan eut une fille qui s'appela Iu-Kiouan. Ces deux enfans étaient à peu près du même âge, et il y avait une telle ressemblance entre eux, qu'on aurait dit qu'ils étaient l'empreinte d'un même cachet. Leurs mères, qui étaient sœurs, se ressemblaient beaucoup ; en outre, elles étaient parfaitement belles.

Leurs enfans n'avaient pas dégénéré à cet égard, et quand ils étaient sur les épaules de leurs nourrices ${ }^{1}$, avant la séparation des deux familles, on pouvait difficilement distinguer la perle d'avec le jaspe ${ }^{2}$. La femme de Tou prenait quelquefois Iu-Kiouan dans ses bras, et la caressait comme si c'eut été son propre fils. La femme de Kouan aussi faisait placer Tchin-Seng près d'elle pour dormir, ne mettant aucune différence entre lui et sa fille ; et cela était devenu pour elle une habitude.

On dit que les nourrices influent beaucoup sur la figure des enfans, ce qui vient peut-être du rapport qu'il y a entre le lait et le sang. Comme Tchin-Seng et Iu-Kiouan étaient enfans lorsqu'ils demeuraient ensemble et qu'ils n'avaient point encore de connaissance, ils ignoraient la ressemblance qui existait entre eux ; mais depuis qu'on avait séparé les deux maisons, ils

\footnotetext{
${ }^{1}$ Manière chinoise de porter les enfans.

${ }^{2}$ Allusion à leurs noms qui, en chinois, signifient ces objets.
} 


\section{Contes chinois}

étaient devenus assez grands pour adopter chacun la coiffure convenable à son sexe, et ils entendaient tout le monde parler de cette ressemblance ; leur curiosité fut vivement excitée par ces propos, et ils soupiraient après l'occasion de faire la comparaison, et de s'assurer de la vérité de ce qu'ils entendaient dire. Mais ils étaient séparés aussi complètement que le nord du midi, et ils n'avaient aucune possibilité de se rencontrer.

Au bout de quelques années, tous les deux, sans s'en rendre raison, commencèrent à faire à ce sujet les mêmes réflexions, et disaient, en se regardant dans le miroir : «Certes, on doit me trouver la plus belle personne qu'il y ait au monde, et il n'est pas possible qu'il y ait quelqu'un qu'on puisse me comparer. » Ces pensées les portaient plutôt à la jalousie qu'à la tendresse car ils n'étaient disposés ni l'un ni l'autre à céder la palme de la beauté. Ils ne se doutaient guère que ces sentimens de jalousie produiraient les évènemens qui suivirent, et que leurs aventures deviendraient le sujet d'une histoire divertissante.

Iu-Kiouan, étant une jeune fille, ne pouvait, malgré tout le désir qu'elle en avait, rendre visite à son cousin. Tchin-Seng, d'un sexe différent, se dit en lui-même : Les querelles de nos parens ne nous concernent pas ? je veux donc aller faire une visite de temps à autre pour entretenir quelques sentimens de parenté. Si nos mères peuvent se voir, pourquoi cela serait-il défendu à leurs enfans ? Par suite de ces réflexions, il enfreignit la vieille coutume établie, et en vint à faire une visite ; mais, à sa grande surprise, comme si son oncle avait prévu son dessein, il trouve une affiche en gros caractères collée sur le mur, portant 


\section{Contes chinois}

cette défense : «Il n'est permis à aucun parent de se présenter ici ; cette mesure ayant été jugée convenable, on prie les gens de la famille, quel que soit le degré de leur parenté, d'y avoir égard.» Lorsque Tchin-Seng aperçut cette défense, il s'arrêta immédiatement, et n'osa pas aller plus loin. Il fit cependant sa visite à Kouan, et le pria de demander à sa tante et à sa cousine de venir le voir. Kouan n'appela que sa femme sans dire un seul mot de sa fille; et lorsque Tchin-Seng laissa encore entendre le désir qu'il avait de la voir, Kouan feignit d'être sourd, et de ne pas comprendre ce qu'il voulait dire, et ne donna pas de réponse. Tchin-Seng, voyant que sa résolution était prise, ne se hasarda pas à le presser davantage ; et, après être resté encore quelques instans, il se leva pour prendre congé 1.

Dès ce moment, Tchin-Seng et Iu-Kiouan renoncèrent à leur curiosité enfantine; et voyant qu'il leur était impossible de vérifier ce qu'ils entendaient dire, ils cessèrent d'y songer, et il leur devint indifférent de savoir s'il y avait ou non de la ressemblance entre eux. Il sembla pourtant un jour, par une aventure singulière, que le sort avait décidé de les réunir, et que ceux qui ne pouvaient trouver moyen de se rencontrer sur terre, se verraient par la réflection de leurs images dans l'onde transparente.

Vers le milieu de l'été, et lorsque la chaleur était accablante, il arriva que le jeune homme et la demoiselle vinrent tous deux en même temps à leur maison d'été pour respirer la fraîcheur.

\footnotetext{
${ }^{1}$ Ici Kouan adresse un long discours à sa femme pour lui expliquer les motifs qu'il a de tenir son neveu éloigné, sans pourtant lui dire la véritable raison, qui était probablement la haine qu'il portait à son frère.
} 


\section{Contes chinois}

Comme il faisait très peu d'air, la surface de l'eau était tranquille, et les deux pavillons s'y réfléchissaient distinctement. Iu-Kiouan avait les yeux fixés sur l'eau, lorsque tout-à-coup elle tressaillit et s'écria : «Comment se fait-il que mon image paraisse de l'autre côté de l'eau, tandis que je suis de ce côté-ci ? Il faut que ce soit un prodige de mauvais augure! »

Après un peu de réflexion, elle changea pourtant d'avis, et reconnut que ce devait être l'ombre de son cousin, et que son erreur venait de ce que ne lui voyant pas de bonnet, elle le prenait pour une femme ; elle considéra la figure avec attention, et convint que c'était véritablement son portrait, et qu'il y avait à peine la plus légère différence entre eux deux : obligée de renoncer au droit exclusif à la beauté, elle éprouva une sorte de sympathie pour ce qui était si semblable à elle-même et peu à peu en vint à concevoir du ressentiment contre les pères qui séparaient ainsi de si proches parens.

Tchin-Seng, qui était assis appuyé contre la balustrade, aperçut aussi la réflection sur le bord opposé et se mit à sauter de joie. Il la regardait fixement et reconnut, après l'avoir examinée quelque temps avec attention, que ce qu'il avait entendu dire était la vérité, et qu'il n'était pas à comparer à sa cousine. Sa passion l'emportant sur sa prudence, et lui faisant oublier toute réserve, il appelle l'ombre à haute voix en lui disant : N'êtes-vous pas Iu-Kiouan ? Oui, vous êtes la contrepartie de moi-même : qui est-ce qui nous empêcherait de nous rejoindre et de nous unir pour la vie ? En disant ces mots, il 


\section{Contes chinois}

étendait ses bras vers l'eau, comme s'il eût voulu en faire sortir I'ombre.

Iu-Kiouan, qui l'entendait et qui voyait ce mouvement, sentit croître l'affection qu'elle avait déjà conçue pour lui, et elle aurait bien désiré lui répondre aussi par signes. Mais elle avait peur de ce qui pourrait arriver si on venait à l'apercevoir ; et comme jusque-là elle n'avait encore rien fait contre les règles, elle se sentit naturellement retenue. Elle se contenta donc de faire connaître les sentiments de son cœur par un sourire. Tchin-Seng, qui ressemblait en tous points à son père, savait fort bien qu'il suffisait à un homme d'un sourire, pour juger si une femme est favorablement disposée pour lui ; et que le sourire seul ne faisant qu'effleurer les lèvres, ce serait encore d'un heureux augure. Le nœud d'amour était déjà serré pour ces deux amans par l'intermédiaire de leurs ombres. Depuis ce moment ils vinrent tous les jours régulièrement au même endroit, sous le prétexte d'éviter la chaleur et sans permettre à aucun de leurs domestiques de les accompagner, préférant être seuls pour regarder par-dessus les balustrades et s'entretenir réciproquement avec leurs ombres réfléchies dans l'eau. Dans ces sortes d'occasions c'était presque Tchin-Seng tout seul qui entretenait la conversation ; la jeune demoiselle n'y répondait que par des signes, car elle craignait de s'exposer à un châtiment rigoureux, et peut-être même de courir risque de la vie si elle parlait et que son père ou sa mère vinssent à I'entendre. Dans cette première partie, on n'a fait que raconter ce qui eut lieu par l'entremise des deux ombres; dans la 


\section{Contes chinois}

suivante vous apprendrez ce qui arriva, lorsque les personnes elles-mêmes se furent rencontrées.

@ 


\section{Contes chinois}

L'OMBRE DANS L'EAU.

CHAPITRE II

Depuis leur première rencontre, les deux amans avaient à la vérité entretenu une correspondance journalière par le moyen de leurs ombres ; mais ils étaient malheureusement encore séparés par un mur très haut qui les empêchait de se trouver ensemble. Un jour Iu-Kiouan n'ayant pu reposer la nuit s'était levée un peu plus tard qu'à l'ordinaire, et il était déjà dix heures quand elle eut achevé de s'habiller ; elle se rendit de suite à sa maison d'été ; mais quand elle fut arrivée, elle n'aperçut pas l'ombre de Tchin-Seng dans l'eau ; elle se dit : il n'aura sans doute pu attendre et ne me voyant pas venir il s'en sera allé ; mais, en se retournant, elle vit à sa grande surprise que l'ombre était devenue un être réel qui tenait les bras étendus vers elle pour l'embrasser. Voici comment cela s'était passé : Tchin-Seng, qui avait déjà résolu de se trouver avec elle, avait profité de ce qu'elle n'était pas encore arrivée pour traverser l'eau et se cacher dans un enfoncement dont il pût sortir dès qu'il la verrait paraître. Iu-Kiouan était très craintive, et si auparavant elle avait eu peur que le moindre chuchotement ne les trahît, qu'on juge de la frayeur qu'elle dut éprouver maintenant qu'on ne la surprît en plein jour dans la compagnie d'un jeune homme ; elle s'enfuit dans la maison en faisant une exclamation, et fut plusieurs jours sans oser retourner au pavillon. Tchin-Seng, lui-même, n'avait pas été moins alarmé en la voyant se sauver en criant ; il retourna immédiatement sur ses pas, et se jetant dans l'eau il 


\section{Contes chinois}

travers à la nage jusqu'à l'autre bord. La retraite précipitée de Iu-Kiouan venait en partie de la frayeur et en partie de l'appréhension qu'on ne la trouvât avec son cousin, mais elle ne désirait aucunement de cesser toute communication avec lui ; elle se repentit bientôt de sa précipitation, et ayant écrit quelques vers elle les enveloppa dans une fleur qu'elle roula ensuite dans une feuille de nymphea-nelumbo pour la garantir de I'humidité. La première fois qu'elle aperçut I'ombre de TchinSeng, elle jeta le rouleau dans l'eau en lui faisant signe de le ramasser. Il sortit aussitôt tout joyeux du pavillon pour tirer le billet hors de l'eau ; il y trouva des vers dont voici le sens : elle lui disait que la surface agitée de l'eau était l'image de son âme ; qu'elle avait été à la vérité dans le plus grand étonnement en le trouvant près d'elle ; mais que c'était plutôt encore la crainte d'être punie si on les trouvait ensemble, que la frayeur qui avait occasionné sa fuite. Tchin-Seng fut dans la joie de ces vers, et se hâta d'en faire quelques-uns en réponse; il les mit dans le même rouleau pour les renvoyer par la même voie. Il y disait que la manière actuelle de s'entretenir ne valait guère mieux que de cueillir des fleurs en songe, et qu'il fallait s'efforcer de trouver un autre moyen qui leur présentât moins de gêne et plus d'intimité ; après avoir parcouru ces vers, Iu-Kiouan fut persuadée que son cousin braverait tout pour revenir et que cela se terminerait par quelque terrible catastrophe ; elle lui écrivit donc quelques lignes pour lui dire : que quoique sa première aventure n'eût pas eu d'autre mauvais effet que de lui causer une extrême frayeur, elle ne pouvait prévoir les suites d'une seconde visite; que son père à elle n'était pas du même 


\section{Contes chinois}

caractère que celui de Tchin-Seng, mais qu'il les ferait certainement mourir tous deux s'il les surprenait ensemble ; qu'il fallait donc qu'il usât de prudence et d'une grande circonspection. Tchin-Seng, d'après cette réponse, n'osa plus renouveler sa demande; mais il lui envoya une proposition formelle de mariage, dans laquelle il déplorait les malheureuses circonstances qui s'opposaient à leur union actuelle, concluant qu'il fallait attendre la tournure que prendraient les événemens, et saisir la première occasion favorable qui se présenterait, et qu'il n'attendait qu'un mot de réponse qui rendît leurs engagemens inviolables pour la vie. Non seulement Iu-Kiouan fut tranquillisée, mais elle consentit avec joie à sa proposition, et lui répondit par quelques signes dans lesquels elle exprimait son approbation, et l'assurait qu'elle se regardait comme appartenant à lui seul, et qu'il n'y avait que la mort qui pût les relever des vœux qu'ils avaient formés en présence du ciel. Cette réponse enchanta Tchin-Seng, et le consola des tourmens de l'absence. Depuis ce moment il avait, chaque jour, de courts entretiens avec l'ombre, en attendant qu'il pût enfin obtenir la réalité ; il écrivait sans cesse des vers dont le refrain était constamment l'ombre dans l'eau, et en six mois il avait composé un petit poème intitulé : la Rencontre des Ombres ; I'ayant laissé ouvert sur sa table, son père et sa mère l'aperçurent par hasard, et ils connurent par là que leur fils n'avait pas dégénéré, mais qu'il ressemblait à son père par la direction de ses études, et que vraisemblablement il irait au devant des désirs de sa mère.

Ils en éprouvèrent beaucoup de joie, et conçurent le désir de lui trouver un parti convenable. Ils pensèrent d'abord à Kouan, 


\section{Contes chinois}

mais ils craignirent qu'il ne fût trop contrariant pour consentir à ce qui pouvait rendre les autres heureux. Il y avait un nommé Lou-Koung qui était du même rang et de la même condition que Kouan, ayant aussi occupé des places subalternes, et, comme lui, sans emploi ; il aimait pareillement et l'étude et le plaisir, et comme il partageait également les goûts de Tou et de Kouan, il s'en était suivi naturellement beaucoup d'intimité entre lui et les deux autres. Après s'être concerté avec sa femme, Tou décida que c'était l'homme qui pouvait le mieux conduire cette négociation. Il alla donc lui-même chez Lou-Koung pour réclamer sa médiation ; il lui dit que son beau-frère et lui ayant eu depuis quelque temps des différends ensemble, il espérait qu'un ami voudrait bien faire le rôle de conciliateur et essayer de rétablir leur ancienne union ; qu'alors la proposition d'un mariage entre leurs enfans pourrait réussir. Lou-Koung répondit qu'il était fort à désirer que de si proches parens vécussent en bonne intelligence, et que pour lui il ferait tous ses efforts pour les réunir.

Très peu de temps après, Lou-Koung eut un entretien avec Kouan ; il commença par lui demander l'âge de sa fille, et si elle était déjà fiancée. Il arriva ensuite par degrés à l'affaire dont Tou I'avait chargé. Aussitôt que Kouan l'eut parfaitement compris, il sourit sans faire de réponse, mais se mit à écrire, avec un pinceau qu'il tenait à la main, quelques lignes sur la table près de laquelle ils étaient assis, et dont voici le contenu :

« Puisque la mésintelligence et l'inimitié ont duré si longtemps entre mon beau-frère et moi, ce n'est pas 


\section{Contes chinois}

une petite affaire que d'amener une réconciliation ; mais l'idée d'un mariage n'est guère mieux qu'un songe. 》

Lou-Koung vit, par la manière dont Kouan avait accueilli sa proposition, qu'il était inutile de le presser davantage, et il ne dit plus rien sur ce sujet. Il alla rendre compte à Tou du résultat de I'entretien ; mais il se contenta de lui dire que Kouan avait refusé son consentement, sans lui parler en aucune manière de ce qu'il avait écrit sur la table. Tou et sa femme abandonnèrent cette idée, et s'occupèrent à chercher un autre parti pour leur fils. Ils se rappelèrent que Lou-Koung avait lui-même une fille adoptive nommée Kin-Yun, qui ne cédait en rien à Iu-Kiouan, tant pour la figure que pour les qualités de l'esprit. Ils chargèrent donc une personne d'aller proposer ce mariage à Lou-Koung. Celui-ci répondit que le mariage étant une chose de la plus haute importance, on ne devait pas seulement consulter ses propres désirs, mais qu'il fallait comparer les pa tseu (les huit caractères) des deux personnes, et que si, après les avoir comparés, les combinaisons ne présageaient aucun malheur, I'union aurait lieu. Tou prit le pa tseu de son fils, et l'envoya à Lou-Koung. Ce dernier fut dans le plus grand étonnement de trouver, en l'examinant, qu'il était parfaitement pareil à celui de Kin-Yun ; car ils étaient nés tous deux la même année, le même mois, le même jour et à la même heure.

- Il paraît évidemment, s'écria-t-il, que cette union est arrêtée dans le ciel ; ainsi, il n'appartient pas aux hommes de s'y opposer plus longtemps. 


\section{Contes chinois}

Il ne vit aucun doute à cet égard. L'entremetteur rapporta cette réponse à Tou et à sa femme, qui s'en réjouirent beaucoup, et ils conclurent le mariage sans en parler à leur fils.

Mais comment se fit-il que Tchin-Seng, qui avait beaucoup d'intelligence et de pénétration, n'eût pas deviné ce que ses parens venaient d'arranger pour lui ? La vérité est que du premier moment que ce jeune homme avait aperçu Iu-Kiouan, il semblait avoir cédé son ame à l'ombre qu'il avait vue dans l'eau, et qu'il paraissait plutôt mort que vif. Si on l'appelait, il ne répondait pas ; et quand on lui adressait la parole, il n'entendait pas. Il passait tout son temps dans la maison d'été, assis, appuyé contre le balcon, sans rien faire et ne voulant permettre à personne de s'approcher de lui ; par conséquent, il ignorait ce qui se passait dans sa famille, et même son mariage avait été conclu sans qu'il en eût appris la moindre chose.

Cependant, Iu-Kiouan, qui, par hasard, en avait entendu parler, conçut immédiatement la crainte qu'il n'eût manqué à la foi qu'il lui avait jurée. Elle lui écrivit aussitôt une lettre remplie d'amertume, et où elle lui exprimait tout son ressentiment. C'est par ce moyen que Tchin-Seng fut informé de ce qui se passait. Il alla sur-le-champ trouver ses parens ; et quand il eut connaissance de l'affaire, il se mit à pleurer comme un enfant gâté, en les priant, s'ils faisaient cas de sa vie, de rompre leurs engagemens. Il fut très irrité contre Lou-Koung, et se prit à dire : « Le refus de mon oncle n'est qu'une invention de sa part ; il est évident qu'il avait envie de m'avoir pour gendre, et que ne voulant pas renoncer à cette idée, il a imaginé ce plan ; si on 


\section{Contes chinois}

avait pris quelqu'autre pour entremetteur mes vœux seraient maintenant exaucés », et il se mit à l'injurier de tout cœur. Tou aurait corrigé son fils pour cette conduite mais l'ayant gâté jusque-là, il ne pouvait plus exercer son autorité. Il savait aussi que le caractère de Tchin-Seng était une copie du sien ; et puisqu'il ne pouvait gouverner ses propres passions, comment aurait-il gouverné celles de son fils ? Il le laissa donc faire à sa guise, se contentant de lui dire qu'il devait modérer son chagrin, et lui laissa le soin d'arranger cette affaire. Tchin-Seng voulait qu'on fixât l'époque à laquelle on romprait l'un des mariages, et où on concluerait l'autre, et il jura que s'il était trompé dans ses espérances, il trouverait un sûr moyen d'étendre la postérité de sa famille. Le pauvre Tou fut obligé de céder et d'aller se présenter comme un vrai criminel chez Lou-Koung. Il sollicita d'abord son pardon pour la méprise qu'il avait commise, et ensuite il lui apprit la détermination de son fils. A cette nouvelle, Lou-Koung changea de couleur et s'écria :

- Pour qui me prenez-vous ? vous vous croyez donc permis de me proposer un mariage, et de le rompre ensuite ? Lorsque mes amis apprendront cela, ils me mépriseront et me tourneront en ridicule. Puisque votre fils a de l'éloignement pour s'allier avec ma famille, il faut qu'il ait déjà contracté quelqu'autre engagement. Dites-moi, je vous prie, quelle personne ce peut être?

- Toutes ses pensées se sont tournées vers la fille de Kouan ; et quoiqu'il sache très bien qu'il ne peut pas 


\section{Contes chinois}

I'obtenir, il veut encore conserver un léger espoir, et attendre quelque heureux changement de fortune.

Lou-Koung sourit en lui-même en entendant cela, et répéta à Tou la réponse énergique que Kouan avait écrite sur la table, lorsque ce mariage lui avait été proposé. Tou ne put s'empêcher de pleurer amèrement et de s'écrier :

- S'il en est ainsi, mon pauvre fils en mourra, et je resterai comme une ombre et privé d'enfans.

- Pourquoi donc ? répliqua Lou-Koung ; votre fils a quelque correspondance avec la jeune personne, et il aura contracté un engagement avec elle.

- Il n'y a eu rien de sérieux entre eux, répondit Tou ; quoiqu'ils aient eu quelques légères relations ensemble sans s'être jamais rencontrés, ils sont depuis six mois amoureux de leur ombre, et leur attachement est devenu si vif, qu'il est impossible de le vaincre. Quelle assistance pouvez-vous me prêter, mon ami ?

Et en disant ces mots, il lui présenta la composition poétique de son fils. Quand Lou-Koung l'eut parcourue, il montra d'abord quelque chagrin ; mais il se prit bientôt à rire en disant :

- Quoique cette affaire soit très contrariante, c'est néanmoins une aventure assez singulière ; car on n'a jamais vu se faire la cour par l'intermédiaire de son ombre, et le récit en passera certainement à la postérité. Les parens auraient dû empêcher les choses d'en venir à ce point ; mais enfin, puisqu'elles en sont 


\section{Contes chinois}

là, le plus tôt qu'elles seront arrangées sera le mieux, et j'imaginerai un moyen de les amener à bien. Je trouverai facilement un autre mari à ma fille.

Tou lui dit que s'il en agissait ainsi, il lui aurait une obligation éternelle de cette conduite, et il retourna chez lui pour informer sa femme de cette conversation. Tchin-Seng passa de la tristesse à une joie excessive; non seulement il cessa d'injurier LouKoung ; mais il se mit à chanter ses louanges, et supplia ses parens de le presser encore de terminer cette affaire, et il alla aussi lui-même le trouver. Lou-Koung lui dit que comme il fallait du temps pour réussir dans cette entreprise, il lui conseillait de ne plus s'en occuper pour le moment, mais de reprendre ses études. Dès cet instant : Lou-Koung s'occupa également et des intérêts de sa fille et de la recherche d'un autre gendre pour luimême. Cependant, il ne voulut pas dire à sa famille qu'on avait rejeté son alliance parce qu'il redoutait le ridicule qu'on pourrait jeter sur lui, et parce qu'il craignait aussi que si sa fille venait à découvrir la perte qu'elle avait faite, il n'en arrivât quelque malheur. Il assura que c'était lui au contraire qui avait rompu le mariage, parce qu'il le croyait désavantageux ; le jeune homme ne répondait pas à l'idée qu'il s'en était faite et n'avait pas toutes les qualités qu'il aurait désirées en lui. Il ne se doutait pas que sa fille viendrait à découvrir la vérité. Kin-Yun savait déjà que les huit caractères de Tchin-Seng étaient pareils aux siens, et on lui avait aussi dit que son prétendu était un homme très bien fait. Elle s'était félicitée de ce mariage, et elle répétait qu'il se ferait incessamment. Elle fut donc extrêmement affligée en apprenant tout-à-coup qu'il était rompu. Ses suivantes témoignaient aussi 


\section{Contes chinois}

beaucoup de ressentiment contre leur maître d'avoir renoncé à un mariage si avantageux, après l'avoir une fois arrêté.

- Quand le gendre était venu chez lui, disaient-elles, il avait persisté à ne pas le recevoir ; pourquoi n'avait-il pas cessé aussi toute autre communication avec lui ? pourquoi l'aider dans la demande qu'il faisait d'une autre personne, et renoncer ainsi à un gendre d'un aussi grand mérite ?

Kiu-Iouen, en entendant ce discours, fut très irrité contre LouKoung.

« Si j'étais sa propre fille, pensait-elle, il n'en agirait pas ainsi ; c'est parce que je ne suis que sa fille adoptive, qu'il s'inquiète si peu de mon bonheur.

L'agitation de son esprit la rendit malade au bout de très peu de jours. On dit avec vérité qu'il n'y a pas de douleur plus cuisante que celle qui se tait ; qu'il n'y a pas de chagrin aussi grand que celui qui ne cherche pas de soulagement. Elle ne voulait faire connaître ses peines à qui que ce fût, et les tenait renfermées dans son sein. Il en résulta qu'elle n'eut plus la force de les supporter, et que rien ne put porter remède à son mal.

Qu'un homme fuie une femme, et que cette femme tombe dans le désespoir, c'est une chose qui ne s'était jamais vue depuis le commencement du monde. Nos lecteurs peuvent s'arrêter ici pour réfléchir sur cette matière ; ils apprendront ensuite la fin de cette histoire. 
Contes chinois

(a) 


\section{Contes chinois}

L'OMBRE DANS L'EAU.

CHAPITRE III.

Kouan, comme on a pu le remarquer, était très sévère dans sa manière de gouverner sa famille, et ses soupçons ayant été éveillés par le mariage que Lou Koung lui avait proposé, il fit aussitôt fermer l'espace qui restait sous le mur avec de la terre et des briques, donnant ordre en même temps qu'il y eût constamment quelqu'un auprès de sa fille et qu'on ne la laissât jamais seule un instant. Depuis cette époque les amans furent non seulement privés de se voir mais leurs ombres même furent séparées. Tchin-Seng, ne pouvant plus avoir de communication avec Iu-Kiouan, fit de nouveaux vers dont cette séparation était I'objet, et les ajouta à ceux qu'il avait faits précédemment. IuKiouan avait appris qu'il avait recherché une autre personne, sans savoir que le mariage avait été rompu. Elle se déchaînait amèrement contre l'inconstance de son amant qui pouvait manquer à ses sermens et se livrer ainsi à la douleur ; elle était aussi très irritée de l'égoïsme de Lou-Koung qui avait pu, à ce qu'elle supposait, prendre pour gendre un homme déjà destiné à une autre, et devenir beau-père au lieu d'être l'entremetteur du mariage. Elle était convaincue que sa proposition n'avait pas été sincère et qu'il ne l'avait faite que pour sauver les apparences, et que c'était la raison pour laquelle son père l'avait rejetée. Ce tourment d'esprit ayant duré quelque temps, elle finit par ne plus vouloir accepter de nourriture, et tomba ainsi dans une indisposition très sérieuse. L'injure que Kin-Yun s'imagina avoir 


\section{Contes chinois}

soufferte n'était autre qu'une méprise ; et il en était de même du ressentiment de Iu-Kiouan à l'égard de Tchin-Seng. Ainsi, quoique leurs maladies provinssent de causes différentes, toutes deux avaient pour premier fondement une erreur. Tchin-Seng, de son côté éprouva une indisposition qui ressemblait en partie à celle de Kin-Yun, et en partie à celle de Iu-Kouan ; car en songeant à celle-ci il envisageait Kin-Yun comme une ennemie, et voyait en elle la cause de son tourment ; et quand il pensait à la première, qui n'était pas inférieure en beauté et qui était du même âge que lui-même, il semblait aigri contre Iu-Kiouan, et l'accusait de perfidie et de fausseté, prétendant que lorsqu'elle avait appris les propositions qu'il avait faites à Kin-Yun, elle avait été trouver son père pour le prier de faire fermer le mur, et se donner par là le mérite d'une grande vertu et d'une sévérité remarquable. Son père et sa mère, voyant qu'il n'y avait pas d'apparence qu'il épousât l'une ou l'autre, se bornèrent à laisser aller les choses et à attendre l'événement.

Lou-Koung, en voyant augmenter I'indisposition de Kin-Yun, n'en sentit que plus de désir de lui trouver un autre parti ; mais il semblait que la sollicitude qu'il montrait à cet égard, loin de calmer son mal, ne faisait que l'accroître ; il l'attribuait uniquement à la rupture de son mariage, et pensait qu'il suffirait de lui trouver un autre mari pour lui rendre sa gaieté. Il chargea donc différentes personnes de s'en occuper; mais tous les prétendans qui se présentaient étaient tellement affreux, que les servantes ne pouvaient s'empêcher de pousser des cris de frayeur, en les voyant entrer. A la suite de plusieurs aventures désagréables du même genre, la maladie de Kin-Yun augmenta 


\section{Contes chinois}

si fort qu'elle fut obligée de garder le lit, et qu'elle était presqu'à I'extrémité. Lou-Koung conçu beaucoup d'inquiétude, et, ayant interrogé vivement ses suivantes, il découvrit enfin la vraie cause de l'état de sa fille. Il commença alors à se repentir de ce qu'il avait fait, et se disait : dès qu'une fois on a pris un engagement pour une femme, c'est une chose très inconvenante d'y renoncer : il n'est pas étonnant qu'elle en soit affligée : c'est de ma faute, ajouta-t-il ; lorsque I'on est venu me trouver pour rompre le mariage, j'aurais dû m'y refuser ; mais, après y avoir consenti, je ne puis revenir là-dessus. D'ailleurs j'ai promis mes bons offices à Tchin-Seng, un honnête homme doit tenir à sa parole plus qu'à son argent : comment pourrais-je manquer à celle que je lui ai donnée ? La seule chose qu'il y ait à faire, sera de convertir les deux mariages en un seul, et de réunir ainsi ces trois personnes; mais il faut pour le moment cacher au vieux Kouan une partie de ce projet jusqu'à ce qu'il soit mis en exécution. Alors on lui communiquera le secret, parce que, tout violent qu'il est, il ne pourra plus y mettre d'obstacle. Néanmoins il restait encore une difficulté, et c'était de savoir à laquelle des deux épouses il faudrait accorder la préférence. Après quelques réflexions, il trouva moyen de lever cette difficulté. Il se rappela que jadis, lorsque Noy-Hong et Niu-Ying, toutes deux de la famille de l'empereur Yao, avaient épousé le grand Chun, on ne leur avait pas assigné le rang de première ou de seconde femme ; mais qu'elles se traitaient de sœurs. Ayant ainsi arrêté son plan, il envoya les suivantes pour donner des consolations à Kin-Yun, et fit ensuite prier Tou de venir lui parler. Il lui dit qu'il avait une manière de tout arranger qui empêcherait que sa fille 


\section{Contes chinois}

adoptive n'eût un autre mari, et qui conserverait la réputation de Iu-Kiouan ; il ajouta que Tchin-Seng était un être fortuné, que le bonheur dont il allait jouir semblait être un effet de son heureuse étoile.

Ce discours causa un grand plaisir à Tou, qui s'informa à LouKoung par quel moyen il amènerait cet heureux événement.

- Votre beau-frère, lui répondit Lou-Koung, est d'un caractère si obstiné qu'il ne faut pas chercher à émouvoir sa sensibilité, mais plutôt recourir à un stratagème pour le gagner. En me voyant sans enfans, au milieu de ma carrière, il m'a souvent conseillé d'adopter un fils. Je lui dirai que je viens de le faire, et que je désire beaucoup avoir Iu-Kiouan pour ma fille. En considération de l'amitié qui nous lie, je suis persuadé qu'il ne me refusera pas. Après avoir obtenu son consentement, je lui dirai encore que, comme ma fille n'est pas mariée, je veux lui faire épouser TchinSeng ; et je le supplierai de donner son agrément à ce double mariage, afin de rétablir la bonne intelligence entre tout le monde. S'il persiste après à rester brouillé avec vous, il perdra aussi mon amitié ; mais je ne crois pas qu'il puisse rien changer à ces conventions dès qu'il aura une fois donné son consentement. Je choisirai ensuite un jour heureux, et sous le prétexte du mariage de sa fille d'une part et de celui de votre fils, je réunirai ces trois personnes pour achever leur union. Ce plan n'est-il pas excellent? 


\section{Contes chinois}

Tou se mit à sourire et ne put s'empêcher de se prosterner jusqu'à terre, s'écriant : «Que l'adresse et la bonté de Koung étaient surnaturelles, et qu'il ne savait comment exprimer sa reconnaissance et son admiration. »

Tou alla ensuite rapporter ces bonnes nouvelles à son fils. Tchin-Seng, qui était livré à son double chagrin, reçut l'assurance de sa félicité avec des transports de joie ; et, quoique son chagrin et ses inquiétudes fussent bien grands, il en fut amplement soulagé dans cet instant. Kin-Yun, qui apprit cette nouvelle par ses suivantes, comprit I'heureux changement qui allait avoir lieu dans sa situation, et se rétablit bientôt sans le secours de la médecine. Il ne lui restait plus qu'à attendre l'époque fixée pour le mariage, pour devenir la sœur de Niu-Ying et la femme de Chun.

Il n'y avait jusqu'ici que deux des trois malades rétablis ; IuKiouan la troisième n'avait encore rien appris de ces heureuses nouvelles. Lou-Koung eut une entrevue avec Kouan et le fit tomber dans le piège qu'il lui avait préparé ; car, en voyant la maladie grave de sa fille, Kouan conçut naturellement le désir de la marier le plus tôt possible ; et Lou-Koung étant son ami intime et son collègue, il était bien aise de cimenter encore leur liaison par cette alliance. Il donna donc son consentement de grand cœur, sans faire la plus petite observation. Lou-Koung, qui craignait qu'il ne vînt à se repentir, ne laissa passer qu'un jour avant d'envoyer les présens de noce, et ne parla du mariage de Tchin-Seng qu'après qu'ils eurent été acceptés. Kouan ne put s'empêcher d'éprouver quelque mécontentement ; mais, 


\section{Contes chinois}

cependant, il ne témoigna pas de désapprobation ; il se mit à rire et dit à Lou-Koung qu'il avait choisi une excellente bru, mais un fort mauvais gendre, et que, s'il admettait un ami par la grande porte, il laissait entrer le diable par celle de derrière ; qu'enfin il avait perdu plus qu'il n'avait gagné ; que pourtant, puisque c'était une chose faite, il était inutile de lui en parler et de le sermonner à ce sujet.

Lorsque Iu-Kiouan apprit que son amant allait épouser KinYun, et qu'elle-même devait se marier dans la famille de LouKoung et vivre avec sa plus grande ennemie, le ressentiment qu'elle éprouva de ce surcroît d'infortune ne peut se rendre. Elle voulait écrire à Tchin-Seng, pour lui faire connaître ses sentimens dans cette circonstance, et ensuite se jeter à l'eau ou se pendre à une fenêtre pour mettre enfin un terme à son existence. Mais ses suivantes la surveillaient avec tant de soin et ses pareils prenaient tant de précautions, que non seulement elle ne put se procurer personne pour porter une lettre, mais il lui fut même impossible de trouver un endroit pour l'écrire.

Un matin, il vint un domestique pour annoncer que Kin-Yun, ayant appris que son amie était malade, désirait venir elle-même s'assurer de l'état de sa santé. Iu-Kiouan fut extrêmement troublée par l'idée que celle qui lui avait enlevé le cœur de son amant et qui avait détruit ses plus chères espérances, venait encore dans la joie de son cœur pour triompher du succès qu'elle avait remporté sur elle, et que, sans attendre le moment où elles devaient se réunir, elle était venue d'avance dans l'intention de I'insulter. Elle résolut toutefois de ne pas donner à Kin-Yun 


\section{Contes chinois}

I'occasion de satisfaire sa malice, et pressa sa mère d'envoyer quelqu'un lui faire réponse.

Elle ne se doutait pas que Kin-Yun, loin d'avoir aucune mauvaise intention, voulait au contraire être comme l'oiseau ${ }^{1}$ qui est le messager des bonnes nouvelles, et porter à son oreille I'heureux secret.

Lou-Koung désirait beaucoup de hâter cette union, sachant bien que la fille d'un homme comme Kouan ne consentirait pas à perdre sa considération, mais que si elle venait à apprendre qu'elle était fiancée à un autre qui Tchin-Seng, sans avoir été prévenue auparavant du véritable état des choses elle s'ôterait certainement la vie ; il savait qu'elle était surveillée de si près que s'il lui envoyait un billet par un étranger, il ne lui parviendrait pas. Ce fut donc sur sa fille qu'il jeta les yeux pour lui communiquer le secret.

Lorsque Iu-Kiouan vit que sa réponse n'avait pas empêché Kin-Yun de venir, il fallut bien qu'elle la laissât entrer, mais elle prit d'avance l'air grave de quelqu'un qui se croit offensé, et résolut, dès que Kin-Yun aurait parlé, de l'accabler par une réponse froide et piquante. Mais à sa grande surprise, Kin-Yun, aussitôt que les cérémonies furent achevées, étendit les mains et les plaça sur ses épaules en l'attirant doucement vers elle, comme ayant à lui communiquer un secret qu'elle ne se souciait pas qui fût entendu par d'autres. Iu-Kiouan fut très étonnée et se hâta, dès qu'elles eurent pris un peu de thé ensemble, de

\footnotetext{
1 L'hirondelle.
} 


\section{Contes chinois}

conduire Kin-Yun dans une autre chambre, pour lui demander les motifs de sa conduite :

- L'objet de ma visite, répondit Kin-Yun, est moins de m'informer de votre santé, que pour vous apporter une bonne nouvelle. Le poème sur la rencontre des Ombres est devenu un roman dont il nous est donné d'amener la conclusion ; on a ajouté une actrice de second rang au principal personnage; mais ne soyez aucunement inquiète du résultat.

Iu-Kiouan lui demanda avec surprise ce qu'elle entendait par là. Kin-Yun lui expliqua alors avec le plus grand détail le projet que son père avait formé pour leur union, ce qui causa une joie extrême à Iu-Kiouan. Maintenant chacun des trois malades avait trouvé un remède à ses maux. Kin-Yun et Iu-Kiouan convinrent ensemble des moyens à prendre pour que le plan réussît, n'exceptant du secret que le seul Kouan. Lou-Koung choisit un jour heureux, et fit venir Tchin-Seng et Iu-Kiouan chez lui, où sa fille attendait ses noces. On acheva alors le mariage, et tous trois se montrèrent ensemble dans la salle pour exécuter les cérémonies d'usage.

Trois jours après la célébration du mariage, Lou-Koung fit préparer un grand festin, et invita Tou et Kouan à faire partie de cette réunion de famille ; craignant cependant que Kouan ne voulut pas s'y rendre, il lui écrivit un petit billet qu'il inséra dans la carte d'invitation. Dans ce billet il rappelait au souvenir de Kouan les paroles qu'il avait écrites sur la table, et le priait, puisqu'il lui était maintenant allié, de ne pas laisser interrompre 


\section{Contes chinois}

des cérémonies importantes par une animosité puérile. Le commencement du billet ne fit aucune impression sur l'esprit de Kouan, mais quand il vint à l'article des cérémonies, il sentit qu'il ne pouvait manquer aux obligations qu'imposent les convenances, et qu'il aurait tort de chercher un prétexte pour se dispenser d'y aller. Il se rendit donc, au jour fixé, à la réunion de famille, où il trouva Tou déjà arrivé, et à la place qu'il devait occuper. Lou-Koung, ayant fait étendre un tapis par terre, pria ses amis de prendre le haut bout, et s'étant placé au plus bas, il exécuta ainsi qu'eux quatre salutations ; ensuite il pria Tou de s'éloigner un peu et se prosterna de nouveau jusqu'à terre quatre fois devant Kouan, en lui disant :

- Les quatre premières salutations vous ont été faites à cause de notre union, mais les quatre dernières sont pour solliciter votre pardon pour moi, et je compte sur votre générosité pour excuser les méprises que je n'ai cessé de commettre dès le premier moment.

- Jusqu'ici, répondit Kouan, vous avez été droit et sans façon ; d'où vient donc que tout-à-coup vous êtes si cérémonieux ? peut-être que me connaissant un peu pointilleux, vous voulez vous moquer de moi.

- Comment oserais-je en agir ainsi, répliqua LouKoung ? j'ai commis mille erreurs depuis le moment où nous avons arrêté ce mariage ; elle sont plus nombreuses que les cheveux que j'ai sur la tête, et il ne me reste qu'à vous prier d'avoir égard aux liens intimes qui nous unissent maintenant, et de m'accorder un 


\section{Contes chinois}

pardon généreux. Le proverbe dit : Quand un fils a offensé son père, il ne peut faire autre chose que de lui présenter l'instrument de sa propre punition ; ceci s'applique parfaitement au cas où nous nous trouvons. Je me suis déjà soumis à la cérémonie de quatre salutations, le mariage est achevé, et il ne vous servirait de rien de me punir, quand bien même vous y seriez disposé.

Kouan ne comprenait encore rien à toute l'affaire et l'attribuait toujours à une simple affectation d'humilité. Mais aussitôt que le discours de Lou Koung fut achevé, la musique qui était placée des deux côtés des marches de l'escalier commença avec un tel bruit, qu'elle produisit l'effet du tonnerre et qu'elle assourdit tout le monde, au point de ne s'entendre ni les uns ni les autres. Au milieu de ce vacarme, les nouveaux mariés, accompagnés d'une suite nombreuse, entrèrent dans la salle et s'étant placés sur le tapis, ils n'attendaient que le signal pour se prosterner. Kouan regardait attentivement, et il vit que sa fille était seule du côté gauche : les autres personnages lui étaient étrangers, et il ne pouvait apercevoir celui qui devait être son gendre. Élevant alors la voix, il dit à sa fille :

- Qui êtes-vous pour rester seule ? sans égard pour les convenances, et pour vous déshonorer par cette conduite irrégulière, demeurez-vous encore ainsi ?

Il parla encore plus haut, et tout hors de lui ; mais personne ne pouvait l'entendre à cause du bruit que faisait toujours la musique. Quand les trois jeunes gens se prosternèrent, Kouan 


\section{Contes chinois}

tourna le dos et voulut s'en aller ; mais ses deux amis s'approchèrent de lui et le prenant chacun par le bras, ils l'empêchèrent non seulement de sortir, mais aussi de rendre le salut, en les pressant des deux côtés comme deux bâtons de torture.

Lorsqu'il eut reçu les douze salutations, c'est-à-dire quatre de chacun des jeunes gens, selon la forme usitée, les deux dames se retirèrent immédiatement, et on donna ordre à la musique de cesser. Kouan changea de couleur, et dit à Lou-Koung :

- Lorsque ma fille est entrée dans la salle, comment se fait-il que je. n'aie pas aperçu votre fils ? Votre fille ainsi que votre gendre ne me sont pas assez proches parens pour accomplir les cérémonies dans cette circonstance. Je ne sais donc pas ce que peut signifier cette cérémonie, et je dois vous demander de me l'expliquer.

- Je ne veux pas vous tromper plus longtemps, lui répondit Lou-Koung ; mon fils adoptif, qui est mon gendre et aussi le vôtre, n'est autre que votre neveu. Il a rempli un double rôle dans cette cérémonie, et c'est à cause de cela que vous avez reçu douze salutations. Comme vous êtes un homme d'une grande pénétration, je ne doute pas que vous ne soyez maintenant bien au fait de l'affaire.

Kouan rêva un peu, mais ne put encore rien deviner.

- Je ne puis, dit-il à Lou-Koung, comprendre un seul mot de tout ce que vous venez de me dire, et c'est un mystère que je ne suis pas en état de débrouiller. 


\section{Contes chinois}

Assistai-je à une réunion de famille, ou bien est-ce un songe que je fais?

- Dans le billet que je vous ai écrit, lui répondit LouKoung, je vous ai fait mention d'un songe ; mais vous devrez vous rappeler que ce n'est pas moi qui en ai parlé le premier ; c'est vous-même qui avez ainsi appelé la proposition de mariage que je vous avais faite, et c'est ainsi que vous avez jeté les racines de ce rêve, qui est devenu maintenant une réalité. Mais puisque la vie humaine n'est qu'un rêve, pourquoi y attacher tant d'importance ? Je vous conseille de prendre la chose comme elle est, et de donner une conclusion heureuse à ce songe.

Kouan, après cette explication, commença enfin à comprendre I'affaire, et il demanda à Lou-Koung comment un homme qui avait autant de délicatesse que lui pouvait s'être permis une pareille tromperie ; il ajouta que puisqu'il voulait être l'entremetteur de ce mariage, il aurait dû parler clairement sans tendre ce piège à sa bonne foi.

- N'avais-je pas parlé clairement ? lui répliqua LouKoung. Mais vous, au lieu de me répondre sans détour, vous avez jugé à propos de parler par figures et par métaphores, comme si vous vouliez me jeter dans un songe. Je ne pouvais donc plus continuer d'agir franchement ; mais j'ai été forcé d'avoir recours à l'adresse. Si toutefois je n'avais cherché que mon avantage particulier, et que je vous eusse exposé au 


\section{Contes chinois}

ridicule en vous amenant par ruse à consentir au mariage de votre fille seulement, je vous aurai fait une offense impardonnable ; mais en mariant ma fille, j'ai marié aussi la vôtre, et je lui ai donné la première place dans les cérémonies qui viennent d'avoir lieu, tandis que la mienne a pris la seconde volontairement. Certes, il n'y a jamais eu de trompeur aussi consciencieux que moi. Je vous conjure donc d'abandonner toute rancune, et de pratiquer les lois de l'indulgence.

Lorsque Kouan eut entendu tout ceci, il prit un air moins sévère ; et, après quelques autres explications, tous redevinrent bons amis, et achevèrent la journée en festins et en réjouissances. 


\title{
Contes chinois
}

\section{LES TROIS FRÈRES.}

\author{
Le bien ou le mal qui éclatent \\ Attirent un bonheur ou un malheur sensibles. \\ C'est là ce qui détourne du vice, \\ C'est là ce qui anime la vertu.
}

Une famille d'une condition médiocre habitait à Wou-si, ville dépendante de la cité de Tchang-tcheou, dans la province de Kiang-nan. Trois frères composaient cette famille : I'aîné s'appelait Liu-iu (ou le jaspe) ; le cadet, Liu-pao (ou le précieux), et le troisième, Liu-tchin (ou la perle). Celui-ci n'était pas encore mûr pour le mariage ; les deux autres étaient mariés. La femme du premier s'appelait Wang, et celle du cadet se nommait Yang ; elles avaient l'une et l'autre toutes les graces qui donnent de l'agrément aux femmes.

Liu-pao n'avait de passion que pour le jeu et le vin : I'on ne voyait en lui nulle inclination vers le bien ; sa femme était du même caractère, et n'était nullement portée à la vertu, bien différente en cela de Wang, sa belle-sœur, qui était un exemple de modestie et de régularité. Ainsi, quoique ces deux femmes vécussent d'assez bonne intelligence, leurs cœurs n'étaient que faiblement unis.

Wang eut un fils surnommé Hi-eul ${ }^{1}$. Ce jeune enfant n'avait encore que six ans, lorsqu'un jour, s'étant arrêté dans la rue avec d'autres enfans du voisinage pour voir passer une

${ }^{1}$ C'est-à-dire fils de la réjouissance. 


\section{Contes chinois}

procession solennelle, il disparut dans la foule, et le soir il ne revint pas à la maison.

Cette perte désola le père et la mère qui firent afficher partout des billets ; il n'y eut point de rues où l'on ne fit des enquêtes ; mais toutes les perquisition furent inutiles : on ne put apprendre aucune nouvelle de ce cher fils. Liu-iu, son père, était inconsolable; et dans l'accablement de tristesse où il était, il songea à s'éloigner de sa maison, où tout lui rappelait sans cesse le souvenir de son cher Hi-eul. Il emprunta d'un de ses amis une somme pour faire un petit commerce de côté et d'autre aux environs de la ville, se flattant que dans ces courtes et fréquentes excursions, il trouverait enfin le trésor qu'il avait perdu.

Comme il n'était occupé que de son fils, il sentait peu le plaisir des avantages qu'il retirait de son commerce. Il le continua néanmoins durant cinq ans, sans s'éloigner trop de sa maison : enfin ne trouvant point son fils après tant d'années, et le croyant perdu sans ressource, voyant d'ailleurs que sa femme Wang ne lui donnait point d'autre enfant, il pensa à se distraire d'une idée si chagrinante ; et comme il avait amassé un petit fonds, il prit le dessein d'aller négocier dans une autre province.

Il s'associa en chemin un riche marchand, lequel, ayant reconnu ses talens et son habileté dans le négoce, lui fit un parti très avantageux. Le désir de s'enrichir le délivra de ses inquiétudes.

A peine furent-ils arrivés l'un et l'autre dans la province de Chan-si, que tout réussit à leur gré. Le débit de leurs 


\section{Contes chinois}

marchandises fut prompt, et le gain considérable. Le paiement qui fut reculé à cause de deux années de sécheresse et de famine dont le pays était affligé, et une assez longue maladie dont Liu-iu fut attaqué, l'arrêtèrent trois ans dans la province : ayant recouvré la santé et son argent, il partit pour s'en retourner dans son pays.

S'étant arrêté, durant le voyage, près d'un endroit appelé Tchin-lieou, pour s'y délasser de ses fatigues, il aperçoit une ceinture de toile bleue, en forme de petit sac long et étroit, tel qu'on en porte autour du corps sous les habits, et où I'on renferme de l'argent : en le soulevant, il sentit un poids considérable. Il se retire aussitôt à l'écart, ouvre le sac, et y trouve environ deux cents taëls 1 .

A la vue de ce trésor, il fit les réflexions suivantes : « C'est ma bonne fortune qui me met cette somme entre les mains : je pourrais la retenir et l'employer à mes usages, sans craindre aucun fâcheux retour. Cependant, celui qui l'a perdue, au moment qu'il s'en apercevra, sera dans de terribles transes, et reviendra au plus vite la chercher. Ne dit-on pas que nos anciens, quand ils trouvaient ainsi de l'argent, n'osaient presque y toucher, et ne le ramassaient que pour le rendre à son premier maître. Cette action de justice me paraît belle, et je veux l'imiter, d'autant plus que je suis d'un âge avancé, et que je n'ai point d'héritier. Que ferais-je d'un argent qui me serait venu par ces voies indirectes ? »

${ }^{1}$ Le taël est une once d'argent et vaut environ $7 \mathrm{fr} .50$. 


\section{Contes chinois}

A l'instant, retournant sur ses pas, il alla se placer près de l'endroit où il avait trouvé la somme, et là il attend tout le jour qu'on vienne la chercher. Comme personne ne parut, il continua le lendemain sa route.

Après cinq jours de marche, étant arrivé sur le soir à Nansou-tcheou, il se loge dans une auberge où se trouvaient plusieurs autres marchands. Dans la conversation, le discours étant tombé sur les avantages du commerce, un de la compagnie dit :

- Il n'y a que cinq jours que, partant de Tchin-lieou, je perdis deux cents taëls que j'avais dans ma ceinture intérieure ; j'avais ôté cette ceinture, et je l'avais mise auprès de moi, tandis que je prenais un peu de repos, lorsque tout-à-coup vint à passer un mandarin avec tout son cortège : je m'éloigne de son chemin, de crainte d'insulte, et j'oublie de reprendre mon argent. Ce ne fut qu'à la couchée, qu'en quittant mes habits, je m'aperçus de la perte que j'avais faite. Je vis bien que le lieu où j'avais perdu mon argent étant aussi fréquenté qu'il l'est, ce serait en vain que je retarderais mon voyage de quelques journées, pour aller chercher ce que je ne trouverais certainement pas.

Chacun le plaignit. Liu-iu lui demanda aussitôt son nom et le lieu de sa demeure.

- Votre serviteur, lui répondit le marchand, s'appelle Tchin, et demeure à Yang-tcheou, où il a sa boutique et 


\section{Contes chinois}

un assez bon magasin. Mais oserais-je, à mon tour, vous demander à qui j'ai l'honneur de parler?

Liu-iu se nomma, et dit qu'il était habitant de la ville de Wou-si.

- Le chemin le plus droit pour m'y rendre, ajouta-t-il, me conduit à Yang-tcheou ; si vous I'agréez, j'aurai le plaisir de vous accompagner jusque dans votre maison.

Tchin répondit comme il devait à cette politesse.

- Très volontiers, lui dit-il, nous irons de compagnie ; je m'estime très heureux d'en trouver une si agréable.

Le jour suivant, ils partent ensemble de grand matin. Le voyage ne fut pas long, et ils se rendirent bientôt à Yang-tcheou.

Après les civilités ordinaires, Tchin invita son compagnon de voyage à entrer dans sa maison, et y fit servir une petite collation. Alors Liu-iu fit tomber la conversation sur l'argent perdu à Tchin-lieou.

- De quelle couleur, dit-il, était la ceinture où vous aviez serré votre argent, et comment était-elle faite ?

- Elle était de toile bleue, répondit Tchin. Ce qui la rendait bien reconnaissable c'est qu'à un bout la lettre Tchin, qui est mon nom, y était tracée en broderie de soie blanche.

Cet éclaircissement ne laissait plus aucun doute ; aussi Liu-iu s'écria-t-il d'un air épanoui :

- Si je vous ai fait ces questions, c'est que, passant par Tchin-lieou, j'y ai trouvé une ceinture telle que vous venez de la dépeindre. 


\section{Contes chinois}

Il la tire en même tems :

- Voyez, dit-il, si c'est la vôtre ?

- C'est elle-même, dit Tchin.

Sur quoi Liu-iu, la tenant encore entre les mains, la remit avec respect à son vrai maître.

Tchin, plein de reconnaissance, le pressa fort d'accepter la moitié de la somme dont il lui faisait présent; mais ses instances furent inutiles, Liu-iu ne voulut rien recevoir.

- Quelles obligations ne vous ai-je pas ? reprit Tchin ; où trouver une fidélité et une générosité pareilles ?

Il fait servir aussitôt un grand repas, où tous deux s'invitaient à boire avec les plus grandes démonstrations d'amitié.

Tchin disait en lui-même :

« Où trouver aujourd'hui un homme de la probité de Liu-iu ? des gens de ce caractère sont bien rares. Mais quoi ! j'aurais reçu de lui un si grand bienfait, et n'aurais pas moyen de le reconnaître! J'ai une fille qui a douze ans ; il faut qu'une alliance m'unisse avec un si honnête homme. Mais a-t-il un fils ? c'est ce que j'ignore.

- Cher ami, lui dit-il, quel âge a présentement votre fils ?

A cette demande', les larmes coulèrent des yeux de Liu-iu.

- Hélas ! répondit-il, je n'avais qu'un fils qui m'était infiniment cher ; il y a sept ans que ce jeune enfant, 


\section{Contes chinois}

étant sorti du logis pour voir passer une procession disparut sans qu'il m'ait été possible d'en avoir depuis ce temps-là aucun nouvelle. Pour surcroît de malheur ma femme ne m'a plus donné d'enfans.

A ce récit Tchin parut un moment rêveur; ensuite prenant la parole :

- Mon frère et mon bienfaiteur, dit-il, quel âge avait ce cher enfant lorsque vous le perdîtes ?

- Il avait six ans, répondit Liu-in.

- Quel était son surnom, ajouta Tchin ? Comment étaitil fait ?

- Nous I'appelions Hi-eul, répliqua Liu-iu. Il avait échappé aux dangers de la petite vérole ; on n'en voyait nulle trace sur son visage ; son teint était blanc et fleuri.

Ce détail causa une grande joie à Tchin, et il ne put s'empêcher de la faire paraître dans ses yeux et dans tout son air. Il appela sur-le-champ un de ses domestiques, auquel il dit quelques mots à I'oreille. Celui-ci, ayant fait signe qu'il allait exécuter les ordres de son maître, rentre dans l'intérieur de la maison.

Liu-lu, attentif à l'enchaînement de ces questions, et à l'épanouissement qui avait paru sur le visage de son hôte, forma divers soupçons dont il s'occupait, lorsqu'il vit tout-à-coup entrer un jeune domestique qui avait environ treize ans. Il était vêtu d'un habit long et d'un surtout modeste, mais propre ; sa taille 


\section{Contes chinois}

bien faite, son air et son maintien, son visage dont les traits étaient réguliers, et où I'on voyait de beaux sourcils noirs, surmontant des yeux vifs et perçans, frappèrent d'abord le cœur et les yeux de Liu-iu.

Dès que le jeune enfant vit l'étranger assis à la table, il se tourna vers lui, fit une profonde révérence, et dit quelques mots de civilité : ensuite s'approchant de Liu-iu, et se tenant modestement vis-à-vis de lui :

- Mon père, dit-il d'un ton doux et agréable, vous avez appelé Hi-eul ; que vous plaît-il m'ordonner?

- Je vous le dirai tout-à-l'heure reprit Tchin ; en attendant tenez-vous à coté de moi.

Le nom de Hi-eul que se donnait le jeune enfant fit naître de nouveaux soupçons dans l'esprit de Liu-iu. Une impression secrète saisit son cœur, qui par d'admirables ressorts de la nature lui retrace à l'instant l'image de son fils, sa taille, son visage, son air, et ses manières. Il voit tout cela dans celui qu'il considère. Il n'y a que le nom de père donné à Tchin qui déconcerte ses conjectures. Il n'était pas honnête de demander à Tchin si c'était là véritablement son fils ; peut-être l'était-il en effet, car il n'est pas impossible que deux enfans ayant reçu le même nom se ressemblent.

Liu-iu, tout occupé de ces réflexions, ne songeait guère à la bonne chère qu'on lui faisait. On lisait sur son visage l'étrange perplexité où il se trouvait. Je ne sais quel charme l'attirait invinciblement vers ce jeune enfant : il tenait les yeux sans cesse attachés sur lui, et ne pouvait les en détourner. Hi-eul de 


\section{Contes chinois}

son côté, malgré la timidité et la modestie de son âge, regardait fixement Liu-iu, et il semblait que la nature lui découvrait en ce moment que c'était son père.

Enfin Liu-iu, n'étant plus le maître de retenir plus longtems les agitations de son cœur, rompit tout-à-coup le silence et demanda à Tchin si c'était là véritablement son fils ?

- Ce n'est point de moi, répondit Tchin, qu'il a reçu la vie, quoique je le regarde comme mon propre fils. Il y a sept ans qu'un homme qui passait par cette ville, menant cet enfant par la main, s'adressa par hasard à moi, et me pria de l'assister dans son besoin extrême. Ma femme, dit-il, est morte, et ne m'a laissé que cet enfant. Le mauvais état de mes affaires m'a obligé de quitter pour un tems mon pays, et de me retirer à Hoaïngan, chez un de mes parens, de qui j'espère une somme d'argent qui m'aide à me rétablir. Je n'ai pas de quoi continuer mon voyage jusqu'à cette ville ; auriezvous la charité de m'avancer trois taëls ? Je vous les rendrai fidèlement à mon retour, et pour gage de ma parole, je laisse ici en dépôt ce que j'ai au monde de plus cher, c'est-à-dire mon fils unique. Je ne serai pas plus tôt à Hoaïngan, que je reviendrai retirer ce cher enfant.

Cette confidence me toucha, et je lui mis en main la somme qu'il me demandait pour lui. En me quittant il fondait en larmes, témoignant qu'il se séparait de son fils avec un extrême regret. Ce qui me surprit, c'est que 


\section{Contes chinois}

l'enfant ne parut nullement ému de cette séparation ; mais ne voyant point revenir son prétendu père, j'eus des soupçons dont je voulus m'éclaircir. J'appelai l'enfant ; et par les différentes questions que je lui fis, j'appris qu'il était né dans la ville de Wou-si ; qu'un jour voyant passer une procession dans sa rue, il s'était un peu trop écarté, et qu'il avait été trompé et enlevé par un inconnu. Il me dit aussi le nom de son père et de sa mère : or ce nom de famille est le vôtre. Je compris aussitôt que ce pauvre enfant avait été enlevé et vendu par quelque fripon ; j'en eu compassion, et il sut entièrement gagner mon cœur : je le traitai dès lors comme mes propres enfans ; et je l'ai envoyé au collège avec mon fils pour y faire ses études. Bien des fois j'ai eu la pensée de faire un voyage exprès jusqu'à Wou-si, pour m'informer de sa famille. Mais il m'est toujours survenu quelque affaire qui m'a fait différer un voyage auquel je n'avais pas tout-à-fait renoncé. Heureusement il y a quelques momens vous m'avez parlé par occasion de ce fils. Certains mots jetés par hasard ont réveillé mes idées. Sur le rapport merveilleux de ce que je savais avec ce que vous me disiez, j'ai fait venir l'enfant pour voir si vous le reconnaîtriez.

A ces mots, $\mathrm{Hi}$-eul se mit à pleurer de joie, et ses larmes en firent aussitôt couler d'abondantes des yeux de Liu-iu. 


\section{Contes chinois}

- Un indice assez singulier, dit-il, le fera reconnaître : il a un peu au-dessus du genou une double marque de couleur noire, et je l'ai envoyé au collège avec mon fils pour y faire ses études.

Hi-eul aussitôt relève le bas de son haut de chausse, et montre au-dessus du genou les deux signes dont il s'agissait. Liu-iu, la voyant, se jette au cou de l'enfant, l'embrasse, l'élève entre ses bras.

- Mon fils, s'écria-t il, mon cher fils, quel bonheur pour ton vrai père de te retrouver après une si longue absence! 》

(a) 


\section{Contes chinois}

\section{LES TROIS FRÈRES.}

\section{CHAPITRE II.}

Pêcher une aiguille au fond de l'eau, c'est merveille ;

Mais perdre un trésor qu'on tenait entre ses mains et le retrouver ensuite, c'est une autre merveille bien plus grande!

O ! le charmant festin, où se fait une si douce reconnaissance ! Ils craignent encore tous deux que ce ne qu'un songe.

Dans ces doux momens on conçoit assez à quels transports de joie le père et le fils se livrèrent. Après mille tendres embrassades, Liu-iu, s'arrachant des bras de son fils, alla faire une salutation à Tchin ;

- Quelles obligations vous ai-je pas, lui dit-il, d'avoir reçu chez vous et élevé avec tant de bonté cette chère portion de moi-même ? Sans vous, aurions-nous jamais été réunis?

- Mon aimable bienfaiteur, répondit Tchin, en le relevant, c'est l'acte généreux de vertu que vous avez pratiqué en me rendant les deux cents taëls qui a touché le ciel. C'est le ciel qui vous a conduit chez moi, où vous avez retrouvé ce que vous aviez perdu, et que vous cherchiez vainement depuis tant d'années. A présent que je sais que ce joli enfant vous appartient, mon regret est de ne lui avoir pas fait plus d'amitié.

- Faites la révérence, mon fils, dit Liu-iu, et remerciez votre insigne bienfaiteur. 


\section{Contes chinois}

Tchin se mettait en posture de rendre des révérences pour celles qu'on venait de lui faire ; mais Liu-iu, confus de cet excès de civilité, s'approcha aussitôt, et l'empêcha même de se pencher. Ces cérémonies étant achevée, on s'assit de nouveau, et Tchin fit placer le petit Hi-eul sur un siège à côté de Liu-iu son père.

Pour lors Tchin prenant la parole :

- Mon frère, dit-il à Liu-iu, j'ai une fille âgée de douze ans ; mon dessein est la donner en mariage à votre fils, de nous unir plus étroitement par cette alliance.

Cette proposition se faisait d'un air si sincère et si passionné, que Liu-iu ne crut pas devoir se servir des excuses ordinaires que la civilité prescrit. Il passa par-dessus, et donna sur-lechamp son consentement.

Comme il était tard, on se sépara. Hi-eul alla se reposer dans la même chambre que son père. On peut juger tout ce qu'ils se dirent de consolant et de tendre durant la nuit. Le lendemain Liu-iu songeait à prendre congé de son hôte ; mais il ne put résister aux empressemens avec lesquels on le retint. Tchin avait fait préparer un second festin, où il n'épargna rien pour bien régaler le futur beau-père de sa fille, et son nouveau gendre, et se consoler par là de leur départ. On y but à longs traits, et l'on se livra à la joie.

Sur la fin du repas, Tchin tire un paquet de vingt taëls, et regardant Liu-iu : 


\section{Contes chinois}

- Mon aimable gendre, dit-il, durant le tems qu'il a demeuré chez moi, aura sans doute eu quelque chose à souffrir contre mon intention et à mon insu. Voici un petit présent que je lui fais, jusqu'à ce que je puisse lui donner des témoignages plus réels de ma tendre affection : je ne veux pas au reste qu'il me refuse.

- Quoi, reprit Liu-iu, lorsque je contracte une alliance qui m'est si honorable, et que je devrais, selon la coutume, faire moi-même les présens du mariage pour mon fils, présens dont je ne suis dispensé pour le moment que parce que je suis voyageur, vous me comblez de vos dons : c'en est trop; je ne puis les accepter ; ce serait me couvrir de confusion.

- Hé! qui pense, dit Tchin, à vous offrir si peu de chose ? C'est à mon gendre et non au beau-père de ma fille que je prétends faire ce petit présent. Et un mot, le refus, si vous y persistez sera pour moi une marque certaine qui mon alliance ne vous est pas agréable.

Liu-iu vit bien qu'il fallait absolument se rendre et que sa résistance serait inutile ; il accepta le présent, et dit à son fils de se lever de table et d'aller remercier Tchin en lui faisant une révérence.

- Ce que je vous donne, dit Tchin, en le relevant, n'est qu'une bagatelle, et ne mérite point de remerciemens.

Hi-eul alla ensuite dans l'intérieur de la maison pour remercier sa belle-mère. Tout le jour se passa en festins et en divertissemens ; il n’y eut que la nuit qui les sépara. 


\section{Contes chinois}

Liu-iu se livra tout entier aux réflexions que faisait naître cet événement. Il faut avouer, s'écria-t-il, que la restitution de cet argent est une action bien agréable au ciel, puisqu'il me fait retrouver mon fils et contracter une si honorable alliance. C'est bonheur sur bonheur ; c'est comme si on mettait des fleurs d'or sur une belle pièce de soie. Comment puis-je reconnaître tant de faveurs ? Voilà vingt taëls que mon allié Tchin vient de donner ; puis-je mieux faire que de les employer à la subsistance de quelques vertueux bonzes ? C'est là les jeter en une terre de bénédictions.

Le lendemain, après avoir bien déjeuné, le père et le fils préparent leur bagage et prennent congé de leur hôte. Ils se rendent au port, et y louent une barque. A peine eurent-ils fait une demi-lieue, qu'ils approchèrent d'un endroit de la rivière d'où s'élevait un bruit confus, et où l'eau agitée paraissait bouillonner. C'était une barque chargée de passagers qui coulait à fond. On entendais crier ces pauvres infortunés :

\section{Au secours, sauvez-nous!}

Les gens du rivage voisin, alarmés de ce naufrage, criaient de leur côté à plusieurs petites barques qui se trouvaient là d'accourir au plus vite, et de secourir ces malheureux qui disputaient leur vie contre les flots. Mais les bateliers, gens durs et intéressés, demandaient qu'on leur assurât une bonne récompense.

Liu-iu, témoin de ce débat, se dit à lui-même, sauver la vie à un homme c'est une œuvre plus sainte et plus méritoire que d'orner des temples et d'entretenir des bonzes. Consacrons les 


\section{Contes chinois}

vingt taëls à cette bonne œuvre; secourons ces pauvres gens qui se noyent. Aussitôt il déclare qu'il donnera vingt taëls à ceux qui recevront dans leurs barques ces hommes à-demi noyés.

A cette proposition, tous les bateliers couvrent en un moment la rivière. Quelques-uns même des spectateurs, placés sur le rivage et qui savaient nager, se jettent avec précipitation dans l'eau, et en un moment tous sans exception furent sauvés du naufrage. Liu-iu distribua de suite aux bateliers la récompense promise.

Ces pauvres gens, arrachés du milieu des flots, vinrent rendre grâces à leur libérateur. Un d'entre eux ayant considéré Liu-iu, s'écria tout-à-coup :

- Hé, quoi ! c'est vous, mon frère aîné ; par quel bonheur vous trouvé je ici ?

Liu-iu, s'étant retourné, reconnut son troisième frère Liu-tchin. Quel prodige, quel bonheur ! s'écria-t-il, en joignant les mains ; le ciel m'a conduit ici à point nommé pour sauver la vie à mon frère. Aussitôt il lui tend la main, le fait passer sur sa barque, I'aide à se dépouiller de ses habits tout trempés et lui en donne d'autres.

Liu-tchin, après avoir repris ses sens, fit la révérence à son frère aîné ; et celui-ci, après une salutation réciproque dit à $\mathrm{Hi}$ eul de venir offrir ses hommages à son oncle : puis il lui raconta I'histoire de la bourse rendue à son premier maître et la manière dont il avait retrouvé son fils. Liu-tchin ne pouvait revenir de la surprise que lui causait ce récit. 


\section{Contes chinois}

- Mais enfin, apprenez-moi, lui dit Liu-iu, le motif qui vous amène en pays-ci.

- Il n'est pas possible, répondit Liu-tchin, d'épuiser en quelques mots les détails que vous désirez. Depuis trois ans que vous avez quitté la maison, on nous est venu apporter la triste nouvelle que vous étiez mort de maladie dans la province de Chan-si. Mon second frère prit des informations, et il assura que la chose était véritable. Ce fut un coup de foudre pour ma bellesœur ; elle fut inconsolable, et prit aussitôt le grand deuil. Pour moi, je ne voulus nullement ajouter foi à cette nouvelle.

- Peu de jours après, mon second frère pressa ma belle-sœur de songer à un nouveau mariage. Elle a toujours rejeté bien loin une pareille proposition ; enfin elle m'a engagé à faire le voyage du Chan-si, pour faire des recherches et savoir de vos nouvelles : et lorsque j'y songe le moins, près de périr dans les eaux, je rencontre mon frère bien-aimé, qui me sauve du naufrage. Ce bonheur inespéré n'est-il pas un bienfait du ciel ? mais mon frère, croyez-moi, il n'y a point de tems à perdre, hâtez-vous de vous rendre à la maison pour calmer ma belle-sœur. Le moindre délai peut causer des malheurs sans remède.

Liu-iu, consterné de ce récit, faite venir le maître de la barque ; et, quoiqu'il fût fort tard, il lui ordonna de mettre à la voile, et de naviguer toute la nuit. 
Contes chinois

(a)

197 


\section{Contes chinois}

\section{LES TROIS FRÈRES.}

\section{CHAPITRE III.}

Le cœur empressé vole comme un trait et s'indigne du retard. La barque court comme la navette du tisserand et sa marche est encore trop lente.

En apprenant la triste nouvelle de la mort de son époux (Liuiu), madame Wang conçut d'abord. des doutes sur la vérité de ce récit, mais à la fin elle se laissa persuader par Liu-pao, et prit des habits de deuil.

Liu-pao avait un mauvais cœur, et était capable des actions les plus indignes. Je n'en doute plus, dit-il, mon frère aîné est mort. Ma belle-sœur est jeune et belle, elle n'a d'ailleurs personne pour la soutenir ; il faut que je la force à se remarier, il m'en reviendra de l'argent.

Aussitôt il communique son dessein à madame Yang sa femme, et l'engage à en parler à sa belle-sœur. Mais madame Wang repoussa avec horreur une pareille proposition. Liu-tchin, par ses réprimandes continuelles, apportait de nouveaux obstacles à ce mariage. Ainsi tous les artifices qu'on employa n'eurent aucun succès. Une nouvelle racontée par mille personnes, se disait-elle en elle-même, ne vaut pas le témoignage d'un témoin oculaire. Quoiqu'on dise que mon mari est mort à mille milles d'ici, qui sait si un bruit venu de si loin n'est pas dénué de fondement ? Je prierai mon beau-frère Liutchin d'aller lui-même, dans la province de Chan-si, prendre sur les lieux des informations exactes. Si, en effet, j'ai eu le malheur 


\section{Contes chinois}

de perdre mon mari, du moins il m'en rapportera les restes précieux.

Liu-tchin fut prié de faire ce voyage, et partit. Son éloignement rendit Liu-pao plus ardent dans ses poursuites. D'ailleurs s'étant acharné au jeu durant quelques jours, et y ayant été malheureux, il ne savait plus quel parti prendre pour trouver de l'argent. Dans l'embarras où il se trouvait, il rencontra un marchand du Kiang-si qui venait de perdre sa femme, et qui en cherchait une autre. Liu-pao saisit l'occasion, et lui proposa sa belle-sœur. Le marchand accepte la proposition, prenant néanmoins la précaution de s'informer secrètement si celle qu'on lui proposait était jeune et bien faite. Aussitôt qu'il en fut assuré, il ne perdit point de tems, et livra trente taëls pour conclure I'affaire.

Liu-pao ayant reçu cette somme,

- Je dois vous avertir, dit-il au marchand, que ma belle-sœur est fière, hautaine ; elle fera bien des difficultés quand il s'agira de quitter la maison, et vous aurez beaucoup de peine à I'y résoudre. Voici donc ce que vous devez faire : Ce soir, à rentrée de la nuit ayez une chaise à porteurs ; venez à petit bruit, et présentez-vous à notre porte. La demoiselle qui paraîtra avec une coiffure de deuil, c'est ma belle-sœur ; ne lui dites mot, et n'écoutez point ce qu'elle voudrait vous dire mais saisissez-la aussitôt, jetez-la dans la chaise, conduisez-la sur votre barque, et mettez à la voile. 


\section{Contes chinois}

Cet expédient plut fort au marchand, et l'exécution lui parut aisée.

Cependant Liu-pao retourne à la maison ; et afin que sa belle-sœur ne pressentît rien du projet qu'il avait formé, il sut se contrefaire en sa présence ; mais dès qu'elle se fut retirée, il fit confidence à sa femme de son dessein, et en désignant sa bellesœur d'un geste méprisant :

- Il faut, dit-il, que cette marchandise à deux pieds sorte cette nuit de notre maison ; mais, pour n'être pas témoin de ses larmes et de ses gémissemens, je vais sortir d'avance, et à la chute de la nuit, un marchand de Kiang-si viendra l'enlever, et la conduira à sa barque dans une chaise à porteurs.

A peine Liu-pao avait-il fini de parler, qu'il entendit le bruit d'une personne qui marchait en-dehors de la fenêtre. Alors il se hâta de sortir ; et la précipitation avec laquelle il se retira ne lui permit pas d'ajouter la circonstance de la coiffure de deuil. Ce fut sans doute par une providence toute particulière du ciel que cette circonstance fut omise.

Madame Wang s'aperçut aisément que le bruit qu'elle avait fait près de la fenêtre avait obligé Liu-pao à rompre brusquement la conversation. Son ton de voix marquait assez qu'il avait encore quelque chose de plus à dire ; mais elle en avait assez entendu ; car ayant reconnu à son air, lorsqu'il entra dans la maison, qu'il avait quelque secret à communiquer à sa femme, elle avait fait semblant de se retirer, et, prêtant 


\section{Contes chinois}

discrètement l'oreille à la fenêtre, elle avait ouï distinctement ces mots : On l'enlèvera, on la mettra dans une chaise.

Ces paroles fortifièrent étrangement ses soupçons. Elle entre dans la chambre, et, s'approchant de Yang, lui déclara d'abord ses inquiétudes.

- Ma belle-sœur, lui dit-elle, vous voyez une veuve infortunée, qui vous est liée par les nœuds les plus étroits d'une amitié qui fut toujours très sincère : c'est par cette ancienne amitié que je vous conjure de m'avouer franchement si mon beau-frère persiste encore dans son ancien dessein, de me forcer à un mariage qui tournerait à ma confusion.

A ce récit, Yang parut d'abord interdite, et rougit ; puis, prenant une contenance plus assurée

- A quoi pensez-vous, ma sœur, lui dit-elle, et quelles idées vous mettez-vous dans l'esprit ? S'il était question de vous remarier, croyez-vous qu'on fût fort embarrassé ? Hé! à quoi bon se jeter soi-même à l'eau, avant que la barque soit prête à faire naufrage ?

Dès que madame Wang eut entendu ce proverbe tiré de la barque, elle comprit encore mieux le sens de l'entretien secret de son beau-frère. Aussitôt elle éclate en plaintes et en soupirs, et, se livrant à toute sa douleur, elle se renferme dans sa chambre, où elle pleure, elle gémit, elle se lamente :

- Que suis malheureuse ! s'écrie-t-elle, je ne sais ce qu'est devenu mon mari ? Liu-tchin, mon beau-frère et 


\section{Contes chinois}

mon ami, sur qui je pouvais compter, est en voyage. Mon père, ma mère, mes parens, sont éloignés de ce pays. Si cette affaire se précipite, comment pourrais-je leur en donner avis ? Je n'ai aucun secours à attendre de nos voisins. Liu-pao s'est rendu redoutable à tout le quartier, personne n'osera me soutenir et prendre ma défense. Infortunée que je suis ! je ne saurais échapper à ses pièges : si je n'y tombe pas aujourd'hui, ce sera demain ou dans fort peu de tems. Tout bien considéré, finissons cette trop pénible vie ; mourons une bonne fois, cela vaut mieux que de souffrir mille et mille morts.

Elle prit ainsi sa résolution ; mais elle en différa l'exécution jusqu'au soir. Aussitôt que la nuit est venue, elle se retire dans sa chambre et s'y enferme ; puis, prenant une corde, elle l'attache à la poutre par un bout, et à l'autre bout elle fait un nœud coulant ; elle approche un banc, monte dessus, ajuste modestement ses habits par le bas autour des pieds; ensuite elle s'écrie : «Ciel suprême, vengez-moi! » Après ces mots et quelques soupirs qui lui échappèrent, elle jette sa coiffure et passe la tête et le cou dans le nœud. coulant ; enfin, du pied elle renverse le banc, et, demeure suspendue en l'air.

C'en était fait, ce semble, de cette malheureuse dame. Il arriva néanmoins que la corde dont elle s'était servi, quoique grosse et de chanvre, se rompit tout-à-coup. Elle tombe à terre à demi-morte : sa chute et la violence dont elle s'agitait firent un grand bruit. 


\section{Contes chinois}

Madame Yang accourut à ce bruit, et, trouvant la porte bien barricadée, elle se douta que c'était là un stratagème d'un esprit à demi-troublé. Elle saisit aussitôt une barre et enfonce la porte. Comme la nuit était très obscure, en entrant dans la chambre, elle s'embarrassa les pieds dans les habits de madame Wang, et tomba à la renverse. Cette chute fit sauter sa coiffure bien loin, et I'effroi dont elle fut saisie lui causa un évanouissement de quelques momens. Aussitôt qu'elle eut repris ses sens, elle se lève, va chercher une lampe, et revient dans la chambre où elle trouve la dame Wang étendue par terre, sans mouvement, et presque sans respiration, la bouche chargée d'écume, et le cou encore serré par la corde. Elle lâche au plus tôt le nœud coulant.

Tout-à-coup elle entend frapper doucement à la porte de la maison. Elle ne douta point que ce ne fût le marchand de Kiangsi qui venait chercher l'épouse qu'il avait achetée. Elle court vite pour le recevoir et l'introduire dans la chambre, afin qu'il fût témoin de ce qui venait d'arriver. Mais songeant qu'elle n'avait plus sa coiffure, et qu'il n'était pas convenable de se présenter ainsi, elle ramassa précipitamment celle qui se trouva sous ses pieds, et qui était la coiffure de deuil de madame Wang, et courut savoir qui c'était.

Elle reconnut le marchand de Kiang-si qui, fidèle au mot d'ordre de Liu-pao, venait enlever la dame qu'on lui avait promise. Il avait une chaise de noces, ornée de banderoles de soie, de festons, de fleurs, et de plusieurs belles lanternes; elle était environnée de domestiques qui portaient des torches allumées, et d'une troupe de joueurs de flûtes et de hautbois. 


\section{Contes chinois}

Tout ce cortège s'était rangé dans la rue sans jouer des instrumens et sans faire de bruit. Le marchand avait frappé doucement à la porte ; mais l'ayant trouvée entr'ouverte, il était entré dans la maison avec quelques-uns de ceux qui tenaient les flambeaux pour l'éclairer.

Dès que la dame Yang parut, le marchand, qui lui vit une coiffure de deuil, qui était le signal qu'on lui avait donné, se jeta sur elle, comme un épervier affamé fond sur un petit oiseau. Les gens de sa suite accourent, enlèvent la dame et l'enferment dans la chaise qui était toute prête à la recevoir. Elle eut beau crier : On se trompe, ce n'est pas moi qu'on cherche ! Le bruit des fanfares fit aussitôt entendre et étouffa sa voix tandis que les porteurs de chaise volaient plutôt qu'ils ne marchaient pour la transporter dans la barque.

@ 


\title{
Contes chinois
}

\author{
LES TROIS FRÈRES. \\ CHAPITRE IV. \\ Une troupe de joueurs d'instrumens monte la barque d'un \\ étranger. \\ La méprise d'une coiffure de deuil produit un mariage. \\ Quand l'épouse pleure et gémit, en prenant un nouveau \\ mari, \\ C'est contre son vrai mari et non coutre le ciel qu'éclatent ses \\ imprécations.
}

Pendant ce tems-là, madame Wang, qui avait été soulagée par les soins de sa belle-sœur, était revenue à elle-même, et avait recouvré la connaissance. Le grand fracas qu'elle entendit à la porte de la maison renouvela ses alarmes et lui causa de mortelles inquiétudes ; mais comme elle s'aperçut que le bruit des fanfares, et cette confusion de voix et d'instrumens, qui s'était élevée tout-à-coup, s'éloignait d'un moment à l'autre, elle se rassura et, après environ un demi-quart $d$ 'heure elle s'enhardit, et alla voir de quoi il s'agissait.

Après avoir appelé sa belle-sœur deux et trois fois, et toujours inutilement, elle comprit que le marchand s'était mépris, et avait emmené celle qu'il ne cherchait pas ; mais elle appréhenda quelque fâcheux retour, lorsque Liu-pao serait instruit de la méprise. Alors, elle s'enferma dans sa chambre, où elle ramassa les aiguilles de tête, les pendans d'oreille, et la coiffure noire qui était à terre. Elle songea ensuite à prendre un peu de repos; mais il ne lui fut pas possible de fermer l'œil durant toute la nuit. 


\section{Contes chinois}

A la pointe du jour, elle se lève, se lave le visage ; et comme elle cherchait sa coiffure de deuil pour la prendre, elle entend du bruit qu'on faisait à la porte de la maison ; on y frappait rudement, et on criait : Ouvrez donc ! C'était justement Liu-pao, dont elle reconnut la voix. Son parti fut bientôt pris ; elle le laissa frapper sans répondre. Il jura, il tempéra, il cria jusqu'à s'enrouer. Enfin, madame Wang s'approcha de la porte, et se tenant derrière sans l'ouvrir :

- Qui est-ce qui frappe, dit-elle, et qui fait tant de bruit ?

Liu-pao, qui distingua fort bien la voix de sa belle-sœur, se mit à crier encore plus fort ; mais voyant qu'elle refusait d'ouvrir, il eut recours à un expédient qui lui réussit.

- Belle-sœur, dit-il, bonne et heureuse nouvelle ! Liutchin, mon frère cadet, est de retour, et notre frère aîné jouit d'une santé parfaite ; ouvrez vite!

A ces mots du retour de Liu-tchin, madame Wang court prendre la coiffure noire qu'avait laissée sa belle-sœur, puis elle ouvre avec empressement ; mais en vain cherche-t-elle des yeux son cher Liu-tchin, elle n'aperçoit que le seul Liu-pao. Celui-ci entra d'abord dans sa chambre ; mais n'y voyant pas sa femme, et remarquant d'ailleurs une coiffure noire sur la tête de sa belle-sœur, ses soupçons se renouvelèrent d'une étrange sorte. Enfin, il éclate :

- Hé ! où est donc votre belle-sœur ? dit-il. 


\section{Contes chinois}

- Vous devez le savoir mieux que moi, répondit madame Wang, puisque c'est vous qui avez ménagé cette belle intrigue.

- Mais dites-moi, répliqua Liu-pao, pourquoi ne portezvous plus la coiffure blanche ? avez-vous quitté le deuil ?

Madame Wang lui raconta I'histoire de ce qui était arrivé pendant son absence.

A peine eut-elle fini de parler, que Liu-pao se frappe rudement la poitrine, et s'agite en désespéré ; mais peu à peu, reprenant ses esprits :

- J'ai encore une ressource dans mon malheur, dit-il en lui-même. Vendons cette belle-sœur ; de l'argent qui m'en viendra, j'achèterai une autre femme, et personne ne saura que j'ai été assez malheureux pour vendre la mienne.

Il avait joué toute la nuit précédente, et avait perdu les trente taëls qu'il avait reçus du marchand de Kiang-si, qui était déjà bien loin avec sa nouvelle épouse.

Il se préparait à sortir de la maison pour aller négocier cette affaire, lorsqu'il aperçut à la porte quatre ou cinq personnes qui se pressaient d'y entrer : c'était son frère aîné Liu-iu, son frère cadet Liu-tchin, son neveu Hi-eul, et deux domestiques qui portaient le bagage. Liu-pao, consterné à cette vue, et n'ayant pas le front de soutenir leur présence, s'évade au plus vite par la porte de derrière, et disparaît comme un éclair. 


\section{Contes chinois}

Madame Wang, transportée de joie, vint recevoir son cher mari. Mais quel surcroît d'allégresse, quand elle aperçut son fils, qu'à peine reconnaissaitelle, tant il était devenu grand et bien fait.

- Hé ! par quelle bonne fortune, dit-elle, avez-vous ramené ce cher fils que je croyais perdu ?

Liu-iu lui fit le détail de toutes ses aventures; et madame Wang à son tour lui raconta fort au long toutes les indignités que lui avait fait souffrir Liu-pao, et les extrémités auxquelles il l'avait réduite.

Alors Liu-iu donna à sa femme les justes éloges que méritait sa fidélité.

$\mathrm{Si}$, par une passion aveugle pour les richesses, s'écria-t-il, j'avais retenu les deux cents taëls que je trouvai par hasard, comment aurais-je pu retrouver notre cher enfant ? Si l'avarice m'avait empêché d'employer ces vingt taëls à sauver ceux qui faisaient naufrage, mon cher frère périssait dans les eaux, et je ne l'aurais jamais vu ; si, par une aventure inespérée, je n'avais pas rencontré cet aimable frère, aurais-je pu découvrir à temps le trouble et le désordre qui régnaient dans sa maison ? Sans cela, ma chère femme, nous ne nous serions jamais vus réunis. Tout ceci est l'effet d'une providence particulière du ciel qui a conduit ces divers événemens. Quant à mon autre frère, ce frère dénaturé qui, sans le savoir, a vendu sa propre femme, il s'est justement attiré le malheur qui l'accable. L'auguste ciel traite les hommes selon qu'ils le méritent ; qu'ils ne croient pas échapper à sa justice. 


\section{Contes chinois}

Apprenons de là combien il est avantageux de pratiquer la vertu ; c'est ce qui rend une maison de jour en jour plus florissante.

Dans la suite du temps, Hi-eul alla chercher son épouse, la fille de Tchin. Le mariage se conclut, et fut très heureux. Ils eurent plusieurs enfans, et virent une foule de petits-fils, dont plusieurs s'avancèrent par la voie des lettres et parvinrent aux premières charges. Ainsi cette famille fut illustrée.

Une restitution fait retrouver un fils perdu.

En vendant sa belle-sœur, un frère perd sa propre femme.

La conduite du ciel dans les choses d'ici-bas est vraiment admirable :

Il sait distinguer les bons d'avec les méchants ; on ne lui en impose pas. 


\title{
Contes chinois
}

\section{LE CRIME PUNI}

\author{
AVERTISSEMENT \\ De l'auteur Chinois.
}

En voulant nuire à autrui, c'est à soi-même qu'on nuit.

Les ruses les mieux concertées se découvrent à la fin.

On dit communément : quiconque ôte la vie à un autre doit la perdre : c'est une loi universellement reçue, et qui est nécessaire à la société. C'est pour cela qu'il est si difficile de faire passer l'innocent pour coupable, et le coupable pour innocent. Êtes-vous innocent ? Celui qui veut vous perdre peut bien à force d'argent corrompre les juges les plus éclairés et échapper au filet de la justice. Mais le juste ciel ne permet pas que vous succombiez. Au moment où il semble avoir oublié le soin de votre vengeance, il dévoile l'erreur dont vous êtes victime.

Au contraire un scélérat justement accusé, et qui crie à la calomnie, soutient quelquefois la question la plus rigoureuse sans rien avouer, et force les accusateurs à se désister de leurs poursuites. Mais enfin vient un jour où le mystère d'iniquité se révèle, et où l'artifice se manifeste.

Le Ciel est souverainement éclairé ; on ne saurait le tromper.

Il n'a pas besoin d'une attention réfléchie : il sait tout d'avance,

La vertu et le vice ne demeurent jamais, I'une sans récompense, et l'autre sans châtiment.

Il n'est question que du temps; tôt ou tard il viendra.

Les plaintes que les gens opprimés poussent durant la vie, ou après la mort, vont au ciel et demandent vengeance. La vérité est quelquefois si embrouillée, que les mandarins ne peuvent la découvrir. Mais l'auguste ciel examine tout, et voit tout très clairement. L'artifice et la fourberie fussent-ils multipliés à l'infini, il les fait servir, pour amener l'occasion favorable où éclatent ses justes et immuables arrêts. 


\section{Contes chinois}

Aussi I'on dit communément dans le monde : les méchans sont craints ; le ciel ne les craint pas : les gens de bien sont trompés; le ciel ne l'est pas. On dit encore : le filet où le ciel tient tous les hommes renfermés est vaste et spacieux ; il fait comme s'il ne les voyait pas ; cependant nul moyen d'en échapper.

Depuis qu'il y a un gouvernement, combien de magistrats intègres ou de juges éclairés ont paru sur la scène! Ignoraient-ils que le ciel prend intérêt et veille à la vie des hommes ? Mais les passions font jouer des ressorts imperceptibles. Cent faits les plus incroyables ne laissent pas d'être vrais ; et cent autres les plus imposans n'en sont pas pour cela moins supposés.

Il suit de là que les procès en matière criminelle, même les plus justes, doivent être examinés avec une scrupuleuse attention, et à plusieurs reprises. Après quoi un juge peut ne pas craindre que ceux qu'il a condamnés crient à l'injustice, et demandent vengeance contre lui.

Aujourd'hui dans les tribunaux, les grands et les subalternes sont dominés par la cupidité ; ils ne cherchent qu'à s'enrichir. Il n'y a guère que les riches et les gens distingués qui puissent les satisfaire. De là il arrive que la justice ne se trouve plus chez nous, et qu'elle a été jetée dans la grande mer orientale.

Je sais fort bien qu'on peut et qu'on doit, sans de longues procédures, châtier des méchancetés notoires, qui demandent une briève justice. Je conviens même que pour les affaires de moindre conséquence, et dont on connaît les divers ressorts, il est bon de les terminer au plus tôt, et de les accommoder. Mais je ne juge pas qu'un homicide puisse jamais être pardonné, et se tirer d'affaire par voie d'accommodement ; l'équité, la droite raison s'y opposent. Si l'accusé qui a trempé ses mains dans le sang d'un autre n'est pas puni de mort, les mânes de celui qui a été tué et qui demandent justice ne seront point en repos.

Quant aux dépositions de ces malheureux, qui dans un interrogatoire

nomment des innocens pour complices de leurs crimes, c'est ce qu'on ne saurait trop examiner. On doit confronter les dépositions d'un jour avec celles d'un autre, et les examiner avec une extrême application.

Il arrive d'ordinaire que ces scélérats appliqués à une violente torture, et sur le point d'être condamnés aux derniers supplices, s'accrochent à tout ce 


\section{Contes chinois}

qu'ils peuvent. Ils feignent de vouloir tout avouer : la calomnie ne leur coûte rien : ils accusent un innocent, sans se soucier beaucoup de perdre, non seulement un homme, mais encore une famille entière : ils ne songent qu'à se soulager eux-mêmes ; et, pour y réussir, tout leur est bon.

Un juge ne doit-il pas pénétrer le fond de leur ame, faire peu de cas de semblables accusations, et en sauvant ceux qu'on veut opprimer, se faire à lui-même un trésor de mérites, dont ses enfans et ses neveux recueilleront un jour mille bénédictions?

J'ai eu en vue dans ce préambule d'instruire et le peuple et ceux qui ont part au gouvernement. Il est constant que la plus petite plante, le plus vil arbrisseau, tient du ciel suprême ce qu'il a reçu de vie. Combien plus doit-on dire qu'il est l'auteur de la vie de tous les hommes, dont il est le premier père.

Ainsi le principal devoir d'un mandarin, c'est d'avoir des entrailles paternelles pour la conservation de ceux qui sont confiés à ses soins. Il doit employer les voies de douceur et de sévérité pour maintenir la tranquillité, et prévenir le désordre; et dans toute sa conduite ne rien faire d'indigne du beau nom de père du peuple. Par là il gagnera entièrement son affection, qui éclatera par les marques d'une éternelle reconnaissance. L'auguste ciel récompensera surtout son équité, et le protégera avec un soin particulier. 


\section{Contes chinois}

\section{LE CRIME PUNI.}

Sous la dynastie des Ming ${ }^{1}$, un homme riche de la ville de Sou-tcheou, nommé Wang-kia, était depuis longtemps l'ennemi déclaré d'un certain Li-yi. Il avait cherché cent fois I'occasion de le perdre, sans avoir pu la trouver. Un jour qu'il faisait un vent terrible, et qu'il pleuvait à verse, il part vers la troisième veille de la nuit, résolu de l'assassiner dans sa maison.

Ce soir-là, Li-yi, après avoir soupé tranquillement, s'était couché, et dormait d'un profond somme avec sa femme, lorsqu'une troupe de dix brigands enfonce sa porte. Ce bruit le réveille : il voit ces scélérats, le visage barbouillé de rouge et de noir, entrer en tumulte dans sa chambre.

A cette vue, madame Tsiang, sa femme, tout effrayée, se glisse dans la ruelle, et ensuite sous le lit où elle se cache : à demi-morte de frayeur, elle aperçoit qu'un de la troupe, qui avait une grande barbe et une large face, saisit Li-yi par les cheveux et lui abat la tête d'un coup de sabre : après quoi, toute la troupe, sans toucher à quoi que ce soit de la maison, sort aussitôt et disparaît.

Madame Tsiang, qui avait vu tout ce qui s'était passé, étant revenue de son extrême frayeur, sort de dessous le lit et s'habille à la hâte, puis se tournant vers le corps et la tête coupée de son mari, elle se lamente, et pousse de grands cris. Les voisins accourent en foule pour voir de quoi il s'agit. Un si triste

${ }^{1}$ C'est sous cette dynastie que vivait l'auteur de cette histoire. 


\section{Contes chinois}

spectacle les consterne. Ils s'efforcent néanmoins de consoler la pauvre dame tout éplorée; mais elle se refusait à toute consolation.

- Vous voyez, leur dit-elle, mon mari égorgé ; ne cherchez pas bien loin I'assassin ; c'est Wang-kia.

- Quelle preuve en avez-vous, répliquèrent les voisins ?

- Quelle preuve, ajouta-t-elle ? J'étais cachée sous le lit ; j'ai considéré le meurtrier. C'est Wang-kia luimême, cet ennemi juré de mon mari : j'ai remarqué sa grande barbe et sa large face : tout barbouillé qu'il était, je l'ai bien reconnu. De simples voleurs seraientils sortis de la maison sans en rien emporter ? Oui, c'est Wang-kia qui est le meurtrier de mon mari ; j'en suis sûre. Aidez-moi, je vous en conjure, aidez-moi à tirer vengeance de ce scélérat, et daignez m'accompagner chez le mandarin, pour demander justice et rendre témoignage de ce que vous avez vu.

Ils lui répondirent qu'ils étaient instruits de l'inimitié qui était entre Wang-kia et son mari, et qu'ils en rendraient volontiers témoignage dans le tribunal ; que d'ailleurs c'était pour eux un devoir indispensable d'avertir le mandarin, lorsque dans le quartier il s'était fait un meurtre ou un vol ; qu'ainsi, dès le lendemain elle n'avait qu'à préparer une accusation, et qu'ils l'accompagneraient, lorsqu'elle irait la présenter ; après quoi ils se retirèrent. 


\section{Contes chinois}

Quand ils furent partis, la dame Tsiang ferme sa porte, et passe le reste de la nuit dans les gémissemens et les sanglots.

A la pointe du jour, elle pria ses voisins de lui faire venir un homme qui dressât et composât l'accusation qu'elle voulait faire. Aussitôt qu'il l'eut écrite, elle se met en chemin, et va droit à l'audience du mandarin. C'était justement I'heure où il tenait son audience, et où il rendait justice. La dame, I'ayant aperçu, hâte le pas, et se prosternant au bas du degré de l'estrade, elle pousse des cris lamentables et demande vengeance.

Le mandarin, lui voyant en main une accusation, s'informe de ce qu'elle contenait ; et ayant appris qu'il s'agissait d'un meurtre fait par des voleurs ou par des assassins, il admet l'accusation, et promet de rendre justice. Les gens du quartier s'avancèrent au même temps, et présentèrent leur requête, pour l'avertir du désordre arrivé dans leur voisinage.

A l'instant le mandarin dépêche des officiers de justice pour faire la visite du corps mort et en dresser procès-verbal. Puis il ordonne aux archers d'arrêter au plus tôt celui qu'on assurait être l'assassin. Wang-kia demeurait tranquille dans sa maison, et paraissait ne point craindre, dans la fausse confiance où il était que, s'étant barbouillé le visage, il était impossible qu'on l'eût reconnu. Il s'applaudissait de son industrie, lorsque tout-à-coup il se vit environné d'une troupe d'archers, qui venaient d'entrer brusquement dans sa maison. Qu'on s'imagine voir un homme qui se bouche les oreilles, pour n'être pas effrayé des éclats du tonnerre, et que la foudre frappe au même instant : tel était Wang-kia. 


\section{Contes chinois}

Aussitôt on se saisit de lui ; on le charge de fers; et on le conduit à l'audience.

- C'est donc toi, malheureux, dit le mandarin, qui es I'assassin de Li-yi ?

- Moi, seigneur, répondit-il, si pendant la nuit Li-yi a été tué par des voleurs, suis-je responsable de sa mort ?

Pour lors le mandarin se tournant vers madame Tsiang :

- Eh bien, lui dit-il, comment prouvez-vous qu'il est I'auteur de ce meurtre?

- Seigneur, répondit-elle, lorsque le coup se fit, j'étais cachée auprès du lit, et de là j'ai vu le malheureux donner le coup de la mort à mon mari : je le reconnus bien.

- Mais, répliqua le mandarin, c'était la nuit que le coup s'est fait, comment dans l'obscurité avez-vous pu le reconnaître?

- Ah ! seigneur, dit-elle, non seulement j'ai remarqué sa taille et son air ; mais j'ai encore un indice bien certain : de simples voleurs se seraient-ils retirés avec tant de précipitation, sans rien enlever de la maison ? Une action si noire et si barbare est l'effet d'une ancienne inimitié qui n'a été que trop publique ; et mon mari n'avait point d'autre ennemi que Wang-kia. 


\section{Contes chinois}

Pour lors le mandarin fit approcher les voisins, et leur demanda s'il y avait effectivement une inimitié ancienne entre Wang-kia et Li-yi ?

- Oui, seigneur, répondirent-ils, elle était connue de tout le quartier. Il n'est pas moins vrai que le meurtre a été fait sans qu'on ait rien emporté de la maison.

Pour lors le mandarin haussant la voix, et prenant le ton de maître :

- Qu'on donne, dit-il, à I'heure même une rude question à Wang-kia.

Ce malheureux, qui était riche et qui avait toujours vécu à son aise, frémit au seul mot de question, et déclara qu'il allait tout avouer.

-Il est vrai, dit-il, que j'avais pour Li-yi une haine mortelle ; c'est ce qui m'a porté à me déguiser en voleur, pour n'être pas connu, et à l'assassiner dans sa propre maison.

Le mandarin, ayant reçu sa déposition, le fit conduire dans le cachot des criminels condamnés à mort.

Wang-kia, se voyant dans la prison, rêvait continuellement aux expédiens qu'il pourrait prendre pour se tirer de cette mauvaise affaire, et pour rendre inutile le fâcheux aveu qui lui était échappé. Plus il rêvait, et moins il y trouvait d'espérance. Enfin, un jour qu'il s'était fort tourmenté l'esprit : Comment se peut-il faire, dit-il en lui-même, que je n'aie pas plus tôt pensé au vieux Seou, cet écrivain si versé dans les ruses les plus 


\section{Contes chinois}

subtiles : j'ai été autrefois en liaison avec lui ; c'est un habile homme, et d'un esprit fertile en ces sortes d'inventions ; il a des expédiens pour tout, rien ne l'arrête.

Comme il s'entretenait de ces pensées, il aperçoit Wang-siaoeul son fils, qui venait le voir : aussitôt il lui fait part de son projet, et lui donne ses ordres.

- Surtout, lui ajouta-t-il, si Seou vous donne quelque espérance, n'épargnez point l'argent, et songez qu'il s'agit de votre père.

Siao-eul promit de tout risquer dans une affaire si importante.

A l'instant il court chez Seou, et, l'ayant heureusement rencontré, il lui expose l'affaire de son père, et le conjure de chercher quelque moyen de le sauver.

- Sauver votre père, répondit ce vieux routier, c'est une chose bien difficile; il a contre lui sa propre déposition. Le mandarin, nouvellement arrivé dans la province, est jaloux de sa gloire ; il a reçu lui-même la déposition, et a prononcé la sentence : vous auriez beau en appeler à un tribunal supérieur ; elle est entre les mains du premier juge. Croyez-vous qu'il veuille jamais avouer que ses procédures ont été défectueuses ? Écoutez : sans tant de discussions, donnez-moi deux ou trois cents taëls, et laissez-moi faire. Je vais aller à la cour (à Nan-king), et j'y trouverai quelque occasion d'y faire un coup de mon métier ; je I'ai déjà dans la tête, et le cœur me dit que je réussirai. 


\section{Contes chinois}

- Comment prétendez-vous donc vous y prendre ? dit Siao-eul.

- Point de curiosité, répliqua Seou ; livrez-moi seulement la somme que je demande, et vous verrez de quoi je suis capable.

Siao-eul retourne promptement à la maison, pèse l'argent, I'apporte, et presse Seou de hâter son voyage.

- Consolez-vous ! s'écria Seou ; à la faveur de ces pièces blanches, il n'y a point d'affaire, quelque mauvaise qu'elle soit, que je ne puisse ajuster : soyez tranquille, et reposez-vous sur moi.

Siao-eul prit congé de lui, et le remercia de son zèle.

Dès le lendemain, Seou partit pour Nan-king, et y arriva en peu de jours. Il alla aussitôt au tribunal suprême, où toutes les causes criminelles de l'empire sont portées. Là il s'informe adroitement de l'état présent de ce tribunal, du nom, du crédit, et du génie des officiers subalternes.

Il apprit qu'un nommé Siu-Koung, de la province de Tchekiang, y était lan-tchoung ${ }^{1}$; que c'était un homme habile à manier les affaires, et d'un accès facile. Il l'aborda avec une lettre de recommandation, qu'il accompagna d'un fort joli présent.

Siu-Koung le reçut avec politesse, et ayant remarqué que Seou était un beau parleur, il l'invita à venir souvent le voir. Seou n'eut garde d'y manquer, et il n'oublia rien pour s'insinuer peu à

${ }^{1}$ C'est une espèce d'avocat. 


\section{Contes chinois}

peu dans son amitié, et pour gagner ses bonnes graces ; mais il ne s'était encore présenté nulle occasion favorable à son dessein.

Un jour qu'il y pensait le moins, il apprit qu'une troupe d'archers venait de conduire au tribunal plus de vingt corsaires qui devaient être condamnés irrémissiblement à avoir la tête tranchée. Il sut en même temps que, parmi ces voleurs, il y en avait deux qui étaient de Sou-tcheou. A cette nouvelle, remuant doucement la tête :

- J'ai, dit-il, ce que je cherche, et me voilà en train de réussir dans mon projet.

Le lendemain il prépare un grand repas, et envoie à SiuKoung un billet d'invitation. Celui-ci monte aussitôt en chaise, et se rend à la maison de Seou. Grande amitié de part et d'autre. Seou introduit son hôte dans son logis avec un air épanoui, et lui donne la place honorable. Durant le repas, ils s'entretinrent agréablement de différens sujets, et burent jusque bien avant dans la nuit. Enfin Seou, ayant fait retirer les domestiques, et se trouvant seul avec son convive, tire un paquet de cent taëls, et le lui présente.

Siu-Koung, rempli d'étonnement, demanda pour quelle raison il lui faisait un présent si considérable?

- J'ai un proche parent appelé Wang, répondit Seou, qu'on a accusé faussement d'un crime pour lequel il est détenu en prison dans sa ville. Il implore humblement votre protection, et vous prie de le tirer du péril où il se trouve. 


\section{Contes chinois}

- Pourrais-je, répliqua Siu-Koung, vous refuser un service qui dépendrait de moi ? Mais l'affaire dont vous me parlez n'est pas de mon district ; comment puis-je m'en mêler?

- Rien de plus aisé, reprit Seou, daignez m'écouter un moment. Toute la preuve qu'on apporte pour perdre mon parent, et pour lui attribuer le meurtre de Li-yi, c'est qu'il était son ennemi déclaré. Comme on n'a pu découvrir le véritable assassin, on a soupçonné mon parent, et, sans autre formalité, on l'a enfermé dans un cachot. Or, je sais que hier on a conduit à votre tribunal plus de vingt corsaires, parmi lesquels il y en a deux qui sont de la ville de Sou-tcheou, où le meurtre a été commis. Il n'est question que d'engager ces deux voleurs d'ajouter l'assassinat de Li-yi aux autres crimes qu'ils avoueront dans leurs dépositions : ils n'en seront pas moins condamnés à avoir la tête coupée, et un pareil aveu n'augmentera en rien la rigueur de leur supplice. Cet aveu justifiera mon parent, et il vous sera à jamais redevable de la vie que vous lui aurez rendue.

Siu-Koung goûta cet expédient, et promit de le faire réussir. Aussitôt il prend le paquet d'argent ; et, après avoir appelé ses domestiques, et fait ses remercîmens du festin qu'on venait de lui donner, il monte en chaise et s'en retourne dans sa maison.

Seou ne s'endormit pas durant ce temps-là : il s'informa sous main quels étaient les parens des deux voleurs de Sou-tcheou ; et, en ayant découvert quelques-uns, il leur fit confidence de son 


\section{Contes chinois}

dessein, en leur faisant les plus belles promesses s'ils voulaient engager ces deux voleurs à faire un aveu qui ne leur serait d'aucun préjudice, et il leur fit présent par avance de cent taëls.

Cette libéralité produisit son effet, et les deux voleurs consentirent à ce qu'on voulut. Ainsi, lorsqu'on les fit venir pour être examinés et jugés en dernier ressort, Siu-koung, qui était chargé de cette commission, les voyant à ses pieds, commença I'interrogatoire de cette sorte :

- Combien avez-vous tué de personnes?

Les deux voleurs répondirent:

- En tel temps et tel lieu nous avons tué tels et tels; dans tel mois et à tel jour, nous allâmes pendant la nuit dans la maison d'un certain Li-yi, et nous l'égorgeâmes.

Siu-koung ayant reçu ces dépositions, fit reconduire les voleurs en prison; ensuite il dressa un procès-verbal où leurs réponses étaient exactement détaillées, et il conclut par prononcer leur sentence. Seou va aussitôt trouver les greffiers, et leur fait faire, au nom du tribunal, une copie bien légalisée de ce jugement ; après quoi, ayant pris congé de Siu-koung, il vole à Sou tcheou, va droit à I'hôtel du mandarin, qui donnait alors son audience, et lui remet le paquet.

Le mandarin I'ouvre ; et ayant lu que l'auteur du meurtre d'un certain Li-yi a été pris et reconnu, il s'écria d'abord :

- Comment cela se peut-il faire, puisque Wang-kia a nettement confessé ce crime ! 


\section{Contes chinois}

Comme il ordonnait qu'on fît comparaître le prisonnier pour être interrogé de nouveau, Wang-siao-eul entre dans le parquet, criant à haute voix :

- On a calomnié mon père, on veut l'opprimer!

Cet assemblage de circonstances étonna le mandarin, et, déposant sur-le-champ tous ses doutes, il ordonna qu'on remit Wang-kia en liberté ; ce qui s'exécuta à l'instant.

Tsiang, ayant appris la nouvelle de ce prompt élargissement, comprit bien qu'elle n'avait plus de démarches à faire, et que ses poursuites seraient inutiles.

- Après tout, dit-elle, comme c'est pendant la nuit que le meurtre s'est fait, il n'est pas impossible que je me sois trompée.

Ainsi elle abandonna cette affaire, et ne songea pas à la pousser davantage.

On peut juger quelle était la joie de Wang-kia. Il retourna dans sa maison, comme en triomphe, au milieu des acclamations de ses parens et de ses amis. Sa démarche était fière et orgueilleuse ; mais, comme il était prêt d'y entrer, il fut tout-àcoup frappé d'une bouffée de vent froid, et cria de toutes ses forces :

- Je suis perdu ! j'aperçois Li-yi ; il me menace, il se jette sur moi !

Et, en proférant ces dernières paroles, il tombe à la renverse sans connaissance, et expire en un instant. Exemple terrible et effrayant! grande leçon! On ne saurait tromper le ciel. 
Contes chinois

(a)

224 


\title{
Contes chinois
}

\section{LA CALOMNIE DÉMASQUÉE.}

\author{
La vertu est récompensée, le vice puni ; \\ C'est ce qui fait éclater l'équité du Ciel. \\ En voulant nuire à autrui \\ On se nuit à soi-même.
}

J'ai trouvé que sous la dynastie présente des Ming, dans la petite ville de Young-kia, du district de Wen-tcheou, dans la province de Tche-kiang, il y avait un lettré appelé Wang, surnommé Kieï, et dont le titre d'honneur était Wen-hao. Il avait épousé une dame nommée Lieou, qui seule possédait toute son affection. Il en eut une fille, qui n'avait encore que deux ans au temps dont je vais parler. Ainsi toute la famille se réduisait à eux trois et à quelques esclaves ou domestiques.

Bien qu'il ne fût pas riche, il ne laissait pas de vivre honorablement. L'étude faisait toute son occupation. Il n'était pas encore gradué, mais il aspirait à cet honneur; pour y parvenir, il vivait dans la retraite; et, toujours occupé de ses livres, il ne se délassait de son travail que par quelques visites qu'il rendait à un petit nombre d'amis, avec qui il était en commerce d'ouvrages d'esprit.

Quant à la dame Lieou, c'était un modèle de vertu ; elle était fort spirituelle, attentive, économe et laborieuse. Deux personnes d'un caractère si aimable vivaient ensemble dans une grande union et avec beaucoup de douceur. Une après-dînée, vers la fin du printemps, que le ciel était parfaitement beau, 


\section{Contes chinois}

deux ou trois de ses amis vinrent le tirer de son étude pour aller faire un tour de promenade hors de la ville.

Les jours sombres et pluvieux qui avaient précédé donnaient un nouvel éclat au soleil, qui ne s'était pas montré depuis plusieurs jours ;

Cent sortes d'oiseaux différens animaient et diversifiaient les bocages.

Une infinité de papillons, voltigeant sur les têtes fleuries des pêchers agités par les doux zéphirs, formaient une brillante parure.

Les fleurs attachées aux branches, sans être encore fanées, tapissaient partout les jardins.

Enfin toute la jeunesse de la ville, répandue dans la campagne, faisait un spectacle charmant.

Chacun était dans la joie et s'y livrait au milieu des festins.

Wang, entraîné par les douces impressions du printemps, ne songea aussi qu'à se divertir ; lui et sa compagnie se régalèrent, et burent plusieurs rasades. Enfin ils se séparèrent.

Wang, arrivant dans sa maison, trouve à sa porte deux de ses domestiques qui s'échauffaient extrêmement contre un homme du dehors. Celui-ci était de la ville de Hou-tcheou, et s'appelait Liu. Il avait en main un panier plein de gingembre qu'il vendait. Les domestiques prétendaient qu'il se faisait payer trop cher la quantité qu'ils en avaient achetée. Le marchand de son côté criait qu'on lui faisait tort. Wang, ayant appris le sujet de leur querelle, se tourne vers le marchand :

- Tu es bien payé, lui dit-il, retire-toi, et ne fais point tant de bruit à ma porte. 


\section{Contes chinois}

Le marchand, homme simple et sincère, répliqua aussitôt avec sa franchise ordinaire :

- Il ne nous est pas possible à nous autres petits marchands de supporter la moindre perte ; cela est bien mal à vous, qui devez avoir l'ame grande et généreuse, de chicaner ainsi avec de pauvres gens.

Wang, qui avait un peu de vin dans la tête, entre à ces mots dans une étrange colère.

- Coquin que tu es, lui dit-il, oses-tu bien me parler avec si peu de respect?

Sur quoi, sans faire réflexion que c'était un homme fort âgé, il le pousse rudement, et le jette à la renverse. La chute fut violente, et le pauvre malheureux resta sans sentiment ni connaissance.

\footnotetext{
L'homme disparaît ici bas comme la lune qui, vers le matin, se précipite en un moment derrière la montagne.

La vie est comme une lampe qui, lorsque l'huile vient à manquer, s'éteint à la troisième veille.
}

Après tout on ne doit jamais se mettre en colère, encore moins contre des gens qui vivent de leur petit commerce. Un ou deux deniers de plus ne valent pas la peine de chicaner. Il est cependant très ordinaire de voir des domestiques se prévaloir du rang et du crédit de leur maître, user de violence, maltraiter le peuple, et par là déshonorer leurs maîtres, ou leur susciter de mauvaises affaires. Aussi voit-on que ceux qui ont de la conduite donnent chez eux des ordres si sévères, et préviennent de semblables inconvéniens. 


\section{Contes chinois}

Il est certain que Wang aurait dû se modérer ; il commit en cela une faute grave ; mais aussi en fut-il bien puni, comme on le verra dans la suite. Lorsqu'il vit cet étranger tomber à ses pieds sans mouvement et presque sans vie, il fut saisi d'une extrême frayeur, qui dissipa bientôt les fumées du vin. Il se met en mouvement ; il crie au secours. On vient en hâte, et I'on transporte cet homme à demi mort dans la salle voisine. Comme il ne donnait point encore de signe de vie, on lui fit avaler du thé bien chaud ; et peu après il revint de son évanouissement.

Alors Wang, lui ayant fait d'humbles excuses, lui fit boire plusieurs coups d'excellent vin, et lui servit à manger pour rétablir ses forces; après quoi il lui fit présent d'une pièce de taffetas, dont il pouvait tirer quelque argent.

Ce bon traitement fit sur-le-champ passer ce pauvre homme de l'indignation à la joie, et il la témoigna par mille actions de graces ; après quoi il prit congé, et se rendit sur le bord de la rivière, qu'il devait passer avant qu'il fût tout-à-fait nuit.

Si Wang avait pu prévoir l'avenir, il aurait retenu cet étranger, et l'aurait nourri dans sa maison, du moins pendant deux mois. Ce trait d'hospitalité l'eût préservé des traverses que nous allons voir fondre sur lui. Sa conduite nous fait une bonne leçon, qui est exprimée dans ce proverbe : On lance des deux mains un filet de fil d'or, et l'on amène cent malheurs.

Wang ne l'eut pas plus tôt vu parti, qu'il entre dans l'intérieur de sa maison, et s'applaudit avec sa femme de s'être si bien tiré d'un si mauvais pas. 


\section{Contes chinois}

Comme il était nuit, la dame Lieou appelle ses esclaves, et leur ordonne de servir incessamment le souper. Elle commence par faire avaler à son mari un bon coup de vin chaud, pour le remettre de sa frayeur. Il avait déjà repris ses esprits, et son cœur se tranquillisait, lorsqu'il entend tout à coup frapper à la porte.

Une nouvelle frayeur le saisit. Il prend vite la lampe, et va voir de quoi il s'agit. Il trouve un nommé Tcheou-se, qui était le chef de la barque sur laquelle on passe la rivière, et qui tenait à la main la pièce de taffetas et le panier du marchand.

Aussitôt qu'il aperçut Wang, il lui dit d'un air effaré :

- Quelle terrible affaire vous êtes-vous attirée ! Vous êtes un homme perdu. Quoi ! un lettré comme vous, tuer un pauvre marchand.

Ce fut un coup de foudre pour le malheureux Wang.

- Que voulez-vous encore dire ? reprit-il en tremblant.

- Est-ce, répliqua Tcheou-se, que vous ne m'avez pas compris ? Ne reconnaissezvous pas ce taffetas et ce panier?

- Eh ! oui, dit Wang : un vendeur de gingembre, qui est de Hou-tcheou, est venu chez moi : cette pièce de taffetas il I'a reçue de moi aujourd'hui ; c'est dans ce panier qu'il portait sa marchandise. Comment est-ce que ces choses se trouvent entre vos mains ?

- Il faisait déjà nuit, dit Tcheou-se, lorsqu'un homme de Hou-tcheou, appelé Liu, me demanda à passer la 


\section{Contes chinois}

rivière sur ma barque. A peine y eut-il mis le pied, qu'il fut surpris d'un mal violent de poitrine, qui le réduisit à l'extrémité : alors m'avertissant que c'était l'effet des coups que vous lui aviez donnés, il me remit la pièce de taffetas et le panier. Cela servira de preuve, poursuivitil, lorsque, comme je vous en conjure, vous suivrez cette affaire en justice. C'est pourquoi allez au plus tôt à Hou-tcheou, pour informer mes parens, et les prier de me venger, en demandant la mort de celui qui me l'a procurée. En finissant ces mots, il expira. Son corps est encore sur la barque que j'ai conduite près de votre porte, qui est à l'entrée de la rivière. Vous pouvez vous en instruire par vous-même, afin d'aviser aux mesures que vous avez à prendre pour votre sûreté.

A ce récit, Wang fut tellement effrayé qu'il ne put proférer une seule parole. Son cœur était agité comme celui d'un jeune faon serré de près, qui va heurter çà et là, sans trouver d'issue pour s'échapper.

Enfin revenant un peu à lui-même, et dissimulant l'embarras où il était.

- Ce que vous me racontez, lui dit-il hardiment, ne saurait être.

Néanmoins il ordonna secrètement à un domestique de visiter la barque, et de bien examiner si la chose était véritable. Celui-ci revint au plus vite et assura que le corps mort y était effectivement. 


\section{Contes chinois}

Wang était un homme d'un esprit irrésolu, et dont les vues étaient bornées. Il rentre dans sa maison tout hors de lui-même, et, racontant à sa femme ce qu'il venait d'apprendre :

- C'en est fait de moi, s'écria-t-il ; je suis un homme perdu ; I'orage est prêt à crever sur ma tête ; je ne vois qu'un remède à mon malheur : c'est de gagner ce batelier, afin qu'à la faveur des ténèbres il jette quelque part ce cadavre. Il n'y a que ce moyen de me tirer d'intrigue.

Sur cela il prend un paquet de plusieurs morceaux d'argent, qui faisaient environ vingt taëls, et vient rejoindre avec précipitation le batelier.

- Mon maître, lui dit-il, je compte que vous me garderez le secret ; je vais vous parler confidemment. Il est vrai que je me suis attiré cette mauvaise affaire ; mais certainement il y a eu plus d'imprudence que de malice. Nous sommes I'un et l'autre de Wen-tcheou ; je me flatte que vous aurez pour moi le cœur d'un bon concitoyen. Voudriez-vous me perdre pour l'amour d'un étranger ? Quel avantage vous en reviendrait-il ? Ne vaut-il pas mieux assoupir cette affaire ? Ma reconnaissance sera proportionnée à votre bienfait. Prenez donc le cadavre, et jetez-le en quelque endroit écarté : I'obscurité de la nuit favorise notre dessein, et il n'y a personne qui puisse en avoir la moindre connaissance. 


\section{Contes chinois}

- Quel endroit puis-je choisir, reprit le batelier ? Si demain, par hasard, quelqu'un vient à découvrir le mystère, et qu'on fasse des recherches en justice, on me regardera comme complice du meurtre, et, pour vous avoir rendu service, je serai également intrigué dans une affaire si fâcheuse.

- Vous savez bien, dit Wang, que la sépulture de mon père est ici proche, et que cet endroit n'est point fréquenté. D'ailleurs la nuit est très obscure, et il n'est point à craindre que vous trouviez une seule ame en chemin. Prenez donc la peine d'y transporter le cadavre sur votre barque.

- Cette vue est assez bonne, reprit le batelier ; mais comment reconnaîtrez.. vous ce service?

Alors Yang tire le paquet d'argent, et le lui donne. Celui-ci, sentant au poids que la somme était peu considérable :

- Quoi, dit-il d'un air dédaigneux, il s'agit d'un homme tué, et vous prétendez en être quitte avec une somme si modique ? C'est ma bonne fortune qui a conduit cet homme sur ma barque. Le Ciel a voulu me fournir une occasion de changer ma condition dans une meilleure ; et vous me donnez si peu ? Cette affaire me doit au moins valoir cent taëls.

Wang, qui souhaitait avec passion de se tirer au plutôt d'intrigue, n'osa le contredire. Il témoigna par un signe de tête qu'il acceptait la condition, et aussitôt il rentre dans sa maison, ramasse à la hâte quelques pièces d'argent qui lui restaient, y 


\section{Contes chinois}

joint des habits, les ornemens de tête de sa femme, et autres choses semblables, et revient promptement offrir le tout à Tcheou-se, en lui disant que ce qu'il lui donnait montait environ à soixante taëls ; que c'était tout ce que sa pauvreté lui permettait de faire, qu'il le priait de s'en contenter.

Effectivement Tcheou-se parut se radoucir.

- Je ne veux point, dit-il, me prévaloir de votre malheur : mais comme vous êtes un homme de lettres, j'espère que dans la suite vous aurez des égards pour moi.

Wang commença dès ce moment à respirer. Devenu plus tranquille, il fit servir la collation au batelier, pendant laquelle il ordonna à deux de ses esclaves de préparer des pelles et des hoyaux. Un des deux s'appelait Hou : c'était un vrai brutal ; aussi lui avait-on donné le surnom de Hou (le tigre). La troupe s'embarqua aussitôt, et, dès qu'on fut arrivé vis-à-vis de la sépulture, on y choisit un endroit où la terre était molle et aisée à fouir. Ils firent une fosse, et y enterrèrent le cadavre. Après quoi ils se rembarquèrent, et retournèrent promptement à la maison.

Ce travail les occupa presque toute la nuit, et ils ne parurent qu'au lever de l'aurore. Le déjeuner était prêt pour le batelier, après lequel il prit congé. Wang avait fait retirer ses valets, et se trouvant seul, il passa dans son appartement pour se consoler avec sa femme. 


\section{Contes chinois}

- Est-il possible, s'écria-t-il, qu'un homme de ma profession et d'une si ancienne famille se voie réduit à recevoir la loi d'un misérable?

A ces mots il versa un torrent de larmes.

Sa femme s'efforça de modérer sa douleur :

- Pourquoi vous attrister ainsi, lui dit-elle ? C'est là une suite inévitable de votre destinée ; il était réglé que vous vous trouveriez un jour dans cet embarras, et qu'il vous en coûterait la somme que vous avez payée. Au lieu de murmurer comme vous faites, bénissez le ciel de ce qu'il vous a protégé dans ce malheur. Ne songez plus qu'à prendre un peu de repos ; vous en avez besoin, après les fatigues et les agitations où vous avez été pendant toute la nuit.

Wang suivit ce conseil, et se mit au lit.

Au bout de quelques jours, Wang, voyant I'affaire assoupie, acheta des victimes et des offrandes, et fit un sacrifice aux Dieux et à ses ancêtres.

Pour ce qui est du batelier, il vendit sa barque, et, de l'argent que le lettré lui avait donné, il ouvrit boutique, et s'adonna au commerce.

Il fallait que ce lettré eût bien peu de conduite : car enfin en prenant le parti de fermer la bouche au batelier, à force d'argent, ne devait-il pas faire mettre dans la barque bon nombre de fagots bien secs, pour brûler le cadavre ? Il n'en serait resté aucun vestige, et il eût été à couvert de toutes recherches; au 


\section{Contes chinois}

lieu qu'en se contentant de le faire enterrer, il se comporta comme ceux qui ne font que couper les mauvaises herbes d'un champ, et qui laissent la racine. Ces herbes croissent de nouveau au printemps, et causent le même dommage. Un laboureur habile les arrache jusqu'à la racine; quand elles sont ainsi déracinées, la première gelée blanche qui survient les pourrit, et il n'y a plus à y revenir.

L'on a bien raison de dire : Le bonheur arrive à pas lents, les malheurs viennent en poste. La fille de Wang dont j'ai parlé commençait sa troisième année, lorsqu'elle fut attaquée d'une petite vérole très maligne. On fit force prières pour cette fille unique ; on consulta les sorts ; on fit venir d'habiles médecins ; tout cela inutilement. Le père et la mère passaient les jours entiers dans les pleurs, à côté du lit de la malade. Enfin ils apprirent qu'il y avait dans la ville un nommé Siu, médecin très expérimenté pour ces sortes de maladies, et qui avait sauvé un grand nombre d'enfans dont la vie était désespérée. Wang lui écrit aussitôt une lettre très pressante qu'il confie à Hou, son esclave, en lui recommandant toute la diligence possible. Il compta toutes les heures du jour sans que le médecin parût. Cependant la malade empirait à chaque instant ; elle traîna jusqu'à la troisième veille, que la respiration étant devenue plus difficile, elle rendit le dernier soupir au milieu des larmes et des gémissemens de ses parens désolés.

Ce ne fut que le lendemain à midi que Hou fut de retour à la maison. Sa réponse fut que le médecin était absent, et qu'il 


\section{Contes chinois}

I'avait attendu inutilement tout le jour. A ce récit, les douleurs du père affligé se renouvelèrent.

- C'était là, dit-il, la destinée de ma chère fille ; je n'ai pu avoir le bonheur de lui procurer le secours d'un si habile médecin.

Et, en disant ces mots, il fondait en pleurs.

A quelques jours de là on découvrit, par le moyen des domestiques, que l'esclave, au lieu de faire sa commission, s'était arrêté à boire dans un cabaret ; qu'il s'y était enivré, et avait perdu le billet destiné au médecin ; et que, les fumées du vin étant dissipées, il avait concerté le mensonge qu'il avait eu l'effronterie de raconter à son retour.

A cette nouvelle, Wang, transporté de colère, appelle les autres esclaves :

- Vite, leur dit-il, prenez ce coquin-là, étendez-le par terre, et déchargez-lui cinquante coups de bâton bien appliqués et de toutes vos forces.

Après l'exécution, dont il fut témoin, il se retire dans son appartement, le cœur serré de douleur.

L'esclave, se levant à peine, tout meurtri des coups qu'il venait de recevoir, se traîna, comme il put, dans sa chambre. Là, plein de rage, et se débattant comme un forcené :

- Maître barbare, s'écria-t-il, ta brutalité te coûtera cher, tu n'échapperas pas à ma vengeance.

Puis, après avoir rêvé un moment : 


\section{Contes chinois}

- Je n'irai pas bien loin pour en chercher l'occasion ; je I'ai dans la main, et je ne la manquerai pas ; dès que mes plaies seront guéries, tu verras de quoi je suis capable, et tu apprendras, comme dit le proverbe, «si c'est le puits qui est tombé dans le seau, ou si c'est le seau qui est tombé dans le puits.

Wang cependant était inconsolable, et ne s'occupait que de sa douleur. Enfin ses parens et ses amis l'invitèrent de tous côtés à venir les voir, et peu à peu ils essuyèrent ses larmes et dissipèrent sa tristesse.

Quelques jours après qu'il fut retourné chez lui, comme il se promenait dans la galerie de la salle, il voit entrer une troupe d'archers qui viennent droit à lui, et lui jettent une corde au cou :

- Hé ! quoi, s'écria Wang tout consterné, ne savezvous pas que je suis lettré, et de famille lettrée ? Traite$\mathrm{t}$-on de cette manière indigne un homme de mon rang ? Et pour quel sujet encore?

Les archers lui répondirent d'un air insultant :

- Oui, vous êtes un joli lettré. Le mandarin vous apprendra s'il convient à un lettré d'assommer les gens.

En même tems ils le traînèrent au tribunal où ce magistrat donnait son audience. A peine l'eut-on fait mettre à genoux, qu'il aperçut, à quelque distance, son esclave qui était devenu son accusateur, et qui faisait paraître sur son visage épanoui la joie secrète qu'il avait de I'humiliation et de l'embarras où se trouvait 


\section{Contes chinois}

son maître. Il comprit d'abord que le perfide n'avait intenté cette accusation que pour se venger du châtiment dont il l'avait fait punir.

Le mandarin commença ainsi son interrogatoire :

- Vous êtes accusé, lui dit-il, d'avoir tué un marchand de la ville de Hou-tcheou : que répondez-vous à cette accusation ?

- Ah ! seigneur, répondit Wang, vous qui tenez ici bas à notre égard la place du juste ciel, n'écoutez pas les calomnies de ce misérable. Faites réflexion qu'un lettré de profession, faible et timide comme je suis, ne peut pas être soupçonné de s'être battu, et d'avoir tué personne. Mon accusateur est un de mes esclaves, que j'ai surpris en faute et que j'ai fait châtier assez rudement, selon le droit que j'ai comme son maître. Ce malheureux a formé le dessein de me perdre. Mais j'espère de vos lumières et de votre équité que vous n'écouterez point un malheureux au préjudice de son maître, et que vous dévoilerez aisément le secret de ses noires intrigues.

Hou, après avoir frappé du front contre terre :

- Seigneur, je vous conjure, dit-il, vous qui faites visiblement la fonction du ciel, de n'avoir point d'égard à ce que vient de dire ce lettré, qui a un talent rare de se contrefaire. Qu'un esclave fasse des fautes, et qu'il en soit puni, rien n'est plus ordinaire, et l'on n'en voit point qui pousse le ressentiment jusqu'à intenter une 


\section{Contes chinois}

accusation capitale. Mais il est aisé de vous en éclaircir. Les ossemens de celui qu'il a tué sont actuellement dans sa sépulture; donnez ordre qu'on les déterre ; si on les trouve, on verra que j'ai dit vrai ; si on ne les trouve pas, je suis un calomniateur, et je consens qu'on me punisse selon toute la rigueur des lois.

Ce fut en effet le parti que prit le mandarin. Des huissiers, par son ordre, se transportèrent sur les lieux, conduits par l'esclave, qui marqua précisément l'endroit où I'on trouverait le cadavre. On le déterra ; ce n'était plus qu'un squelette, qui fut porté sur un brancard à l'audience. Le mandarin, se levant de son siège, et considérant le cadavre :

- Le crime est avéré, dit-il.

Wang allait être appliqué à la question, lorsqu'il supplia qu'on voulût bien l'écouter un moment,

- Ce squelette, dit-il, dont les chairs sont desséchées et pourries, fait assez voir que ce n'est pas un homme tué tout récemment. Si donc j'ai été coupable de ce meurtre, pourquoi mon accusateur a-t-il attendu jusqu'à ce jour à me déférer ? N'est-il pas plus naturel de penser que Hou est allé chercher, je ne sais où, ce squelette pour hasarder cette calomnie, et m'écraser, s'il pouvait, comme d'un coup de foudre?

- La réponse est assez bonne, dit le mandarin.

Mais Hou répliqua aussitôt : 


\section{Contes chinois}

- Il est vrai, c'est ici le corps d'un homme tué il y a un an. L'attachement d'un esclave pour son maître le retient, et il lui coûte infiniment de faire le personnage d'accusateur. J'avoue que j'ai eu de la connivence, ne pouvant me résoudre à faire de la peine à un maître que j'affectionnais. J'espérais qu'avec le temps il corrigerait son naturel bouillant et emporté ; mais comme il devenait de jour en jour plus brutal, j'ai appréhendé qu'il ne fit encore quelque mauvais coup qui m'entraînât avec lui dans le précipice ; c'est ce qui me fait prendre le parti de le déférer enfin au tribunal, quoique j'eusse dû le faire plus tôt. Mais si I'on a encore quelque difficulté sur ma déposition, qu'on fasse venir les voisins et qu'on les interroge ; il n'y a aucun d'eux qui ne déclare que l'année dernière, à tel mois et tel jour, Wang a effectivement tué un homme ; c'est là une voie sûre pour découvrir qui de nous deux a dit la vérité.

- Il a raison, dit le mandarin ; qu'on fasse venir au plus tôt les voisins de Wang.

Ils arrivèrent, et aussitôt on leur demanda ce qu'ils savaient du meurtre en question.

- Il est vrai, répondirent-ils, que l'an passé, à tel mois et à tel jour, Wang battit violemment un marchand de gingembre : on le crut mort pendant quelque temps ; mais enfin on le fit revenir, et nous ne savons pas ce qui lui est arrivé dans la suite. 


\section{Contes chinois}

A ce témoignage des voisins, Wang pâlit d'une manière sensible, et ne fit plus que se contredire et se couper dans ses réponses.

- Il n'y a plus de questions à faire, dit le mandarin ; vous êtes convaincu de ce meurtre ; mais vous ne I'avouerez jamais, si l'on n'emploie les voies de rigueur.

Il commande en même temps qu'on lui donne la bastonnade.

Aussitôt deux estafiers du tribunal, poussant un grand cri pour marquer leur promptitude à obéir, saisissent le lettré, l'étendent par terre, et lui déchargent de toutes leurs forces vingt coups de bâton. C'en était déjà trop pour un lettré d'une complexion faible et délicate. Dans la crainte d'être encore plus cruellement traité, il n'hésita pas à avouer tout ce qu'on voulut.

Le mandarin ayant écrit la déposition :

- Quoiqu'il ne soit plus douteux, que tu mérites la mort, cependant, comme on ne voit point de parent du mort qui vienne demander justice, rien ne presse d'en venir à exécution. Attendons qu'il vienne quelqu'un qui reconnaisse le mort pour son parent; alors je déterminerai le genre de supplice dont tu dois être puni.

Wang fut donc conduit dans un cachot, et le squelette enterré derechef dans l'endroit d'où il avait été tiré, avec défense de le brûler, afin qu'il pût être représenté et livré aux parens lorsqu'ils viendraient à paraître.

L'audience finie, le mandarin rentra dans son hôtel. Hou se retira bien content du succès qu'avait eu son accusation, et s'applaudissant de la bastonnade qu'il avait vu donner à son 


\section{Contes chinois}

maître. D'autres esclaves de Wang, qui avaient été envoyés à I'audience par la dame son épouse, lui rapportèrent tout ce qui s'y était passé.

A cette nouvelle elle tomba évanouie, et elle demeura longtemps dans cet état, comme si trois ames l'eussent abandonnée ; puis étant un peu revenue à elle-même, elle fit retentir tout le quartier de cris et de lamentations qui furent suivis d'une nouvelle pâmoison encore plus violente. Enfin, au moyen du prompt secours que lui donnèrent ses suivantes, elle reprit insensiblement connaissance. Mon cher mari ! s'écria-telle ; elle ne put proférer d'autres paroles. Les cris et les sanglots recommencèrent et durèrent plus de deux heures.

Ces grands accès de douleur étant passés, elle amasse quelque argent et change d'habit ; puis elle ordonne à une de ses esclaves de la suivre, et à une autre de marcher devant elle. Elle traverse ainsi la ville, et va se présenter à la porte de la prison publique. Dès que le mari et la femme s'aperçurent, ils parurent interdits jusqu'à ne pouvoir se parler.

Enfin Wang reprit ses esprits, et, d'une voix entrecoupée de sanglots :

- Ma chère épouse, dit-il, c'est Hou, cet esclave dénaturé qui m’a précipité dans cet abîme de malheurs!

La dame Lieou éclata sur I'heure en imprécations contre ce malheureux ; puis elle tire l'argent qu'elle avait apporté, et le remet à son mari. 


\section{Contes chinois}

- Voici, dit-elle, de quoi distribuer au geolier et à vos gardes, afin qu'ils vous traitent avec douceur.

La nuit les obligea de se séparer.

La dame Lieou se retira accablée de tristesse, et le cœur pénétré de la plus vive douleur. Wang ne manqua pas de faire ses libéralités au geolier et aux gardes, et par là il fut exempt des coups de fouet et de bâton qui pleuvent d'ordinaire sur les prisonniers ; mais il avait infiniment à souffrir de la compagnie d'une foule de scélérats au milieu desquels il se trouvait, et de l'inquiétude où il était de finir ses jours par une mort honteuse et cruelle.

Il y avait déjà six mois qu'il traînait sa triste vie dans l'obscurité d'une prison, lorsqu'il fut attaqué d'une maladie violente. L'art des médecins, et tous les remèdes qu'on lui donna, n'eurent aucun effet, et il se vit réduit à l'extrémité. Le jour même qu'on désespérait de sa vie, un domestique vint lui apporter quelque secours. Aussitôt que Wang I'aperçut :

- Retourne au plus vite, lui dit-il, et va dire à ta maîtresse que le mal me presse, et qu'elle se hâte de me venir voir, si elle veut que je l'embrasse pour la dernière fois.

L'esclave n'eut pas plus tôt averti sa maîtresse, qu'elle sort tout éperdue et se rend à la prison, où, à la vue du triste état de son mari, elle versa un torrent de larmes ; alors Wang reprenant ses forces : 


\section{Contes chinois}

- Ah ! ma chère épouse, faut-il que ton infortuné mari se soit attiré cette suite affreuse de malheurs, et ait couvert de confusion une si sage et si vertueuse femme ! Mon mal augmente à chaque moment. Chère compagne, puisque j'ai la consolation de te voir, je meurs content ! Ce que je demande, c'est qu'on ne laisse pas impunie la noire trahison de mon perfide esclave. Jusque dans l'autre monde j'en demanderai vengeance.

La dame Lieou retenant ses pleurs pour ne point contrister son mari :

- Cessez, lui dit-elle, de pareils discours, et ne songez qu'à vous tranquilliser et à prendre les remèdes propres à rétablir votre santé. Jusqu'ici il ne s'est trouvé personne qui pousse l'affaire pour laquelle vous languissez dans cette prison; et je suis résolue de vendre généralement nos terres, nos maisons, et tout ce que j'ai, afin de vous délivrer, et que nous puissions vivre encore longtemps ensemble. Quant à votre esclave infidèle, la justice du ciel saura bien le punir: immanquablement vous serez vengé, n'en ayez point d'inquiétude.

- Quand je vois, répondit Wang, une femme si attentive à me secourir, je regarde comme un don précieux les jours que le Ciel me prolonge.

Il allait continuer, Iorsqu'on obligea sa femme de sortir, à cause de la nuit qui approchait. 


\section{Contes chinois}

Ce fut alors qu'éclata la douleur qu'elle avait retenue dans son sein. Elle arriva dans sa maison fondant en pleurs, et se retira dans son appartement, où elle ne s'occupait que du malheur et de la triste situation de son mari. Pendant ce tempslà, les domestiques étaient dans la salle basse, sur le devant de la maison, où ils tâchaient de dissiper leur mélancolie, lorsque tout-à-coup ils virent entrer un homme avancé en âge qui apportait des présens, et qui leur demanda si leur maître était à la maison.

Lorsqu'ils eurent considéré de près cet étranger, tous se mirent à crier : Les morts reviennent ! et chacun d'eux prit la fuite. Ils avaient reconnu le vendeur de gingembre, ce marchand de Hou-tcheou, nommé Liu. Lui, voyant ainsi fuir tous ces domestiques effrayés, en saisit un par le bras :

- Etes-vous fou ? lui dit-il. Je viens rendre visite à votre maître, et vous me prenez pour un esprit qui revient.

La dame Lieou, ayant entendu le bruit qu'on venait de faire, sort promptement pour voir de quoi il s'agissait. Le bon vieillard s'avance, et la salue d'une manière fort civile.

- Madame, lui dit-il, vous n'avez pas sans doute oublié le vieillard de Hou-tcheou qui vendait du gingembre, appelé Liu ? C'est moi-même, et je conserve toujours le souvenir du repas que me donna votre mari, et du présent qu'il me fit d'une pièce de taffetas blanc. Au sortir de votre maison, je retournai à Hou-tcheou. Il y a un an et demi que mon petit commerce me retient en 


\section{Contes chinois}

divers endroits. Je suis venu faire un tour dans votre noble ville, et j'ai apporté quelques bagatelles de mon pays, que je prends la liberté de vous offrir. Je ne comprends pas ce qui a pu porter vos gens à me prendre ridiculement pour un esprit revenu de l'autre monde.

Un des domestiques qui était à un coin de la salle se mit aussitôt à crier :

- Madame, gardez-vous bien de l'écouter ; certainement il sait que vous travaillez à tirer notre maître de prison, et il est venu sous un corps fantastique pour embrouiller son affaire et achever de le perdre.

La dame Lieou fit taire ce valet, et adressant la parole à l'étranger :

- A ce que je vois, lui dit-elle, et à la manière dont vous me parlez, je suis persuadée que vous n'êtes point un revenant ; mais sachez que mon mari a bien souffert., et qu'il souffre beaucoup à votre sujet.

Le bon homme Liu, consterné de cette réponse :

- Hé ! comment est-il possible, dit-il, que contre mon gré j'aie pu faire le moindre tort à un si honnête homme?

Alors la dame Lieou lui exposa en détail tout ce qu'avait fait le batelier Tcheou-se. 


\section{Contes chinois}

- Il a conduit, lui dit-elle, sur sa barque un corps mort jusqu'auprès de la porte de notre maison ; il a produit le panier et la pièce de taffetas que nous vous donnâmes, et que, disait-il, vous lui aviez laissés en mourant, pour servir de preuve que mon mari vous avait tué. A force d'argent nous gagnâmes ce batelier, afin qu'il cachât ce meurtre, et qu'il aidât à transporter le mort et à I'enterrer. Un an après, Hou est allé déférer son maître au tribunal. La question à laquelle on a appliqué mon mari l'a contraint de tout avouer ; en conséquence on l'a jeté dans une prison, où il languit depuis six mois.

A ce récit, Liu se frappant rudement la poitrine :

- Ah ! madame, s'écria-t-il, j'ai le cœur saisi de la plus vive douleur ! Se peut-il trouver sous le ciel un homme capable d'une action si noire ? Quand je vous eus quitté, I'année dernière, j'allai droit à la barque pour passer la rivière. Le batelier, vouant la pièce de taffetas blanc que je tenais, demanda de qui je l'avais reçue. Moi, qui n'avais garde de pénétrer son mauvais dessein, je lui avouai ingénûment qu'ayant été frappé par votre mari, j'avais perdu pendant quelque temps la connaissance ; qu'ensuite il m'avait régalé et m'avait fait présent de cette pièce de taffetas. Il me pria de la lui vendre; ce que je fis. Il demanda pareillement mon panier de bambou, et je le lui abandonnai pour le paiement de mon passage sur sa barque. Aurait-on pu 


\section{Contes chinois}

s'imaginer qu'il ne tirait tout cela de moi que pour tramer la plus horrible méchanceté ?

- Mon bon ami, reprit la dame Lieou, à I'heure que je vous parle, si vous n'étiez pas venu, je n aurais pas pu m'assurer que l'accusation faite contre mon mari fût une calomnie. Mais où a-t-on pu prendre ce corps mort qu'on disait être le vôtre ?

Liu avant rêvé un moment :

- Je suis au fait, dit-il ; lorsque j'étais sur la barque, et que je racontais mon histoire au batelier, je vis un corps mort flotter sur le bord de la rivière. Je le considérais attentivement et je ne doutais point que ce ne fût le corps d'une personne qui s'était noyée par imprudence. Aurait-on pu croire que ce batelier eût pu former un dessein si diabolique ? C'est un monstre qui fait horreur. Mais, madame, il n'y a point de temps à perdre ; recevez, je vous prie, ce petit présent, et de ce pas allons ensemble à l'audience du mandarin ; je le convaincrai de la calomnie, et j'obtiendrai la liberté de votre mari : c'est ce qu'il est important de faire au plus tôt.

La dame Lieou reçut le présent, et fit servir à dîner au bon vieillard Liu.

Pendant ce temps-là elle dressa elle-même sa requête ; car, étant d'une famille de lettrés, elle écrivait avec élégance : après quoi ayant fait venir une chaise à porteurs, elle part 


\section{Contes chinois}

accompagnée de quelques esclaves, et suivie du bon vieillard elle se rend à l'hôtel du mandarin.

Aussitôt que ce magistrat parut sur son siège, l'un et l'autre s'écrièrent : « L'innocent est opprimé par la calomnie ! » et en même temps la dame présenta sa requête. Le mandarin, I'ayant lue, fit approcher la dame et lui fit diverses questions. Elle expliqua fort en détail tout ce qui avait causé la disgrace de son mari ; et elle finit par dire que ce jour-là même le vendeur de gingembre étant heureusement arrivé dans la ville, elle venait d'être convaincue de l'affreuse calomnie dont elle demandait justice dans sa requête.

Le mandarin l'ayant écoutée attentivement, fit approcher Liu à son tour, pour l'interroger. Celui-ci raconta le commencement et la fin de la dispute où il avait reçu quelques coups. Il expliqua de quelle manière il avait été engagé à vendre la pièce de taffetas, et satisfit entièrement par ses réponses à toutes les questions qui lui furent faites.

- Mais, répliqua le mandarin, n'auriez-vous pas été gagné à force d'argent par cette femme, pour venir rendre ici ce témoignage?

Liu, frappant du front contre terre, répondit aussitôt :

- Une pareille feinte n'est pas praticable : je suis un marchand de Hou-tcheou, qui fais mon commerce dans cette ville depuis plusieurs années ; j'y suis connu d'un grand nombre de personnes ; comment pourrais-je en imposer ? Si ce qu'on a dit sur ma mort était vrai, estce que, me sentant prêt à mourir, je n'aurais pas chargé 


\section{Contes chinois}

le batelier d'avertir quelqu'un de ma connaissance de me venir voir, pour lui donner la commission de demander justice ? Était-il naturel que je donnasse ce soin à un inconnu ? Mais, si j'étais effectivement mort, est-ce que je n'ai point à Hou-tcheou de proche parent, qui, me voyant si longtemps absent, aurait pris sûrement le parti de venir ici s'informer de mes nouvelles ? Et si j'eusse été tué, comme on le dit, aurait-il manqué à porter son accusation à votre tribunal ? Comment donc est-il arrivé que, durant une année entière, personne n'ait paru, et qu'au lieu d'un de mes parens, ce soit un esclave qui se porte pour accusateur de son maître ? Ce n'est que d'aujourd'hui que je suis de retour en cette ville ; ainsi je n'ai pu être instruit plus tôt d'une calomnie si noire. Au reste, quoique je n'aie contribué en rien au malheur de cet infortuné lettré, néanmoins comme c'est à mon occasion qu'il souffre, il ne m'a pas été possible de voir opprimer son innocence, et c'est là l'unique motif qui m'a conduit à vos pieds. Ordonnez, je vous prie, qu'on fasse des perquisitions sur ce qui me regarde ; rien n'est plus aisé.

- Puisque vous êtes connu ici de plusieurs personnes, reprit le mandarin, nommez quelqu'un que je puisse interroger :

Liu en indiqua jusqu'à dix. Le mandarin prit le nom de chacun d'eux ; mais il se fixa aux quatre derniers, qu'il envoya chercher. 


\section{Contes chinois}

Quand ils entrèrent dans la salle d'audience, on remarqua que, dès qu'ils aperçurent le vieillard Liu, ils se dirent l'un à I'autre :

- Hé ! voilà notre ancien ami Liu de la ville de Houtcheou ; il n'est donc pas mort, comme on le publiait.

Le mandarin les fit approcher de plus près, pour mieux le reconnaître.

- Nous aurait-on fasciné les yeux, ajoutèrent-ils ? Non, c'est lui-même. C'est ce vendeur de gingembre qu'on disait avoir été tué par le lettré Wang.

Le mandarin commença à démêler la vérité, et se détermina à prendre juridiquement leur déposition. Après quoi il leur ordonna de se retirer, en leur enjoignant, sous des peines sévères, de ne point parler au-dehors de ce qu'ils venaient de voir. Ils promirent d'obéir, et sortirent de l'audience.

Le mandarin donna ordre aussitôt à quelques-uns de ses officiers de s'informer secrètement où demeurait le batelier Tcheou-se, et de l'amuser par de belles espérances afin de l'engager adroitement à se rendre au tribunal, sans qu'il pût avoir le moindre soupçon de l'affaire dont il s'agissait. Quant à Hou, qui avait intenté I'accusation calomnieuse, comme il avait une caution, il était aisé à trouver. L'ordre portait qu'on les amenât l'un et I'autre à l'audience dès I'après-midi. Les officiers répondirent par un cri, qui marquait leur prompte obéissance, et ils se partagèrent sur-le-champ dans les différens quartiers de la ville. 


\section{Contes chinois}

Cependant la dame Lieou, qui avait ordre de se trouver avec le vieux Liu à la même audience, se rendit à la prison, où elle informa son mari de tout ce qui venait d'arriver. Ce récit le transporta de joie. On eût dit qu'on venait de lui répandre sur la tête l'essence la plus spiritueuse, ou que la plus douce rosée était tombée dans son cœur. Dès ce moment il ne sentit plus de mal.

- Je n'étais courroucé, dit-il, que contre un vil esclave ; je le regardais comme un monstre, et je ne croyais pas qu'il pût se trouver un homme plus méchant. Mais la méchanceté du batelier est encore plus noire. Peut-on pousser la scélératesse à un tel excès ? Si ce bon vieillard n'était venu lui-même, je n'aurais jamais bien su que je mourais pour un crime réellement supposé. $A$ la fin la vérité se manifeste. 


\section{Contes chinois}

\section{LA CALOMNIE DÉMASQUÉE. CHAPITRE II.}

On commence à voir le cormoran, lorsqu'il quitte la neige sous laquelle il était caché et qu'il s'envole dans les airs.

Le perroquet se fait remarquer quand il fait entendre sa voix du milieu des saules qui lui servent de retraite.

La dame Lieou ne manqua pas de se trouver à l'audience avec le vieux Liu, qu'elle avait bien régalé dans sa maison. On y avait conduit adroitement Tcheou-se, lequel, après avoir renoncé à sa barque, avait ouvert une boutique, et était devenu marchand de toiles. Les officiers du tribunal lui avaient persuadé que leur maître voulait faire une bonne emplette : aussi entra-t-il dans la salle d'audience d'un air fort satisfait. Cependant la justice du ciel était sur le point d'éclater.

Lors donc qu'il s'y attendait le moins, qu'il tournait çà et là la tête avec je ne sais quel air de confiance, il aperçoit le vieux Liu. A l'instant, par un mouvement d'esprit qu'il ne lui fut pas libre d'arrêter, ses deux oreilles devinrent rouges comme du sang. Le vieux Liu de son côté l'appelle à haute voix.

- Hé bien ! notre maître de barque, lui dit-il, comment vous êtes-vous porté depuis le jour que je vous vendis la pièce de taffetas blanc et le panier de bambou ? Le commerce a-t-il été heureux ?

A ces questions Tcheou-se baissait la tête, et ne répondait rien : mais son visage parut tout-à-coup comme un pied d'arbre qui sèche à I'heure même. On introduisit en même temps Hou. 


\section{Contes chinois}

Ce malheureux, après avoir trahi son maître, n'était plus retourné à la maison de Wang. Il logeait ailleurs, comme s'il eût cessé d'être esclave. Il était revenu ce jour-là dans sa ville natale pour voir ses parens. Les officiers du tribunal l'ayant rencontré fort à propos :

- Nous te cherchons, lui dirent-ils, c'est aujourd'hui que ton maître doit être jugé ; des parens de celui qu'il a tué pressent l'affaire, et l'on n'attend plus que toi qui as été son délateur, pour le condamner au supplice que mérite son crime.

Hou, ne se possédant pas de joie, suit les officiers, et va se mettre à genoux au pied du tribunal. Dès que le mandarin I'aperçut :

- Connais-tu cet homme-là, lui dit-il, en montrant du doigt le vieux Liu?

Hou, après l'avoir un peu envisagé, fut tout-à-coup interdit, et si troublé qu'il ne put dire une seule parole.

Le mandarin, voyant l'embarras et le trouble de ces deux scélérats, réfléchit pendant un moment, puis désignant de la main Hou :

- Chien d'esclave, lui dit-il, qu'est-ce donc que ton maître t'avait fait pour comploter sa ruine avec ce batelier, et inventer une si noire calomnie ?

- Rien n'est plus vrai, répliqua l'esclave. Mon maître a tué un homme ; ce n'est point un fait que j'aie supposé. 


\section{Contes chinois}

- Quoi ! dit le mandarin, il s'opiniâtre à soutenir ce mensonge : qu'on prenne ce scélérat, et qu'on I'applique à une rude question jusqu'à ce qu'il avoue son crime.

Hou, au milieu de la torture, criait de toutes ses forces:

- Ah ! seigneur, si vous me reprochez d'avoir conçu dans le cœur une haine mortelle contre mon maître, et de m'être fait son accusateur, je conviens que je suis coupable : mais, dût-on me tuer, on ne me fera jamais avouer que j'aie comploté avec qui que ce soit, pour inventer ce qu'on appelle calomnie. Oui, mon maître, un tel jour ayant eu dispute avec Liu, le frappa rudement, en sorte qu'il tomba évanoui ; à l'instant il lui fit avaler je ne sais quelle liqueur qui le fit revenir : puis il lui servit à manger, et lui fit présent d'une pièce de taffetas blanc. Liu alla de-là à la rivière pour la passer. Cette nuit-là même, vers la seconde veille, le batelier Tcheouse conduisit sur sa barque jusqu'à notre porte un corps mort ; et pour marque que c'était celui de Liu, il montra la pièce de taffetas blanc et le panier de bambou. Il n'y eut aucun des domestiques qui ne crût la chose véritable. L'argent et les bijoux que mon maître donna au batelier lui fermèrent la bouche, et il promit de cacher cette mort. Je fus un de ceux qui aidèrent à enterrer le cadavre. Dans la suite mon maître m'ayant fort maltraité, je formai le dessein de me venger, et je I'accusai à votre tribunal. Quant à cet homme mort, je 


\section{Contes chinois}

jure que je n'en ai aucune connaissance ; et même, si je n'avais pas vu aujourd'hui ici le vieux Liu, je ne me serais jamais imaginé qu'on calomniât mon maître, en le faisant l'auteur de cette mort. Maintenant quel est ce cadavre, et d'où vient-il ; c'est ce que j'ignore. Il n'y a que ce batelier qui puisse en rendre compte.

Cette déposition ayant été reçue du mandarin, il fit approcher Tcheou-se, afin de l'interroger à son tour. Celui-ci prenait divers détours pour déguiser son crime. Mais Liu, qui était présent, découvrait aussitôt sa fourberie. Le mandarin le fit mettre à la question, et lui arracha promptement son aveu.

- Je déclare, dit-il, que l'année dernière, à tel mois et à tel jour, Liu, étant venu me demander le passage sur sa barque, tenait à la main une pièce de taffetas blanc. Je lui demandai, par hasard, qui lui avait fait ce présent. Il me raconta toute son histoire. Au même temps il parut sur le rivage un corps mort, que le courant y avait jeté. Il me vint dans l'esprit de m'en servir pour tromper Wang. C'est ce qui me fit acheter la pièce de taffetas et le panier de bambou. Liu étant débarqué, je tirai de l'eau le cadavre : je le mis dans ma barque, et le conduisis à la porte de Wang. Contre toute apparence il crut ce que je lui rapportai de la mort de Liu, et me donna une bonne somme pour ne la pas divulguer. J'allai avec quelques-uns de ses domestiques enterrer le cadavre, qu'ils s'imaginaient, sur parole, être le corps du vieux Liu. Il n'y a rien que de vrai dans l'aveu que je 


\section{Contes chinois}

fais, et je consens à tout souffrir, s'il y a la moindre particularité qui soit fausse.

- Tout cela, dit le mandarin, s'accorde avec ce que je sais déjà. Il n'y a qu'un article embarrassant, et où je ne vois pas clair. Est-il possible qu'à point nommé il se trouvât sur le rivage un corps mort ? De plus, est-il croyable que ce corps fût ressemblant à celui du vieux Liu ? Sans doute c'est un homme que tu as tué ailleurs, et ton dessein a été de faire passer Wang pour l'auteur de ce meurtre.

- Ah ! seigneur, s'écria Tcheou-se, si j'avais songé à tuer quelqu'un, n'aurais-je pas tué Liu plutôt que tout autre ? Ayant vu un cadavre flotter sur l'eau, je crus qu'il me serait aisé de m'en servir pour tromper Wang ; et c'est ce qui me fit acheter de Liu et le taffetas et le panier. Ce qui me persuada que je pourrais y réussir, c'est que je connaissais Wang pour un homme simple et crédule ; que je savais d'ailleurs qu'il n'avait vu Liu que cette fois-là ; encore était-ce pendant la nuit, et à la faveur d'une lampe. J'étais muni de la pièce de taffetas blanc et du panier de bambou, ce qui devait lui rappeler aussitôt l'idée du vendeur de gingembre. Voilà ce qui me fit croire que ma ruse pourrait réussir, et qu'il donnerait dans le piège que je lui tendais. Quant au corps mort, je jure que je ne sais qui il est. Je me doute que c'est un homme à qui le pied a manqué, et qui, 


\section{Contes chinois}

étant tombé dans la rivière, s'est noyé. Mais je n'ose rien assurer sur cela de positif.

Pour lors le vieux Liu se mettant à genoux :

- Pour moi, dit-il, j'assurerai bien qu'au moment où je passais la rivière sur sa barque, il parut un corps mort qui flottait sur l'eau. Son témoignage est très véritable.

Le mandarin reçut et mit par écrit et en ordre ces dépositions.

Tcheou-se, fondant en larmes, s'écria aussitôt :

- Ayez pitié, seigneur, de ce pauvre malheureux qui est à vos pieds : je n'avais d'autre vue que d'escroquer, par cet artifice, de l'argent à ce lettré, et non pas de nuire à sa personne. Ainsi, modérez le châtiment, je vous en conjure.

Le mandarin élevant la voix :

- Quoi, scélérat que tu es, tu oses demander grace, après que ta passion pour le bien d'autrui vient de mettre un homme à deux doigts de sa ruine. Ce tour-là n'est pas ton coup d'essai. Il y a de l'apparence que tu en as déjà fait périr bien d'autres par de semblables artifices. Je dois délivrer ma ville d'une si dangereuse peste.

A l'égard de Hou, c'est un esclave dénaturé, qui, oubliant les bienfaits qu'il a reçus de son maître, a conjuré sa perte. Il mérite d'être sévèrement puni.

En même temps il ordonna aux exécuteurs de justice de prendre ces deux fripons, et de les étendre par terre ; de donner à Hou 


\section{Contes chinois}

quarante coups de bâton, et de frapper Tcheou-se jusqu'à ce qu'il expirât sous les coups.

On ne savait pas que Hou sortait de maladie, et qu'ainsi il n'était guère en état de supporter ce châtiment. Mais la justice du ciel ne voulait plus souffrir cet esclave infidèle. Il expira sur le pavé de l'audience avant qu'on eût achevé de lui donner les quarante coups. Tcheou-se ne mourut sous le bâton qu'après en avoir reçu soixante-dix.

Après cette expédition, le mandarin fit tirer Wang de prison, et, en pleine audience, il le déclara innocent, et lui rendit la liberté. De plus, il ordonna que toutes les pièces de toile qui étaient dans la boutique de Tcheou-se, et qui avaient été achetées de l'argent de Wang, lui seraient livrées. Ce fonds de boutique montait bien à cent taëls.

- Selon le cours de la justice, dit le mandarin, tout cela devrait être confisqué : mais, comme Wang est un lettré qui a beaucoup souffert, j'ai compassion du pitoyable état où il a été réduit ; que tout ce qui se trouvera chez le voleur retourne à celui qui a été volé.

Ce fut un trait de bonté de la part du mandarin.

On alla aussi, selon ses ordres, déterrer le corps mort, et l'on remarqua qu'il avait encore les ongles des mains remplis de sable ; ce qui prouvait qu'étant tombé dans la rivière près du bord, il s'était noyé, en tâchant de grimper sur le rivage. Comme aucun de ses parens ne le réclamait, le mandarin ordonna aux officiers de l'ensevelir dans la sépulture publique des pauvres. 


\section{Contes chinois}

Wang, sa femme, et le vieux Liu, après avoir remercié humblement le mandarin, se retirèrent dans leur maison, où ils firent à ce bon vieillard, qui s'était si fort employé à détruire la calomnie, toutes les caresses et toutes les amitiés qu'on peut attendre de la plus sincère reconnaissance.

Depuis ce temps-là, Wang apprit à modérer sa vivacité naturelle, et à dompter son humeur impétueuse. S'il rencontrait un pauvre qui lui demandât quelque secours ou quelque service, il le recevait avec un air affable, et il tâchait de le soulager. Enfin il prit la résolution de travailler avec assiduité, afin de parvenir aux emplois, et de faire oublier l'humiliation où il s'était trouvé. Il était sans cesse occupé à lire, et n'avait nul rapport au-dehors. Il vécut de la sorte durant dix ans ; après quoi il fut élevé au degré de docteur.

On a raison de dire que les magistrats et les officiers de justice sont dans l'obligation de ne pas regarder la vie d'un homme comme celle d'une vile plante; et qu'ils sont bien coupables, quand ils apportent aussi peu d'application à l'examen d'un procès, que s'ils assistaient aux débats d'une troupe d'enfans qui se divertissent. Ils ne doivent rien précipiter. Par exemple, dans la cause de Wang, le point capital était de pénétrer les menées secrètes et les artifices du batelier. Si le vendeur de gingembre ne fût pas heureusement venu à la ville de Wen-tcheou, et si, par trop de précipitation, on n'eût pas attendu son arrivée, le domestique qui accusait son maître n'aurait pas cru l'avoir calomnié ; la femme ne se serait pas imaginé que son mari fût innocent du meurtre dont on l'accusait : I'accusé lui-même aurait ignoré qu'il était injustement 


\section{Contes chinois}

opprimé. A combien plus forte raison le juge l'aurait-il ignoré ! Comment deviner des choses cachées avec tant de soin ? Comment les débrouiller ? Que les magistrats bienfaisans, et qui, comme ils le doivent, ont des entrailles de père pour le peuple, apprennent par ce trait $d$ 'histoire de quelle manière ils doivent se conduire. 


\title{
Contes chinois
}

\author{
HISTOIRE \\ DE FAN-HI-TCHEOU.
}

Sous le règne de Kian-yan et dans la vingt-septième année du cycle courant, Fan-jouï leva l'étendard de la révolte dans la ville de Kian-tcheou ; profitant de la famine qui désolait le pays, il parvint à rassembler sous sa bannière près de cent mille hommes.

Dans le cours du printemps suivant, le mandarin Liu-tchoung fut nommé collecteur des douanes à Fou-tcheou. Il quitta le Kouang-si où il résidait et fut obligé de passer par Kian-tcheou pour se rendre dans cette ville. Un parti de rebelles arrêta son cortège, et sa fille à peine âgée de dix-sept ans tomba malheureusement entre leurs mains.

Le général Fan-jouï avait un fils nommé Fan-hi-tcheou, jeune homme de mérite qui venait d'atteindre sa vingt-cinquième année et n'avait jamais été marié. Frappé des charmes de cette belle captive et apprenant que sa famille était noble, il choisit un jour heureux, et après avoir reçu le consentement de ses parens, il l'épousa avec toutes les cérémonies d'usage.

Pendant I'hiver de la même année, l'empereur envoya un de ses propres enfans, le prince Han-kiun-wang, à la tête d'une grande armée, pour mettre fin à la rebellion.

En apprenant cette nouvelle, la fille du mandarin Leutchoung-ye dit à Fan-hi-tcheou : 


\section{Contes chinois}

- Je sais qu'une femme vertueuse ne peut avoir deux maris ; depuis que nous sommes unis par les lois, j'ai toujours rempli envers vous les devoirs d'obéissance et d'affection conjugales. Votre ville, presque sans défense, ne saurait résister longtemps à un ennemi victorieux. Comme fils d'un chef distingué des révoltés, vous n'éviterez pas les coups de la fortune. Souffrez donc que ce poignard termine mon existence, je ne veux plus vivre pour être témoin de la mort de mon époux.

Fan-hi-tcheou lui répondit :

- Ce n'est pas par inclination que je sers dans le parti des rebelles, vous avez été injustement séparée de vos nobles parens, n'aggravez pas mon crime et mes infortunes en vous arrachant la vie. L'armée impériale qui marche contre nous vient du nord, les soldats sont vos compatriotes, vous entendrez leur langage, vous trouverez peut-être dans leurs rangs votre famille et vos amis, vivez et consolez-vous.

- Soyez assuré, s'écria-t-elle, que votre femme ne se soumettra jamais aux embrassemens d'un autre époux ; je crains cependant la violence brutale des soldats, et j'ai résolu de mourir plutôt que d'être déshonorée.

- Vous ne me donnerez pas seule cette marque de votre attachement, dit Fan-hi-tcheou, et je vous 


\section{Contes chinois}

promets solennellement de n'avoir jamais d'autre femme que vous.

Le général impérial connaissait depuis longtemps le mandarin Liu-tchoung-ye, et, ayant fait halte avec son armée à Fou-theou, il lui offrit un commandement près de sa personne. Bientôt après ils s'avancèrent ensemble contre le principal corps des rebelles à Kian-tcheou. Après un siège de dix jours, la ville fut prise d'assaut. Fan-hi-tcheou disparut dans la confusion générale ; mais sa femme, la fille de Liu-tchoung-ye, effrayée de l'approche des vainqueurs, chercha à s'ôter la vie dans l'appartement intérieur. Son père, qui entra un des premiers dans la ville, arriva assez tôt pour prévenir cette triste catastrophe ; ses tendres soins la rappelèrent peu à peu à la vie. La reconnaissance du père et de la fille fut entremêlée de joie et de reproches.

Après la prise de Kian-tcheou, la révolte fut aisément apaisée et la tranquillité rétablie dans toute la province.

Le mandarin Liu-tchoung-ye pensa que le moment était favorable pour proposer un second mariage à sa fille ; mais aucune prière ne put I'y déterminer.

- Quoi, dit-il irrité, vous regretterez toujours un rebelle dont je vous ai délivrée?

- Hélas ! répondit-elle, quoique vous I'appeliez rebelle, c'est un homme intègre et vertueux. Après avoir eu le malheur d'être séparée de vous, je tombai entre ses mains ; parmi les révoltés, il était distingué par son indulgence et ses bienfaits, le ciel qui le protège 


\section{Contes chinois}

permettra que je le revoie. Je vous supplie, mon père, ne me pressez plus de contracter un second mariage, souffrez qu'en fille soumise je reste avec mes parens.

Liu-chi demeura dans la maison de son père pendant plusieurs années.

Dans la vingt-neuvième année du cycle, Liu-tchoung-ye fut élevé au rang de commandant en chef à Foung-tcheou. Quelque temps après qu'il fut établi dans cette ville, un officier supérieur, nommé Kiu, arriva de Kouang-tcheou avec des dépêches du gouvernement. Lei-tchoung-ye reçut cet hôte avec beaucoup d'hospitalité ; et, après le départ de celui-ci, Liu-chi demanda au mandarin quel était cet étranger ?

- C'est un officier, dit-il, qui apportait des dépêches du gouvernement.

-Mais sa voix et sa démarche, ajouta-t-elle, m'ont beaucoup rappelé le fils de Fan-jouï, le révolté de Kiantcheou.

-Ne vous trompez pas, lui dit son père, cet officier se nomme Kiu. Quel rapport peut exister entre lui et le rebelle de Kian-tcheou?

Liu-chi n'ayant rien à répondre se retira en silence.

Une demi-année s'était écoulée, lorsque l'officier Kiu arriva de nouveau pour les affaires publiques. Liu-tchoung-ye le reçut de la même manière qu'auparavant. Liu-chi, apprenant son retour, se plaça près d'une crevasse qui se trouvait dans le mur, et par laquelle on apercevait ce qui se passait dans l'appartement 


\section{Contes chinois}

voisin. Sitôt qu'elle eût vu l'étranger, elle demeura persuadée que c'était Fan-hi-tcheou, son premier mari. Elle en fit de suite part à son père, qui, après avoir dîné et bu quelques tasses avec l'étranger, I'engagea à lui raconter sa véritable histoire.

Kiu rougit, et dit :

- Je dois confesser que mon véritable nom est Fan, et que mon père, Fan-jouï, était un des généraux des révoltés ; j'étais moi-même au milieu d'eux ; les rebelles furent complètement défaits par l'armée impériale, notre ville fut soumise à ces vainqueurs. Je m'échappai, et sachant que j'étais condamné à cause de ma famille révoltée, je pris le nom de Kiu, afin d'éviter les poursuites. Quelque temps après, je m'engageai dans l'armée impériale à Yo-tchoung, et nous reçûmes I'ordre de marcher contre les rebelles du Sud : nous livrâmes plusieurs combats ; j'étais au premier rang, où je tâchai de me distinguer ; mes efforts fixèrent l'attention de notre général, et lorsque la province fut rentrée dans le calme et l'armée licenciée, il voulut bien récompenser mes services en me nommant commandant en second à Ho-tcheou. De là je fus élevé au grade de commandant en chef que je quittai ensuite pour la place que j'occupe sous le gouverneur de Kouang-tcheou.

- Je vous demanderai encore le nom de votre femme, et pourquoi vous n'avez pas formé de nouveaux nœuds? 


\section{Contes chinois}

- Hélas ! répondit-il, en pleurant, je fus marié à la fille d'un mandarin, qui tomba entre nos mains, lorsque j'étais dans le camp des rebelles ; mais la même année, lorsque nos troupes furent défaites et notre ville prise d'assaut, nous fûmes malheureusement séparés : dans I'espérance de nous retrouver, nous avons mutuellement fait serment de nous conserver l'un à I'autre.

J'ai depuis retrouvé ma vieille mère à Sin-tcheou ; au lieu de penser à un nouveau mariage, j'ai concentré sur elle mes soins et ma tendresse, et....

Ici ses paroles furent interrompues par ses pleurs.

Liu-tchoung-ye répandit des larmes d'attendrissement à cette heureuse découverte, et courant à l'appartement intérieur, il eut le bonheur de réunir deux époux qui avaient été si longtemps séparés. Après quelques jours Fan-hi-tcheou fut obligé de retourner à Kuang-tcheou : mais il revint chez son beau-père aussitôt que le temps de son service fut expiré ; le gouvernement de Liu-tchoung-ye étant terminé à la même époque, ils fixèrent leur résidence à Sin-tcheou, où Liu-tchoungye fut nommé juge et Fan-hi-tcheou, collecteur des douanes.

\section{MORALE.}

Fan-hi-tcheou était coupable en se révoltant, et Liu-chi en l'épousant, mais la nécessité et l'amour peuvent leur servir d'excuse. Le ciel a voulu récompenser leur fidélité en les réunissant de la manière extraordinaire que nous venons de voir. 


\section{Contes chinois}

FIN DU DEUXIÈME VOLUME.

(a) 


\section{Contes chinois}

\section{CONHES \\ Clyinois,}

TRADUITS

PAR MM. DAVIs, ThOMS, LE P. D'BXTRECOIIEs, etc.

ET I'URLIÉS

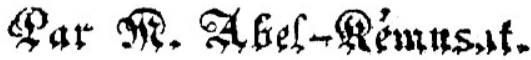

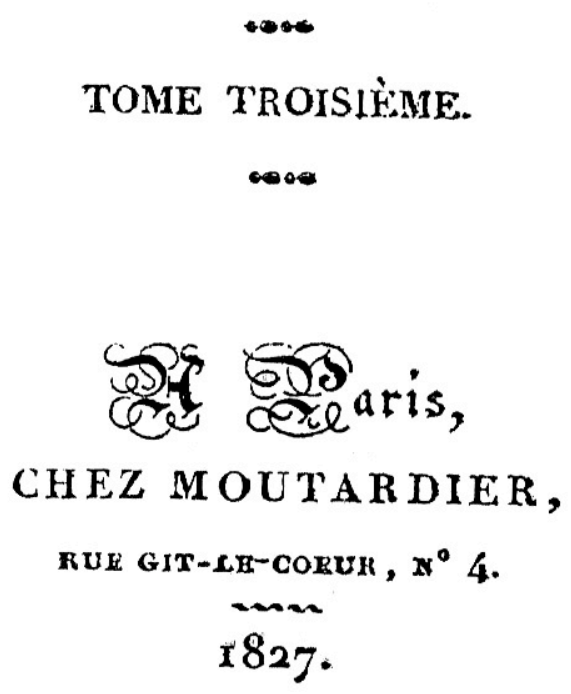


Contes chinois

270 


\section{Contes chinois}

\section{SAN-IU-LEOU}

\section{ou LES TROIS ÉTAGES CONSACRÉS}

\section{CHAPITRE I}

@

Le jardin et le pavillon sont vendus avant d'être achevés. Les acheteurs avides désirent posséder la propriété entière.

Ma maison avant changé de propriétaire, appartient maintenant à un homme riche.

Je vais donc, prenant sous mon bras mon Kin ${ }^{1}$ et mes livres me retirer dans un autre village.

Je me suis défait des appartemens superbes que j'avais bâtis pour moi-même,

« Parce que je n'ai point voulu ruiner ma postérité, en lui léguant un aussi vaste édifice.

«Dans une période de cent ans, n'aurait-il pas fallu que cette maison changeât de maître ?

«Ne vaut-il pas mieux la vendre tandis qu'elle est neuve que lorsqu'elle sera vieille?

«Les pins des bambous et les fleurs de meï ${ }^{2}$ sont compris dans le même marché.

« Mais mon Kiu, mes livres, mes chiens et mes poulets m'accompagneront.

${ }^{1}$ Instrument de musique à cordes. C'est une espère de violon, mais dont les cordes se pincent. Les aveugles qui sont à la Chine en beaucoup plus grand nombre en proportion qu'en France, jouent d'ordinaire de cet instrument dans les rues pour gagner leur vie.

2 La fleur Meï est célèbre dans toutes les compositions chinoises ; c'est celle d'une espèce d'amandier. (Amygdalus nana.) 


\section{Contes chinois}

« L'acquéreur fixera le prix qu'il voudra pour les lambeaux de vieux poèmes ${ }^{1}$ accrochés aux murailles.

« Je ne lui demanderai rien pour les haillons humides qui pendent à l'extérieur ${ }^{2}$.

«Si quelque jour, dans un moment de loisir, je viens lui faire une visite,

«L'ancien propriétaire sera honoré du titre d'hôte.

Les vers qui viennent d'être cités, ainsi que la stance régulière dont ils sont suivis furent composés par un personnage éminent qui, sous la dynastie des Ming, vendit sa maison et en bâtit une autre. Vendre sa maison, cependant, n'est pas une affaire peu embarrassante, et on ne saurait s'y décider sans regrets. Quel plaisir a donc pu trouver à cela I'homme qui a composé sur ce sujet des vers sur toutes les mesures?

Si vous désirez de connaître la nature de la propriété en ce monde, elle n'est hélas ! que transitoire. Il n'est point de montagne et de rivière qui ne subisse quelque changement dans l'espace de mille années ; quant à une maison, il ne se passe jamais cent ans sans qu'elle soit vendue. Si vous la laissez à vos fils et à vos petits-fils, ils la livreront à d'autres avec une valeur détériorée. Il vaut mieux chercher soi-même un acheteur avant qu'elle dépérisse, car ne la vendriez-vous pas même tout ce qu'elle vaut, vous laisserez encore après vous une réputation de libéralité. On dira :

${ }^{1}$ Il est d'usage, dans les maisons particulières, de suspendre aux murs des bandes de papier sur lesquelles sont écrites dss sentences morales ou des vers tirés des anciens livres. Le sens en est ordinairement très obscur.

2 Les Chinois, dans les temps pluvieux, font usage d'une espèce de surtout fait avec des feuilles, sur lequel la pluie glisse comme sur un toit couvert de chaume ; c'est à cette sorte de vêtement que le texte fait allusion. 


\section{Contes chinois}

- Il savait combien une maison est coûteuse, et il préféra de s'en défaire même à bas prix ; il conféra une faveur, mais il ne fut pas pris pour dupe.

Si c'est au contraire par vos enfans ou vos petits-enfans qu'elle est vendue à bon marché, mille propos sont tenus sur votre compte ; on s'écrie

- Il a gaspillé le patrimoine de ses pères ; c'est un homme sans mœurs, il a démembré ce que ses pères aimaient, c'est un méchant : il ne sait point avec quelle difficulté on établit une fortune, c'est un insensé ! Ces trois mauvaises qualités sont ce que lui ont légué principalement ses ancêtres, fondateurs de leur famille et de leur opulence !

Ah ! ne vaut-il pas mieux n'avoir pas hérité seulement d'une brique ! Quoique I'homme qui n'a pas assez de terre pour y piquer une alêne soit cause que ses enfans se mettront à la poursuite de la fortune avec des mains avides, ceux-ci du moins auront la gloire de n'avoir pas hérité d'un pouce de terrain où ils pussent mettre le pied lorsqu'ils ont commencé à courir après elle. Il faut donc que les hommes qui ont des enfans et des petits-enfans, en approchant du terme de leurs jours, tournent leur tête en arrière, et jettent un coup-d'œil sur ceux qui viennent après eux. Si leur conduite leur paraît mal ordonnée, ils ne doivent pas hésiter à se défaire sur-le-champ de leurs propriétés ; ils les empêcheront ainsi de devenir les fils prodigues d'un père frugal, et d'attirer sur eux la censure de leurs semblables. 


\section{Contes chinois}

Depuis les temps anciens jusqu'à nos jours, il n'y a eu que deux hommes qui se soient particulièrement distingués par cette excellence de raison. L'un avait nom Thang-yeou, l'autre s'appelait Iu-chin ${ }^{1}$. Voyant qu'ils n'avaient que des fils dégénérés, et qu'après eux leurs propriétés seraient livrées à des étrangers dans un état de délabrement, ils jugèrent qu'il était préférable d'en disposer eux-mêmes. Il existe encore deux vers d'une ancienne ode, qui font allusion à cela :

Donnez des armes splendides pour orner le flanc du soldat.

Donnez du fard et des mouches à la belle fiancée.

S'ils en laissaient, pensèrent-ils, la disposition à leurs enfans, il était très probable que ceux-ci ne trouveraient pas par la suite quelqu'un qui en voulût pour rien. Ils se querelleraient d'abord inévitablement, et ils finiraient ensuite par se battre. Non seulement il ne resterait à leurs fils et aux femmes de leurs fils aucune demeure assurée, mais leurs propres tombeaux ne seraient pas à l'abri de leurs débats. Si tel peut être le cas pour ceux qui possèdent l'empire, que n'ont pas à craindre les hommes de condition ordinaire?

Je vais maintenant parler d'un personnage éminent par son bon sens, et d'un autre qui en était dépourvu, afin que l'un et l'autre puissent servir d'exemple au monde. Le patrimoine de ces deux hommes n'équivalait pas à une tuile du palais de Thang-

1 Ce sont les noms de deux empereurs fameux, huitième et neuvième successeurs de Fo-hi, fondateur de la monarchie. Le premier, après avoir régné au-delà de soixante-dix ans, céda le trône au second, ou du mois, l'associa à l'empire. Ce dernier fit aussi choix d'un successeur hors de sa famille.

Les deux empereurs célèbres dans I'histoire chinoise pour s'être choisis des successeurs hors de la ligne que l'ordre de la naissance appelait au trône, sont Yao et Chun. 


\section{Contes chinois}

yeou, ou à une brique des murailles de Iu-chin. Mais pourquoi, en parlant de gens d'une condition aussi inférieure, fais-je usage d'une comparaison aussi élevée ? La raison en est que l'un des deux se nommait Thang et l'autre Iu. On prétendait qu'ils descendaient de Thang-yeou et de Iu-chin, et qu'ils en avaient tiré leurs noms comme étant issus d'eux en ligne directe. Ayant à peindre les descendans, je fais donc un emprunt aux ancêtres, pour rendre ce qui est dû à la source originelle.

L'homme de bon sens avait toutes les dispositions de son grand-aïeul ; l'autre ne participait que très peu du caractère de sa famille. Leurs dispositions étaient aussi divergentes que les cieux le sont de l'abîme. On va voir combien différaient entre elles deux branches sorties du même tronc.

Sous le règne de Kia-tsing ${ }^{1}$, de la dynastie des Ming, dans la province de Sse-tchouan, le fou 2 de Tching-tou et le hian de Tching-tou, vivait un homme opulent, et dans un état croissant de prospérité. Son nom de famille était Thang, et son nom propre Yo-tchouan. Il possédait une immense étendue de terre. Chaque fois qu'il lui rentrait de l'argent, il ne se plaisait qu'à acquérir du terrain et à acheter des champs nouveaux ; mais il ne faisait point bâtir et n'achetait même qu'en petit nombre les meubles qui sont de l'usage le plus ordinaire ; quant aux vêtemens et aux mets recherchés, en faisait peu de cas. Son inclination le portait à amasser de l'argent par tous les moyens.

\footnotetext{
${ }^{1}$ Kia-tsing n'est point le nom d'un empereur, mais celui du règne de l'empereur Chi-tsoung de la dynastie des Ming. Ce règne a commencé en 1522 et a fini en 1566 .

2 Le fou est une division de la province ou Seng ; et le hian est une subdivision du fou.
} 


\section{Contes chinois}

A peine avait-il acquis des propriétés nouvelles, que de nouveaux profits lui arrivaient ; ils s'accroissaient journellement comme la lune, lorsqu'elle marche vers son plein. Les maisons, les meubles, pensait-il, non seulement ne donnent aucun profit à leur maître, mais encore il doit craindre que le dieu du feu ${ }^{1}$ ne les détruise, et qu'ils ne soient ainsi réduits à rien en un moment. Si une famille est pourvue de vêtemens précieux, il survient aussitôt des importuns pour en emprunter ; si sa table est abondamment servie, une foule de gens cherchent à s'y asseoir sous le prétexte d'avoir des liaisons avec elle; enfin il n'y a rien de tel que de se contenter de ce qu'il y a de plus grossier en tout genre, car on évite ainsi les emprunteurs et les mendians.

Il se nourrissait de ces idées, et il n'aurait pas employé un condorin ou un cache 2 , à acheter autre chose que des immeubles. Cependant ce n'était point assez pour lui que de satisfaire sa lésinerie, il voulait aussi dérober un grand nom. Il disait qu'il était issu de l'empereur Than-yeou, et que ses ancêtres avaient été très célèbres, qu'ils logeaient dans une maison couverte de chaume, et ayant des escaliers de terre ; qu'ils se nourrissaient de brouet et buvaient du vin de Youan ; qu'ils se servaient de jarres et de vases d'argile, et qu'ils portaient des habits de toile et de peaux de bêtes fauves. Le père étant si économe, le fils ne pouvait que se conformer à ses

\footnotetext{
${ }^{1}$ Hoei-lo, I'Esprit que les Chinois supposent présider au feu.

${ }^{2}$ Ce sont les noms que les Européens donnent au feu et au li. Le premier est la centième partie du liang ou once d'argent, et le second est la dixième partie du premier, c'est-à-dire la millième partie du liang.

La valeur du liang, suivant la règle de change établie à Canton, est d'environ dix francs.
} 


\section{Contes chinois}

dispositions. Ses voisins, témoins de sa parcimonie, le critiquaient en arrière de lui. Ils citaient le proverbe qui dit : « Le père avare a un fils prodigue. Certainement, disaient-ils, son successeur renversera tout ce qu'il aura élevé. 》Cependant, contre leur attente, le fils imita le père. Dès ses plus jeunes ans, il s'adonna à l'étude, cherchant à s'avancer par tous les moyens, et il devint Sieou-thsaï ${ }^{1}$ titulaire. Frugal dans son boire et dans son manger, ne portant que les vêtemens les plus simples, il ne cherchait de même que les amusemens les moins coûteux. Dans ses désirs, il ne différait de ceux de son père qu'en ce qui concernait les maisons : sur ce point l'économie ne lui plaisait pas. La maison qu'il habitait ne lui semblait pas égaler la plus obscure dépendance de celle d'un homme riche, et il en était tout-à-fait honteux. Il aurait voulu bâtir, mais il craignait de commencer, de peur que les moyens ne lui manquassent. Il avait entendu dire : «Qu'il vaut mieux acheter une vieille maison que d'en bâtir une nouvelle. » Consultant donc son père, il lui dit :

\footnotetext{
${ }^{1}$ C'est le titre littéraire le moins élevé. Au-dessus du Sieou-Thsaï est le Kiujin, et au-dessus de celui-ci est le Tsin-sse. Dans l'examen qui est toujours fait par l'empereur lui-même, les trois premiers parmi les Tsin-sse sont appelés Tchouan-youan, Than-hoa et Pang-yan.

Le titre de Sieou-thsaï correspond chez nous à celui de bachelier, le titre de Kin-jin à celui de licencié, et le titre de Tsin-sse à celui de docteur.

Un magistrat du premier ordre, appelé Hio-youan, et dont les fonctions correspondent à celles de nos examinateurs, reçoit de l'empereur une commission dont la durée est de trois ans. Il se transporte dans la province qui lui a été assignée, et passe tour-à-tour dans les villes du premier rang, en faisant annoncer son arrivée un mois d'avance.

Les Sieou-thsaï et ceux qui aspirent à ce degré littéraire et qu'on nomme Toung-seng, ou déjà maîtres ès-arts, après avoir subi un ou plusieurs examens préliminaires auprès de leurs propres mandarins, se rendent au jour marqué dans la ville de leur ressort qui leur a été assignée par le Hio-youan ; et leur examen dure depuis le point du jour jusqu'à la nuit. Ces examens se renouvellent tous les trois ans, et les Sieou-thsaï ne sont dispensés de cette épreuve qu'après dix examens, c'est-à-dire après trente ans, à moins qu'ils ne soient dans certains cas d'exception.
} 


\section{Contes chinois}

- Si nous pouvons acheter une belle maison qui nous convienne, nous chercherons ensuite à acquérir un jardin, et nous y ferons bâtir une bibliothèque, telle que nous la désirons.

Yo-tchouan, qui aspirait à devenir un Foung-kiun ${ }^{1}$, ne voulut pas contrarier son fils, et sans y prendre garde, il dévia de ses principes. Il lui répondit :

- Il n'est pas nécessaire de nous presser ; il y a dans cette rue même une maison et un jardin qui nous conviendront. Elle n'est pas encore complètement bâtie ; mais le jour où elle sera achevée sera inévitablement celui où elle sera vendue ; ainsi donc, vous et moi devons attendre encore un peu.

Le fils répliqua :

- Quand les gens veulent vendre leurs maisons, ils n'en bâtissent point ; ceux qui les bâtissent n'ont pas intention de les vendre. Est-il probable qu'aussitôt que leur maison sera terminée, ils voudront s'en défaire?

Yo-tchouan dit :

- Où avez-vous pris ce raisonnement ? Sans doute I'homme qui possède dix mille pièces d'or peut faire élever une maison qui ne lui en coûtera que mille ; mais celui qui bâtit une maison dont la valeur est égale à celle des terres qu'il possède, peut être considéré comme un grand arbre sans racines que le premier vent

\footnotetext{
${ }^{1}$ C'est ainsi qu'ou appelle ceux qui ont des fils parvenus à un rang éminent.
} 


\section{Contes chinois}

doit inévitablement renverser. Combien mieux encore peut être appelé « arbre sans racines », cet homme-ci, qui, sans posséder cent arpens de terre, se met tout-àcoup à faire construire une maison qui a mille appartemens ? Certainement il n'attendra pas que le vent souffle, et il tombera de lui-même. Il ne peut y avoir aucun doute à cet égard.

Le fils reconnut la vérité de ces paroles, et de nouveau tomba d'accord sur ce que disait son père. Il se mit à la recherche des terres à vendre, et ne s'enquit plus des maisons. Seulement il désirait que le voisin eût bientôt fini la sienne, afin de l'acquérir et d'y mettre la dernière main, selon sa fantaisie. Les plans de I'homme riche réussirent; le résultat justifia ses discours. Il y a deux vers du Chi-king, qui sont applicables à ce cas :

A peine l'oiseau soigneux a-t-il achevé son nid, Qu'un autre survient et s'en empare.

L'homme qui faisait bâtir descendait de Chun-hoa. Son nom de famille était $\mathrm{Iu}$, son nom propre Hao, et son surnom Souchin. Il se plaisait à lire des ouvrages de poésie, mais il n'aspirait point à devenir lui-même un littérateur distingué. Par indolence de caractère, il avait de l'aversion pour tout emploi, et il n'était pas taillé pour être mandarin. Il n'avait donc jamais désiré d'acquérir de la renommée, et il se contentait de chanter et de boire. De tels goûts ne pouvaient le conduire qu'à la pauvreté.

Durant tout le cours de sa vie, il n'avait fait consister ses délices qu'à dessiner des jardins et qu'à bâtir des maisons de plaisance. Depuis le commencement de l'année jusqu'à la fin, il 


\section{Contes chinois}

ne se passait pas un jour sans qu'il ajoutât quelque chose à son ouvrage. Il souhaitait surtout que la maison qu'il élevait actuellement fût au-dessus du genre ordinaire, et que rien ne manquât à sa perfection. Il se disait : «Que d'autres possèdent de vastes champs et un grand nombre d'arpens de terre ; les plaisirs et les richesses qui les occupent n'auraient aucune influence sur moi ! » Il n'y avait que trois choses auxquelles il s'intéressât réellement, et qu'il était décidé à se procurer de la meilleure qualité : c'étaient la maison qu'il habitait, le lit dans lequel il se couchait et le cercueil où il devait reposer après sa mort. Entretenant ces idées dans son sein ${ }^{1}$, il se livrait à son ouvrage de terre et de bois ${ }^{2}$ avec une constance infatigable.

Le fils de Thang-yo-tchouan ayant attendu quelques années que cette bâtisse fût finie, vexé et furieux dans son cœur de ce qu'elle ne s'achevait pas, dit à son père :

- Qu'a produit notre longue attente ? La maison de cet homme n'est pas achevée, et son argent n'est pas épuisé ; il paraît d'après cela que c'est un homme qui a des moyens et des ressources ; il me semble donc plus incertain que jamais qu'il se décide à vendre sa maison.

Yo-tchouan lui répliqua :

- Plus la chose tarde, plus elle est certaine, et chaque jour la rend plus avantageuse pour nous. Ne vous

\footnotetext{
${ }^{1} \mathrm{M}$. Davis pense que chez les Chinois le ventre est le siége des idées; il se trompe. Les Chinois placent le siège des idées dans le cœur et non point dans le ventre ; ils ne font mention à cet égard du dernier que proverbialement.

2 Les maisons des Chinois sont presque toutes construites en terre; de-là vient qu'un briquetier s'appelle en chinois ni chouï tsiang, c'est-à-dire ouvrier en boue et en eau.
} 


\section{Contes chinois}

impatientez pas ; la véritable raison qui fait que cette maison ne se termine pas, c'est que I'homme qui la bâtit change toutes les minutes de plans, d'après de nouveaux caprices ; il détruit son ouvrage pour le recommencer sans cesse. Lorsqu'il approche de la perfection, il aspire à plus d'excellence encore ; de sorte que les altérations et les embellissemens qu'il fait chaque jour ne tournent qu'à notre seul avantage. Voulez-vous savoir pourquoi son argent n'est point entièrement épuisé ? C'est parce que les entrepreneurs et les usuriers, voyant qu'il bâtit à grands frais, lui prêtent leur crédit pour mieux s'emparer de sa fortune. Les journaliers eux-mêmes ne le pressent pas d'acquitter leurs salaires, parce qu'ils pensent que chaque jour de travail leur vaut un jour de plus de gages, et que s'ils le tourmentaient trop pour être payés, il suspendrait certainement leurs travaux pendant quelque temps, et qu'alors ils demeureraient sans ouvrage. Voilà pourquoi il lui reste encore de l'argent ; c'est ce qui s'appelle « prendre de la chair pour nourrir un ulcère ». Non, ce n'est point un homme qui ait des moyens et des ressources. Lorsqu'il arrivera à l'époque où le crédit lui manquera, les personnes qui ont son nom inscrit dans leurs livres le presseront inévitablement toutes à la fois, et commenceront à le maudire. D'abord il vendra ce qu'il possède de terre pour les satisfaire, et, comme cela ne suffira pas, il en viendra à penser à sa maison elle-même. Tant que ses 


\section{Contes chinois}

dettes ne surpasseront pas le montant de ce qu'il aura réalisé, il demandera un prix élevé pour sa maison, et il ne se décidera pas à la vendre à bon marché. Il faut donc attendre un peu plus tard, c'est-à-dire l'instant où ses dettes se seront accrues au point où, forcé de vendre sans différer, il se verra contraint d'accepter nos propres termes. Telle est la conduite qu'il nous faut tenir ; ainsi, allez, et ne vous inquiétez pas davantage à cet égard.

Le fils applaudit et acquiesça au discours de son père. Les dettes de Iu-sou-chin s'accrurent en effet d'année en année, et ses créanciers en vinrent à se rassembler chaque jour devant sa porte pour réclamer ce qui leur était dû ; il en était même parmi eux qui ne voulaient plus se retirer. La maison qu'il bâtissait ne put pas être achevée, et à la fin il fut obligé de chercher un acheteur.

Ceux qui veulent vendre des maisons se trouvent dans une position différente de celle des vendeurs de terres. Il faut nécessairement qu'ils cherchent un acheteur dans leur voisinage, parmi ceux qui ont des fondations contiguës ou des croisées opposées aux leurs. Si quelque acheteur éloigné se présente, il prendra nécessairement des renseignemens chez les voisins. Si ceux-ci lui disent un mot au désavantage de l'acquisition qu'il veut faire, il s'en dégoûte à l'instant. Il n'en est pas ainsi des champs, des coteaux, des viviers, situés au milieu même d'un désert ; le premier venu peut en tirer parti ; il est donc désirable de vendre sa maison à un voisin plutôt qu'à un autre. 


\section{Contes chinois}

Thang-yo-tchouan était un homme à argent ; on ne pouvait agir à son égard avec légèreté. Le propriétaire de la maison vint le trouver ; le père et le fils, quoique brûlant du désir d'être en possession de ce qu'il leur offrait, répondirent froidement « qu'ils n'en avaient pas besoin ». Ils eurent l'air ensuite de céder à ses supplications, et sortirent avec lui, mais ils ne jetèrent sur sa maison qu'un regard indifférent, et comme si elle leur déplaisait, ils dirent

« qu'elle était mal bâtie ; que les appartemens ne convenaient pas à des gens comme il faut, et que ses avenues contournées n'étaient bonnes qu'à faire perdre du temps. Les portes sculptées avec soin n'étaient pas assez fortes pour résister aux voleurs; les chambres se ressemblaient toutes ; la situation était humide et l'air épais ; il était peu surprenant qu'il ne trouvât pas à s'en défaire; les fleurs et les bambous ressemblaient à des plantations de mûriers ${ }^{1}$ et de chanvre ; il faudrait constamment servir du vin et des collations à tous les oisifs qui en feraient leur lieu de rendez-vous ; une telle maison n'était propre qu'à être convertie en un couvent de femmes ou de bonzes ${ }^{2}$; et si le nouveau propriétaire voulait faire construire dans l'intérieur des appartemens pour ses enfans, il ne saurait où en trouver la place.

\footnotetext{
${ }^{1}$ On ne cultive les mûriers à la Chine que pour l'éducation des vers à soie, et on ne les laisse en conséquence croître qu'à la hauteur d'un arbrisseau ordinaire.

${ }^{2}$ Les noms dans I'original sont An-thang et Sse-youan. Le premier s'applique aux résidences des religieuses, et le second à celles des religieux de la secte de Fo.
} 


\section{Contes chinois}

Iu-sou-chin avait, dès l'aurore de sa vie, mis à son ouvrage tout le sang de son cœur, et voyant maintenant que, loin d'obtenir l'approbation des autres, il n'en recevait que dédain et mépris, il en gémit au fond de l'ame. Cependant, comme il ne pouvait pas vendre sa maison à d'autres, il jugea qu'il valait mieux ne pas se quereller avec eux.

Tous ceux qui étaient présens conseillèrent à Yo-tchouan de ne pas être si difficile. Le prix qu'on lui demandait n'était pas trop élevé, et dût-il même mettre la maison en pièces pour la rebâtir après, il y trouverait encore son compte. Yo-tchouan et son fils se mirent donc à louer et à blâmer tour-à-tour, jusqu'à ce qu'ils eussent enfin obtenu une réduction excessive; de manière qu'ils payèrent tout au plus le cinquième de la valeur de leur acquisition.

Iu-sou-chin fut forcé d'en passer par où ils voulurent, et comme vendeur obligé, il fallut qu'il se soumît à tout. Les appartemens de réception, les pavillons, les viviers, tout fut compris dans l'acte de vente. Il y avait cependant quelques chambres dont il s'était occupé toute sa vie, et qu'il avait plus particulièrement fait arranger selon son goût ; quant à celles-là, il se refusa à les vendre ; il dit qu'il bâtirait un mur de séparation, qu'il ferait ouvrir une autre entrée, et qu'il prétendait les habiter jusqu'à sa mort.

Le fils voulait décidément le forcer à tout vendre, afin d'avoir la maison entière ; mais Yo-tchouan fit semblant d'entrer dans les sentimens des autres. Il dit en pinçant les lèvres, 


\section{Contes chinois}

- Il est maître de vendre et de ne pas vendre ; à quoi bon user de contrainte ? Il désire sans doute de conserver ce petit recoin ${ }^{1}$, afin de recouvrer par la suite sa propriété, lorsque sa fortune se sera améliorée. Elle retournera alors comme par le passé à son premier maître, et ce sera une bonne chose.

Ceux qui l'entendirent parler ainsi déclarèrent tous « que c'était là le discours d'un homme bienveillant ; » pouvaient-ils deviner que c'était le mépris seul qui lui faisait au contraire tenir ce langage ? Il avait en secret la certitude que jamais le vendeur n'aurait les moyens de rentrer dans sa propriété, et il lui en laissait la petite portion qu'il voulait conserver ; elle lui était inutile, et inévitablement le tout ne ferait un jour qu'une seule maison ; il n'y avait de différence que dans le plus tôt ou le plus tard. Ayant donc accédé aux désirs du vendeur, ils tombèrent d'accord en apparence. La maison fut séparée en deux parties, le nouveau propriétaire en eut les neuf dixièmes, et le reste demeura à I'ancien.

Il paraît que la portion qu'il conserva était dans le style des pagodes, et consistait en trois étages. A chaque étage était une tablette portant des inscriptions tracées par divers personnages éminens, qu'il pouvait tous nommer. Dans la pièce du rez-dechaussée étaient des lambris sculptés, des treillages, des sièges de bambou et des vases de fleurs ; c'était son appartement. Sur

\footnotetext{
${ }^{1}$ Dans I'original, il y a sian, qui veut dire littéralement un fragment. II existe une loi chinoise qui porte que si un homme, en vendant sa propriété, s'en réserve la moindre partie, il a le droit de pouvoir par la suite annuler le marché, si les circonstances de sa fortune lui permettent de racheter ce qu'il avait vendu. Cette remarque peut servir à expliquer quel est le motif de Iusou-chin, en voulant conserver une portion de sa maison.
} 


\section{Contes chinois}

le front de la tablette se lisaient quatre caractères, dont la signification était :

\section{CONSACRÉ AUX HOMMES.}

La chambre du milieu avait des tables polies et des croisées transparentes; on y voyait des curedens et quelques tableaux. C'était là qu'il avait coutume de lire et d'écrire. Les quatre caractères écrits sur la tablette signifiaient :

\section{CONSACRÉ AUX ANCIENS.}

L'étage supérieur était vide et d'une construction légère. On n'y voyait qu'une cassolette pour brûler de l'encens, et un livre de morale religieuse. Ici il s'éloignait du bruit, il se retirait de la foule ; il se séparait des hommes et fermait la porte à leurs exemples. La tablette portait de même quatre caractères qui voulaient dire :

\section{CONSACRÉ AU CIEL.}

Ayant divisé l'édifice en trois compartimens pour ces différens usages, il dressa une quatrième tablette pour leur donner un nom général, et il les appela :

\section{LES TROIS ÉTAGES CONSACRÉS.}

Avant qu'il se fût défait du reste de sa propriété, ces trois titres, quoique bien choisis, étaient encore vainement appliqués. Il ne s'était point réellement servi de ces appartemens, excepté cependant de celui du rez-de-chaussée ; car, comme il aimait beaucoup à recevoir du monde, si quelqu'un venait d'un lieu un peu éloigné pour le visiter, il y faisait aussitôt dresser un lit, et dans ce cas, le titre de Consacré aux hommes était certainement 


\section{Contes chinois}

justifié ; quant aux deux pièces supérieures, il ne s'y était jamais établi. Maintenant qu'il ne lui restait plus ni pavillons ni jardins, l'appartement consacré aux anciens était le seul où il pût lire et écrire, comme celui qui était « consacré au ciel » était l'unique abri qui lui restât contre la foule et le bruit. Il y passait toutes ses journées, et il y comprit enfin qu'on pouvait faire beaucoup de choses dans une petite maison, et qu'il était peu sage de mépriser le nom et de prendre la qualité. Les quatre vers populaires que nous allons citer reviennent à ceci :

\footnotetext{
Seigneur opulent de dix mille arpens,

Quelques bouchées suffisent pour rassasier ton appétit ;

Mille plafonds sollicitent tes soins,

Et cependant six pieds d'espace te suffisent chaque jour.
}

La petite force qu'il avait possédée jusqu'ici avait été dissipée en vain ; dès ce moment il appliqua collectivement sur un seul point toute l'étendue et l'activité de son génie, et il fit décorer ces trois appartemens d'une manière extraordinaire. En les habitant exclusivement, Iu-sou-chin non seulement ne sentit point le malheur d'avoir été forcé de se défaire de son jardin, car c'était un embarras de moins, mais il ne souffrit pas non plus de la violence de son voisin. Nous verrons dans le chapitre suivant quelle était la sécurité dont il pouvait jouir dans son habitation. 


\section{Contes chinois}

\section{CHAPITRE II.}

N'étant ni un voleur, ni un receleur de vols, il arrive tout-à-coup à la possession d'un trésor considérable. La maison et ceux qui I'habitent retournent à leur premier maître.

Après que Yo-tchouan et son fils eurent acquis cette maison et ces jardins, le goût de I'homme riche se montra, comme on peut le penser, différent de celui de l'ancien propriétaire, et il voulut à son tour y faire des changemens. Il n'était pas question cependant de transposer les poutres, de déplacer les colonnes, et d'opérer une transformation entière. C'était comme un superbe paysage, où il ne faut que retirer un arbre ou ajouter un brin d'herbe. L'apparence pittoresque n'était pas entièrement conforme à son idée. Lorsqu'il y eut travaillé quelque temps, il s'aperçut cependant qu'il avait manqué son but originel, qui était de transformer le fer en or, et que, contrairement à son attente, il changeait l'or en fer.

Les personnes qui venaient les voir disaient toutes, « que ces jardins étaient grands et incommodes ; qu'après tout on ne pouvait les comparer avec les trois étages, quoique, s'ils y étaient réunis, la chose serait assez bien ; qu'il n'était pas étonnant que l'autre homme eût voulu conserver la petite partie, et eût méprisé la plus grande, ou qu'il tînt si fortement à ce qu'il avait conservé, et qu'il ne voulût pas le vendre ; que le partage qui avait eu lieu avait mis d'un côté un pouce d'or, et de l'autre dix coudées de fer. 


\section{Contes chinois}

Yo-tchouan et son fils, entendant ces propos, commencèrent, sans s'en apercevoir, à être fâchés et à se repentir de leur marché ; ils apprirent alors qu'on peut être riche sans être satisfait. Ils recoururent aux courtiers qui allèrent trouver le vendeur, pour l'engager à se dessaisir de ce qu'il avait conservé, et à le comprendre dans la vente. Iu-sou-chin, depuis qu'il s'était défait de sa maison et de ses jardins, n'avait plus employé d'ouvriers, et n'avait fait aucune extravagance. Ainsi, comme il n'avait plus de dettes, et qu'il lui restait de quoi vivre, il n'avait pas de motifs pour vendre ce qu'il s'était réservé. Il leur répondit donc :

- Si je n'avais plus cette habitation, dites-moi où je pourrais me reposer ? Quand même vous me réduiriez à être privé de vêtemens et à avoir à peine de. quoi me nourrir, je tiendrais encore bon contre votre envie.

Pouvait-il en effet se déterminer à les satisfaire, lorsque sa fortune s'était réellement améliorée?

Les courtiers revinrent et firent connaître sa réponse au fils de Yo-tchouan, qui ne put s'empêcher de prendre son père à partie, et de lui dire :

- Vous avez toute votre vie étudié les hommes, mais en cette occasion votre jugement a erré sur tous les points.

Ya-tchouan répliqua :

- Cet homme peut être un entêté pendant sa vie, mais il ne saurait l'être après sa mort. Il est maintenant d'un 


\section{Contes chinois}

âge mûr, et il n'a point d'héritiers. Lorsque son dernier souffle se sera exhalé, ses femmes, ses maîtresses, ses domestiques passeront inévitablement à d'autres, et à plus forte raison, les chambres qu'il habite encore. Sa famille entière et tout ce qu'elle porte avec elle tomberont en notre pouvoir ; n'ayez pas peur que tout cela s'envole.

Le fils, entendant son père raisonner ainsi, lui dit :

- Que, quoique ses paroles fussent vraies, cependant la vie de cet homme lui paraissait interminable ; qu'il n'y avait pas à attendre sa fin, et que le plus tôt qu'on le déposséderait serait le mieux.

Depuis ce moment, ils firent de Iu-sou-chin le principal sujet de toutes leurs pensées ${ }^{1}$, et si leurs malédictions n'allaient point jusqu'à souhaiter qu'il mourût promptement, c'est qu'ils espéraient de le voir bientôt pauvre, et qu'arrivé au moment où il serait dépourvu de tout, il faudrait bien qu'il se soumît à ce qu'ils voulaient de lui.

Qui se serait imaginé que le ciel pût se refuser à exaucer des vœux si pleins de vertu ? Leurs malédictions cependant ne firent point mourir Iu-sou-chin, il ne devint pas pauvre au gré de leurs espérances, et en vieillissant il acquérait au contraire plus de vigueur. Il ne manquait ni de vêtemens ni de vivres ; il n'avait aucun besoin de vendre ses appartemens.

\footnotetext{
${ }^{1}$ L'original dit : «Ils placèrent Iu-sou-chin sur le sommet de leurs cœurs. » Cette citation littérale confirme la remarque faite dans la note placée au bas de la page 25. [css : le siège des idées]
} 


\section{Contes chinois}

Yo-tchouan et son fils, vexés et enragés au-delà de toute mesure, concertèrent un nouveau plan. Ils s'adressèrent encore aux courtiers, et les chargèrent d'insister pour qu'il reprît tout ce qu'il leur avait rendu.

- Deux familles, disaient-ils, ne peuvent demeurer séparément dans un même jardin. Du haut de ses étages consacrés, ses regards plongent dans notre pavillon. Il peut voir l'intérieur de nos appartemens les plus secrets, tandis que nous ne pouvons apercevoir ceux de ses femmes. Il y a trop d'inégalité dans cette affaire.

Iu-sou-chin écouta ce message, mais il devina qu'il n'y avait que de la feinte dans ce désir de rompre le marché, et que la vérité était qu'ils mouraient d'envie d'avoir le tout. Il répéta donc ce qu'il avait dit auparavant, et sa réponse fut tranchante et décisive.

Yo-tchouan et son fils en furent excessivement courroucés, et il ne leur resta plus qu'à chercher à l'opprimer, en se servant du pouvoir du mandarin. Ils dressèrent une requête pour faire connaître publiquement leur désir de rompre le marché ; ils se flattaient qu'avec quelques présens, ils pourraient acheter le mandarin et se le rendre favorable, et qu'avec son appui ils viendraient à bout de leurs desseins.

Ils se doutaient peu que cet officier était incorruptible ; qu'il n'avait été jadis qu'un pauvre lettré, qui s'était vu tromper et insulter par un homme opulent ; il leur dit : 


\section{Contes chinois}

- Celui dont vous me parlez est un indigent, comment voulez-vous qu'il rachète ce qu'il a été obligé de vendre ? Il est évident que vous avez comploté de le ruiner et de le dévorer. Vous possédez de grands biens, et vous voulez être riches sans être vertueux ; moi qui suis un magistrat, je désire être vertueux sans être riche.

Alors il les réprimanda en pleine salle, et, après avoir déchiré leur requête, il les fit mettre à la porte.

Iu-sou-chin avait un ami qui lui était attaché par les premiers principes de I'honneur. Il habitait une partie éloignée du pays, et il possédait une grande fortune. Son plaisir était d'employer ses richesses à accomplir des actes de bienfaisance. Il vint un jour faire une visite à Iu-sou-chin, et il poussa un profond soupir en apprenant qu'il avait vendu sa maison et son jardin. Lorsqu'il fut aussi informé qu'il y avait des gens qui complotaient contre son ami ; qu'il ne pouvait pas vivre en sûreté même dans son petit nid, et qu'il serait vraisemblablement obligé de l'abandonner entièrement, il chercha aussitôt les moyens de lui fournir de l'argent pour racheter sa propriété.

Mais Iu-sou-chin n'avait point d'égal pour l'indépendance de son esprit, et pour ne rien dire de la répugnance qu'il avait à mettre un autre dans l'embarras pour de fortes sommes, il est certain que, si un homme était venu lui présenter un taël ou cinq mas, sans lui démontrer qu'il y avait tous les droits possibles, il aurait refusé de les accepter. Avant donc entendu les offres de son ami, il lui répondit : 


\section{Contes chinois}

«Que c'était vainement qu'il cédait en cette occasion à la chaleur de son cœur ; qu'il était tout-à-fait dans l'erreur à ce sujet ; que de toutes les propriétés de ce monde, il n'y en avait aucune qui ne fût vendue à son tour ; qu'il était vrai qu'on pouvait prendre le soin de conserver la sienne tandis qu'on était en vie ; mais qu'on ne pouvait la garder après qu'on était mort.

- Quoique en ce moment, ajouta-t-il, vous vous intéressiez à moi, et que vous soyiez prêt à avancer des sommes considérables pour me racheter une petite portion de ce qui m'a appartenu, je ne saurais vivre que peu d'années encore, et l'un de ces jours, lorsque je mourrai sans laisser d'héritiers, chaque brique et chaque tuile de ma maison passera à d'autres personnes. Quoique votre générosité vous porte aujourd'hui à vous défaire de votre argent pour moi, vous ne sauriez m'assister deux fois. Hélas ! vous me rendrez ma propriété en ce moment, mais dans quelque temps d'ici pourriez-vous l'assurer à mon ombre?

Son ami, voyant que sa résolution à cet égard était fixée, cessa de le presser davantage.

Il logea pendant plusieurs jours chez Iu-sou-chin, et lorsqu'il prit congé de celui-ci pour s'en retourner chez lui, il lui adressa ces dernières paroles avant de se mettre en route :

- Une nuit, tandis que j'étais couché dans l'appartement du rez-de-chaussée, j'ai aperçu un rat blanc qui, après avoir rodé çà et là, s'est tout-à-coup 


\section{Contes chinois}

glissé dans une fente du plancher. Je ne doute point que quelque trésor n'y soit caché. Ne vendez cette maison à personne pour aucun motif. Dans quelque temps peutêtre vous y trouverez de quoi rétablir votre fortune ; je ne puis cependant vous en donner l'assurance positive.

Iu-sou-chin sourit froidement en écoutant son ami, et se contenta de lui répondre :

- Je vous remercie.

Après cela ils se séparèrent.

Le vieux proverbe dit très bien, qu'aucune fortune n'est jamais arrivée, même par hasard, à celui dont la destinée est d'être pauvre. Il n'y a que les riches acheteurs de maisons qui y découvrent en fouillant des trésors cachés. On n'a jamais vu un homme vendre sa propriété, lorsqu'il a trouvé dans son propre terrain la moitié de la plus vile pièce de monnaie. Iu-sou-chin était un homme de bon sens, comment aurait-il pu se livrer à des idées aussi chimériques ? Il se borna donc à sourire en écoutant son ami, et il ne se mit pas aussitôt à faire enlever des briques et à fouiller la terre.

Yo-tchouan et son fils, depuis qu'ils avaient été rebutés par le mandarin, avaient laissé la honte succéder à leur ressentiment. Cependant ils complotaient toujours, et ils espéraient que Iusou-chin mourrait bientôt, et qu'avant peu il ne resterait de lui que son ombre solitaire. Alors ils pensaient qu'ils pourraient entrer dans sa maison la tête levée.

Qui se serait imaginé que, lorsqu'un homme riche avait deviné juste dans toutes ses conjectures, il y aurait seulement 


\section{Contes chinois}

deux circonstances de vie et de mort, qui ne voudraient pas s'accorder avec ses calculs ? Non seulement Iu-sou-chin ne mourut pas, mais encore ayant passé l'âge de soixante ans, il devint tout-à-coup fringant, et il eut un fils. Un grand nombre de convives vinrent aussitôt le féliciter, et se rassemblèrent dans les trois étages consacrés; tous ils disaient « que c'était maintenant le cas de racheter la maison entière. »

Lorsque Yo-tchouan et son fils furent informés de cet événement, ils en furent fort troublés. Auparavant ils ne craignaient que de ne pouvoir acquérir la portion qui leur manquait ; maintenant ils avaient l'appréhension de perdre le tout ; leur inquiétude était extrême.

Un mois s'était écoulé quand ils virent tout-à-coup paraître différens courtiers qui leur dirent que Iu-sou-chin, après la naissance de son fils, avait été réduit à la pauvreté par ses hôtes nombreux ; qu'ils avaient mangé tout son sel et tari son vinaigre ; qu'il ne lui restait aucun moyen d'existence, hors la vente de sa maison ; que déjà il en avait fait circuler l'avis, et l'avait fait afficher sur toutes les portes ; qu'ils ne devaient pas laisser échapper cette occasion, mais la saisir le plus promptement possible.

Quand Yo-tchouan et son fils apprirent ceci, ils en devinrent fous de joie. Leur seule crainte était qu'il ne se souvînt de tout ce qui s'était passé, et ne leur gardât de la haine ; qu'il ne préférât de vendre à une autre personne, plutôt que d'avoir rien à faire avec eux. 


\section{Contes chinois}

Ils se doutaient peu que la façon de penser de Iu-sou-chin était tout-à-fait différente de la leur. Il dit :

- Les descendans des deux familles de Thang et de Iu ne sont pas semblables à ceux des autres. Son ancêtre Ti-yao conféra l'empire à mon aïeul, qui n'avait rien à lui donner en retour. Cette obligation étant descendue à sa postérité, ce ne serait donc pas faire une chose impropre, que de donner pour rien cette petite propriété ; et si tel est le cas, combien dois-je m'estimer heureux de pouvoir en retirer quelque chose ? Il ne me siérait point, pour un mince ressentiment du présent, de perdre tout-à-fait de vue les grandes faveurs conférées dans le passé. Dites-lui donc de n'avoir aucune inquiétude ; qu'il ait la confiance de m'offrir une petite somme, et je lui céderai tout-àfait ma maison.

Yo-tchouan et son fils furent au comble du bonheur en apprenant ce qui se passait. Le père dit :

- Je me suis toujours plu à m'appuyer sur mes ancêtres, et j'ai toujours éprouvé leur influence favorable. C'est à leur ancienne générosité que je dois cette magnifique habitation. C'est ainsi que les hommes peuvent se réjouir d'avoir eu des ancêtres vertueux.

Il alla alors trouver les courtiers, et conclut le marché. Jusqu'à ce moment il n'avait cherché que son avantage, mais maintenant qu'on rappelait les choses des anciens temps, il voulait aussi continuer à obliger. Iu-sou-chin, de son côté, n'était 


\section{Contes chinois}

pas en disposition de marchander, et il imita le grand aïeul de Yo-tchouan, qui avait cédé son trône et son royaume. Il chercha ensuite une chaumière où il pût résider, sans plus songer à ce dont il s'était dépouillé.

Iu-sou-chin avait quelques honnêtes amis qui désapprouvaient sa conduite ; ils lui dirent :

- Lorsque vous possédiez encore votre maison, y avaitil impossibilité de trouver un autre acheteur que celui dont vous excitiez l'envie, et qui n'a cessé de comploter contre vous ? Il est maintenant parvenu à ses fins, et le père et le fils vont partout babillant et se félicitant. Avant que vous fussiez père, votre ressentiment ne s'était point affaibli, et maintenant que vous avez un fils, sa naissance eût pu servir de fondement au recouvrement de toute votre propriété. Ne fussiez-vous pas même rentré dans la possession du reste de votre maison, ce que vous en aviez conservé aurait pu vous suffire encore; pourquoi donc vous en défaire pour le donner à Yo-tchouan?

Iu-sou-chin, les ayant écoutés, leur répondit en souriant :

- Vos intentions sont très bonnes, mais sans songer à I'avenir, vous ne considérez que ce qui est devant vos yeux. Quant à moi, je juge que les plans de Yo-tchouan tourneront à mon avantage. Si j'avais voulu rentrer dans ma propriété entière, il m'aurait fallu attendre que mon fils eût atteint un âge plus avancé. Peut-être que lorsqu'il serait parvenu à sa virilité, il m'aurait été en 


\section{Contes chinois}

effet possible de recouvrer ma maison ; cependant je suis vieux, et il me semble que je ne devais pas me flatter de vivre jusqu'à cette époque. Hé, qui pourrait m'assurer qu'après ma mort, mon fils lui-même n'aurait pas vendu ma maison à Yo-tchouan ? Celui-ci, ayant attendu jusqu'à cette époque, se serait moqué de mon fils, et aurait insulté à ma mémoire. Ne vaut-il pas mieux qu'un père vende ses propriétés ? Alors du moins ceux qui lui survivent plaignent son fils.

«Ce n'est pas tout encore ; il y a dix mille à parier contre un que bientôt je ne vivrai plus, et mon fils ne sera point encore arrivé à l'âge d'homme. Si je ne m'étais pas défait moi-même du reste de ma maison, ma femme aurait mieux aimé lutter contre la faim que de la vendre à Yo-tchouan. Alors celui-ci voyant qu'il ne pouvait point obtenir ce qui lui manquait, et craignant de voir échapper de ses mains ce qu'il avait précédemment acquis, aurait inévitablement comploté la perte de mon fils. Ainsi, non seulement ma propriété n'aurait point été recouvrée, mais mon fils lui-même aurait été sacrifié. Voilà ce qu'on eût pu appeler une perte ! Au lieu qu'en faisant maintenant un marché désavantageux, je fais contracter à mon acquéreur une dette envers mon enfant, que peut-être il lui paiera un jour. S'il ne la paie pas lui-même, d'autres l'acquitteront pour lui. Le vieux proverbe dit : La prudence commande d'endurer les injures. 


\section{Contes chinois}

Ceux auxquels il s'adressait, quoique un peu ébranlés par ses raisonnemens, dirent pourtant que sa tête n'était pas trop saine. Enfin Iu-sou-chin mourut subitement au bout de quelques années, et laissa son fils, encore dans l'enfance, sous la garde de sa veuve, qui ne possédait à peu près rien. La mère et l'enfant n'avaient pour subsister que le modique intérêt que leur produisait la somme peu considérable pour laquelle le reste de leur maison avait été vendu. Yo-tchouan, au contraire, s'enrichissait de jour en jour. Il savait comment on gagne de l'argent, et son fils savait à son tour comment on le conserve. Tout entrait chez eux, et rien n'en sortait ; la maison qu'ils avaient achetée était si solide, qu'elle aurait pu durer mille ans. Tous ceux qui les connaissaient accusaient la sagesse du ciel, et s'écriaient :

- Voyez ! les descendans de ces hommes qui furent libéraux et justes ne possèdent rien ou presque rien, tandis que les enfans de ceux qui ont enrichi leur famille par d'indignes moyens nagent dans l'opulence.

Cependant les anciens ont dit avec vérité, « que lorsque la vertu ou le vice ont atteint leur plus haut degré, ils reçoivent à la fin le prix qui leur est dû, et que toute la différence consiste dans le plus ou le moins de retard. » Ces paroles sont dans la bouche de tous les hommes, mais elles ne font que peu d'impression sur leurs cœurs. Si la récompense arrive tard, elle n'en est pas moins une récompense, tout comme si elle était venue de bonne heure, et c'est notre impatience seule qui en atténue la valeur. 


\section{Contes chinois}

Si vous désirez de bien comprendre la théorie des récompenses plus ou moins tardives, je vous dirai qu'elles ressemblent beaucoup à l'acte de prêter son argent pour en retirer un intérêt. Si vous exigez le capital un jour plus tôt, vous toucherez un jour d'intérêt de moins ; si vous le laissez au contraire une année de plus dans les mains de celui auquel vous l'avez prêté, votre intérêt se sera accru d'autant. Si vous attendez avec anxiété la récompense que vous croyez vous être due, le ciel ne réglera pas ses comptes avec vous, et vous ne recevrez rien ; il attendra que vous ayez perdu toute espérance, que vous ayez cessé de vous en occuper, et alors il vous la décernera tout-à-coup. Il en est de même d'une ancienne dette qui, lorsque le créancier l'a entièrement oubliée, arrive subitement à sa porte avec une grande accumulation d'intérêts. N'est-ce donc pas plus avantageux que de prêter pour se faire rendre aussitôt ?

Lorsque le fils de Iu-sou-chin fut parvenu à l'âge de dix-sept ou dix-huit ans, il obtint à l'improviste un titre littéraire. Son nom était Iu-tseu-chin, et son surnom Ke-wou. Il fut créé Tchihian, et ayant été choisi pour aller à Péking, il fut élevé à I'office de Tchang-ko. Il avait de la vertu et de la franchise, et il devint le favori de l'empereur régnant.

Lorsque sa mère eut atteint un âge avancé, il demanda la permission de se retirer de la cour pour aller la soigner dans sa vieillesse. Comme il approchait du terme de son voyage, il aperçut une femme qui, tenant un mémoire à la main, s'agenouillait sur les bords du canal, et s'écriait : 


\section{Contes chinois}

- Je supplie le seigneur Iu de recevoir et d'examiner ceci.

Ke-wou lui fit dire d'entrer dans son bateau ${ }^{1}$, et prenant le papier, il le parcourut. C'était une pétition dressée au nom de l'époux de cette femme, par laquelle il le suppliait de le recevoir lui et sa famille sous sa protection, et de les accepter pour esclaves. Ke-wou lui dit :

- Vous me paraissez être d'une bonne famille ; qui peut vous porter à rechercher ainsi ma protection ? Pourquoi votre mari ne se montre-t-il pas lui-même, et vous expose-t-il, vous qui êtes une femme, à courir les chemins, et à les faire retentir de vos cris ?

La femme répondit :

- Il est vrai, je descends d'une famille ancienne. Mon beau-père durant sa vie était possédé de la manie d'acheter des terres, et s'efforçait constamment d'ajouter à ses propriétés toutes celles qui en étaient voisines. Ceux qui les lui vendaient ne s'en défaisaient point volontiers, et le détestaient au fond de leurs cœurs. Les temps lui furent favorables presque jusqu'à la fin, et il n'eut aucun sacrifice important à faire pour conserver sa fortune. Il était d'ailleurs homme de rang, et lorsqu'un mandarin lui en voulait pour quelque chose, il savait l'apaiser au moyen d'un peu d'argent. Mais cette prospérité commença à s'altérer, et mon beaupère mourut. Son fils, mon mari, était jeune et ne

\footnotetext{
${ }^{1}$ A la Chine, presque tous les voyages se font par eau.
} 


\section{Contes chinois}

possédait aucun titre. Les persécuteurs de l'orphelin et de la veuve I'assaillirent en masse, et tous l'accusèrent auprès du Tchi-hian ; dans le cours d'une seule année, il eut à soutenir un grand nombre de procès qui lui enlevèrent la meilleure moitié de sa fortune. Maintenant il gémit sous le poids d'un malheur plus grand encore. Il est en prison, et ce n'est pas l'argent qui peut l'en tirer ; un personnage puissant peut seul opérer sa délivrance. Si un tel protecteur daigne se charger de son affaire et la traiter comme si elle le concernait luimême, il pourra alors recouvrer sa liberté. Votre seigneurie peut donc seule nous secourir aujourd'hui, d'autant plus que cette affaire la regarde elle-même. Elle appartient à votre seigneurie autant qu'à mon époux. Voilà pourquoi il s'est décidé à vous écrire et à me commander de venir au-devant de vous pour mettre sous votre protection nos personnes et nos propriétés. Il ne nous reste qu'à supplier votre seigneurie de ne pas les rejeter comme indignes d'elle, et de les accepter le plus tôt possible.

Ke-wou ne put, en l'écoutant, dissimuler sa surprise.

- Dans quelle affaire, dit-il, puis-je être mêlé avec vous ? Sans doute que, pendant mon absence, mes esclaves, complotant avec vous et avec votre mari, ont par quelque machination secrète tenté de m'envelopper dans ce malheur. Voilà ce qui vous oblige maintenant à recourir à ma protection. Dois-je recevoir des étrangers 


\section{Contes chinois}

chez moi, les reconnaître comme membres de ma famille, et en les protégeant, me rendre coupable moimême d'une extension injuste de pouvoir?

La femme répliqua :

- Vous ignorez ce dont il s'agit. Au milieu de l'emplacement de notre propriété est un bâtiment élevé, connu sous le nom des trois étages consacrés. Il vous appartenait autrefois, et il nous a été vendu postérieurement. Nous en avons joui durant plusieurs années de suite sans inquiétude ; mais dernièrement un ennemi qui nous est inconnu adressa tout-à-coup à I'autorité une dénonciation, portant que mon mari appartenait à une troupe de voleurs, et que depuis trois générations notre famille n'avait grandi que par le brigandage ; qu'il y avait un trésor considérable divisé en vingt portions, et caché sous les trois étages consacrés, et que, lorsqu'il aurait été déterré, on en apprendrait les particularités. Le mandarin, après avoir lu ce mémoire, s'empressa d'envoyer chez nous une troupe d'archers pour opérer cette recherche, et à la grande surprise de tout le monde, ils trouvèrent en effet sous le plancher un trésor tel qu'il avait été indiqué. Mon mari fut aussitôt arrêté et conduit par devant le tribunal du mandarin. On le traita comme receleur, on le battit et on lui donna la torture pour lui faire découvrir ses complices et le reste de ce qu'ils pouvaient avoir volé. 


\section{Contes chinois}

« C'est en vain que mon époux essaya d'arranger cette affaire, il ne put ni l'expliquer ni se justifier. Cet argent, il est vrai, ne lui appartenait pas, mais il ne pouvait dire d'où il était venu. Les circonstances ne lui étant pas connues, comment pouvait-il en expliquer la cause ? La seule consolation que nous eussions, c'est qu'il ne se présentait personne pour le réclamer. Cependant le mandarin fit emprisonner mon mari, et il n'a point encore prononcé sur son sort. Après de mûres réflexions, mon mari a pensé que cette maison appartenant autrefois à votre famille, il était possible que votre grand-père $y$ eût enfoui ce trésor, et que votre père, ignorant son existence, n'eût point cherché à le retirer de la terre. Ainsi, ce qui devait profiter à quelqu'un est devenu pour nous une source de malheurs.

« Nous ne discutons point en ce moment la vérité ou la fausseté de cette conjecture ; nous supplions seulement votre seigneurie de réclamer ce trésor et d'en disposer. Par là elle peut rendre mon mari à la vie, en I'arrachant des bras de la mort. Après que nous aurons été sauvés par votre seigneurie, il sera tout simple que nous lui fassions hommage de notre propriété. Nos jardins, notre maison furent l'ouvrage de son père, il est juste qu'ils reviennent à la famille de leur auteur. Nous y renoncerons sans aucune peine, et nous nous croirons heureux, au contraire, si votre seigneurie veut bien ne pas dédaigner nos offres. 


\section{Contes chinois}

Ke-wou, en écoutant ces paroles, sentit naître en lui quelques soupçons ; il répondit donc :

- Ma famille a de tout temps observé comme règle de conduite, de ne point contracter d'obligations envers les personnes d'un rang inférieur. Je n'ai rien à vous dire pour le moment sur l'offre que vous me faites de vous donner à moi. Il est vrai que le jardin et la maison que vous possédez appartenaient autrefois à ma famille ; mais elle en a disposé avec toutes les formes légales, et vos pareils ne les ont point dérobés. Si donc je veux les recouvrer, il faut que je vous restitue le prix de I'acquisition que vous en avez faite. C'est la seule manière de procéder, et il n'existe aucune raison pour que vous me les rendiez pour rien. Quant au trésor, je reconnais n'y avoir aucun droit, et il ne me convient pas de le réclamer. Retirez-vous maintenant, et attendez chez vous que j'aie eu une entrevue avec le Tchi-hian. Je l'inviterai à examiner soigneusement cette affaire, afin de pouvoir prononcer un jugement équitable. Si l'accusation n'est point fondée, votre mari recouvrera sa liberté, et sans doute on ne le mettra pas à mort injustement.'

A ces mots la femme se réjouit extrêmement, et après lui avoir fait mille remercimens, elle partit.

Le lecteur ignore encore d'où le mal était provenu, et si la vérité fut ensuite connue. Il saura tout cela dans le chapitre suivant, s'il veut se donner la peine de le lire. 


\section{Contes chinois}

@

306 


\section{Contes chinois}

\section{CHAPITRE III}

@

Iu-ke-wou, après avoir congédié cette femme, continua sa route. Il se mit, par la pensée, à la place du magistrat chargé de juger cette affaire, et il la considéra sous tous ses aspects.

« Ce trésor sans doute, se dit-il, n'a jamais appartenu à mes ancêtres ; car, si l'on supposait qu'ils en furent les propriétaires, comment expliquerait-on l'ignorance où leur fils est resté à cet égard, et le peu d'empressement de mes parens à le réclamer ? La personne qui en connaissait l'existence et qui l'a révélée dans sa pétition, est étrangère à ma famille, et comme d'ailleurs sa pétition est anonyme, il est évident qu'elle a agi par des motifs d'inimitié ; je ne puis élever aucun doute sur ce point. Mais en reconnaissant qu'il est probable que ce personnage inconnu a été guidé par quelque motif de mécontentement, on ne peut néanmoins que le blâmer d'avoir impliqué celui dont il avait à se plaindre dans une affaire aussi vile, et de l'avoir signalé comme un receleur de vols. Il est vrai cependant que, lorsque le trésor a été déterré, on l'a trouvé tel que le dénonciateur l'avait spécifié, et qu'il n'y avait rien de plus ni de moins. Il est difficile de concevoir que celui qui a fait cette dénonciation pour satisfaire à une haine secrète, ait poussé l'esprit insensé de vengeance jusqu'à sacrifier une aussi forte somme, et à aller 


\section{Contes chinois}

l'enterrer sous la maison d'un autre, au risque de la perdre pour toujours.

Telles étaient ses réflexions. Pendant plusieurs jours il y revint sans cesse ; mais il ne se présenta à son esprit aucune explication satisfaisante de I'affaire qui l'occupait. Il ne pouvait s'empêcher d'y penser à chaque instant, et pendant son sommeil et dans ses rêves, il poussait des cris et prononçait des mots entrecoupés. Sa mère, l'ayant entendu, lui demanda ce qu'il avait. Il lui répéta alors avec exactitude et sans rien oublier ce que lui avait dit la femme qui était venue à lui. Sa mère partagea d'abord ses doutes et sa défiance ; mais après avoir réfléchi quelque temps, elle s'écria :

- C'est cela ! c'est cela ! Ce trésor en vérité appartient à notre famille ! Les conjectures de cet homme se sont vérifiées ! Apprenez, mon fils, que, tandis que votre père était encore en vie, un de ses amis vint de fort loin pour lui faire une visite. Il coucha plusieurs nuits dans la chambre du rez-de-chaussée de notre maison, et vit un rat blanc qui, après avoir couru de tous les côtés, se glissa tout-à-coup dans une fente du plancher. Au moment de son départ, il raconta à votre père ce qu'il avait vu, et il l'invita à ne jamais se défaire de sa maison dans aucun cas, parce qu'il pourrait par la suite y découvrir quelque trésor. Il est probable que ce trésor vient d'être maintenant découvert. Votre père, en ne le retirant pas de la place où il était, a été la cause du 


\section{Contes chinois}

malheur d'autrui. Allez donc le réclamer, et sauver ainsi la vie d'un homme.

Ke-wou lui répondit :

- Il y a quelque chose de plus à dire à cet égard. Une histoire aussi futile serait déplacée dans la bouche d'un personnage respectable, et lorsque j'irai entretenir le Tchi-hian d'un rat blanc, n'est-il pas probable qu'il imaginera que je veux m'approprier injustement ce trésor, et que je n'ai inventé cette histoire que pour tromper les esprits crédules ? D'ailleurs, ce rat blanc n'a point été vu par mon père, et ce n'est pas de sa bouche qu'est sorti ce conte absurde. Plus j'y réfléchis, moins je puis y ajouter foi ; c'est, à proprement parler, le rêve d'un insensé.

« Si ce trésor dit appartenu à ma famille, mon père l'aurait connu, et j'en aurais su quelque chose moimême ; comment se fait-il qu'un étranger ait eu plus de notions sur ce point ? Toute cette histoire est fausse ; il n'y a aucune raison qui puisse me porter à la croire. Cependant il est convenable de consulter le Tchi-hian, et de tâcher d'éclaircir cette affaire pour sauver un homme innocent. J'agirai ainsi en magistrat vertueux.

Il finissait de parler, quand un domestique entra pour lui annoncer que le Tchi-hian venait lui rendre ses devoirs. Ke-wou dit :

- Je comptais aller à l'instant le voir moi-même ; hâtez-vous, et priez-le d'entrer. 


\section{Contes chinois}

Après que le Tchi-hian l'eut salué et qu'il eut causé quelques instans d'une manière générale, il n'attendit pas que Ke-wou lui parlât de l'affaire qui l'occupait, et il entama ce sujet de luimême, en le priant de l'éclairer de ses conseils. «Thang, un tel ${ }^{1}$, lui dit-il, le possesseur du trésor a été souvent questionné sans qu'on ait pu tirer de lui aucun éclaircissement. Dans sa déposition d'hier, il a déclaré que sa maison appartenait autrefois à votre famille, et que, par conséquent, le trésor qu'on a trouvé y avait sans doute été déposé par vos ancêtres. Je suis venu vers vous, d'abord pour vous rendre mes hommages, et ensuite pour vous supplier de m'informer de ce que vous savez à cet égard.

Ke-wou répondit :

- Ma famille a été pauvre pendant plusieurs générations, et aucun de mes aïeux les plus proches n'a jamais rien accumulé. En conséquence, si je me hâtais témérairement de réclamer ce trésor, je me donnerais une mauvaise réputation. Mais de ce que je ne pense pas que ce trésor ait appartenu à mes ancêtres, il ne s'ensuit point nécessairement qu'il ait été caché par des voleurs dans la maison autrefois vendue par mon père. Je vous conjure donc de continuer vos recherches, afin d'arriver à la vérité, et si vous pouvez convaincre le prisonnier Thang de culpabilité, alors il méritera d'être puni.

\footnotetext{
${ }^{1}$ Le Tchi-hian ne connaissait que son sing, c'est-à-dire son nom de famille, lequel chez les Chinois se place toujours avant le Ming ou le Tseu qui est le surnom ou le titre; il dit donc: Thang meou, Thang un tel.
} 


\section{Contes chinois}

Le Tchi-hian dit :

- A l'époque où votre père quitta cette vie, vous étiez encore enfant, et il est probable que vous n'avez pu être entièrement informé de ce qui a précédé ou suivi de près votre naissance. Nous pourrions, il me semble, demander à votre mère si, avant la vente de votre maison, elle n'avait rien vu ou entendu dire de particulier.

Ke-wou lui répliqua :

- J'ai déjà questionné ma mère à ce sujet, mais elle en parle un peu au hasard, et ce qu'elle dit, elle ne le tient pas de mon père. Comme je suis maintenant interrogé par une personne respectable, je ne dois rien dire inconsidérément ; c'est pourquoi trouvez bon que je ne m'explique pas davantage.

Le Tchi-hian, en entendant ceci, insista aussitôt pour qu'il lui dît tout ce qu'il paraissait savoir, mais Ke-wou ne voulut rien ajouter de plus.

Il arriva fort heureusement que sa mère était dans ce moment derrière l'écran ${ }^{1}$, et qu'elle entendit toute cette conversation. Désirant de faire une bonne action, elle ordonna à son intendant d'aller raconter tout ce qu'elle savait. Après que le Tchi-hian l'eut écouté, il réfléchit en silence pendant quelque temps, puis il dit à l'intendant:

\footnotetext{
${ }^{1}$ Sorte de treillis ou de rideau qu'on suspend dans un appartement, et derrière lequel se placent les femmes pour voir sans être vues.
} 


\section{Contes chinois}

- Veuillez prendre la peine d'aller demander à votre maîtresse où demeure I'homme qui vit le rat blanc, et s'il est encore en vie ou non ; si sa famille est riche ou pauvre; quel était le degré de son intimité avec votre maître, et s'ils avaient coutume de se rendre réciproquement des services ? Je prie votre maîtresse de parler avec précision, parce que les renseignemens qu'elle donnera peuvent jeter du jour sur cette affaire obscure et difficile.

L'intendant rentra et revint quelques momens après.

- Ma maîtresse, dit-il, m'ordonne de vous informer que la personne qui vit le rat blanc habite une contrée lointaine, et qu'elle est du fou de..., et du hian de.... Il n'est point encore mort, et il possède une grande fortune. C'est un homme éminent par ses vertus, qui attache peu de prix aux richesses, et qui était lié à mon maître par les nœuds de la plus étroite amitié. Voyant que son ami avait vendu ses jardins, et qu'il serait peutêtre aussi obligé de se défaire du petit bâtiment qui lui restait, il offrit de lui fournir l'argent nécessaire pour racheter sa propriété ; mais comme mon maître ne voulut pas l'accepter, il ne le pressa pas davantage sur ce point. Ce fut au moment de son départ qu'il dit ce que vous savez.

Le Tchi-hian, ayant réfléchi de nouveau, ordonna à l'intendant de rentrer encore, et d'aller demander à sa maîtresse si cet homme, depuis la mort de son époux, était venu rendre ses hommages 


\section{Contes chinois}

au défunt, si elle l'avait revu, et de répéter, dans ce dernier cas, tout ce qu'elle aurait pu lui entendre dire.

L'intendant obéit, et lorsqu'il rentra, il dit :

- Il y avait dix ans que mon maître était mort, lorsque son ami en fut informé ; il vint aussitôt pour rendre des honneurs à sa mémoire. Voyant que la maison de mon maître avait été vendue, il parut très surpris, et demanda si, après son départ, on avait trouvé le trésor dont il avait prédit la découverte ? Ma maîtresse lui répondit que non. Il soupira, et dit :

« C'est une belle chose pour ceux qui ont acheté la propriété. Trompeurs dans le fond de leurs cœurs, et machinateurs de complots et d'artifices pour envahir les biens de votre mari, ils ont acquis une fortune qu'ils ne méritaient pas ; mais patience ! ils pourront aussi éprouver quelque malheur auquel ils sont loin de s'attendre. »

Quelques jours après son départ, la famille de Thang fut dénoncée, et vous savez ce qui est arrivé. Ma maîtresse a constamment, depuis lors, loué et admiré I'ami de son mari, en disant que c'était un homme qui lisait dans l'avenir.

Quand il eut cessé de parler, le Tchi-hian se mit à rire de toutes ses forces et allant vers l'écran, il fit une profonde révérence en disant : 


\section{Contes chinois}

- Je rends mille graces à votre seigneurie pour les renseignemens qu'elle m'a donnés; elle a éclairé ma faible intelligence, et je pénètre maintenant dans cette affaire extraordinaire. Il n'est pas besoin de faire d'autres recherches. Qu'un de vos gens prenne la peine de m'apporter un reçu, et je vais envoyer le trésor chez vous.

Ke-wou lui demanda ce qu'il voulait dire, et le pria de lui faire connaître sa pensée à ce sujet ; le Tchi-hian lui répondit :

- Ce trésor, en vingt portions, n'a été laissé par aucun de vos ancêtres, et n'est point le résultat des vols du prisonnier Thang. Voici le fait : ce vertueux étranger désirait de racheter les propriétés de votre père, mais votre père, étant un homme d'un caractère indépendant, refusa obstinément les offres de son ami, et celui-ci, pour lui donner malgré lui le moyen de racheter sa maison par la suite, y déposa l'argent qu'on y a trouvé. Ne voulant pas le dire ouvertement, il supposa l'intervention d'un esprit, dans l'idée qu'aussitôt après son départ votre père déterrerait le trésor. Quand il vint pour rendre des honneurs à sa mémoire, et qu'il apprit que non seulement son ami n'avait pas recouvré ses jardins, mais encore qu'il avait vendu le reste de sa propriété, il vit que le trésor était dans des mains étrangères, et il fut extrêmement fâché. A son départ, il dressa une pétition anonyme, pour la faire remettre en temps opportun. Telle est I'explication 


\section{Contes chinois}

de cette affaire, et maintenant que la vérité est reconnue, il est juste que vous rentriez dans vos biens. Qu'avez-vous à dire à cela ?

Ke-wou, quoique applaudissant à cette décision dans le fond de son cœur, avait encore quelques objections à faire, par le désir d'éviter tout soupçon de connivence. Il ne voulait pas se hâter de faire des remercîmens au Tchi-hian, mais, s'inclinant devant lui, il lui dit

« que sa conclusion lui paraissait parfaite, et qu'il était doué sans doute d'une sagesse admirable ; que Loungtou 1 lui-même, reparaissant au monde, n'aurait pu mieux juger ; mais en même temps, ajouta-t-il, quoiqu'il paraisse évident, d'après vos raisonnemens, que ce trésor nous est venu d'un ami généreux, cependant, comme il n'y a personne qui puisse rendre témoignage du fait, il ne me conviendrait pas de me hâter de reprendre cet argent. Je vous supplie donc de le garder par devers vous, pour l'appliquer à soulager les pauvres dans les temps de famine.

Tandis qu'il parlait ainsi, un de ses serviteurs entra, portant un billet rouge, et s'approchant de son oreille, il lui dit :

- L'homme dont vous venez de vous entretenir est à la porte. Il dit qu'il vient d'une distance de plus de mille li 2 , pour rendre ses devoirs à ma maîtresse. Je ne puis

\footnotetext{
${ }^{1}$ Magistrat fameux des anciens temps. Le nom de sa place était Loung-tou-tahio-sse, et son nom propre Pao-wen-tching. Il est maintenant déifié et on lui a élevé des temples.

2 Environ cent lieues.
} 


\section{Contes chinois}

I'annoncer tandis que le Tchi-hian est présent ; cependant, comme il est instruit de l'affaire qui vous occupe, il ne pouvait arriver plus à propos sans doute, et j'ai cru devoir vous en informer, parce que vous pouvez peut-être désirer de le questionner.

Ke-wou témoigna la joie qu'il éprouvait de son arrivée, et en fit part aussitôt au Tchi-hian. Celui-ci fut près d'en sauter de plaisir, et il demanda qu'on le fit entrer sur-le-champ.

L'étranger leur parut un homme respectable, ayant un visage plein et des cheveux blancs. Il rendit ses devoirs à son ami, mais il fit peu d'attention au Tchi-hian qui lui était inconnu. Après s'être incliné, il s'avança en disant :

- L'objet de mon voyage est de venir voir la veuve de mon ancien ami. Je ne me propose point de faire ma cour aux riches et aux grands ; moi, homme de la campagne, je n'ai rien à démêler avec vous et ce n'est donc pas à vous que je prends la liberté de faire une visite. Veuillez seulement me permettre d'entrer dans la maison pour que j'aille en saluer la maîtresse.

Ke-wou lui dit aussitôt :

- Comme mon vénérable ami est venu de très loin, nous ne devons pas le traiter ainsi qu'un hôte ordinaire. Le Tchi-hian et moi sommes en ce moment à consulter sur une affaire difficile, et comme votre présence peut nous être d'un grand secours, nous vous supplions de ne pas refuser de vous asseoir un moment avec nous. 


\section{Contes chinois}

Le vieillard à ces mots fit une révérence et s'assit. Le Tchihian prit du thé avec lui, et le saluant ensuite, il lui dit :

- Il y a environ vingt ans que vous avez accompli un acte d'une grande vertu. Personne n'en était d'abord instruit, et il m'est échu à l'instant en partage de le mettre en lumière. Dites-nous, je vous prie, si ce n'est pas vous qui voulûtes donner un trésor à votre ami, en lui faisant croire qu'il le devait à l'intervention d'un esprit ?

Quand l'étranger entendit ces paroles, il parut fort surpris, et il ne répondit pas tout de suite ; ayant cependant surmonté son embarras, il dit :

- Comment un homme du commun tel que moi auraitil pu faire quelque chose qui vous paraît si louable ? Je ne sais ce que vous voulez dire.

- On se souvient, lui dit Ke-wou, de vous avoir entendu proférer quelques mots concernant un rat blanc. On était sur le point de traiter un homme honnête comme un receleur de vols. Je n'ai pu supporter cela, et j'ai prié le Tchi-hian de le mettre en liberté. Cependant nous nous sommes entretenus de cette affaire, et par degrés nous croyons être parvenus à la solution ; mais, comme nous n'avons pas de certitude sur la vérité ou la fausseté de I'histoire du rat blanc, nous vous conjurons de vouloir bien résoudre nos doutes à cet égard.

Le vieillard se refusait toujours à donner des explications, lorsqu'il reçut un message de la part de la mère de Ke-wou, pour 


\section{Contes chinois}

I'inviter à révéler la vérité et à justifier par là un innocent. Il sourit et laissa échapper enfin le secret enseveli depuis vingt ans dans le fond de son cœur. Ce qu'il dit s'accordait parfaitement avec tout ce que le Tchi-hian avait conjecturé, et l'ordre ayant été donné à quelques hommes d'aller examiner et reconnaître les lettres et les marques empreintes sur le trésor, il ne resta plus aucun doute sur son identité.

Le Tchi-hian et Ke-wou firent éclater leur admiration pour les vertus du vieillard; le vieillard et Ke-wou se répandirent en éloges sur la pénétration du Tchi-hian, et le Tchi-hian et le vieillard exaltèrent la conduite désintéressée de Ke-wou.

- De telles actions, disaient-ils tous ensemble, feront du bruit dans le monde ; il n'est pas besoin d'être devin pour prédire leur célébrité.

Ils passèrent quelque temps à se louer ainsi l'un l'autre, et tous les domestiques qui étaient présens mettaient la main devant leur bouche pour s'empêcher d'en rire.

- Le Tchi-hian, disaient-ils, avait donné des ordres pour découvrir et saisir l'auteur de la pétition anonyme. Il l'a trouvé maintenant, et au lieu de le faire battre, ils sont assis et causent ensemble. C'est là du nouveau !

Aussitôt que le Tchi-hian fut de retour à son tribunal, il envoya le trésor chez Ke-wou, et en demanda un reçu ; mais celui-ci ne voulut pas le recevoir, et il écrivit au Tchi-hian pour le prier de remettre cet argent à la famille de Thang, pour racheter d'elle sa propriété. Ainsi j'accomplirai, disait-il, les intentions de mon père, et les désirs de son généreux ami ; enfin je mettrai la 


\section{Contes chinois}

famille Thang à même d'acheter une autre maison, et personne ne sera maltraité dans cette affaire.

Chacun donna des éloges aux nobles sentimens de Ke-wou. Le Tchi-hian, pour complaire à ses intentions, mit Thang en liberté, et Ke-wou, remboursant à celui-ci l'argent que son père avait autrefois payé, exigea de lui en retour les actes et les titres en vertu desquels il était propriétaire. Les jardins et les bâtimens rentrèrent en la possession de leur ancien maître.

Le même jour, dans le plus haut des trois étages consacrés, Ke-wou fit une offrande de vin au ciel, en témoignage de sa gratitude.

« C'est ainsi, s'écriait-il, que les vertus de mon père ont été récompensées ! C'est ainsi que les artifices de Thang ont rencontré leur punition ! Comment les hommes peuvent-ils renoncer à la vertu pour se complaire dans le vice!

Thang et sa femme firent dresser un acte par lequel ils disposaient de leurs personnes et de leurs biens, et le présentèrent à Ke-wou, en suppliant d'agréer leurs services pour le reste de leur vie; mais celui-ci refusa absolument de I'accepter, et les tranquillisa par des paroles obligeantes. Alors le mari et la femme ayant fait graver une tablette pleine de leurs vœux pour lui, la placèrent dans le lieu le plus honorable de leur maison, pour y faire leurs offrandes : Quoiqu'ils ne pussent pas le persuader de les prendre à son service, ils ne s'en considérèrent pas moins comme ses serviteurs, et non seulement ils s'efforcèrent de reconnaître ses bienfaits, mais 


\section{Contes chinois}

encore ils firent savoir à tout le monde qu'ils appartenaient à la famille de Iu, et dès lors personne ne songea à leur faire injure.

Pour consacrer la mémoire de ces événemens, on composa une stance qui avait pour objet de conseiller aux hommes riches de ne pas envier la propriété de leurs voisins. Nous la donnons telle qu'elle s'est conservée :

Contraint par le besoin, il vendit sa maison et ses terres,

Maintenant la maison, les terres et les acheteurs lui reviennent.

C'est ainsi que la vertu reçoit enfin sa récompense,

Tandis qu'il ne reste au vice envieux que des infortunes à déplorer.

MORALITÉ.

La perspicacité du jugement du Tchi-hian, la générosité désintéressée du vieillard et la modération de Ke-wou, méritent toutes trois une renommée éternelle. Les magistrats doivent suivre I'exemple du Tchi-hian, et les citoyens doivent imiter la modération de Ke-wou. Ceux qui ont de la fortune et de la bienveillance auraient tort cependant de se modeler tout-à-fait sur le vieillard, parce qu'on ne saurait le justifier à l'égard de sa pétition anonyme. Les actions de l'amitié généreuse ne sont pas toutes dignes d'être imitées. Ceux dont la vie se recommande principalement par de bonnes actions sont invariablement des hommes intègres. Ainsi, à l'égard des amis, la différence qui existe entre ceux qui sont justes et ceux qui sont seulement généreux, c'est que la conduite des premiers doit servir de modèle, et qu'il faut se garder d'imiter celle des autres. 


\section{Contes chinois}

@

321 


\section{Contes chinois}

\section{LES DEUX JUMELLES.}

Au commencement du règne d'un empereur de la dynastie des Ming, il y avait dans une ville de la province de Hou-Kouang un marchand, nommé Siao-kiang, qui avait le malheur de vivre en mauvaise intelligence avec sa femme. Ils furent privés d'enfans très longtemps, mais enfin au bout de quelques années ils eurent deux filles jumelles. C'est une remarque vulgaire que les garçons ressemblent généralement au père et les filles à la mère ; mais contre l'ordinaire, les deux sœurs n'avaient aucun des traits de leurs parens, et on les aurait prises pour les enfans d'une autre femme. Cette différence ne se bornait pas à leur extérieur, mais s'étendait également à leur esprit. Le père et la mère étaient d'une figure commune et d'un esprit borné ; les filles, au contraire, étaient très belles, et, de plus, douées d'une intelligence remarquable. A peine avaient-elles atteint leur dixième année, qu'elles commencèrent à ressembler à de belles fleurs brillantes de rosée, ou à des herbes odoriférantes agitées par le zéphir ; leur beauté augmenta de jour en jour, à tel point qu'à quinze ans on ne pouvait les considérer sans émotion. Ce n'était pas seulement les jeunes gens qui devenaient amoureux d'elles ; les hommes d'un âge plus avancé reconnaissaient aussi le pouvoir de leurs charmes.

Elles avaient une grande facilité pour apprendre, et néanmoins elles savaient peu de chose, car toute leur science se 


\section{Contes chinois}

bornait au calcul ${ }^{1}$. Quant aux ouvrages d'aiguille et autres talens des femmes, il ne leur aurait fallu que peu de leçons pour les acquérir. Leurs habits et leurs ornemens à cause de leur état étaient grossiers et communs. Cependant, quand on comparait ces jeunes filles aux demoiselles les plus riches et du plus haut rang, chacun avouait qu'elles n'avaient pas besoin de changer leur costume simple ni leurs bijoux de métal contre les soieries ni les pierres précieuses.

Si belles et si attrayantes, elles furent recherchées par des jeunes gens riches et de bonne famille.

Siao-kiang et sa femme vivaient plu tôt en ennemis qu'en époux. Le premier voulait marier ses filles sans que sa femme s'en mêlât ; celle-ci, d'un autre côté, voulait se procurer deux gendres à l'insu de son mari ; c'est avec le dessein de se tromper mutuellement, qu'ils prirent chacun, en secret, des engagemens avec des amis différens.

Quoique le père fût sévère dans sa maison, il était d'un naturel doux et aimant ; il n'en était pas de même de sa femme, qui, pour peu qu'on l'irritât, faisait retentir tout le voisinage de ses emportemens. Les gens pensaient donc qu'il serait plus facile de tromper I'un que l'autre, et que, des deux, il fallait plutôt aider la femme que le mari. De là il arriva qu'elle réussit plutôt parmi ses partisans, et au bout de très peu de temps, elle trouva un mari pour chacune de ses filles. On choisit un jour heureux pour la célébration du mariage, et les futurs furent priés d'envoyer les présens de noces ; mais afin d'éviter que son mari

\footnotetext{
${ }^{1}$ Leur père étant marchand.
} 


\section{Contes chinois}

ne refusât son consentement à ces unions, elle ne lui donna connaissance de rien.

Il se trouva quelques personnes de bon sens qui dirent que c'était au père qu'il appartenait de choisir un mari pour sa fille, et que si la mère refusait son consentement, on devait porter l'affaire devant le magistrat qui, à coup sûr, ne soutiendrait jamais une femme entêtée contre les droits du mari. Ces personnes cherchaient quelqu'un pour faire leurs propositions à ce dernier ; mais malheureusement tous ceux à qui ils s'adressaient se trouvaient portés à le tromper, à raison de la peur que leur inspirait sa femme, ou bien ils avaient quelque prétexte tout prêt pour s'excuser de témoigner contre elle lorsqu'on les en priait. Ils n'osaient pas s'exposer à son ressentiment et ils disaient que s'ils offensaient le mari, ils pouvaient raisonner avec lui s'il se fâchait, et qu'ils avaient la ressource de se plaindre au magistrat s'il commettait quelque violence ; mais que, si la femme se trouvait offensée et qu'elle se mît en colère, il ne serait pas convenable qu'ils se disputassent avec une femme; et quand bien même elle leur dirait des injures ou les maltraiterait, ils ne pourraient rien lui faire, mais seraient obligés de tout endurer sans se venger. Ainsi donc il arriva que ceux qui désiraient faire faire des propositions au bon homme ne trouvèrent personne qui voulût s'en charger et furent obligés de s'en ouvrir eux-mêmes avec lui : il avait été très piqué de voir que les gens s'adressaient d'abord à sa femme sans l'avoir consulté ; ainsi lorsqu'on lui proposa des partis pour ses filles, il s'empressa de donner son consentement avec la plus grande satisfaction et sans faire la moindre objection. 


\section{Contes chinois}

Les prétendans lui dirent que tout le monde craignait sa femme, ce qui était cause que personne ne voulait agir comme entremetteur, et ils lui demandèrent ce qu'il fallait faire.

- Quand les parties sont étrangères l'une à l'autre, répondit-il, il est nécessaire de se servir de ces sortes d'agens ; mais quand j'ai déjà donné mon consentement, que faut-il de plus ?

Cette réponse fit grand plaisir aux prétendans, et on choisit un jour heureux peur l'envoi et pour la réception des présens de noces.

Le plan du mari était conforme à celui de sa femme, et il avait décidé, ainsi qu'elle, de ne rien faire connaître d'avance, mais de laisser l'événement s'annoncer quand il aurait lieu. Le hasard voulut que les deux partis eussent choisi le même jour heureux et que les cadeaux des quatre prétendus fussent apportés au même instant à la porte. Les tamtams faisaient un si grand bruit et les différens objets qui composaient les présens étaient tellement étalés qu'on ne pouvait distinguer au nom de qui ils étaient offerts.

Il vint d'abord à l'idée que les fiancés, connaissant la mauvaise intelligence qui régnait entre les parens des demoiselles, et dans la crainte d'offenser I'un ou l'autre, avaient envoyé deux billets de cérémonie, I'un pour Siao-kiang, I'autre pour sa femme, pensant qu'il valait mieux mettre trop de cérémonie que pas assez. Quand on en vint à examiner ces billets de plus près, il se trouva, au grand étonnement de tous 


\section{Contes chinois}

deux, que les noms ne se rapportaient pas et que chacune des cartes offrait des titres différens.

Le père et la mère se regardaient avec étonnement et ils éclatèrent en même temps.

- D'où viennent, s'écria l'un, ces deux misérables qui se sont joints à mes gendres ? Qui est-ce qui a envoyé tous ces présens pour être placés près des miens ?

- Qui aura l'audace, dit-il à sa femme, de recevoir un seul de ces cadeaux sans mon consentement ? c'est moi qui suis le maître de la maison.

- Et sans ma permission, à moi qui suis la maîtresse, répliqua-t-elle, qui osera toucher à rien de ce qui est ici ?

A quoi le bon homme répondit :

- C'est une maxime que la femme avant son mariage doit obéir à son père et ensuite à son mari ; mes filles doivent donc maintenant m'obéir à moi qui suis leur père ; et quant à vous, j'ai le droit de vous gouverner puisque je suis votre mari. Pourquoi donc vous conduisez-vous de cette manière ?

- C'est, répliqua-t-elle sur-le-champ, une autre maxime, que le père doit avoir la direction du mariage de son fils, mais que celui de la fille regarde sa mère ; s'il s'agissait d'un fils, vous pourriez donc faire comme il vous plairait : dans ce cas-ci, c'est moi seule qui ai le 


\section{Contes chinois}

droit de commander ; sous quel prétexte voulez-vous donc vous mêler de mes affaires?

Des paroles, ils en seraient bientôt, venus aux coups, si ceux qui étaient auprès d'eux ne les en eussent empêchés en les tenant séparés. La femme ne voulait plus rien entendre ; elle reçut les présens de ses protégés dans l'ordre où ils étaient inscrits et dit aux gens d'aller rendre sa réponse. En même temps, elle donna ordre de mettre tous les autres objets hors de la porte et ne voulut pas qu'il en restât un seul dans la maison.

Son mari fut, comme de raison, très en colère de ce procédé, et, à son tour, il ordonna qu'on les rapportât tous, et, après avoir vidé lui-même les boîtes et les jattes, il écrivit une réponse qu'il envoya.

Il se doutait bien qu'il faudrait, en définitif, porter ce double mariage devant les magistrats ; mais il différa de faire un rapport écrit, afin de voir ce qu'il pourrait obtenir par des mesures fortes et décisives. Il pria les parens des gendres qu'il s'était choisis de louer plusieurs hommes vigoureux pour les aider à enlever ses filles de force, pensant que si cette mesure venait à manquer, il serait encore à temps de présenter un mémoire.

Les parens adoptèrent cette idée avec empressement et choisirent un jour peu éloigné pour la célébration des noces. Ils payèrent une troupe $d$ 'hommes déterminés pour suivre les chaises à porteurs, dans l'espoir qu'ils réussiraient par le nombre. 


\section{Contes chinois}

Il leur restait à apprendre que ce projet eût pu être bon, s'ils avaient eu affaire à un homme, mais qu'un ennemi femelle n'est pas si vite abattu. La femme se plaça à sa porte, avec un des barreaux à la main, et à son air décidé, on voyait aisément qu'elle n'aurait aucune pitié de ceux qui essaieraient de passer le seuil. Tous s'enfuirent comme des souris vers leurs trous, en laissant derrière eux la moitié des chaises à porteurs, des lanternes et des torches, ce qui pouvait s'appeler lever des contributions sur les vaincus. La dame s'empara de tous ces objets, et les garda pour son propre usage.

Son mari, très irrité, alla sur-le-champ pour engager ses amis à présenter sans délai une requête ; mais ces gens savaient bien qu'elle n'aurait pas de succès dans cette circonstance, et qu'il n'était pas d'habitude que des personnes s'appartenant de si près eussent recours aux lois I'un contre l'autre. Ils résolurent donc de ne pas se mettre en opposition ouverte avec la femme, mais d'exposer qu'ils avaient été repoussés avec violence de la porte de Siao-kiang, et de laisser d'abord tomber tout le blâme sur lui ; ils s'adressèrent au Tchi-fou, le premier magistrat du district, au lieu du Tchi-hian. Lorsqu'ils eurent présenté leur requête, le mari envoya, par forme de réponse, le récit des faits, tels qu'ils s'étaient passés. Les deux amis firent aussi des mémoires particuliers ; et comme ils trouvaient peu convenable de mettre une femme mariée trop en évidence dans une telle circonstance, ils se contentèrent de la placer en tête des témoins, disant qu'elle était la mère des deux filles qu'on avait fiancées, et que le magistrat devait l'interroger. 


\section{Contes chinois}

Il se trouva que dans ce moment la charge de premier magistrat était exercée par un. lieutenant ; il n'y avait pas longtemps qu'il occupait cette place; mais il jouissait de la réputation d'un homme droit, et il avait acquis dès sa jeunesse un rang distingué dans la littérature. Quand la requête lui eut été remise, il donna ordre qu'on affichât un avis fixant à quelques jours l'époque du jugement. Il fit venir d'abord le mari pour I'interroger, et ensuite les quatre autres parties, ainsi que toutes les personnes mentionnées dans le mémoire, à l'exception de la femme ; il supposait qu'étant sous la direction d'un mari, son témoignage ne pouvait être que conforme au sien, puisqu'il n'était pas ordinaire qu'un mari et une femme différassent d'opinion dans un cas semblable.

Il ne se doutait guère que dans cette circonstance, la mère des jeunes fiancées était l'ennemie des futurs beaux-pères ; il avait bien déjà vu des procès entre amis, mais rarement entre des personnes si étroitement liées. Lorsque la femme remarqua qu'on ne l'appelait pas en témoignage, elle se plaignit hautement de l'injustice qu'on lui faisait, ce qui obligea le mandarin à I'envoyer chercher.

- Quoiqu'il veuille se piquer d'être un homme, dit-elle en montrant son mari, il n'en a pas le jugement, et chacun à qui il en prendra fantaisie pourra en faire sa dupe ; il n'a aucun égard au bonheur de ses filles, et les maris qu'il leur a choisis sont les plus mal famés du quartier ; voilà pourquoi j'ai cherché à les mieux 


\section{Contes chinois}

pourvoir, et que je n'ai pas voulu lui laisser diriger cette affaire.

Quand elle eut fini de parler, le mandarin trouva qu'elle avait quelque raison, et fit appeler le mari, afin de l'interroger encore. Celui-ci dit que sa femme était d'un caractère violent, et qu'elle cherchait toutes les occasions d'humilier et de contrecarrer son mari ; que dans les circonstances ordinaires, il prenait patience ; mais que le mariage de ses filles était un objet de trop haute importance, pour qu'il consentît à lui abandonner ses droits.

Le juge, voyant qu'il avait aussi raison, se trouva fort embarrassé pour décider entr'eux. S'adressant donc à tous deux, il leur dit :

- Suivant l'usage, le mari a le droit d'être l'arbitre dans la question qui nous occupe; mais dans les affaires de famille, il est quelquefois impossible de se conformer entièrement aux règles générales, et de juger les choses d'une manière tout à fait abstraite. Restez ici jusqu'à ce que j'aie fait venir vos filles pour entendre ce qu'elles peuvent avoir à dire, et pour savoir lequel à leur avis a mieux choisi pour eux, de leur père ou de leur mère.

Le mari et la femme se prosternèrent et dirent qu'ils étaient très satisfaits de cet arrangement.

Alors le mandarin donna un ordre écrit pour faire paraître les deux filles, et envoya du monde pour les chercher. Lorsque ces gens furent partis, il se dit à lui-même que, d'après la tournure commune et grossière des parens, il n'était pas probable qu'il 


\section{Contes chinois}

sortît de belles fleurs de semblables roseaux ; mais que si les filles étaient encore plus laides que leurs parens, il était difficile de dire où cela s'arrêterait. Il attendit donc leur arrivée avec une contenance où la surprise se peignait d'avance. Aussitôt qu'elles parurent, tous les officiers subalternes et les gens de service, oubliant leur réserve habituelle, se pressèrent en foule pour les regarder comme si quelque prodige fût tombé des nues; le mandarin lui-même fut également étonné et ne pouvait deviner comment ces deux beautés célestes se trouvaient ainsi transportées là. Heureusement pour lui, ses émissaires vinrent au moment même lui annoncer que les filles d'un tel étaient arrivées : il reconnut alors que pour cette fois des roseaux avaient produit la beauté, et que non seulement les filles étaient supérieures à leurs parens, mais qu'elles n'avaient gardé aucune ressemblance avec eux.

Lorsqu'il fut revenu de sa surprise, il leur parla ainsi :

- Il paraît que votre père et votre mère, ne pouvant s'accorder ensemble, vous ont fiancées à quatre personnes différentes, et ont enfin eu recours à moi pour terminer leur débat. Votre père dit que sa femme est dans son tort ; elle, de son côté, se plaint de lui : il est reconnu depuis longtemps qu'il n'est guère possible à un magistrat intègre de se mêler des affaires de famille ; je vous ai donc fait venir pour m'informer de vous lequel de votre père ou de votre mère agissait ordinairement avec le plus de circonspection et de discernement. 


\section{Contes chinois}

Toutes deux étaient naturellement timides et honteuses, et la vue d'un homme même seul les aurait disposées à s'enfuir ; qu'on juge donc de l'embarras où elles durent se trouver ayant tant de regards fixés sur elles ; elles étaient prêtes à se cacher sous la table.

Le juge fut plus clairvoyant que les autres. Après les avoir observées quelque temps, il leur demanda comment elles pourraient répondre si elles étaient si timides. Voyant qu'elles ne disaient pas un seul mot, quoiqu'il eût répété sa question plusieurs fois, il commença à n'écouter que le témoignage de leurs yeux qui semblaient dire que leurs parens avaient tous deux quelque tort ; mais qu'il ne convenait pas à leurs elles de le déclarer.

Le juge saisit leur pensée et se dit :

- Il ne faut pas que deux si charmantes personnes appartiennent à des maris ordinaires ; je ne veux plus demander qui a raison ou du père ou de la mère ; mais je ferai venir les quatre prétendus pour les comparer ensemble, et si les jeunes personnes consentent à en épouser deux d'entr'eux, je les unirai.

Ayant pris cette décision, il se disposait à écrire un ordre pour les faire comparaître, lorsque les quatre pères s'agenouillèrent devant lui, en disant :

- Il n'est pas nécessaire que votre seigneurie envoie un ordre : nos fils sont tous à attendre dehors, chacun d'eux espérant que sa femme lui sera accordée. Pouvons-nous les faire entrer ? 


\section{Contes chinois}

- S'il en est ainsi, dit le juge, dépêchez-vous de les appeler.

Ils sortirent tous quatre et revinrent aussitôt amenant chacun leur fils, en disant :

- Voici mon fils, j'espère que votre seigneurie voudra bien lui adjuger sa femme.

Le juge cependant secoua la tête et examina minutieusement les quatre jeunes gens qui semblaient sortir de la même souche, ayant la tournure la plus commune et la plus étrange. Loin d'avoir bonne mine, il n'y en avait pas un seul dont les membres ou les traits n'offrissent quelque défaut.

« Vouloir choisir un mari parmi ces quatre personnages, se dit le juge, serait comme si on cherchait un héros parmi des nains. Comment puis-je donc l'essayer ? Je ne pensais pas qu'un si mauvais sort fit échu en partage à tant de beauté.

Alors il soupira et faisant placer les protégés du père à gauche et ceux de la mère à droite, il dit aux jeunes filles de se mettre à genoux au milieu ; puis il leur parla ainsi :

- Tous ceux à qui votre père et votre mère vous ont promises sont ici présens ; je vous ai déjà demandé de faire connaître vos véritables sentimens ; mais puisque vous n'avez pas voulu parler, je suppose que vous avez été d'abord empêchées par la honte, et ensuite par l'embarras de vous expliquer sur les défauts de vos parens ; maintenant je ne vous demande pas de prononcer un seul mot, mais de tourner un peu la tête 


\section{Contes chinois}

d'un côté ou de l'autre, et d'indiquer ainsi quels sont vos vrais désirs. Si vous voulez épouser les favoris de votre père, tournez-vous à gauche; si au contraire vous préférez ceux de votre mère, tournez-vous à droite ; mais souvenez-vous que de ce léger mouvement dépend le bonheur du reste de vos jours. Ainsi donc prenez garde à faire un bon choix.

Lorsqu'il eut prononcé ces mots, les yeux de toute l'assemblée se fixèrent avec intérêt sur les deux jeunes demoiselles pour voir de quel côté elles tourneraient la tête. Elles cependant, au moment où les prétendans étaient entrés, les avaient regardés ; et en remarquant leur mauvaise mine, elles avaient laissé tomber la tête et fermé les yeux, en laissant couler leurs larmes en silence. Lorsque le juge eut fini de leur parler, elles ne se tournèrent $\mathrm{ni}$ à droite ni à gauche, mais elles restèrent immobiles, avec la figure dirigée vers lui et se mirent à pleurer tout haut. Plus il les pressait de parler, plus elles sanglottaient, au point que tous les assistans se mirent à pleurer par sympathie, et prirent une grande part à leur peine.

- Il paraîtrait d'après ceci, dit le juge que les personnes que vos parens ont choisies ne vous conviennent pas, ainsi vous n'avez pas besoin de songer à en épouser aucun ; je me charge moi-même de vous marier. Ce serait une chose inexcusable que de donner à des rustres deux personnes telles que vous. Mettez-vous sur le côté, j'ai d'avance arrangé les affaires. Appelez le père et la mère. 


\section{Contes chinois}

Ils vinrent tous les deux et se mirent à genoux devant la table, sur laquelle le juge donna un coup de poing en disant avec colère :

- Il faut que vous soyez dénués de tout principe pour traiter le bonheur de vos filles comme de simples jeux d'enfans. Si vous vouliez les marier, il fallait vous entendre ensemble, et voir si les parties pouvaient se convenir, sans chercher à unir des personnes qui se ressemblent si peu. Vous pouvez juger par ce qui vient de se passer ici du résultat probable qu'aurait amené cette union si elle avait eu lieu ; il est très heureux que cette affaire ait été apportée devant moi ; je la terminerai d'une manière tout opposée à ce qui se fait communément. Si vous vous étiez adressés à un autre magistrat, il aurait suivi la voie ordinaire et aurait adjugé vos filles aux uns ou aux autres parmi les prétendans. Ainsi le bonheur de ces deux jeunes femmes aurait été détruit par un seul coup de son pinceau. Elles n'épouseront aucun de ceux à qui elles avaient été promises ; je vais charger quelqu'un de leur procurer un parti convenable. Ne croyez pas qu'en prenant ce parti je consulte mes vues privées ou que je veuille violer la justice; au contraire, j'agis suivant la raison et les convenances ; attendez jusqu'à ce que j'aie publié un arrêt dont vous serez tous satisfaits.

Il prit alors son pinceau et se mit à écrire la pièce suivante : 


\section{Contes chinois}

- Il paraît que Siao-kiang et sa femme ayant deux filles jumelles d'une beauté extraordinaire, plusieurs personnes ont désiré les obtenir en mariage, et ont employé différens moyens pour parvenir à leur but. Comme le père et la mère n'étaient pas d'accord, et que les agens d'un parti essayaient de tromper le mari, tandis que ceux de l'autre tâchaient d'agir à l'insu de la femme, il s'en est suivi des méprises et de la confusion. Ils avaient choisi quatre maris pour les deux mariées, et comme ces deux dernières ne pouvaient se diviser, il a été impossible que le mariage s'effectuât.

Comme les deux filles semblent avoir de la répugnance pour ceux qu'on leur destinait, j'ai été touché de leur malheur, et je me suis départi de la route ordinaire, afin d'accomplir un acte de bienveillance sans enfreindre les lois pour mon intérêt particulier. Dans tous les contrats de mariage le consentement du père et de la mère, ainsi que l'entremise des négociateurs, sont indispensables. Ici, quoique les protégés de la mère aient eu des négociateurs, ils n'ont pas obtenu le consentement du père. Ainsi je donnerais un exemple dangereux en sanctionnant leurs prétentions ; et quoique les protégés de Siao-kiang aient eu le consentement du père, il n'y a pas eu de négociateurs, et si je les favorisais, l'exemple serait également pernicieux, et les deux jugemens blesseraient à la fois et la loi ancienne et les opinions modernes. Les quatre prétendans n'ont donc qu'à chercher d'autres femmes, 


\section{Contes chinois}

car ces deux-ci ne peuvent leur appartenir : il vaut mieux qu'ils soient séparés maintenant que d'être malheureux, une fois qu'ils seraient unis ainsi. Quoique cette décision vienne de la compassion que m'a inspirée I'une des deux parties, elle est également dans l'intérêt de l'autre ; il n'est pas nécessaire que personne me fasse de réclamations à ce sujet ce jurement est définitif.

Après qu'on eut expédié le jugement, il le fit lire à haute voix par un crieur. On renvoya tout le monde, sans qu'il fût permis à qui que ce fût de faire aucune observation ultérieure. On envoya prévenir les agens que le magistrat voulait employer pour procurer des partis convenables aux jeunes demoiselles, en leur ordonnant, dès qu'ils auraient réussi dans leurs recherches, d'avertir le magistrat qui permettrait que le mariage eût lieu s'il approuvait le choix des personnes.

Ces agens, après avoir mis beaucoup de soin dans leurs recherches, amenèrent plusieurs jeunes gens qui n'obtinrent pas l'agrément du juge, quoiqu'ils eussent été annoncés comme capables de le mériter. Il s'arrêta donc à un autre expédient, et résolut de choisir, pour ces deux jeunes filles, des maris suivant leur mérite littéraire, de manière qu'ils possédassent le talent aussi bien que les agrémens personnels.

Il arriva que des paysans, qui avaient attrapé tout récemment un couple de daims vivans, en firent présent au magistrat, ce qui s'arrangeait parfaitement avec le projet qu'il venait de former. Il fit publier un avis qui fixait le jour pour un examen littéraire, et 


\section{Contes chinois}

qui ordonnait aux compétiteurs de mettre simplement sur l'enveloppe de leurs compositions s'ils étaient mariés ou non, au lieu de marquer leur âge, suivant la coutume, ajoutant que l'examen périodique pour les degrés littéraires n'étant pas éloigné, il souhaitait de se former d'avance une idée du mérite des candidats ; que, pour ceux qui n'étaient pas mariés, deux charmantes filles seraient le prix accordé ; qu'aux autres déjà mariés on donnerait une paire de daims très rares, et que ceux qui emporteraient le prix seraient les premiers candidats littéraires de l'année.

Dans l'endroit où se font les examens, il y avait un bâtiment vacant. Le juge envoya chercher la mère avec ses deux filles pour les établir dans l'étage supérieur et fit mettre les daims dans un endroit au-dessous. Dès que l'avis fut publié, il éveilla l'ardeur de tous les candidats des districts environnans. Ceux qui étaient déjà mariés étaient principalement animés par le désir du succès, et ne considéraient les daims que comme en étant le gage. Les jeunes gens qui étaient encore garçons voyaient avec plaisir la chance qui leur était offerte d'obtenir tout à la fois et des honneurs littéraires et une épouse charmante.

Quand le jour de l'examen arriva, ils firent les plus grands efforts pour mériter une si belle récompense, et l'examen fini, loin de penser à retourner chez eux, ils restèrent tous en place pour apprendre de suite le résultat du concours.

Trois jours après, on publia une liste où il y avait environ dix personnes par district désignées pour être examinées de nouveau. Ceux qu'on avait choisis se doutèrent bien que le 


\section{Contes chinois}

second examen avait moins pour but de déterminer leur mérite littéraire que celui de leur personne, et les jeunes gens d'entre eux qui avaient bonne mine commencèrent à concevoir de grandes espérances.

Au jour désigné, ils mirent le plus grand soin à s'habiller et à se parer, s'efforçant, lorsqu'ils se présentèrent devant le juge, de prendre la physionomie la plus agréable, dans l'espoir que celuici serait charmé de leur air et qu'il les placerait en tête des candidats.

Le juge était aussi capable de discerner leurs qualités extérieures que leur mérite et leurs connaissances, et, désirant s'assurer des premières, il faisait ses observations à mesure qu'on appelait leurs noms, et remarquait si leur tournure annonçait des gens riches et de bonne famille.

Lorsque l'examen fut terminé, il dit à I'huissier de réunir des musiciens le lendemain matin, et d'aller ensuite chercher les deux demoiselles et les daims, et de les conduire à son tribunal avant son arrivée. On devait mettre les daims d'un côté de la salle et faire placer de l'autre les deux dames assises dans les chaises ornées dont on se sert pour les noces. On devait aussi tenir prêtes les lanternes entourées de fleurs et la musique, afin de faire le mariage de suite.

Lorsque le juge eut donné ses ordres, il retourna chez lui pour examiner les compositions. Le lendemain, à la pointe du jour, il publia une liste contenant le nom des quatre candidats qui avaient réussi, dont deux étaient mariés et deux étaient garçons. Les autres candidats qu'on avait classés suivant leur mérite 


\section{Contes chinois}

devaient recevoir quelques marques de distinction moins considérables. Il n'y a pas lieu de remarquer ceux qui obtinrent les daims, ainsi nous ne les nommerons pas. L'un des deux qui avaient mérité les demoiselles était un gradué, nommé Tsi-tsin ; l'autre, un plus jeune candidat, s'appelait Tchi-wen.

Tous ceux qui avaient été mentionnés à l'examen entrèrent dans la salle d'audience pour apprendre le résultat. Quand ils eurent remarqué de quel côté étaient les deux dames, ils s'y portèrent en foule pour voir celles dont la beauté était si célèbre, et cette partie de la salle fut remplie de spectateurs. Du côté où on avait mis les daims, un seul jeune homme' en costume de gradué, était debout, l'air triste, et ne témoignant aucun désir d'aller contempler les deux beautés. Quelques personnes dans la salle l'ayant remarqué, pensèrent qu'il devait être un des candidats mariés qui avaient réussi, et que, sachant qu'aucune des deux dames ne pouvait lui appartenir, mais qu'il avait du moins gagné un des daims, il était venu d'avance faire son choix, afin de prendre la plus belle, quand l'instant du partage serait arrivé.

Cependant, à la grande surprise de ces personnes, quelquesuns des candidats qui étaient de l'autre côté de la salle vinrent à lui, et lui dirent en le saluant :

- Nous vous félicitons, monsieur, une de ces belles dames vous appartient.

Mais le gradué fit un signe de refus avec la main en disant :

- Je n'ai rien à démêler avec elles. 


\section{Contes chinois}

- Comment, s'écrièrent-ils tous, vous êtes le premier des quatre candidats heureux, vous n'êtes pas marié, et vous pouvez dire que vous n'avez rien à démêler avec elles.

- Le juge va bientôt paraître, répondit-il, et alors vous saurez tout.

Les assistans ne pouvaient deviner ce qu'il voulait dire, et supposaient qu'il ne parlait ainsi que par modestie.

Lorsqu'on eut battu trois fois du tambour, le juge entra dans la salle, et tous ceux dont le nom avait été distingué s'avancèrent pour le saluer.

- Quels sont les candidats heureux, demanda-t-il alors ? Je les prie de se placer à part, afin que je puisse leur parler.

Quand il eut fini ce discours, I'huissier lut sa liste tout haut. Outre Tsi-tsin, il aurait dû en paraître trois autres, mais il n'y en avait que deux présens, et ils étaient tous deux mariés, celui qui ne l'était pas était absent.

Alors le juge s'écria :

- Comment se fait-il que dans une circonstance comme celle-ci, il ne soit pas ici ?

- C'est un de mes amis, répondit Tsi-tsin, et il demeure dans le même district que moi ; n'ayant pas été prévenu de l'affaire d'aujourd'hui, il ne sera pas venu.

- Est-ce vous, monsieur, qui êtes le gradué Tsi-tsin, lui dit le juge ? J'ai admiré votre mérite et votre savoir : il 


\section{Contes chinois}

ne pouvait y avoir de doute sur vos succès dans cet examen. Les deux dames sont véritablement très belles, et c'est une justice du ciel de leur avoir accordé deux maris d'un si grand mérite.

A ces paroles, Tsi-tsin s'inclina, et répondit :

- Votre seigneurie a trop de bonté ; mais je suis un homme dont la destinée est malheureuse, et je suis indigne de jouir d'une si grande félicité : je vous prie de choisir quelqu'un pour me remplacer, car je ne voudrais pas troubler le bonheur de l'épouse qu'on me destinerait.

- Que signifie ceci, s'écria le juge, quel peut être le motif de cet étrange refus ? Dites à I'huissier de demander aux deux dames laquelle est l'aînée et de l'engager à venir vers son mari.

Tsi-tsin s'inclina de nouveau, et arrêtant I'huissier, il le pria de n'y pas aller.

- Quelle est la raison de cette conduite ? dit le juge.

- C'est mon malheureux destin, répliqua Tsi-tsin, qui me condamne au célibat, puisque je ne dois jamais être uni à une femme. Toutes celles à qui j'ai fait des propositions de mariage ne m'ont pas été plus tôt fiancées qu'elles sont tombées dangereusement malades et qu'elles sont mortes ; de cette manière, j'ai été successivement la cause innocente de la mort de six jeunes personnes, avant d'avoir atteint ma vingtième 


\section{Contes chinois}

année. Tous les astrologues que j'ai consultés disent que je ne dois jamais avoir une femme, et qu'ainsi je devrais me faire prêtre, soit de la religion de Fo ou de celle de Tao, et quoique je sois maintenant dans la classe des lettrés, il faut que j'abandonne bientôt l'étude pour devenir prêtre. Je ne veux plus mettre en danger la vie d'aucune jeune femme pour ajouter par-là au nombre de mes péchés.

Le juge l'ayant écouté, lui répliqua :

- Pourquoi prendriez-vous ce parti ? il y a peu de confiance à accorder à de semblables prédictions. Les devins qui vous les ont faites n'étaient que des ignorans, et si vous avez été malheureux dans vos premières recherches de mariage, c'est un effet du pur hasard ; pourquoi donc vous conduisez-vous comme un homme qui a une obstruction dans le gosier et qui ne peut manger ? Quoique votre résolution semble prise, je n'y donnerai pas mon consentement. Toutefois j'ai une observation à faire : comment se fait-il que le candidat Tchi-wen ne soit pas présent ? J'avais choisi un jour heureux, afin qu'il pût venir se marier ; et comme l'écriture de son second morceau n'est pas la même que celle du premier, j'aurais voulu le questionner un peu à ce sujet. Que signifie son absence?

Tsi-tsin, en entendant ce discours, répondit :

- C'est un secret que je ne devrais pas divulguer; mais, d'après ce que votre seigneurie vient de dire, je 


\section{Contes chinois}

serais peut-être plus coupable, si je le cachais plus longtemps. Ce candidat est un de mes amis intimes; comme il est très pauvre et qu'il n'a pas de quoi se marier, j'avais formé le dessein de l'aider. Les compositions sont toutes deux de moi : la première est de son écriture ; mais, à cause de son absence, j'ai écrit la seconde pour lui. J'avais résolu de lui céder le prix si j'obtenais la première place ; je ne m'attendais pas à ce que, par un bonheur extraordinaire, nous serions tous deux préférés ; puisque la grande pénétration de votre seigneurie vous a fait découvrir la vérité, mes efforts pour servir mon ami ont tourné à son détriment. Je suis forcé d'implorer de vous son pardon et de vous prier de lui accorder vous-même ce que je voulais lui faire obtenir.

- Les choses sont-elles ainsi ? reprit le juge. Si je n'avais heureusement tiré de vous la vérité, j'aurais fait une grande injustice à une de ces deux dames ; puisque c'est vous qui avez fait les deux compositions, la première et la seconde place vous appartiennent également, et les deux dames sont à vous. Chacun peut prétendre aux honneurs et à la richesse ; mais on trouve rarement une beauté aussi parfaite que celle de ces charmantes personnes. Celui-là seul qui est digne d'elles doit les obtenir, et non pas un prétendant qui n'a que des droits supposés. Que l'officier fasse immédiatement approcher les jeunes dames, et que le mariage soit accompli. 


\section{Contes chinois}

Tsi-tsin persistait avec obstination dans son refus, observant qu'il était impossible à un homme d'épouser deux femmes, lorsque sa mauvaise fortune l'avait empêché d'être uni à une seule.

- Ce qui est arrivé aujourd'hui, dit le juge en riant, est exactement conforme à votre destinée. En vous interdisant un mariage unique, on a voulu dire que vous ne pourriez former un couple. Si vous épousiez une seule femme, alors vous feriez un couple et vous pourriez redouter les fâcheuses influences de votre destinée ; mais maintenant que vous allez avoir deux femmes, il y aura une personne de plus que le couple et cela s'accordera merveilleusement avec la prédiction. Ceci fait voir que tel en était le véritable sens, et par conséquent vous n'avez plus à craindre le retour de vos malheurs passés.

Lorsqu'il eut fini de parler, tous les assistans exprimèrent leur approbation, en disant que ce jour-là la décision du juge avait commencé pour Tsi-tsin une nouvelle destinée et que l'explication qu'il venait de donner était admirable ; ils conseillèrent à Tsi-tsin de renoncer à sa résolution et de se joindre aux dames pour remercier le juge. Il n'y avait pas d'alternative pour Tsi-tsin et il fut obligé de céder. Accompagné des deux dames, il se tenait debout devant le juge et tous trois saluèrent leur bienfaiteur. Tsi-tsin demanda alors son cheval et accompagna les deux chaises ornées chez lui. Lorsqu'il fut parti, on distribua les récompenses inférieures. Tous ceux qui avaient été témoins du bonheur de Tsi-tsin s'écrièrent que sa félicité 


\section{Contes chinois}

égalait celle des dieux immortels et qu'il en était redevable à l'estime que le juge faisait du talent et du mérite.

Trois personnes seulement avaient réussi à cet examen ; les droits de la quatrième n'étaient que supposés et il était juste que celui qui avait composé pour elle eût la récompense.

Peu de temps après, Tsi-tsin fut élevé à un plus haut rang littéraire. Cette décision donna tant de célébrité au nom du juge, qu'elle parvint enfin à la cour ; l'empereur l'appela à Péking, et lui confia un emploi dans le tribunal de la guerre. Tsi-tsin fut promu à une place dans le collège des lettrés et continua de vivre avec son ami le juge, sur le pied de père et de fils. Ainsi se trouva vérifiée l'ancienne maxime qui dit qu'il n'y a que les gens de mérite qui puissent distinguer le mérite. 


\section{Contes chinois}

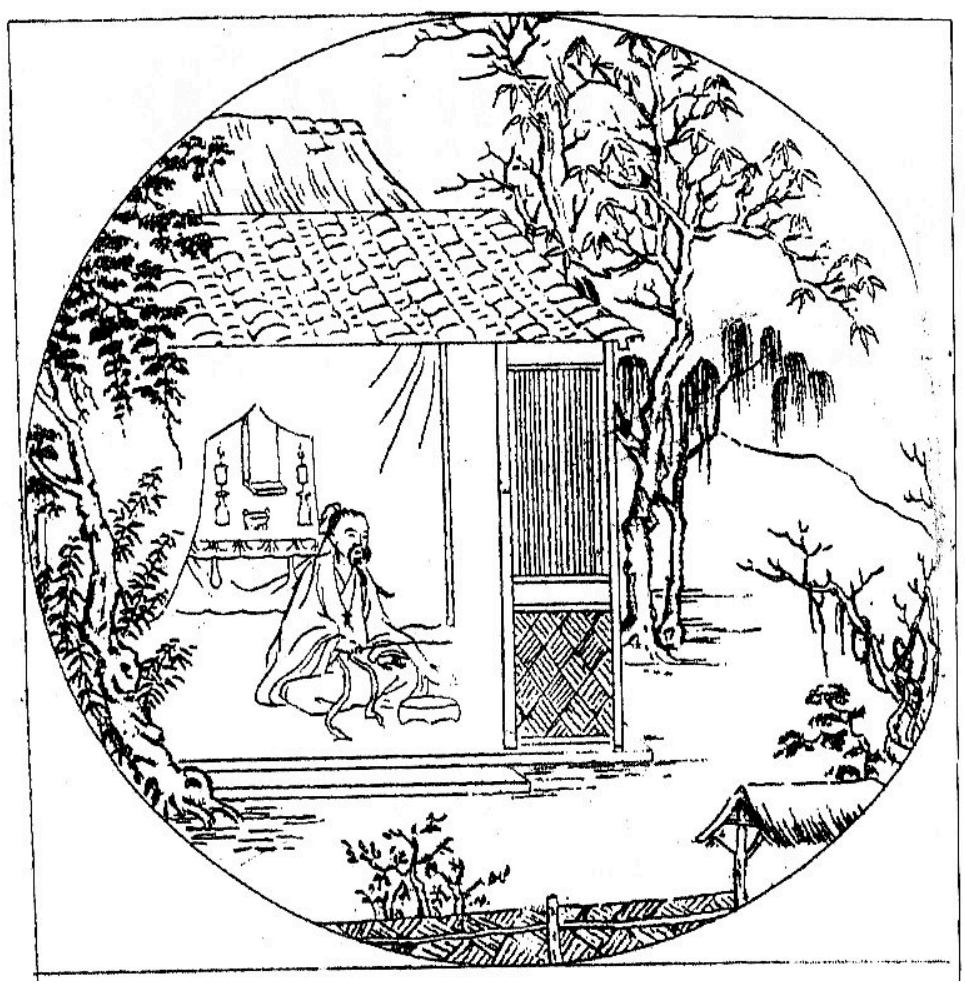

\section{LA MATRONE DU PAYS DE SOUNG.}

Les richesses et les avantages qui les suivent sont comme un agréable songe de quelques momens.

Les honneurs et la réputation ressemblent à un nuage brillant, mais qui est bientôt dissipé.

L'affection de ceux-là mêmes que la chair et le sang unissent, n'est le plus souvent qu'une vaine apparence.

Les amitiés les plus tendres se changent quelquefois en de cruelles inimitiés.

Gardons-nous d'aimer à porter un collier parce qu'il est d'or, Et des chaînes, parce qu'elles sont de pierreries.

Purifions notre cœur, modérons nos désirs et détachons-nous des affections terrestres.

Regardons comme un point capital de nous conserver dans un état de liberté et de joie qui ne dépende de personne. 


\section{Contes chinois}

En se garantissant de toute passion violente, on mène une vie douce et agréable, loin des inquiétudes qui nuisent à la santé. Ce n'est pas qu'on veuille blâmer l'amour naturel qui lie un père avec son fils, ou qui unit des frères ensemble. Ils sont les uns aux autres ce que sont les branches d'un arbre avec le tronc. Cet amour doit durer autant que ce rapport mutuel. Gardez-vous de travailler pour eux comme un cheval ou une bête de somme.

Les sectes de Tao et de Fo, quoique très différentes de la secte littéraire, s'accordent avec elle sur ces grands devoirs, et n'ont jamais pensé à les combattre ou à les affaiblir. Il est pourtant vrai que l'amour des pères pour les enfans ne doit pas jeter dans des inquiétudes excessives, quand il s'agit de procurer leur établissement : aussi dit-on communément : La fortune des enfans doit être leur propre ouvrage.

Pour ce qui est du mari et de la femme, ils sont unis très étroitement, et par des liens infiniment respectables ; mais enfin, ou le divorce, ou la mort, rompent souvent cette union. C'est ce que nous apprend le proverbe qui dit : L'époux et l'épouse sont comme des oiseaux de la campagne; le soir les réunit dans un même bocage, et le matin les sépare. Il faut pourtant l'avouer ; il y a bien moins à craindre l'excès dans I'amour paternel que dans l'amitié conjugale. Celle-ci s'entretient et s'accroît en secret dans des tête-à-tête, et par de grands épanchemens de cœur. Ainsi il n'est pas rare qu'une jeune femme se rende maîtresse de l'esprit d'un mari, et de là naissent les refroidissemens d'un fils envers son père. Ce sont de ces défauts grossiers, dont les gens de mérite savent bien se défendre.

A ce sujet je vais raconter un trait de la vie du fameux Tchouang-tseu ; mais je proteste d'abord que ce que je dirai ne 


\section{Contes chinois}

tend point à affaiblir l'union et la paix qui doivent régner entre les gens mariés. Je prétends seulement faire voir qu'on doit être attentif à distinguer le vrai et le faux mérite pour régler son affection. A parler en général, celui qui travaille sans relâche à dompter ses passions s'en rendra enfin le maître ; la sagesse sera son partage, et une vie douce et tranquille sera le fruit de son travail.

Nos anciens, voulant moraliser sur la manière dont le laboureur cultive son champ, se sont exprimés ainsi dans les vers suivans :

Il transplante le riz en herbe dans une terre nouvellement défrichée.

En peu de temps il voit dans ce champ verdoyant et inondé l'image d'un beau ciel azuré.

Notre cœur est ce champ ; il a sa parure et ses richesses lorsque les passions y sont pures et réglées.

Il ne faut que quelques pas, et déjà le sage a fait des progrès dans la vertu.

Sur la fin de la dynastie des Tcheou, parut à la Chine un fameux philosophe appelé Tchouang-tseu. Il naquit à Meng, ville du royaume de Soung ${ }^{1}$. Il eut un petit mandarinat, et il se fit disciple d'un sage très célèbre en ce temps-là, et auteur de la secte du Tao. Son nom était $\mathrm{Li}$, et son surnom Eul. Mais comme il était venu au monde avec des cheveux blancs, il fut appelé Lao-tseu, c'est-à-dire, I'enfant vieillard.

Toutes les fois que Tchouang-tseu dormait, son sommeil était interrompu par un songe. Il s'imaginait être un gros papillon voltigeant çà et là, ou dans un verger, ou dans une prairie.

${ }^{1}$ C'est la province de Chan-tong. 


\section{Contes chinois}

L'impression de ce songe était si forte, que même à son réveil il croyait avoir des ailes attachées aux épaules, et qu'il était près de voler. Il ne savait que penser d'un rêve si fréquent et si extraordinaire.

Un jour profitant d'un moment de loisir, après un discours de son maître Lao-tseu sur le Yi-king ${ }^{1}$, il lui proposa le songe qui se formait si souvent dans son imagination, et lui en demanda l'explication.

- La voici, répondit cet homme admirable, qui n'ignorait rien des merveilles de la nature. La cause de ce songe opiniâtre doit se chercher dans les temps qui ont précédé celui où vous vivez. Sachez qu'au temps que le chaos se débrouilla, et que cet univers fut formé, vous étiez un beau papillon blanc. Les eaux furent la première production du ciel : la seconde, ce furent les arbres et les plantes dont la terre fut parée, car tout fleurit et brilla à l'instant. Ce beau papillon blanc errait à son gré, et allait flairer les fleurs les plus exquises. Il sut même tirer du soleil et de la lune des agrémens infinis; il se procura enfin une force qui le rendit immortel. Ses ailes étaient grandes et presque arrondies, son vol était rapide.

Un jour qu'il prenait ses ébats, il s'attacha à des fleurs du jardin de plaisance de la grande reine, où il avait trouvé le secret de s'insinuer, et gâta quelques boutons à peine entr'ouverts. L'oiseau mystérieux à qui on avait

${ }^{1}$ Livre canonique de la Chine. 


\section{Contes chinois}

confié la garde de ce jardin donna au papillon un coup de bec dont il mourut.

Il laissa donc sans vie son corps de papillon ; mais l'ame qui était immortelle ne se dissipa point ; elle a passé en d'autres corps et aujourd'hui elle se trouve dans celui de Tchouang-tseu. C'est là ce qui met en vous de si heureuses dispositions à devenir un grand philosophe, capable de s'élever, d'acquérir l'art que j'enseigne, de se purifier par un entier détachement, et de s'établir dans la parfaite connaissance d'esprit et de cœur.

Dès-lors Lao-tseu découvrit à son disciple les plus profonds mystères de sa doctrine, et le disciple se sentit tout-à-coup devenir un autre homme ; et suivant désormais sa première origine, il eut véritablement l'inclination du papillon, qui est de voltiger continuellement sans se fixer à aucun objet, quelque charmant qu'il lui parût. La fortune la plus brillante ne fut plus capable de le tenter. Son cœur devint insensible aux plus grands avantages : il les trouva aussi peu solides que la vapeur déliée dont se forme un même nuage, qui est le jouet des vents ; et aussi peu stables que l'eau d'un ruisseau, dont le cours est extrêmement rapide. Enfin son ame ne tenait plus à rien.

Lao-tseu, voyant que son disciple était tout-à-fait revenu des amusemens du siècle, et goûtait la vérité, l'introduisit dans les mystères du Tao-te-king, car les cinq mille mots dont ce livre est composé sont tous mystérieux. Il n'eut plus rien de réservé pour un tel disciple. 


\section{Contes chinois}

Tchouang-tseu, de son côté, se donna tout entier à cette étude ; il lisait sans cesse, il méditait, il mettait en pratique la doctrine de son maître, et, à force de sonder son intérieur, de le purifier, de le raffiner, pour ainsi dire, il comprit parfaitement la différence qui se trouvait entre ce qu'il y avait en lui de visible et d'imperceptible, entre le corps qui se corrompt, et l'esprit, qui, en quittant cette demeure, acquiert une nouvelle vie par une espèce de transformation admirable.

Tchouang-tseu, frappé de ces lumières, renonça à la charge qu'il possédait. Il prit même congé de Lao-tseu, et se mit à voyager, dans l'espérance d'acquérir de belles connaissances et de faire de nouvelles découvertes.

Cependant quelque ardeur qu'il eût pour le dégagement et le repos du cœur, il ne renonça pas aux plaisirs de I'union conjugale. Il se maria successivement jusqu'à trois fois. Sa première femme lui fut promptement enlevée par une maladie ; il répudia la seconde pour une faute qu'elle avait commise. La troisième sera le sujet de cette histoire.

Elle s'appelait Tian, et descendait des rois de Tsi ${ }^{1}$. Tchouangtseu s'était fait beaucoup estimer dans ce royaume, et un des principaux de cette famille, nommée Tian, épris de son mérite, lui donna sa fille en mariage.

Cette nouvelle épouse l'emportait de beaucoup sur les deux autres qu'il avait eues. Son teint avait la blancheur de la neige, et sa taille était élégante et légère comme celle d'une immortelle. Aussi, quoique ce philosophe ne fût pas

\footnotetext{
${ }^{1}$ Le royaume de Tsi est à présent la province de Chan-si.
} 


\section{Contes chinois}

naturellement passionné, il aima tendrement cette dernière épouse.

Cependant le roi de Tsou ${ }^{1}$, étant informé de la haute réputation de Tchouang-tseu, prit le dessein de l'attirer dans ses états : il lui députa des officiers de sa cour avec de riches présens en or et en soieries, pour l'inviter à entrer dans son conseil en qualité de premier ministre.

Tchouang-tseu, loin de se laisser éblouir à ces offres, répondit en soupirant par cet apologue :

-Une génisse destinée aux sacrifices, et nourrie depuis longtemps avec délicatesse, marchait en pompe, chargée de tous les ornemens dont on pare les victimes. Au milieu de cette espèce de triomphe, elle aperçut sur sa route des bœufs attelés, qui suaient sous la charrue. Cette vue redoubla sa fierté. Mais, après avoir été introduite dans le temple, lorsqu'elle vit le couteau levé et prêt à l'immoler, elle eût bien voulu être à la place de ceux dont elle méprisait le malheureux sort. Ses souhaits furent inutiles ; il lui en coûta la vie.

Ce fut ainsi que Tchouang-tseu refusa honnêtement et les présens et les offres du roi.

Peu après il se retira avec sa femme dans le royaume de Soung, qui était sa terre natale. Il choisit pour sa demeure I'agréable montagne de Nan-hoa, dans le district de Tsao-tcheou,

${ }^{1}$ C'est la province de Hou-kouang. 


\section{Contes chinois}

afin d'y passer sa vie en philosophe, et d'y goûter, loin du bruit et du tumulte, les innocens plaisirs de la campagne.

Un jour qu'il promenait ses rêveries au bas de la montagne, il se trouva insensiblement proche des sépultures de I'habitation voisine. Cette multitude de tombeaux le frappa.

- Hélas ! s'écria-t-il en gémissant, les voilà donc tous égaux ; il n'y a plus de rang ni de distinction. L'homme le plus ignorant et le plus stupide est confondu avec le sage : un sépulcre est enfin la demeure éternelle de tous les hommes : quand on a une fois pris sa place dans le séjour des morts, il n'y a plus de retour à la vie.

Après s'être occupé pendant quelque temps de ces tristes réflexions, il avança le long de ces sépultures et se trouva, sans y penser, près d'un tombeau nouvellement construit. La petite éminence faite de terre battue n'était pas encore entièrement sèche. Tout auprès était assise une jeune dame en grand deuil ${ }^{1}$. Elle était placée un peu à côté du sépulcre, tenant à la main un éventail blanc, dont elle éventait sans cesse l'extrémité supérieure du tombeau.

Tchouang-tseu, surpris de cette aventure :

- Oserais-je, lui dit-il, vous demander de qui est ce tombeau, et pourquoi vous vous donnez tant de peine pour l'éventer ? Sans doute qu'il y a quelque mystère que j'ignore?

${ }^{1}$ C'est-à-dire qu'elle était vêtue d'un long habit blanc d'une grosse étoffe sans couture. 


\section{Contes chinois}

La jeune dame, sans se lever, et continuant toujours à remuer l'éventail, dit quelques mots entre ses dents, et répandit des larmes ; ce qui faisait voir que la honte plutôt que sa timidité naturelle l'empêchait de s'expliquer.

Enfin elle lui fit cette réponse :

- Vous voyez une veuve au pied du tombeau de son mari, la mort me l'a malheureusement ravi ; celui dont les os reposent sous cette tombe m'a été bien cher durant sa vie ; il m'aimait avec une égale tendresse ; même en expirant, il ne pouvait me quitter. Voici quelles furent ses dernières paroles : Ma chère épouse, me ditil, si dans la suite tu songeais à un nouveau mariage, je te conjure d'attendre que l'extrémité de mon tombeau soit entièrement desséchée. Je te permets alors de te remarier. Or, j'ai fait réflexion que la surface de cette terre nouvellement amoncelée ne sécherait pas aisément ; c'est pourquoi vous me voyez occupée à l'éventer continuellement, afin de dissiper l'humidité.

A un aveu si naïf, le philosophe eut bien de la peine à s'empêcher de rire. Il se posséda néanmoins, mais il se disait en lui-même :

« Voilà une femme bien pressée ! Comment ose-t-elle se vanter d'avoir aimé son mari, et d'en avoir été aimée ? Qu'eût-elle donc fait s'ils se fussent haïs ?

Puis, lui adressant la parole :

- Vous souhaitez donc, lui dit-il, que le dessus de ce tombeau soit bientôt sec ? Mais, étant aussi délicate 


\section{Contes chinois}

que vous êtes, vous serez bientôt lasse et les forces vous manqueront; agréez que je vous aide.

Aussitôt la jeune femme se leva, et, faisant une profonde révérence, elle accepta I'offre, et lui présenta un éventail tout semblable au sien.

Alors, Tchouang-tseu, qui avait l'art d'évoquer les esprits, les appela à son secours. Il donna quelques coups d'éventail sur le tombeau, et bientôt toute I'humidité disparut. La dame, après avoir remercié son bienfaiteur avec un visage gai et riant, tira d'entre ses cheveux une aiguille de tête d'argent, et la lui présenta avec l'éventail dont elle s'était servie, le priant d'accepter ce petit présent comme une marque de sa reconnaissance. Tchouang-tseu refusa l'aiguille de tête et retint l'éventail ; après quoi la dame se retira fort satisfaite. Sa joie éclatait dans sa contenance et sa démarche.

Pour ce qui est de Tchouang-tseu, il demeura tout interdit, et, s'abandonnant aux réflexions qui naissaient d'une pareille aventure, il retourna dans sa maison. Assis dans sa chaumière, il considéra pendant quelque temps l'éventail ; puis, jetant un grand soupir, il dit les vers suivans :

Ne dirait-on pas que deux personnes ne s'unissent ensemble que par un reste de haine conservée dès la vie 1 précédente,

Et qu'elles se cherchent dans le mariage afin de se maltraiter le plus longtemps qu'elles peuvent?

C'est donc ainsi, à ce que je vois, qu'on est indignement oublié après sa mort par la personne qu'on avait le plus chérie.

${ }^{1}$ Il parle selon I'opinion de ceux qui croient à la métempsycose. 


\section{Contes chinois}

Qu'il faut être insensé pour aimer durant sa vie tant de cœurs volages!

La dame Tian était derrière son mari, sans en être aperçue. Après avoir ouï ce qu'il venait de dire, elle s'avança tant soit peu, et se faisant voir :

- Peut-on savoir, lui dit-elle, ce qui vous fait soupirer, et d'où vient cet éventail que vous tenez à la main ?

Tchouang-tseu lui raconta l'histoire de la jeune veuve, et tout ce qui s'était passé au tombeau de son mari, où il I'avait trouvée.

A peine eut-il achevé son récit, que la dame Tian, le visage allumé d'indignation et de colère, chargea cette jeune veuve de mille malédictions, I'appela l'opprobre du genre humain et la honte de son sexe. Puis, regardant Tchouang-tseu :

- Je l'ai dit, et il est vrai, c'est là un monstre d'insensibilité. Se peut-il trouver nulle part un si mauvais cœur?

Tchouang-tseu dit encore les quatre vers suivans :

Tandis qu'un mari est en vie, quelle est la femme qui ne le flatte et ne le loue?

Est-il mort ? la voilà prête à prendre l'éventail, pour faire au plus tôt sécher le tombeau.

La peinture représente bien I'extérieur d'un animal ; mais elle ne montre pas ce qu'il est en dedans.

On voit le visage d'une personne; mais on ne voit pas le cœur.

A ce discours, Tian-chi entra dans une grande colère.

- Les hommes, s'écria-t-elle, sont tous égaux quant à leur nature. C'est la vertu ou le vice qui met entre eux la différence. Comment avez-vous la hardiesse de parler 


\section{Contes chinois}

de la sorte en ma présence, de condamner toutes les femmes, et de confondre injustement celles qui ont de la vertu avec des malheureuses qui ne méritent pas de vivre ? N'avez-vous pas honte de porter des jugemens si injustes, et ne craignez-vous pas d'en être puni ?

- A quoi bon tant de déclamations, répliqua le philosophe ? Avouez-le de bonne foi : si je venais à mourir maintenant, restant comme vous êtes, à la fleur de votre âge, avec la beauté et l'enjouement que vous avez, seriez-vous d'humeur à laisser couler trois, et même cinq années, sans penser à un nouveau mariage ?

- Ne dit-on pas, répondit la dame : Un ministre fidèle ne sert pas un second prince; une vertueuse veuve ne pense jamais à un second mari. A-t-on jamais vu des dames de mon rang, qui, après avoir été mariées, aient passé d'une famille à une autre, et qui aient quitté le lit de leurs noces, après avoir perdu leur époux ? Si pour mon malheur vous me réduisiez à l'état de veuve, sachez que je serais incapable d'une telle action, qui serait la honte de notre sexe, et que de secondes noces ne me tenteraient pas ; je ne dis point avant le terme de trois ou de cinq ans, mais durant toute la vie. Oui, cette pensée ne me viendrait pas même en songe. C'est là ma résolution, et rien ne pourrait m'ébranler.

- De semblables promesses, reprit Tchouang-tseu, se font aisément, mais elles ne se gardent pas de même. 


\section{Contes chinois}

Ces paroles mirent encore la dame de mauvaise humeur, et elle éclata en paroles peu respectueuses.

- Sachez, dit-elle, qu'une femme a souvent l'ame plus noble et plus constante dans son affection conjugale, que ne l'a un homme de votre caractère. Ne dirait-on pas que vous êtes un parfait modèle de fidélité ? Votre première femme meurt, peu après vous en prenez une seconde : celle-ci, vous la répudiez : je suis enfin la troisième. Vous jugez des autres par vous-même, et c'est pour cela que vous en jugez mal. Pour ce qui est de nous autres femmes mariées à des philosophes, qui faisons profession, comme eux, d'une vertu austère, il nous est bien moins permis de nous remarier : si nous le faisions, nous deviendrions un objet de risée. Mais vous vous portez bien; à quoi bon ce langage, et quel plaisir prenez-vous à me chagriner ?

Alors, sans rien dire davantage, elle se jette sur l'éventail que son mari tenait à la main : elle le lui arrache, et de dépit elle le met en pièces.

- Calmez-vous, dit Tchouang-tseu, votre vivacité me fait plaisir, et je suis ravi que vous preniez feu sur un pareil sujet.

La dame se calma en effet, et on parla d'autre chose.

A quelques jours de là, Tchouang-tseu tomba dangereusement malade, et bientôt il fut à l'extrémité. La dame Tian ne quittait pas le chevet du lit, fondant en pleurs, poussant de continuels sanglots. 


\section{Contes chinois}

- A ce que je vois, dit Tchouang-tseu, je n'échapperai pas de cette maladie : ce soir ou demain matin, il faudra nous dire un éternel adieu : quel dommage que vous ayez mis en pièces l'éventail que j'avais apporté. il vous aurait servi à éventer et faire sécher la terre de mon tombeau.

- Eh ! de grace, monsieur, s'écria la dame, en l'état où vous êtes, ne vous mettez pas dans la tête des soupçons si chagrinans pour vous, et si injurieux pour moi. J'ai étudié nos livres, je sais nos rits : mon cœur vous a été une fois donné, il ne sera jamais à un autre, je vous le jure; et si vous doutez de ma sincérité, je consens, et je demande de mourir avant vous, afin que vous soyez bien persuadé de mon fidèle attachement.

- Cela suffit, reprit Tchouang-tseu ; je suis rassuré sur la constance de vos sentimens à mon égard. Hélas ! je sens que j'expire, et mes yeux se ferment à jamais pour vous.

Après ces paroles, il demeura sans respiration, et sans le moindre signe de vie.

Alors la dame éplorée, et jetant les plus hauts cris, embrassa le corps de son mari, et le tint longtemps serré entre ses bras. Après quoi elle se couvrit d'un long vêtement de deuil. Nuit et jour elle fait retentir tous les environs de ses plaintes et de ses gémissemens, et donne les démonstrations de la plus vive douleur. Elle la portait à un tel excès, qu'on eût dit qu'elle était à demi folle : elle ne voulait prendre ni nourriture ni sommeil. 


\section{Contes chinois}

Les habitans de l'un et l'autre côté de la montagne vinrent rendre les derniers devoirs au défunt qu'ils savaient être un sage du premier ordre. Lorsque la foule commençait à se retirer, on vit arriver un jeune bachelier bien fait et d'un teint brillant : rien de plus galant que sa parure. Il avait un habit de soie violet, et un bonnet noir ${ }^{1}$, une ceinture brodée, et des souliers rouges ; un vieux domestique le suivait. Ce seigneur fit savoir qu'il descendait des rois de Tsou 2.

- Il y a quelques années, dit-il, que j'avais déclaré au philosophe Tchouang-tseu que j'étais dans la résolution de me faire son disciple : je venais à ce dessein, et j'apprends à mon arrivée qu'il est mort : quel dommage ? quelle perte!

Aussitôt il quitte son habit de couleur, et se fait apporter un habit de deuil ; ensuite s'étant rendu près du cercueil, il frappa quatre fois de la tête contre terre, et s'écria d'une voix entrecoupée de sanglots :

- Sage et savant Tchouang ! votre disciple est malheureux, puisqu'il n'a pu vous trouver en vie, et profiter à loisir de vos leçons ; je veux au moins vous marquer mon attachement et ma reconnaissance, en restant ici en deuil pendant l'espace de cent jours.

Après ces dernières paroles, il se prosterna encore quatre fois, arrosant la terre de ses larmes.

\footnotetext{
${ }^{1}$ Bonnet que portent les jeunes lettrés.

${ }^{2}$ Le royaume de Tsou est maintenant la province de Hou-kouang.
} 


\section{Contes chinois}

Ensuite il demanda à voir la dame pour lui faire son compliment ; elle s'excusa deux ou trois fois de paraître. Wangsun (c'est-à-dire le petit-fils du roi) représenta que selon les anciens rits, les femmes pouvaient se laisser voir lorsque les intimes amis de leur mari lui rendaient visite.

- J'ai encore, ajouta-t-il, plus de raison de jouir de ce privilège, puisque je devais loger chez le savant Tchouang-tseu, en qualité de son disciple.

A ces instances, la dame se laisse fléchir, elle sort de l'intérieur de sa maison, et, d'un pas lent, elle s'avance dans la salle pour recevoir les complimens de condoléance ; ils se firent en peu de mots et en termes généraux.

Dès que la dame vit les belles manières, l'esprit et les agrémens de ce jeune seigneur, elle en fut charmée, et elle sentit au fond de l'ame les mouvemens d'une passion naissante, qu'elle ne démêlait pas bien elle-même, mais qui lui firent souhaiter qu'il ne s'éloignât pas sitôt.

Wang-sun la prévint en disant :

- Puisque j'ai eu le malheur de perdre mon maître, dont la mémoire me sera toujours chère, j'ai envie de chercher ici près un petit logement où je resterai les cent jours de deuil ; puis, j'assisterai aux funérailles. Je serais bien aise aussi de lire, durant ce temps-là, les ouvrages de cet illustre philosophe : ils me tiendront lieu des leçons dont je suis privé. 


\section{Contes chinois}

- Ce sera un honneur pour notre maison, répondit la dame, je n'y vois d'ailleurs aucun inconvénient.

Sur quoi elle prépara un petit repas et le fit servir.

Pendant le repas, elle ramassa sur un pupitre bien propre les compositions de Tchouang-tseu, elle y joignit le livre du Tao-te, présent de Lao-tseu, et elle vint offrir le tout à Wang-sun qui le reçut avec sa politesse naturelle.

A côté de la salle du mort où était le cercueil, il y avait sur une des ailes deux chambres qui regardaient cette salle tout ouverte par devant ; elles furent destinées au logement du jeune seigneur. La jeune veuve venait fréquemment dans cette salle pour pleurer sur le cercueil de son mari ; puis en se retirant, elle disait quelques mots d'honnêteté à Wang-sun qui se présentait pour la saluer. Dans ses fréquentes entrevues, bien des œillades échappaient qui trahissaient les cœurs de l'un et de l'autre.

Wang-sun était déjà à-demi pris, et la jeune veuve l'était tout-à-fait ; ce qui lui faisait plaisir, c'est qu'ils se trouvaient placés à la campagne, et dans une maison peu fréquentée, où la négligence des rits du deuil ne pouvait guère éclater. Mais comme il coûte toujours à une femme de faire les premières démarches, elle s'avisa d'un expédient. Elle fit venir secrètement le vieux domestique du jeune seigneur. Elle lui fit d'abord boire quelques coups de bon vin, elle le flatta et l'amadoua ; ensuite elle vint insensiblement jusqu'à lui demander si son maître était marié ?

- Pas encore, répondit-il. 


\section{Contes chinois}

- Eh ! continua-t-elle, quelles qualités voudrait-il trouver dans une personne pour en faire son épouse.

Le valet, que le vin avait rendu gai, répliqua aussitôt :

- Je lui ai ouï dire que, s'il en trouvait une qui vous ressemblât, il serait au comble de ses désirs.

Cette femme repartit incontinent :

- Ne mens-tu point ? M'assures-tu qu'il ait parlé de la sorte ?

- Un vieillard comme moi, répondit-il, serait-il capable de mentir, et aurait-il le front d'en imposer à une personne de votre mérite?

- Hé bien, poursuivit-elle, tu es très propre à ménager mon mariage avec ton maître, tu ne perdras pas ta peine ; parle-lui de moi, et si tu vois que je lui agrée, assure-le que je regarderais comme un grand bonheur d'être à lui.

- Il n'est pas besoin de le sonder sur cet article, dit le valet, puisqu'il m'a avoué franchement qu'un pareil mariage serait tout-à-fait de son goût. Mais, ajoutait-il, cela n'est pas possible, parce que je suis disciple du défunt : on en gloserait dans le monde.

-Bagatelle que cet empêchement, reprit la veuve passionnée, ton maître n'a point été réellement disciple de Tchouang-tseu : il n'avait fait que promettre de le devenir, ce n'est pas l'avoir été. D'ailleurs étant à la campagne et à l'écart, qui songerait à parler de notre 


\section{Contes chinois}

mariage ? Va, quand il surviendrait quelque autre obstacle, tu es assez habile pour le lever, et je reconnaîtrai libéralement tes services.

Elle lui versa en même temps plusieurs coups d'excellent vin pour le mettre en bonne humeur.

Il promit donc d'agir, et, comme il s'en allait, elle le rappela.

- Écoute, dit-elle, si ton maître accepte mes offres, viens au plus tôt m'en apporter la nouvelle à quelque heure du jour et de la nuit que ce soit ; je t'attendrai avec impatience.

Après qu'elle l'eut quitté, elle fut d'une inquiétude extraordinaire; elle alla bien des fois dans la salle sous divers prétextes ; mais au fond, c'était pour s'approcher un peu de la chambre du jeune seigneur. A la faveur des ténèbres, elle écoutait à la fenêtre de la chambre, se flattant qu'on y parlait de l'affaire qu'elle avait si fort à cœur.

Pour lors, passant assez près du cercueil, elle entendit quelque bruit, elle tressaillit de peur.

- Hé ! quoi, dit-elle tout émue, serait-ce que le défunt donnerait quelque signe de vie?

Elle rentre au plus tôt dans sa chambre, et, prenant la lampe, elle vient voir ce qui avait causé ce bruit. Elle trouve le vieux domestique étendu sur la table posée devant le cercueil pour y brûler des parfums et y placer des offrandes à certaines heures. Il était là à cuver le vin que la dame lui avait fait boire. Toute autre femme aurait éclaté à une pareille irrévérence à l'égard du 


\section{Contes chinois}

mort. Celle-ci n'osa se plaindre ni même éveiller cet ivrogne. Elle va donc se coucher; mais il ne lui fut pas possible de dormir.

Le lendemain elle rencontra ce valet qui se promenait froidement, sans songer même à lui rendre réponse de sa commission. Ce froid et ce silence la désolèrent. Elle l'appela, et l'ayant introduit dans sa chambre :

- Eh bien, dit-elle, comment va l'affaire dont je t'ai chargé ?

- Il n'y a rien à faire, répondit-il sèchement.

- Eh ! pourquoi donc, reprit-elle ? Sans doute tu n'auras pas retenu ce que je t'ai prié de dire de ma part, ou tu n'as pas su le faire valoir.

- Je n'ai rien oublié, poursuivit le domestique ; mon maître a été même ébranlé ; il trouve l'offre avantageuse et est satisfait de ce que vous avez répliqué sur l'obstacle qu'il envisageait d'abord dans sa qualité de disciple de Tchouang-tseu. Ainsi cette considération ne l'arrête plus. Mais, m'a-t-il dit, il y a trois autres obstacles insurmontables, et j'aurais de la peine à les déclarer à cette jeune veuve.

- Voyons un peu, reprit la dame, quels sont ces trois obstacles.

- Les voici, poursuivit le vieux domestique, tels que mon maître me les a rapportés : $1^{\circ}$ le cercueil du mort étant exposé encore dans la salle, c'est une scène bien lugubre : comment pourrait-on $s^{\prime} y$ réjouir et célébrer 


\section{Contes chinois}

des noces ? $2^{\circ}$ L'illustre Tchouang ayant si fort aimé sa femme, et elle ayant témoigné pour lui une si tendre affection, fondée sur sa vertu et sa grande capacité, j'ai lieu de craindre que le cœur de cette dame ne reste toujours attaché à son premier mari, surtout lorsqu'elle trouvera en moi si peu de mérite. $3^{\circ}$ Enfin, je n'ai pas ici mon équipage; je n'ai ni meubles, ni argent : prendre des présens de noces, et de quoi faire des repas ? Dans le lieu où nous sommes, je ne trouverais pas même à qui emprunter. Voilà, madame, ce qui l'arrête.

- Ces trois obstacles, répondit-elle, vont être levés à I'instant, et il ne faut pas beaucoup y rêver. Quant au premier article : cette machine lugubre, que renfermet-elle ? Un corps inanimé, dont on n'a rien à craindre. J'ai dans un coin de mon terrain une vieille masure ; quelques paysans du voisinage que je ferai venir $y$ transporteront cette machine, sans qu'elle paraisse ici davantage. Voilà déjà un obstacle levé.

Quant au second article, ah ! vraiment feu mon mari était bien ce qu'il paraissait être, un homme d'une rare vertu et d'une grande capacité. Avant de m'épouser, il avait déjà répudié sa seconde femme : c'était un beau ménage, comme tu vois. Sur le bruit de sa réputation, qui était assez mal fondé, le dernier roi de Tsou lui envoya de riches présens, et voulut le faire son premier ministre. Lui, qui sentait son incapacité très réelle, et 


\section{Contes chinois}

qui vit qu'elle éclaterait dans un pareil emploi, prit la fuite, et vint se cacher dans ce lieu solitaire. Il n'y a qu'un mois que, se promenant seul au bas de la montagne, il rencontra une jeune veuve occupée à faire sécher à coups d'éventail l'extrémité supérieure du tombeau de son mari, parce qu'elle ne devait se remarier que quand il serait sec. Tchouang I'accosta, la cajola, lui ôta des mains l'éventail, et se mit à en jouer pour lui plaire, en séchant au plus vite le tombeau. Ensuite il voulut retenir cet éventail comme un gage de son amitié, et l'apporta ici ; mais je le lui arrachai des

mains et le mis en pièces. Étant sur le point de mourir, il remit cette histoire sur le tapis, ce qui nous brouilla encore ensemble. Quels bienfaits ai-je reçus de lui, et quelle amitié m'a-t-il tant témoignée ? Ton maître est jeune ; il aime l'étude ; il se fera immanquablement un nom dans la littérature : sa naissance le rend déjà illustre ; il est, comme moi, du sang des rois. Voilà entre nous un rapport admirable de conditions. C'est le ciel qui l'a conduit ici pour nous unir. Telle est notre destinée.

« Il ne reste plus que le troisième empêchement. Pour ce qui regarde les bijoux et le repas des noces, c'est moi qui y pourvoirai. Crois-tu que j'aie été assez simple pour ne pas me faire un petit trésor de mes épargnes ? Tiens, voilà déjà vingt taëls ; va les offrir à ton maître ; c'est pour avoir des habits neufs; pars au plus vite, et informe-le bien de tout ce que je viens de te dire. S'il 


\section{Contes chinois}

donne son consentement, je vais tout préparer pour célébrer ce soir même la fête de notre mariage.

Le valet reçut les vingt taëls, et alla rapporter tout l'entretien à Wang-sun, qui enfin donna le consentement si fort souhaité. Dès que la dame eut appris cette agréable nouvelle, elle fit éclater sa joie en cent manières. Elle quitte aussitôt ses habits de deuil, elle se pare, s'ajuste, se farde, tandis que, par ses ordres, on transporte le cercueil dans la vieille masure. La salle fut à l'instant nettoyée et ornée pour la cérémonie de l'entrevue et des noces. En même temps on préparait le festin, afin que rien ne manquât à la réjouissance.

Sur le soir, la jeune dame fit préparer la chambre nuptiale : la salle fut éclairée d'un grand nombre de belles lanternes garnies de flambeaux. Sur la table du fond était le grand cierge nuptial. Lorsque tout fut prêt, Wang-sun parut avec un habit et un ornement de tête qui relevaient beaucoup la beauté de ses traits et de sa taille. La dame vint aussitôt le joindre, couverte d'une longue robe de soie enrichie d'une broderie très fine : ils se placèrent I'un à côté de l'autre, vis-à-vis le flambeau nuptial : c'était un assemblage charmant. Ainsi rapprochés ils se donnaient mutuellement de l'éclat l'un à l'autre, à-peu-près comme des pierreries et des perles rehaussent la beauté d'un drap d'or, et en paraissent plus belles.

Après avoir fait les révérences accoutumées dans une pareille cérémonie, et s'être souhaité toutes sortes de prospérités dans leur mariage, ils se prirent par la main et passèrent dans l'appartement intérieur : là ils pratiquèrent le grand rit, de boire 


\section{Contes chinois}

tous deux, I'un après l'autre, dans la coupe d'alliance. Après quoi ils se mirent à table.

Le festin étant fini, et lorsqu'ils étaient sur le point de se coucher, il prit tout-à-coup au jeune époux d'horribles convulsions : son visage paraît tout défiguré, ses sourcils se froncent et s'élèvent, sa bouche fait d'affreuses contorsions : il ne peut plus faire un pas, et voulant monter sur le lit, il tombe par terre. Là étendu tout de son long, il se frotte la poitrine des deux mains, criant de toutes ses forces qu'il a un mal de cœur qui le tue.

La dame éperduement amoureuse de son nouvel époux, sans penser ni au lieu où elle est, ni à l'état où elle se trouve, crie au secours, et se jette à corps perdu sur Wang-sun. Elle l'embrasse, elle lui frotte la poitrine où était la violence de la douleur : elle lui demande quelle est la nature de son mal ? Wang-sun souffrait trop pour répondre. On eût dit qu'il était près d'expirer.

Son vieux domestique accourant au bruit, le prend entre ses bras, et l'agite.

- Mon cher Wang-sun, s'écria la dame, a-t-il déjà éprouvé de semblables accidens ?

- Cette maladie l'a déjà pris plusieurs fois, répondit le valet ; il n'y a guère d'année qu'il n'en soit attaqué. Un seul remède est capable de le sauver.

- Dis-moi vite, s'écria la nouvelle épouse, quel est ce remède ? 


\section{Contes chinois}

- Le médecin de la famille royale, continua le valet, a trouvé ce secret, qui est infaillible. Il faut prendre de la cervelle d'un homme nouvellement tué, et lui en faire avaler dans du vin chaud; aussitôt les convulsions cessent, et il est sur pied. La première fois que ce mal le prit, le roi, son parent, ordonna qu'on fit mourir un prisonnier qui méritait la mort, et qu'on prît de sa cervelle : il fut guéri à l'instant. Mais hélas ! où en trouver maintenant ?

- Mais, reprit la dame, est-ce que la cervelle d'un homme qui meurt de sa mort naturelle, n'aurait pas un bon effet?

- Notre médecin, reprit le vieux domestique, nous avertit qu'au besoin on pourrait absolument se servir de la cervelle d'un mort, pourvu qu'il n'y eût pas quaranteneuf jours qu'il fût expiré, parce que la cervelle n'étant pas encore desséchée, conserve sa vertu.

- Hé ! s'écria la dame, il y a vingt jours que mon mari est mort ; il n'y a qu'à ouvrir son cercueil, et y prendre un remède si salutaire.

- J'y avais bien pensé, répliqua le valet ; je n'osais vous le proposer, et je craignais que cette seule pensée ne vous fit horreur.

- Bon, répondit-elle, Wang-sun n'est-il pas à présent mon mari : s'il fallait de mon sang pour le guérir, est-ce que j'y aurais regret ? Et j'hésiterais par respect pour un cadavre qui bientôt va tomber en poussière ! 


\section{Contes chinois}

Sur-le-champ elle laisse Wang-sun entre les bras du vieux domestique : elle prend d'une main la hache destinée à fendre le bois de chauffage, et la lampe de l'autre : elle court avec précipitation vers la masure où était le cercueil : elle retrousse ses longues manches, empoigne la hache des deux mains, l'élève, et de toutes ses forces en décharge un grand coup sur le couvercle du cercueil, et le fend en deux.

La force d'une femme n'aurait pas été suffisante pour un cercueil ordinaire. Mais Tchouang-tseu, par un excès de précaution et d'amour pour la vie, avait ordonné que les planches de son cercueil fussent très minces.

Ainsi du premier coup la planche fut fendue : quelques autres coups achevèrent d'enlever le couvercle. Comme ce mouvement extraordinaire l'avait essoufflée, elle s'arrêta un moment pour prendre haleine. Au même instant elle entend pousser un grand soupir ; et jetant les yeux sur le cercueil, elle voit que son premier mari se remue et se met sur son séant.

On peut juger quelle fut la surprise de la dame Tian. La frayeur subite dont elle fut saisie lui fit pousser un grand cri : ses genoux se dérobent sous elle; et dans le trouble où elle se trouve, la hache lui tombe des mains sans qu'elle s'en aperçoive.

- Ma chère épouse, lui dit Tchouang, aidez-moi un peu à me lever.

Dès qu'il fut sorti du cercueil, il prend la lampe, et s'avance vers I'appartement. La dame le suivait, mais d'un pas chancelant et suant à grosses gouttes, parce qu'elle y avait laissé le jeune 


\section{Contes chinois}

Wang-sun et son valet, et que ce devait être le premier objet qui se présenterait à la vue de son mari.

Lorsqu'ils entrèrent dans la chambre, tout y parut orné et brillant : mais heureusement Wang-sun et le valet ne s'y trouvèrent pas. Elle se rassura un peu, et songea aux moyens de plâtrer une si mauvaise affaire : ainsi jettant un regard tendre sur Tchouang-tseu :

- Votre petite esclave, lui dit-elle, depuis le moment de votre mort, était occupée jour et nuit de votre cher souvenir : enfin ayant entendu un bruit assez distinct qui venait du cercueil, et me ressouvenant des histoires qu'un rapporte de certains morts qui sont retournés à la vie, je me suis flattée que vous pourriez bien être de ce nombre : j'ai donc couru au plus vite, et j'ai ouvert le cercueil. Béni soit le ciel, mon espérance n'a pas été trompée : quel bonheur pour moi de retrouver un mari si cher, dont je pleurais continuellement la perte !

- Je vous suis obligé, dit Tchouang-tseu, d'un si grand attachement pour moi. J'ai pourtant une petite question à vous faire : pourquoi n'étiez-vous pas en deuil ? Comment vous vois-je vêtue d'un habit de brocard brodé ?

La réponse fut bientôt prête : J'allais, dit-elle, ouvrir le cercueil avec un secret pressentiment de mon bonheur : la joie dont je devais être comblée ne demandait pas un vêtement lugubre, et il n'était pas convenable de vous recevoir plein de vie 


\section{Contes chinois}

dans des habits de deuil : c'est ce qui m'a fait prendre mes habits de noces.

A la bonne heure, dit Tchouang-tseu, passons cet article. Pourquoi mon cercueil se trouve-t-il dans cette masure, et non dans la salle, où naturellement il devait être ? Cette question embarrassa la dame, et elle ne put y répondre.

Tchouang-tseu jettant les yeux sur les plats, sur les tasses, et sur tous les autres signes de réjouissance, les considéra attentivement : et puis, sans s'expliquer, il demanda du vin chaud pour boire : il en avala plusieurs coups, sans dire un seul mot, tandis que la dame était fort intriguée. Après quoi il prit du papier et le pinceau, et il écrivit les vers suivans :

Épouse infidèle, ta conduite passée est celle d'un implacable ennemi.

Aujourd'hui tu me parles de ta tendresse ; mais je n'en suis nullement touché.

Si je consentais à vivre avec toi comme un bon mari doit faire avec sa femme,

N'aurais-je pas à craindre que tu ne vinsses me fendre la tête d'un coup de hache?

Cette méchante femme, ayant lu ces vers, changea tout-àcoup de couleur ; et dans la confusion dont elle était couverte, elle n'osa ouvrir la bouche. Tchouang-tseu continua à écrire quatre autres vers, dont voici le sens :

Qu'ai-je gagné par tant de témoignages de la plus tendre amitié ?

Un inconnu n'a eu qu'a paraître, j'ai été aussitôt oublié.

On est venu m'assaillir dans le cercueil à grands coups de hache :

C'est un empressement bien plus grand que celui de sécher le tombeau avec l'éventail. 


\section{Contes chinois}

Après quoi Tchouang-tseu dit à la dame :

- Regarde ces deux hommes qui sont derrière toi,

et il les montrait du doigt. Elle se tourne, et aperçoit Wang-sun et son vieux domestique, qui étaient près d'entrer dans la maison. Ce fut pour elle un nouveau sujet de frayeur. Ayant tourné une seconde fois la tête, elle s'aperçut qu'ils avaient disparu.

Enfin cette malheureuse, au désespoir de voir ses intrigues découvertes, et ne pouvant plus survivre à sa honte, se retire à l'écart. Là elle dénoue sa ceinture de soie, et se pend à une poutre. Fin déplorable, où conduit d'ordinaire une passion honteuse à laquelle on se livre : Celle-ci pour le coup est sûrement morte sans aucune espérance de retour à la vie.

Tchouang tseu l'ayant trouvée en cet état, la détache, et, sans autre façon, va raccommoder un peu le cercueil brisé, où il enferme le cadavre. Ensuite faisant un carillon ridicule, en frappant sur les pots, sur les plats, et sur les autres ustensiles qui avaient servi au festin des noces, il entonna la chanson suivante, appuyé sur un côté du cercueil.

Grosse masse sans ame ! durant ta vie noue avons été unis ensemble ;

Mais fus-je jamais bien ton mari et te dois-je regarder comme ma femme?

Le pur hasard nous réunit, ma malheureuse destinée nous plaça sous le même toit.

Le terme est enfin expiré ; j'en suis quitte.

Si nous fûmes unis, nous voilà éternellement séparés, ingrate et infidèle.

Dès que tu me crus mort, ton cœur volage passa à un autre : 


\section{Contes chinois}

Il fit voir ce qu'il était : avait-il été auparavant un moment à moi ?

Il n'y a qu'un instant que tu te donnais un nouvel époux ;

Serais-tu morte pour aller le rejoindre dans le séjour des ombres ?

Les plaisantes funérailles dont tu $\mathrm{m}$ 'honorais !

Tu me régalais d'un grand coup de hache.

Ce sont ici de vraies funérailles ;

C'est pour te consoler qu'est faite cette chanson avec sa symphonie.

Le sifflement de la hache se fit entendre à mes oreilles,

Et il me délivra du sommeil de la mort.

Les accens de ma voix dans ce concert ont dû aller jusqu'à toi.

Je crève de dépit et de joie : mettons en pièces ces pots et ces plats de terre, ridicules instrumens de ma symphonie :

La fête de tes obsèques est finie. $O$ ! qui t'aurait bien connue! Tu dois à-présent me connaître.

Tchouang-tseu ayant achevé de chanter, se mit à rêver un moment, et il fit ces quatre vers :

Te voilà morte, il n'y a plus qu'à t'enterrer.

Quand tu me crus mort, tu disais : je me remarierai.

Si je m'étais trouvé véritablement mort, Que de plaisanteries tu aurais faites sur mon compte !

Après quoi Tchouang-tseu fit de grands éclats de rire ; et donnant à droite et à gauche sur les ustensiles, il brisa tout. Il fit plus : il mit le feu à la maison, qui n'était couverte que de chaume. Ainsi tout fut bientôt réduit en cendre : et ce fut là le bûcher de la malheureuse Tian, dont il ne resta plus de vestige. On ne sauva de l'incendie que le livre Tao-te. Ce furent des voisins qui le recueillirent, et qui le conservèrent.

Après cela Tchouang tseu se remit à voyager, bien résolu de ne jamais se remarier. Dans ses voyages, il rencontra son maître 


\section{Contes chinois}

Lao-tseu, à qui il s'attacha le reste de sa vie, et devint lui-même philosophe célèbre.

Le fameux Ou, dans un transport de jalousie, tue sa femme ; c'est sa brutalité.

L'illustre Siun meurt presque de douleur à la mort de sa femme ; c'est folie.

Le philosophe Tchouang s'égaye par le carillon des pots et des verres;

Il prend le parti de la liberté et se livre à la joie ; voilà le maître que je veux suivre.

(a) 